\title{
PLUTONIUM ISOTOPES IN THE NORTH ATLANTIC \\ by
}

KEN O. BUESSELER

B.A., University of Californta at San Diego, 1981

\author{
SUBMITTED IN PARTIAL FULFILLMENT \\ OF THE REQUIREMENTS FOR THE DEGREE OF \\ DOCTOR OF PHILOSOPHY \\ at the \\ MASSACHUSETTS INSTITUTE OF TECHNOLOGY \\ and the
}

WOODS HOLE OCEANOGRAPHIC INSTITUTION

SEPTEMBER 1986

OKen 0. Buesseler, 1986

The author hereby grants to MIT and WHOI permission to reproduce and distribute copies of this thesis document in whole or in part.

Signature of Author

Joint Program in Oceanography, Massachusetts Institute of Technology and Woods Hole Oceanographic Institution, and the Department of Earth, Atmospheric, and Planetary Sciences, Massachusetts Institute of Technology

Certified by

Edward R. Sholkovitz, Thesis Supervis br

Accepted by

Edward Boyle, Chatr, Joint tommittee for Chemical Oceanography,

Massachusetts Institute of Technology/Woods Hole Oceanographic

Institution 


\section{ABSTRACT}

The artificial radionuclide Plutonium ( $\mathrm{Pu}$ ) has been introduced into the environment primarily as fallout from atmospheric nuclear weapons testing during the 1950's and 1960's. Earlier studies of Pu geochemistry are generally based upon the measurement of the combined activities of ${ }^{239} \mathrm{Pu}$ and ${ }^{249} \mathrm{Pu}$ (detected by alpha-counting and written as $239,240 \mathrm{Pu}$ ) and assume an identical geochemical behavior for Pu from any of its fallout sources. A major focus of this thesis is the development of a mass spectrometric (m.s.) technique for the analysis of Pu in marine sediments, pore waters, sediment trap material and sea water from the North Atlantic. With the m.s. technique, not only is the detection limit for 239,240 Pu increased by over an order-of-magnitude, but the $240 \mathrm{Pu}$ and ${ }^{239} \mathrm{Pu}$ isotopes can be separated as well.

The increased sensitivity for Pu provided by m.s. allowed me to measure $\mathrm{Pu}$ in deep-sea pore waters for the first time. Pore water studies are sensitive indicators of early diagenetic reactions, and can be used to examine the unresolved question of the extent of Pu remobilization out of marine sediments. Along a transect of cores ranging from highly reducing muddy sediments on the shelf to more oxic and carbonaterich sediments in the deep-sea, I have found that the solubility of Pu is predominantly controlled by the distribution of $\mathrm{Pu}$ in the solid phase. The calculated $239,240 \mathrm{Pu}$ distribution coefficients $\left(K_{d}=d p m\right.$ per $\mathrm{kg}$ on solids/dpm per $\mathrm{kg}$ in solution) range from $0.2-23 \times 10^{4}$, with some suggestion of a trend towards lower values in the deeper cores ( $K_{d}{ }^{\prime} s<10^{4}$ in cores from water depths $>2500 \mathrm{~m}$ ). Diffusive flux calculations based upon the observed Pu pore water gradients suggest that since its introduction, negligible Pu has been remobilized out of the sediments at all of the sites. On a time scale of $10^{2}-10^{3}$ years however, Pu remobilization may be significant.

A large suite of sedimentary $\mathrm{Pu}$ and ${ }^{210} \mathrm{~Pb}$ inventory data are also examined from the Northwest Atlantic shelf, slope and deep-sea sediments. 
Comparisons between $\mathrm{Pu}$ and ${ }^{210} \mathrm{~Pb}$ are of interest since both isotopes are predominantly supplied by atmospheric delivery to coastal waters, and since both isotopes are used to study recent accumulation and mixing processes in marine sediments. Inventories of these tracers will reflect their source function, removal efficiencies, and lateral transport in water and particles. A major conclusion is that the sediment inventories decrease with increasing water depth, reflecting a decrease in the net scavenging of these elements off-shore. Pu sediment inventories drop-off with increasing water depth much more rapidly than $210_{\mathrm{Pb}}{ }^{\text {ex }}$ inventories, due to either the shorter residence time of ${ }^{210} \mathrm{~Pb}$ compared to Pu with respect to water column removal processes, or due to comparisons between the naturally occurring $210 \mathrm{~Pb}$ steady-state scenario and the more recently introduced fallout $\mathrm{Pu}$. When $\mathrm{Pu}$ and ${ }^{210} \mathrm{~Pb}$ ex inventories are summed over water depths out to $4000 \mathrm{~m}$ in the Northwest Atlantic, the sediments can account for roughly $24 \pm 8 \%$ of the expected $\mathrm{Pu}$ and $83 \pm 15 \%$ of the expected ${ }^{210} \mathrm{~Pb}^{\text {ex }}$ inputs.

The ${ }^{240} \mathrm{Pu} /{ }^{239} \mathrm{Pu}$ ratio data provided by the m.s. provide a unique insight into the relationship between the specific sources of fallout Pu and its geochemical behavior in the oceans. I find a systematic decrease in the ${ }^{240} \mathrm{Pu} /{ }^{239} \mathrm{Pu}$ ratio in sediments from 0.18 on the shelf to 0.10 in deep-sea $(4500-5000 \mathrm{~m})$ sediments from the Northwest Atlantic. This trend is consistent with a model whereby Pu from surface based testing at the Nevada Test Site $\left({ }^{240} \mathrm{Pu} /{ }^{239} \mathrm{Pu}=0.035\right)$ is carried by tropospheric fallout particles of a distinct physical/chemical form which are rapidly removed from the water column at all depths, in contrast to global stratospheric fallout $\left({ }^{240} \mathrm{Pu} /{ }^{239} \mathrm{Pu}=0.18\right)$ which is only efficiently deposited to the sediments in the shallower cores where scavenging is more intense. This two source model was chosen since there is no evidence for the present day fractionation of ${ }^{239} \mathrm{Pu}$ from ${ }^{240} \mathrm{Pu}$ in the water column and sediment trap data.

This two source model is supported by the analysis of ${ }^{240} \mathrm{Pu} /{ }^{239} \mathrm{Pu}$ ratios in marine sediments from the 1950's and 1960's which show lower or equivalent ${ }^{240} \mathrm{Pu} /{ }^{239} \mathrm{Pu}$ ratios than present day samples from the same locations (Nevada fallout was confined to 1951-1958 while global fallout 
inputs peaked in 1961/62). Also, while all of the North Atlantic deep-sea sediments show some evidence of the Nevada inputs (1.e. $\left.{ }^{240} \mathrm{Pu} /{ }^{239} \mathrm{Pu}<0.18\right)$, the net inventory of $\mathrm{Pu}$ from the Nevada source can be shown to decrease with increasing distance away from the Nevada source. Using the observed sediment ${ }^{240} \mathrm{Pu} /{ }^{239} \mathrm{Pu}$ ratios and a two endmember mixing model, the Pu supplied by the Nevada source in deep Northwest Atlantic sediments (>4500 $\mathrm{m}$ ) is shown to account for roughly $40 \%$ of the total sediment $239,240 \mathrm{Pu}$ inventory. The very low inventories of $239,240 \mathrm{Pu}$ in the deep-sea sediments in general serves to accentuate the Nevada fallout signal at these sites.

A pronounced dis-equilibrium is observed between the solit phase ${ }^{240} \mathrm{Pu} /{ }^{239} \mathrm{Pu}$ ratios (which range from $0.10-0.18$ ) and the pore water $240 \mathrm{Pu} /{ }^{239} \mathrm{Pu}$ ratios (which are constant at $\cong 0.18$ ) at all sites. The low ratio Nevada fallout $\mathrm{Pu}$ is apparently more tightly bound by its solid phase carrier than Pu from global fallout sources and is therefore not participating in the general solid/solution exchange reactions.

Within an individual sediment profile, the ${ }^{240} \mathrm{Pu} /{ }^{239} \mathrm{Pu}$ ratios are relatively constant from core top to core bottom. Using a sediment mixing model which combines the Pu activity data and the resulting ${ }^{240} \mathrm{Pu} /$ ${ }^{239} \mathrm{Pu}$ ratios given the two $\mathrm{Pu}$ sources, I have been able to constrain the input function of Pu to the slope and deep ocean sediments. The data are consistent with a model which suggests that the bulk of the Pu deposited to the deep ocean sediments arrived early-on in the fallout record. 


\section{ACKNOWLEDGEMENTS}

It is with great pleasure that I have the chance to acknowledge the help and support I received from my co-workers, friends, and family during the past five years. I am deeply indebted to Ed Sholkovitz for both his encouragement and guidance as my main thesis supervisor and for his confidence and respect for my abilities as a scientist. As an editor, he has been most constructive in his laborings over my writing skills. Finally, I know I can count on Ed and his family for their continued friendship.

The other members of my Thesis Committee - J. Kirk Cochran, Mike Bacon, and Harry Hemond - were a valuable source of guidance throughout the development of this thesis. In particular, a visit to the labs of Dr. Cochran at SUNY in 1985 aided and encouraged my attempts at the modeling of radiotracer distributions in sediments. In addition to my Thesis Committee, Hugh Livingston provided a wealth of knowledge concerning his longstanding research interests in artificial radionuclide geochemistry. As an incoming student at M.I.T., Ed Boyle was very helpful and supportive. I feel that I certainly benefited from an exposure to a wide range of interesting research activities engaged in by the scientists at Woods Hole and M.I.T.

Within the Redfield radiochemistry group, I would like to thank Don Mann, Will Clarke, Dave Schneider, Lolita Suprenant, Susan Casso, and Julie Palmieri - all of these co-workers have aided me or encouraged me in many ways. When I leave I know I'll miss the 10 o'clock coffee conversations and the stimulating discussions I had with Don concerning matters beyond the world of oceanographic science. Marilyn Hess must be thanked for her assistance in typing - most often on papers that were written in ineligible script and with pressing deadilines. Throughout my graduate career, the other Joint Program students have been a unique source of friendship and support - I want to thank them all.

Far removed from Yankee Massachusetts in Aiken, South Carolina, I 
developed a second scientific home in the mass spectrometry facilities run inftially by Justin Halverson at the Savannah River Laboratory. With his help, we were able to push Pu detection limitations beyond a radiochemist's dreams. At the same time, his home has become a familiar and friendly haven during my stays in the South. In these labs, Arthur and Leon have really kept the nuts and bolts of the m.s. together during my visits and continuously worked beyond the call of duty on my behalf. More recently, Phil Chastagner has continued to provide the support for the lab work I need. In general, the management of the Savannah River Laboratory must be thanked for their support of my work and the use of their facilities.

Outside of the strictly scientific world, I certainly could not have maintained the effort needed to complete this thesis without the support and love of my parents and entire family. It is hard to put in words the extent of their encouragement - suffice it to say that enough confidence was placed in me that 19 members of the Buesseler clan travelled 1000's of miles to be here for my thesis defense. Thanks, Mom and Dad, for making this all possible.

Eight years ago we met as undergraduates, five years ago we married, and today our marriage not only survived graduate school iffe, but it is better than ever! Without the love of my wife, Wendi, I could never have enjoyed myself so much and grown in so many ways with her, during the work on this thesis.

A final thanks is in order to Falmouth, for being a nice place to live; to Roxanne, our cat, for many enjoyable purrs; the members of F.A.N.D. Who have become my friends and support, in a somewhat crazy world; and to Eric and Liane Schreffler, friends and co-survivors of a U.C.S.D. to M.I.T. transition.

Financial support was provided primarily by the Education office of the Massachusetts Institute of Technology/Woods Hole Oceanographic Institution Joint Program in Oceanography, by Department. of Energy contract DE-FG02-85ER60358, and by the Oak Ridge Associated Universities program for travel support to the Savannah River Laboratory. 
TITLE PAGE ABSTRACT ACKNOWLEDGEMENTS: TABLE OF CONTENTS. LIST OF FIGURES LIST OF TABLES

CHAPTER 1- Plutonium in the Marine Environment: Introduction, objectives and Background

I. INTRODUCTION

II. OBJECTIVES

III. THE STUDY REgION: THE NORTHWEST ATLANTIC SHELF, SLOPE AND RISE

A. The SEEP Program.

IV. SOURCES OF PLUTONIUM

V. AQUATIC CHEMISTRY OF PLUTONIUM

CHAPTER 2- The Non-destructive Analysis of $210 \mathrm{pb},{ }^{234} \mathrm{Th}$ and ${ }^{226} \mathrm{Ra}$ by Gamma-ray Spectrometry

I. INTRODUCTION

II. DETECTION TECHNIQUES

III. SAMPLE ANALYSES

A. Cpm (Counts Per Minute) . . . . . . . . 28

B. Eff (Efficlency) . . . . . . . . . . . 30

C. Abs (Self Absorption) . . . . . . . . . 32

IV. OTHER FACTORS

V. RESULTS

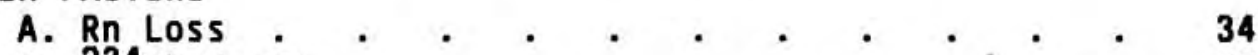

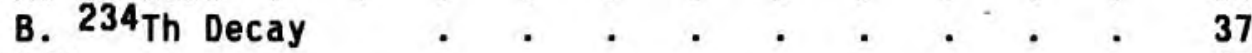

CHAPTER 3- The Mass Spectrometric Analysis of Fallout $239 \mathrm{Pu}$ and $240 \mathrm{Pu}$ in Marine Samples

I. INTRODUCTION

II. THERMAL IONIZATION MASS SPECTROMETRY

A. Source and Loading . . . . . . . . . 40

B. Detection . * . . . . . . . . 43

III. PREPARATION AND PURIFICATION OF MARINE SAMPLES

A. Sample Preparation

a. Sediment preparation procedures . . . . 44

b. Seawater/pore water preparation procedures . 45

c. Sediment trap sample preparation procedures . 46 
CHAPTER 3, cont.

Page

III. PREPARATION AND PURIFICATION OF MARINE SAMPLES

B. Plutonium Purification by ion exchange
a. Sediment ion exchange column \#1.
b. Sediment column \#2
c. Sediment column \#3
d. Seawater, pore water and sediment trap sample column \#1
e. Seawater, pore water and sediment trap sample column \#2

IV. RESULTS AND DISCUSSION

CHAPTER 4- A Pore Water Study of Plutonium in Shelf, Slope and Deep-sea Sediments

I. INTRODUCTION

II. SAMPLING

III. ANALYTICAL METHODS

IV. RESULTS AND DISCUSSION

A. Geochemical Setting ${ }_{\mathrm{Pu}}, 21 \dot{0}_{\mathrm{Pb}}$ ex and $13 \dot{7}_{\mathrm{Cs}} \cdot \cdot \cdot \cdot \begin{aligned} & 71 \\ & 75\end{aligned}$

B. Sedimentary $239,240 \mathrm{Pu}, 210 \mathrm{~Pb} e x$ and $137 \mathrm{Cs}$. 75

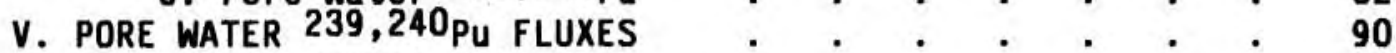

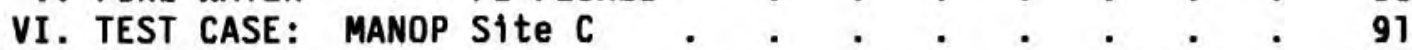

VII. SUMMARY

CHAPTER 5- 239,240 Pu and Excess 210 pb Inventories Along the Shelf and Slope of the Northeast U.S.A. (reprinted from Earth Planet. Sci. Letters)

1. INTRODUCTION

2. METHODS

3. SOURCES

4. RESULTS

5. DISCUSSION

5.1. Sediment Inventory vs. Water Depth . . . 114

5.2. Total Storage of $\mathrm{Pu}$ and $210 \mathrm{pb}$ ex in the NASS Sediments . . . . . . . . 116

5.3. A Comparison Between East and West Coast Sites . 117

6. SUMMARY AND CONCLUSIONS ACKNOWLEDGEMENTS AND REFERENCES (CHPT. 5 on ly) : $: \quad 118$ 
CHAPTER 6- The Geochemistry of Fallout Plutonium in the North

Page

Atlantic: $240 \mathrm{Pu} / 239 \mathrm{Pu}$ Ratios and Their Significance

I. INTRODUCTION

A. Fallout Data . . . . . . . . . . 122

B. Previous Studies . $\quad . \quad$. $\quad . \quad . \quad . \quad . \quad . \quad 125$

III. SAMPLING

IV. ANALYTICAL TECHNIQUES

V. RESULTS AND DISCUSSION

A. $240 \mathrm{Pu} / 239 \mathrm{Pu}$ Ratios Along a Sediment Transect from the N.W. Atlantic

B. $240 \mathrm{Pu} / 239_{\mathrm{Pu}}$ Data in Sediments from the 1950 's and 1960's

C. The Solubility and Removai Rates of Giobai Failout Versus Nevada Fallout . . . . . . . . 140

D. Pore Water $240 \mathrm{pu} / 239 \mathrm{pu}$ Ratios . . . 142

E. Nevada Fallout Inventories and the Spatial Extent of This Debris . . . . . . . . 144

VI. $240 \mathrm{Pu} / 239 \mathrm{Pu}$ RATIOS Proftles Within Individual Cores 147

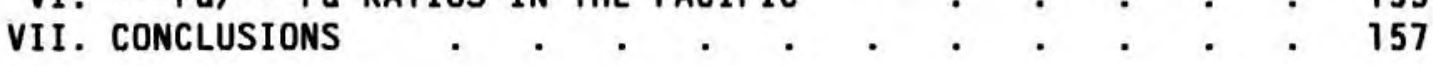

CHAPTER 7- The Modelling of Sediment Mixing using 210 pbex, $239,240 \mathrm{Pu}$ and $240 \mathrm{Pu} / 239 \mathrm{Pu}$ Data

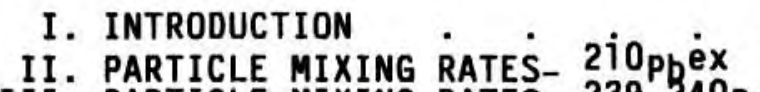

III. PARTICLE MIXING RATES- $239,240 \mathrm{PU}$

IV. SEPIMENTMIXING MODEL- 239,240 Pu ACTIVITIES AND $240 \mathrm{Pu} / 239 \mathrm{Pu}$ RATIOS

v. SEDIMENT MIXING PROCESSES- DEEP-SEA CORES G AND $H$

VI. SEDIMENT MIXING RATES- SPATIAL VARIABILITY

\section{CHAPTER 8- SUmmary}

I. INTRODUCTION

II. CONCLUSIONS

REFERENCES-

APPENDIX I- "CPM.BAS": A Program in BASIC for Calculating Count

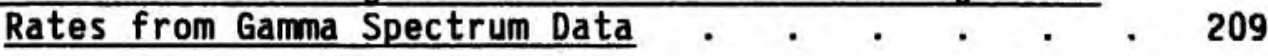

APPENDIX II- Data from Non-destructive Gamma Analyses . . . 211

APPENDIX III- PU Data by Mass Spectrometry . . . . . . 216 


\section{LIST OF FIGURES}

CHAPTER 1

Figure 1.1 : Sampling Location Map . . . . . . . . . 7

1.2 : SEEP I Mooring Dlagram . . . . . . . . 8

1.3 : Plutonium Isotopes and Nuclear Decay Products . 14

1.4 : Atmospheric Weapons Testing Yield vs. Year. . 16

1.5 : Quarterly Deposition of $90 \mathrm{Sr}$ at New York City 16

1.6 : Worldwide Nuclear Testing Sites. . . . . 19

1.7 : Concentration of $239,240 \mathrm{Pu}$ as a Function of

Latitude in Integrated Soll Samples . . . 19

CHAPTER 2

Figure 2.1: Efficiency vs. Energy Plot for Gamma Detectors

2.2a: Gamma Spectrum of Standard Sediment Sample on the Planar Detector . . . . . . . 27

2.2b: Gamma Spectrum of Standard Sediment Sample on the $\mathrm{Ge}(\mathrm{Li})$ Detector . . . . . . . 27

2.3 : Self Absorption Correction Scheme . . . . . 33

2.4 : Naturally Occurring $238_{U}$ Decay Series . . 36

CHAPTER 3

Figure

3.1a: "Goose-neck" Ion Exchange Column . . . . 48

3.1b: $1 \mathrm{ml}$ Final Ion Exchange Column.... .48

3.2a: Summary of Ion Exchange Procedures- Sediments . $\quad 52$

3.2b: Summary of Ion Exchange Procedures- Water Samples 52

3.3 : The Ranges of Fallout Pu Activity Found in Typical

Marine Samples Relative to Detection by M.S.

CHAPTER 4

Figure

4.1 : Sampling Location Map- Pore Water Studies
4.2 : Solid Phase $239,240 \mathrm{Pu}, 210 \mathrm{~Pb}$, and $137 \mathrm{Cs}$

4.3 : Proflles Water and Solld Phase $239,240 \mathrm{Pu}$ Data, $\mathrm{K}_{d}{ }^{\prime} \mathrm{s}$ and Redox Characteristics-Cores $A$ through $H$
$4.4,2$ MAN

4.4 : MANOP Site C Mixing Models . . . . . . 97

CHAPTER 5

5.1 : Map of NASS Region and Core Locations
5.2 : Sediment $239,240 \mathrm{Pu}$ and $210_{\mathrm{Pb}}$ Inventories 


\section{LIST OF FIGURES- cont.}

CHAPTER 6

Figure 6.1: Sampling Location Map- $240 \mathrm{Pu} / 239 \mathrm{Pu}$ Isotope

Page

$$
\text { Analyses . . . . . . . . . . } 126
$$

6.2 : $240 \mathrm{Pu} / 239 \mathrm{Pu}$ Atom Ratios in Sediments vs. Water Depth in the Northwest Atlantic . . . . 134

6.3 : Atlantic Fallout Pu Model . . . . . . 136

6.4 : Testing Yield Data vs. Time for the Nevada Test

6.5 : $240 \mathrm{Pu} / 239 \mathrm{Pu}$ Atom Ratios in U.S. Lake Sediments 139

6.6 : $240 \mathrm{pu} / 239 \mathrm{pu}$ Atom Ratios in Pore Waters vs.

Sediments . . . . . . . . . . 143

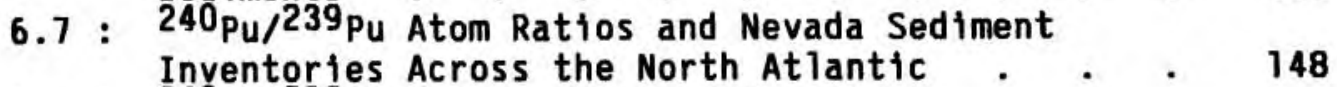

6.8 : $240 \mathrm{Pu} / 239 \mathrm{Pu}$ Atom Ratio Profiles and Pu
Activity Profiles within Cores A through H . . 149

6.9a: Schematic Diagram of "Pulse/Pulse" and 152

6.9b: $240 \mathrm{Pu} / 239 \mathrm{Pu}$ Atom Ratio Data from Core D and

6.9c: $239,240 \mathrm{Pu}$ Activity Data from Core D and Modei 154 Mixing Curves . . . . . . . . . . 154

CHAPTER 7

Figure 7.1 : Solid Phase 210 pbex Profiles and Model Mixing Curves .

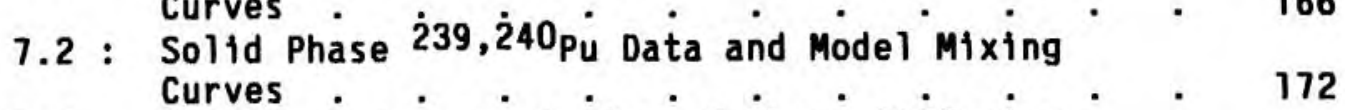

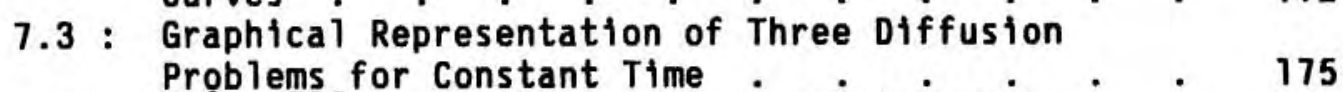

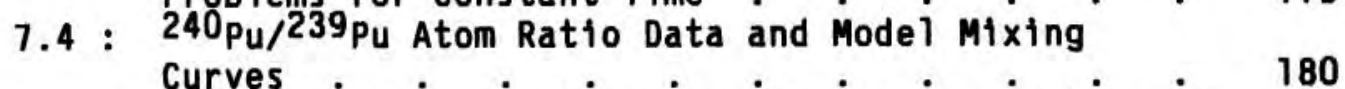

7.5 : Schematic Summary of Pu Input Scenarios to the
Sediments of the Northwest Atlantic 183 7.6 : Sediment Mixing Rates vs. Water Depth from 80 to
$2700 \mathrm{~m}$ in the Northwest Atlantic . . . 186 


\section{LIST OF TABLES}

CHAPTER 1

Table 1.1: Relative Abundances of Plutonium Isotopes in Global fallout vs. Power Reactors . . . . 14

1.2 : Announced Atmospheric Nuclear Test Yields . $\quad 17$

CHAPTER 2

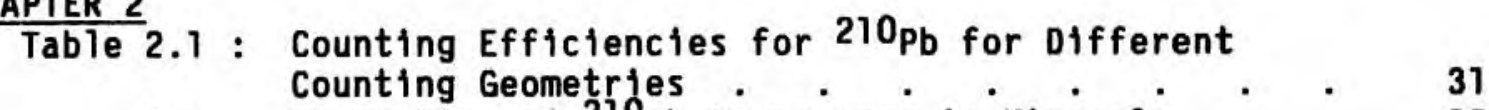

2.2 : Absorption of 210 $\mathrm{Pb}$ Gamma-rays in Minerals 33

2.3 : Self Absorption Factors for $20 \mathrm{~g}$ Sediment "Wafers" 35

CHAPTER 3

Table 3.1 : Pu Isotope Ratios by M.S. in 242Pu Spike and in Marine Sample Blanks . $\cdot{ }^{\circ} \cdot{ }^{\circ} \cdot 54$

3.2 : Selected Pu analyses by M.S. in North Atlantic Marine Samples (with Comparison to Alpha-counting) 58

CHAPTER 4

Table 4.1 : Location of Pore Water Sampling Sites and Date of Collection . . . . . . . . . . 67

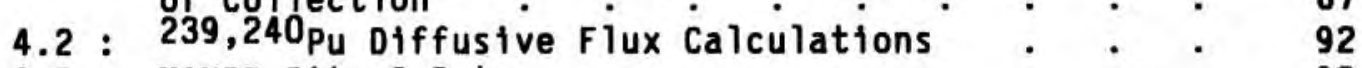

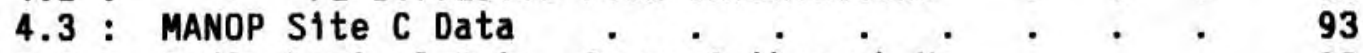

4.A : Radiochemical Data- Cores A through H . . . 99

4.B : Non-radiochemical Data- Cores A through H . . 103

CHAPTER 5

Table 5.1 : Northwest Atlantic Continental Margin Core Summary 110

5.2A: Total Pu Sediment Inventories for the North Atlantic Shelf and Slope Region . . . . . 113

5.2B: Total $210 \mathrm{pbex}$ Sediment Inventories for the
North Atlantic Shelf and Slope Region . . . 113

\section{CHAPTER 6}

Table 6.1 : Sampling Locations and Date of Collection . . 128

6.2 : Pu Data by Mass Spectrometry . . . . . 130

6.3 : Percentage of Nevada Fallout in Northwest
Atlantic Sediments... . . . . . 145

\section{CHAPTER 7}

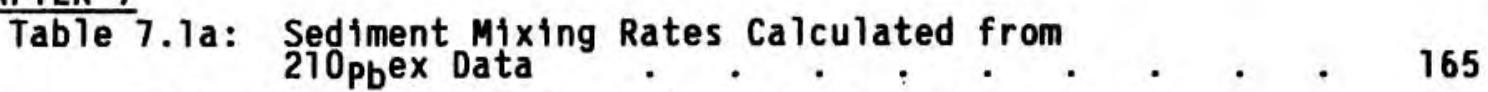

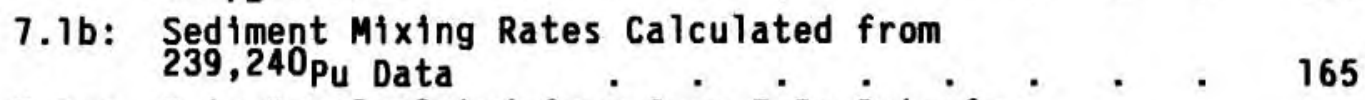

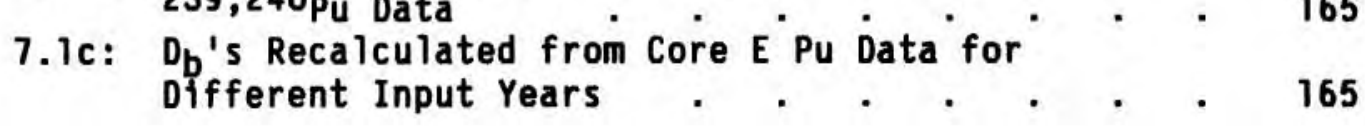




\section{CHAPTER 1}

\section{Plutonium in the Marine Environment:}

Introduction, Objectives and Background

\section{INTRODUCTION}

This thesis will examine the distribution and behavior of fallout plutonium in the marine environment. The main source of this plutonium (Pu) is atmospheric nuclear weapons testing during the 1950's and early 1960's (Perkins and Thomas, 1980; Harley, 1980). Researchers have been able to use the known pattern of fallout Pu deposition, to study removal processes in the water column (Bowen et a1., 1980; Santschi et a1., 1980; Livingston and Anderson, 1983; Fowler et a1., 1983; Bacon et a1., 1985), and in understanding mixing processes in marine sediments (Guinasso and Schink, 1975; Krishnaswami et a1., 1980; Benninger and Krishnaswami, 1981.; Kershaw et a1., 1983; Cochran, 1985). Such studies are based upon the measurement of the combined activities of ${ }^{239} \mathrm{Pu}$ and ${ }^{240} \mathrm{Pu}$ (written as $239,240 \mathrm{Pu}$ ) and assume an identical geochemical behavior for Pu from any of its fallout sources. The results of this thesis will show that the oceanographic chemistry of Pu is more complex than previously suspected.

A major focus of this work is on the mass spectrometric (m.s.) analysis of fallout $\mathrm{Pu}$ in a series of marine sediments and pore waters. With a m.s. method, not only is the detection limit for $239,240 \mathrm{Pu}$ lowered, but the ${ }^{239} \mathrm{Pu}$ and $240 \mathrm{Pu}$ isotopes can be separated as we 11. The ${ }^{240} \mathrm{Pu} /{ }^{239} \mathrm{Pu}$ ratio data are used in this thesis to show that there are significant differences in the geochemistry of Pu depending upon the specific sources of fallout Pu at a given site. More specifically, it appears that Pu from surface-based nuclear testing is delivered to the oceans in a distinct physical/chemical form which is more rapidly removed from the water column than stratospheric fallout from high altitude tests. These results have major implications for the interpretation of $\mathrm{Pu}$ 's 
geochemical behavior in deep sea sediments, where $239,240 \mathrm{Pu}$ inventories are generally quite low, and in ocean basins which have received substantial fallout from surface based tests, such as the North Pacific basin (Bowen et al., 1980).

The major objectives of this thesis are outlined below, and correspond to results and discussions in Chapters 3-7 of this thesis. Once the objectives have been presented, the remainder of this chapter will include an introduction to the study site, followed by a short review of the sources and general aquatic chemistry of Pu.

\section{OBJECTIVES}

1. A primary objective is the development of a thermal ionization mass spectrometry technique to measure fallout plutonium concentrations and isotope ratios at the extremely low levels found in marine sediments, pore waters, seawater and sediment trap samples. Mass spectrometric detection techniques for Pu have been developed primarily for use within the nuclear power and nuclear weapons industries. The application of this technique, however, has mainly been confined to precise determinations of $\mathrm{Pu}$ isotope ratios rather than for determining low level Pu concentrations. With isotope dilution m.s., the detection limit for ${ }^{239} \mathrm{Pu}$ and ${ }^{240} \mathrm{Pu}$ is at least an order-of-magnitude lower than detection by traditional alpha-counting techniques, which allows one to detect ${ }^{239,240} \mathrm{Pu}$ at the $10^{-18} \mathrm{M} / \mathrm{kg}$ level in liter volumes of water. Furthermore, the m.s. technique has the added advantage of yielding separate ${ }^{239} \mathrm{Pu}$ and ${ }^{240} \mathrm{Pu}$ determinations, in contrast to alpha-counting, where the alpha-decay energies of these two isotopes are essentially identical and hence inseparable.

2. This thesis will examine the distribution of plutonium between pore waters and sediments in the Northwest Atlantic shelf, slope and rise region, in order to link Pu solubility and mobility to the general blogeochemical cycles operating over this wide range of geochemical settings. The question of the potential remobilization of Pu from sediments has remained an unresolved topic for many years (Koide et 
a1., 1975, 1980; Edginton et al., 1976; Livingston and Bowen, 1979; Noshk in and Wong 1979; Bowen et al., 1980; Carpenter and Beasley, 1981; Santschi et a1., 1980; Sholkovitz and Mann, 1984; Cochran, 1985). Plutonium diffusion out of sediments has been postulated to explain deep water enrichments of ${ }^{239,240} \mathrm{Pu}$ in the Pacific (Bowen et al., 1980) and in lakes (Alberts and Orlandini, 1981; Sholkovitz et al., 1982), as well as apparent discrepancles between solid phase $239,240 \mathrm{Pu},{ }^{137} \mathrm{Cs}$ and ${ }^{210} \mathrm{~Pb}$ records (Livingston and Bowen, 1979; Cochran, 1985). Convincing evidence for or against Pu remobilization is difficult if not impossible to obtain from solid phase results alone. Pore water studies have long been known to provide the most sensitive indication of diagenetic behavior (Froelich et al., 1979; Berner, 1980). Plutonium pore water work has been 1 imited due to the extremely low concentrations of ${ }^{239,240} \mathrm{Pu}$ in pore solutions, therefore difficulties arise in collecting enough solution for $239,240 \mathrm{Pu}$ analyses by alpha counting. To date only two oceanic cores have been analyzed for ${ }^{239,240} \mathrm{Pu}$ in pore waters, one from the shallow sediments of the Irish Sea (contaminated from nuclear fuel reprocessing wastes) (Ne1son and Lovett, 1981), and the other from Buzzards Bay, Massachusetts, U.S.A. (Sholkovitz and Mann, 1984). The distribution coefficient, $K_{d}(\simeq \mathrm{dpm} 239,240 \mathrm{Pu}$ per $\mathrm{kg}$ of solids/dpm $239,240 \mathrm{Pu}$ per $\mathrm{kg}$ solution), found in both of these studies was $\simeq 10^{5}$, with no evidence for the sharp pore water gradients necessary to support significant remobilization of Pu. One of the objectives of this thesis was to extend this type of study to continental shelf, slope, and deep-sea sediments, where Pu pore water profiles could be examined under a variety of geochemical settings.

3. Given the relatively large number of cores which have been analyzed for $239,240 \mathrm{Pu}$ and/or $210 \mathrm{~Pb}$ from the Northwest Atlantic shelf and slope region, an examination of regional sediment inventory patterns with respect to water column removal and deposition processes is possible. Plutonium and ${ }^{210} \mathrm{~Pb}$ inventories are compared since both of these isotopes are supplied by atmospheric deposition, and because both of these tracers are used to study sediment accumulation and 
mixing on the 10-100 year time scale (Benninger and Krishnaswami, 1981; Carpenter et a1., 1982; Beasley et a1., 1982; Officer and Lynch, 1982; Cochran, 1985). A mass balance for ${ }^{239,240} \mathrm{Pu}$ and $210_{\mathrm{Pb}}$ excess will be made in order to determine their total fluxes into and out of the study region. This mass balance will be used to test the hypothesis of Spencer et al. (1981), which suggests that the lateral transport of $210 \mathrm{~Pb}$ from the ocean's interior is a significant source of $210 \mathrm{pb}$ to these slope sediments.

4. Isotopic ratios of ${ }^{240 / 239} \mathrm{Pu}$ in these North Atlantic samples are examined in order to understand the specific sources and removal rates of fallout Pu at a given site. A systematic decrease in the $240 \mathrm{Pu} /{ }^{239} \mathrm{Pu}$ ratio in sediments with increasing water depth is found, similar to the Gulf of Mexico data of Scott et a1. (1983). My evidence from ${ }^{240} \mathrm{Pu} /{ }^{239} \mathrm{Pu}$ ratios in sediment trap samples, water column profiles, and early 1960's sediment samples all support the existence of at least two distinct sources of fallout Pu to the North Atlantic, each with different geochemical properties and removal rates. This evidence for the input of different fallout Pu types will have important bearing on: a) the use of Pu as a geochemical tracer to study the present day removal of radionuclides from the water column, b) estimates of the transport of Pu by large biogenic particles and the remineralization rate of this material at the sediment/water interface, and c) studies which must assume an input function for Pu to pelagic sediments in order to model benthic mixing rates (see below).

5. A model approach is used to constrain the input function of fallout $\mathrm{Pu}$ to marine sediments by combining the $\mathrm{Pu}$ isotopic data with $239,240 \mathrm{Pu}$ and ${ }^{210} \mathrm{~Pb}$ activity data in the sediments. Since the input and removal of $\mathrm{Pu}$ to the ocean cannot be considered to be in steady-state due to its recent introduction to the oceans, any sediment mixing model must assume an input function for Pu deposition. This input function will not be proportional to the known fallout patterns if the removal rates of $\mathrm{Pu}$ to the sediments have not been constant. For example, one extreme case is that the bulk of Pu delivered to deep sea sediments arrived as a pulse centered around the years of maximum 
Pu fallout, and hence maximum surface water Pu concentrations. A second scenario is that Pu removal rates have remained constant with time, with present day fluxes being equal to previous removal rates. Both of these input approximations have been used in previous 239,240 Pu modelling attempts (Officer and Lynch, 1982; Sayles and Livingston, 1985; Cochran, 1985; Anderson et a1., 1986). In my model, $210 \mathrm{~Pb}^{\text {ex }}$ activity profiles are used to obtain benthic mixing rates. These mixing rates are then used in a Pu pulse or continuous input model to look at $\mathrm{Pu}$ isotopic ratios in the sediments resulting from the Nevada and stratospheric fallout sources, each with their characteristic ${ }^{240} \mathrm{Pu} /{ }^{239} \mathrm{Pu}$ ratio. Given the large number of $239,240 \mathrm{Pu}$ and/or $210_{\mathrm{Pb}}$ ex profiles from this study region, an attempt can also be made to statistically examine benthic mixing rate variability in shelf, slope, and deep-sea sediments.

\section{THE STUDY REGION: THE NORTHWEST ATLANTIC SHELF, SLOPE AND RISE}

\section{A. The SEEP Program}

Most of the samples which were analyzed for this thesis were collected as part of the U.S. Department of Energy sponsored program called SEEP (Shelf Edge Exchange Processes). The SEEP program is a multi-disciplinary undertaking involving marine biologists, chemists and physical oceanographers. The SEEP program is broadly designed to study cross-shelf exchange in the Mid-Atlantic Bight region. It was hypothesized that fine-grained, organic-rich matter being produced on the shelf was being transported to the upper slope sediments where fine-grained sediment deposits are known to occur. The main focus of attention in the SEEP research includes: 1) a study of the physical forces driving the off-shore transport of suspended matter in the shelf region, 2) an examination of the importance of the shelf/slope front in the transfer of material to the upper slope, 3 ) determine if the upper slope is truly the final site of deposition of particle reactive elements and organic carbon, and 4) establish evidence for or against the horizontal removal of particle reactive tracers from the ocean's 
interior to this margin site. In the following discussion the N.W. Atlantic shelf, slope, and rise regions will refer to the U.S. continental margin from Cape Hatteras to Nova Scotia out to water depths of $4000-5000 \mathrm{~m}$ (Fig. 1.1).

The first stage of the SEEP experiment (SEEP-I) consisted of a variety of measurements and sampling activities along a transect essentially due south of Martha's Vineyard at $71^{\circ} \mathrm{W}$ (Stations A-F, Fig. 1.1). Samples were collected from stations with water depths ranging from less than $50 \mathrm{~m}$ on the shelf to close to $3000 \mathrm{~m}$ on the upper-rise. A series of seven moorings (at 90-2700 m water depths) were deployed during the winter, spring, and summer of 1983-1984 to collect seasonal and depth-dependant sediment trap samples (using 10to 14-day sampling intervals and two separate deployments of the sediment trap arrays). These moorings were also used to collect long term transmissometer and current data (see Fig. 1.2 for mooring depths and typical configurations). Box cores and gravity cores were collected at many depths along this transect, and my pore water and sediment samples were analyzed from box core samples at five depths along the transect-90,500, 1200, 2300, and $2700 \mathrm{~m}$ (in addition, I analyzed box core samples from the deep-sea at 4469 and $4990 \mathrm{~m}$ from box cores collected independent of the SEEP program, 1.e. Stations $G$ and $H$ in Fig. 1.1). Large volume samples for suspended particulates and dissolved natural and artificlal radionuclides were obtained by an in-situ pumping system (Mann et a1., 1984; Bacon, 1986). Discrete water column samples and extensive CTO and transmissometer data were collected during these same cruises. Satellite imagery and wind speed data have also been obtained to support the field observations.

The results from this first SEEP experiment are just emerging, with reports and abstracts from two major meetings being the chief source of information thus far (AGU Spring meeting, Baltimore (1985) Eos 66(18); AGU/ASLO winter meeting, New Orleans (1986) Eos 66(51)). Manuscripts by numerous participants in SEEP-I have already been submitted for an upcoming volume of Continental Shelf Research. This issue will provide a comprehensive analysis of the SEEP results to 
Fig. 1.1: Map showing the location of cores used in this study. box cores are identified by letters $A$ through $H$ on this map, as discussed in the text.

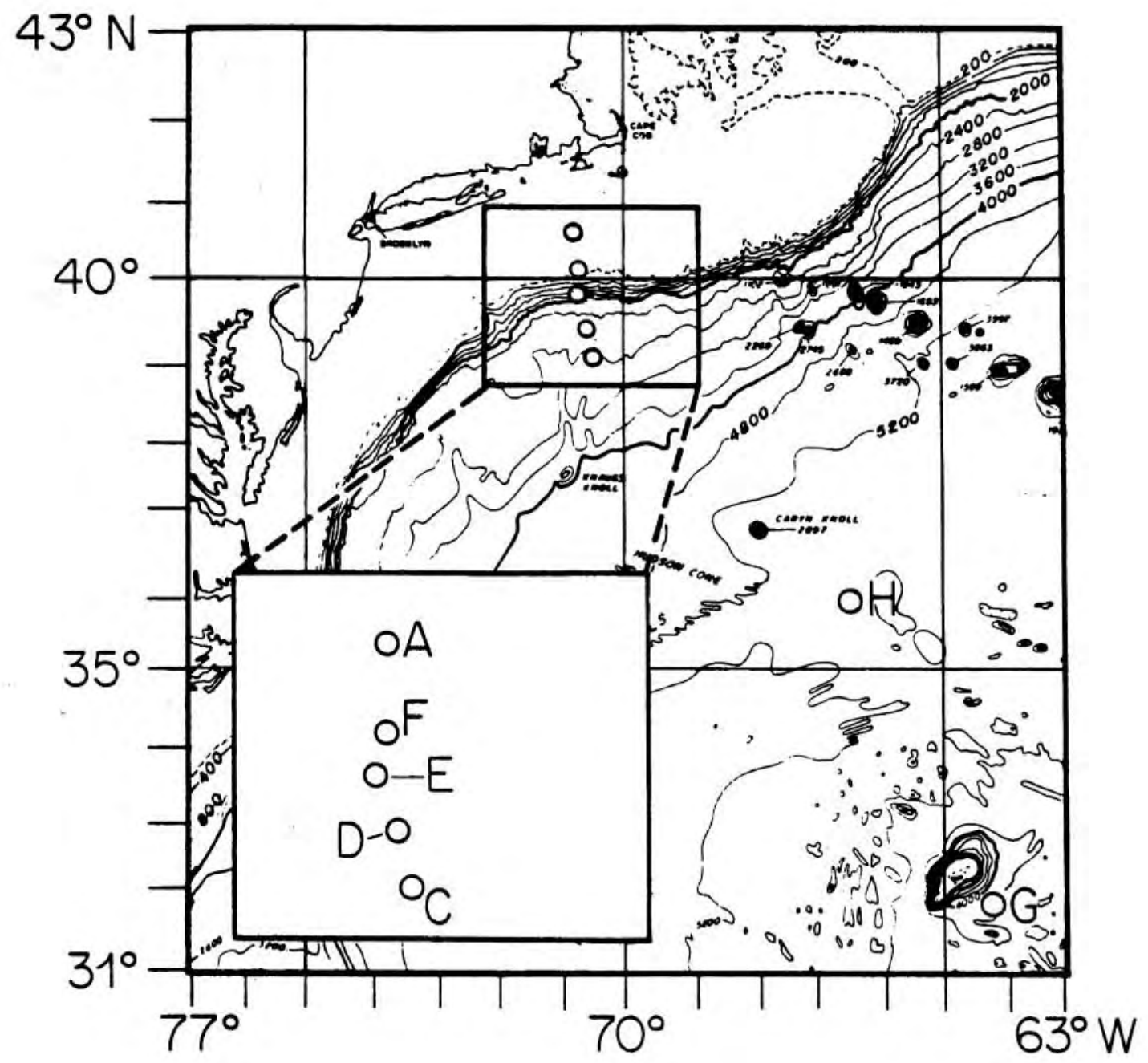


Fig. 1.2: Schematic dlagram of mooring arrays deployed during the SEEP-I experiment.

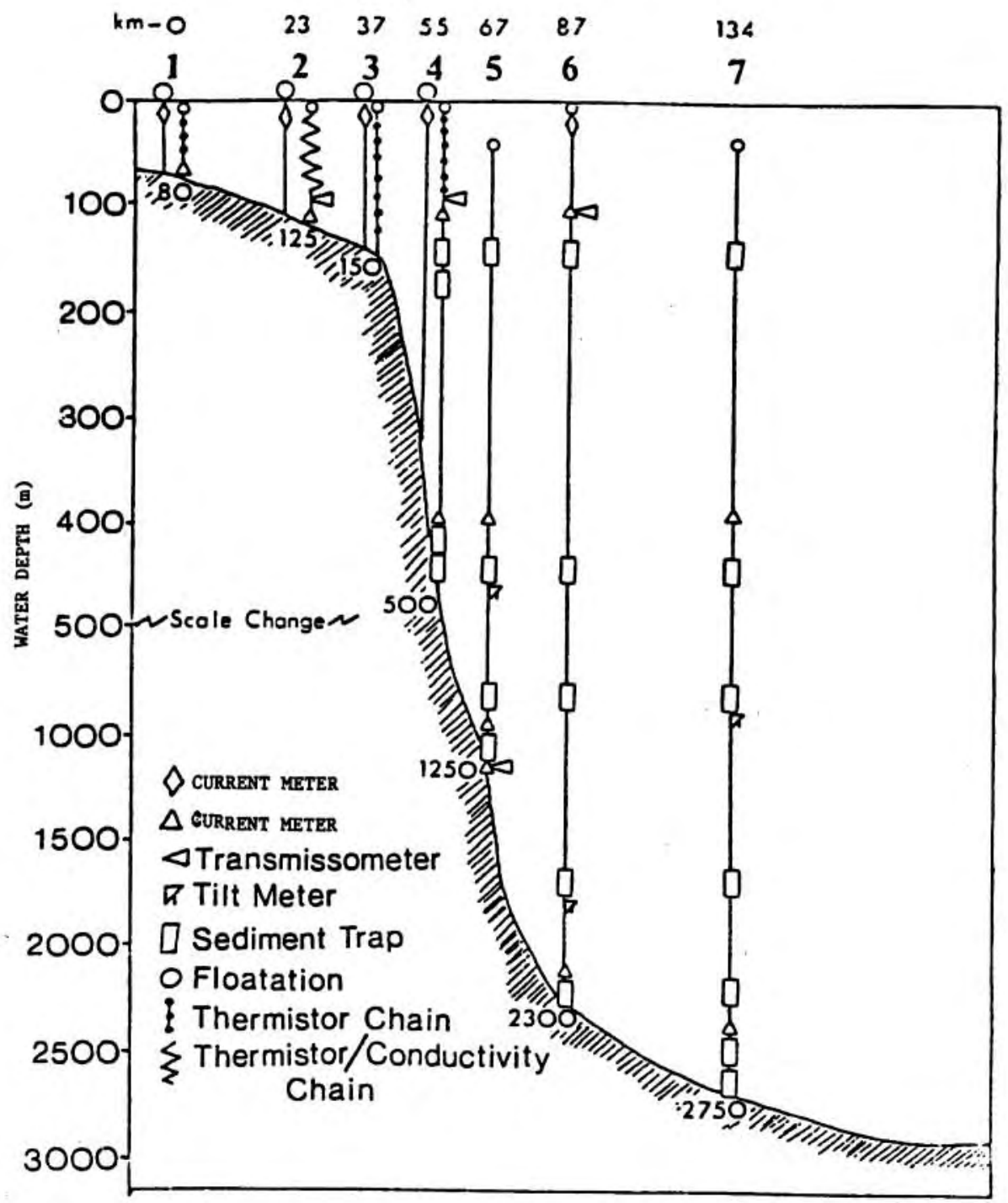


date. The general geological and biological research of this region which is of importance to this thesis will be briefly described below, based upon previous studies and some early SEEP-I results.

A prominent feature of the SEEP region is the continental slope, which is a topographic discontinuity between the continental shelf and the upper continental rise. While the shelf has an average seafloor gradient of $<1^{\circ}$, the slope has a relatively much steeper gradient of 2-6 $6^{\circ}$ with variations from $4-11^{\circ}$ around its steepest sections (Garrison and McMaster, 1966; Tucholke, 1984). The slope is a relatively narrow feature (10-50 km wide) which is heavily dissected by a large number of submarine canyons and channels. The shelf/slope break occurs between $100-200 \mathrm{~m}$ water depths, while the base of the slope occurs at $2000 \pm$ $200 \mathrm{~m}$, where there is a marked gentling of the seafloor gradient at the upper rise (see Fig. 1.1).

Evidence exists for wave cut terraces at the outer shelf edge, which were formed at lower sea level stages during previous glaciations (Garrison and McMaster, 1966). During the last glaciation (15,000 years before present), northern rivers crossed the present day shelf carrying melt water and suspended sediments directly to the slope region. At latitudes $>41^{\circ} \mathrm{N}$, glaciers are likely to have deposited sediment directly to the slope. With the rising sea level, the winnowing of shelf clays occurred. At present, a majority of river suspended sediments are trapped in the estuaries and at inner shelf sites adjacent to the major northern rivers (Militiman et al., 1972). Biogenic and ice rafted debris appear to be the major net contributors of sediment accumulation to the continental margin region since the last glaciation. The continued reworking and erosion of existing sediments will also affect sediment redistribution and accumulation within the region.

Quite extensive data exist on the sedimentology of the surface sediments of the U.S. Atlantic continental margin. The most extensive surveys were conducted in the 1960's and early 1970's by the Woods Hole Oceanographic Institution, the U.S. Geological Survey, and Duke University. These surveys involved the collection of over 6000 surface 
sediments from the shelf and slope regions along the entire U.S. continental margin. Results from this work have been published by Hathaway (1971, 1972), Milliman et al. (1972), and Schlee (1973), among others, and this data set will be the primary source for the background minerology discussions below.

Shelf sediments are generally characterized by a high sand content, with clay and silt contents rarely exceeding $1 \%$. The exception to this is the "Mud Patch" region where, as the name implies, shelf sediments exist which contain a high fraction of muddy sediment (>30\% silt and clay, 1-2\% organic carbon). The original source of these fine-grained sediments is likely the previous winnowing and erosion of fine sediment by strong tidal currents which occur on Georges Bank and Nantucket Shoals, resulting in the southwestward transport of suspended sediments to the Mud Patch site (Bothner et al., 1981). A possible present-day source of fine-grained material is the continued reworking of subsurface material on Georges Bank or the erosion of outcrops of older sediment. Evidence for physical resuspension at the Mud Patch site can be seen in bottom photographs which show high suspended sediment loads $(5-10 \mathrm{mg} / 1)$ in the overlying bottom water following high wind events (Twichell et al., 1981). Extensive biological reworking of Mud Patch sediments has also been seen in numerous ${ }^{210}{ }_{\mathrm{Pb}}{ }^{\mathrm{ex}}$ and $239,240 \mathrm{Pu}$ sediment profiles from this site (Santsch1, 1980; Bothner et al., 1981; Buesseler and Sholkovitz, 1984; Anderson et al., 1986; and following chapters in this thesis). It should be noted that the total area of this atypical shelf feature is rather small, representing only $\simeq 5 \%$ of the total shelf area between Cape Hatteras and Nova Scotia (Buesseler et al., 1985).

The slope sediments in this region contain somewhat higher organic carbon contents and higher silt and clay contents than sandy shelf sites ( $\approx 0.5 \%$ organic carbon, 20-30\% silt and clays (Hathaway, 1971; Steinberg and Kaplan, 1985)). It is precisely the presence of these fine grained deposits on the upper slope that have led to the hypothesis of the existence of cross-shelf transport and preferential accumulation of particle reactive tracers and organic carbon on the 
upper slope.

The slope sediments contain 5-20\% carbonate, consisting mainly of planktonic foraminifera tests, and generally increasing with depth (Tucholke, 1984). This is in contrast to $<5 \%$ carbonate levels on most of the shelf. The clays which are present on the slope in this study region are predominantly illite and chlorite, the so-called "northern clay assemblage" (Hathaway, 1972). The slope south of Cape Hatteras is the site of the "southern clay assemblage", consisting predominantly of montmorillonite and kaolinite. The cause of this difference in clay minerology is due to differences in the drainage basins of the northern and southern rivers.

Less is known about continental rise sediments than either slope or shelf sites. Blogenic debris appears to contribute to the net accumulation of sediment in this region. Carbonate from settling pelagic planktonic foraminifera makes up about $25 \%$ or more of the weight of the rise sediments. Biogenic silica is also significant out to $2250 \mathrm{~m}\left(10-15 \%\right.$ amourphous $\left.\mathrm{SiO}_{2}\right)$ (Walsh et al., 1985).

The fine-grained slope sediments, combined with the relatively steep slope topography, are conducive to down slope gravitational sediment movement. Evidence exists in the geological record for slumps, slides, debris flows, and turbidity flows over much of the continental slope and rise (Embley, 1980; Knebe1, 1984). These mass flows represent a continuous spectrum of gravity-driven transport mechanisms on both the large (travel distances on the order of 100's to 1000 's of kilometers) and small scale. Selsmic data and core samples provide the bulk of the evidence for such mass wasting processes.

The two tracers which I use in this thesis to examine sediment mixing and accumulation are ${ }^{239,240} \mathrm{Pu}$ and $210 \mathrm{~Pb}$. Both of these radionuclides record sedimentary processes which have occurred during the past few decades, and cannot be expected to record evidence for large scale mass wasting events which occur very infrequently. In only 5 out of the 25 cores which have been analyzed for $239,240 \mathrm{Pu}$ and/or $210_{\mathrm{Pb}}$ ex during the SEEP program is there any obvious evidence for non-steady state physical or biological, mixing or accumulation events 
(Anderson et a1., 1986). While sediment slumping and slides are often suspected to be important in this region, these radioisotopic tracers support generally steady-state mixing and accumulation mechanisms during the recent decades.

Previous studies of benthic fauna along the New England slope can be used to estimate the species abundance along the SEEP-I transect (Rowe et al., 1974; Grassle, 1977; Wiebe, 1984; Grassle, 1986). The number of benthic macrofauna collected in box core samples along the slope is on the order of 4000 individuals $\mathrm{m}^{-2}$ (using a $0.5 \mathrm{~mm}$ mesh size) and does not change systematically within the 1000-3000 m depth range (Rowe et a1., 1982; Grassle, 1986). At depths greater than $3000-4000 \mathrm{~m}$, the abundance of benthic organisms decreases (Rowe et al., 1982); however, the amount of data from continental rise cores from this region is quite limited. The most numerous benthic macrofauna along the slope are the polychaetes, with Aurospiro dibranchata being the dominant species in the $1700-3600$ m depth range (Grassle, 1977). Many of the polychaetes and deep-sea fauna, in general, feed at the sediment-water interface, removing particles from the surface and depositing them at depth in the sediment. In addition to the vertical transport of sediment by burrowing organisms, considerable lateral mixing of sediments may occur due to the horizontal burrowing activities of hard urchins (along a subsurface plane at depth of $10-15 \mathrm{~cm}$ ) (Grassle, 1986). $239,240_{\mathrm{Pu}}$ and $210_{\mathrm{Pb}}{ }^{\text {ex }}$ profiles from this region will be used to quantify benthic mixing rates and to examine the variability in these rates within individual cores, between cores at the same depth, and between cores along the entire transect $(80-5000 \mathrm{~m})$.

\section{SOURCES OF PLUTONIUM}

Plutonium was first produced and hence discovered in 1940 by Seaborg et al. (1946). To date 15 isotopes of $\mathrm{Pu}$, ranging from ${ }^{232} \mathrm{Pu}$ to ${ }^{246} \mathrm{Pu}$, have been produced and studied (Taube, 1964; Milyokuva et al., 1969). Of these isotopes, only six have decay half-lives of 
greater than one year (see Fig. 1.3), with the 238,239,240 and 241-Pu isotopes being the most abundant. The tremendous energy released during the fission of ${ }^{239} \mathrm{Pu}$ and hence its military weapons applications, resulted in the immediate large scale production of this artificial radioisotope. The production of ${ }^{239} \mathrm{Pu}$ is commonly performed by the irradiation and subsequent capture of slow neutrons by ${ }^{238} \mathrm{U}$ in a nuclear reactor or cyclotron. The relevant reaction is as follows:

$$
{ }^{238} \mathrm{U}(n, \gamma) \rightarrow{ }^{239} \mathrm{U} \underset{23 \mathrm{~min}}{\stackrel{B^{-}}{239}}{ }^{23 p} \frac{B^{-}}{2.3 \mathrm{~d}}{ }^{239} \mathrm{Pu}
$$

Heavier isotopes of Pu can be produced by subsequent neutron capture steps from ${ }^{239} \mathrm{Pu}$, either in a nuclear reactor setting, or during the large neutron flux which is produced during the explosion of an atomic or thermonuclear bomb. The relative abundances of the Pu isotopes in a reactor fuel or in nuclear weapons fallout will depend upon the nature and intensity of the neutron flux and the time span over which this flux and subsequent radioactive decay occurs. Although the resulting isotopic ratio of $\mathrm{Pu}$ in fallout and irradiated reactor fuel is variable, these sources can generally be characterized by their isotopic signatures. Typical Pu isotopic ratios in fallout and irradiated reactor fuel are given in Table 1.1 .

The input of fallout Pu from atmospheric nuclear weapons testing programs is the largest source of $\mathrm{Pu}$ to the environment, including the oceans. (Harley, 1980; Perkins and Thomas, 1980). In total, roughly $400 \mathrm{kCl}$ of ${ }^{239} \mathrm{Pu}$ and ${ }^{240} \mathrm{Pu}$ have been deposited in the environment from these atmospheric weapons tests, with $\simeq 330 \mathrm{kCi}$ being deposited as stratospheric, or so-called global fallout (Harley, 1980). A discussion of the historical input of fallout $\mathrm{Pu}$ will be presented in order to assist in interpreting some of the Pu isotopic and activity patterns observed in present day marine samples.

The first significant environmental release of Pu occurred with the "Trinity" nuclear test shot on 16 July 1945 in Alamogordo, New Mexico, U.S.A.. The complete historical input pattern of fallout Pu has been obtained in several ways: 1) through reference to announced 
Fig. 1.3: Plutonium isotopes and nuclear decay products (from Taube, 1964).

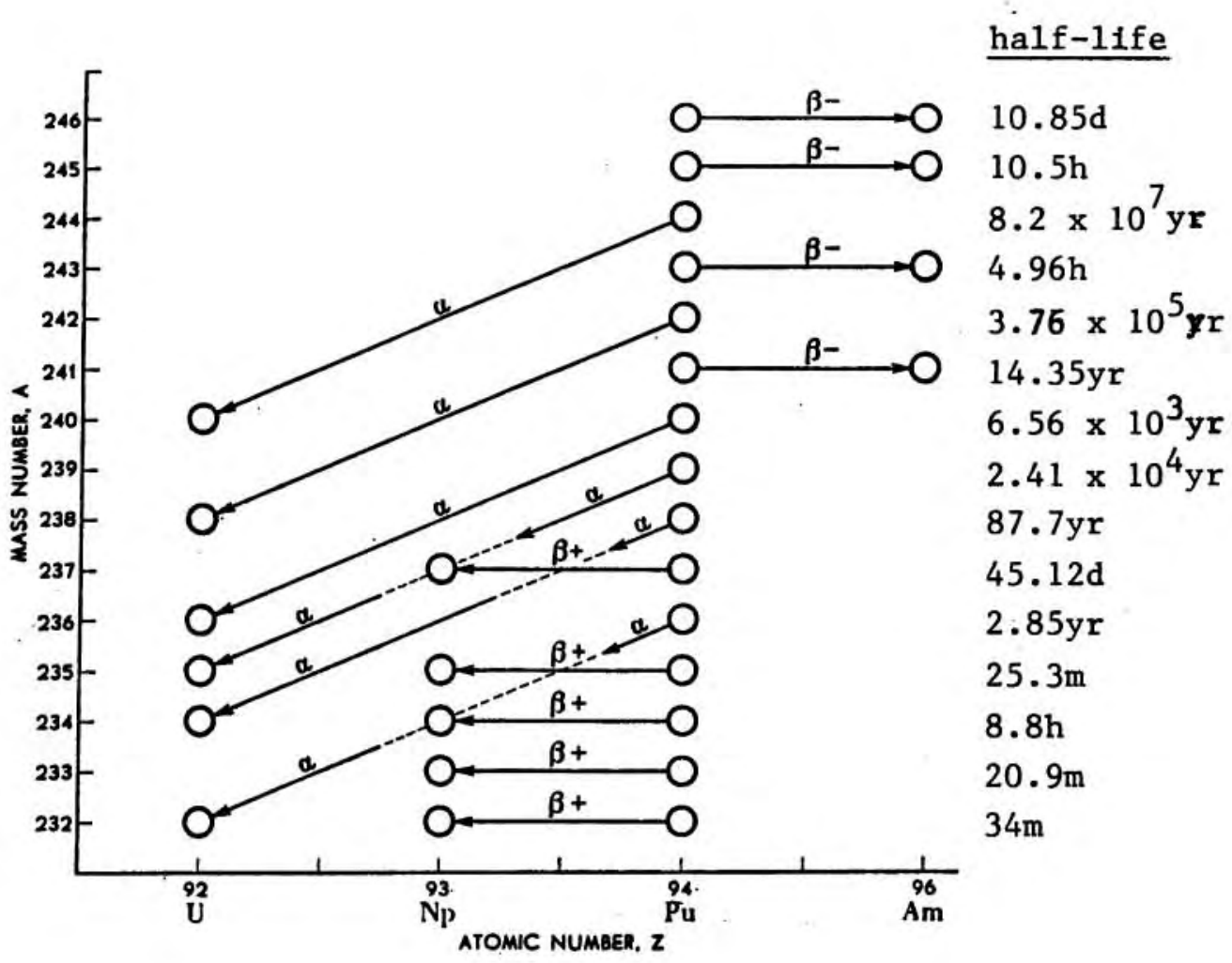

TABLE 1.1. Relative Abundances (1) of Plutonium Isotopes in Global Fallout vs. Power Reactors

$\begin{array}{lll}\frac{\text { Mass }}{238 \mathrm{Pu}} & \text { Global Fallout } & \text { Nuclear Reactor (2) } \\ 239 \mathrm{Pu} & 3.5 \times 10^{-5} & 6.42 \\ 240 \mathrm{Pu} & 1 & 1 \\ 241 \mathrm{Pu} & 0.18 & 0.45 \\ 242 \mathrm{Pu} & 0.0035 & 0.168 \\ & 0.004 & 0.067\end{array}$

(1) Data are normalized to ${ }^{239} \mathrm{Pu}$ and are reported on a mass bas 15 , (2) Assuming 30,000 Mwd/ton exposure

Ref.: Perkins and Thomas (1980). 
atmospheric nuclear weapons testing ylelds (see Fig. 1.4 and Table 1.2), 2) through the determination of fallout activity patterns in wet and dry deposition (E.M.L., 1980), or 3) through the examination of fallout records in dated ice cores (Koide et a1., 1979, 1985), sediment cores (Koide et a1., 1975, 1980, 1982; Krey, 1983; Breteler et a1., 1984), or corals (Freeman et a1., 1985). The ${ }^{90} \mathrm{Sr}$ (a fission product in nuclear fallout) depositional pattern at New York City has been reliably monitored since 1954 and is shown in Figure 1.5. Since the ${ }^{90} \mathrm{Sr} /{ }^{239}, 240 \mathrm{Pu}$ activity is essentially constant in fallout debris ( $\simeq 56$ in 1980), this ${ }^{90} \mathrm{Sr}$ record can be regarded as representing the historical input pattern of fallout $\mathrm{Pu}$ at this site. The main features of this record include considerable fallout in the mid-to-late 1950's and a drop-off in fallout deposition in 1960 and early 1961 (during the U.S.A.IU.S.S.R. testing moratorium). This is followed by the largest input of fallout in the early 60's and a sharp reduction in fallout in the later 1960's with some minor fluxes in the late 60's through the 1970's. This pattern is consistent with the announced testing records (see Table 1.2 for detalls).

The first thermonuclear (H-bomb) test (U.S. "Mike" test-14Mt) in 1952 injected considerable fallout into the stratosphere for the first time. Fallout consists of a range of radloactive debris types, each with varying physical/chemical properties depending upon the nature of the nuclear test, and variability in fallout particle formation within a single testing event. The terms stratospheric or global fallout vs. tropospheric or close-in fallout refer only to whether or not fallout from a particular test gained sufficient height to reach stratospheric altitudes. Both large yield surface tests and large and small yield high altitude tests will inject fallout debris into the stratosphere. In surface-based tests of any yield, considerable surface material will become incorporated into the nuclear fireball. As this partially or completely melted matter condenses, radioactive fission products and unfissioned elements will become incorporated into this debris (Adams, 1960). Depending upon the nature of the surface material (1.e. either sand, so11, or coral matter), the resulting close-in fallout particles 
Fig. 1.4: Reported Atmospheric Weapons Testing yields vs. year and by type. Surface bursts include all surface, tower, barge, and low altitude ( $<500 \mathrm{ft}$.) balloon shots. Air bursts include all other tests.

Ref.: DOE (1982); Zander and Araskog (1973); Perkins and Thomas (1980).

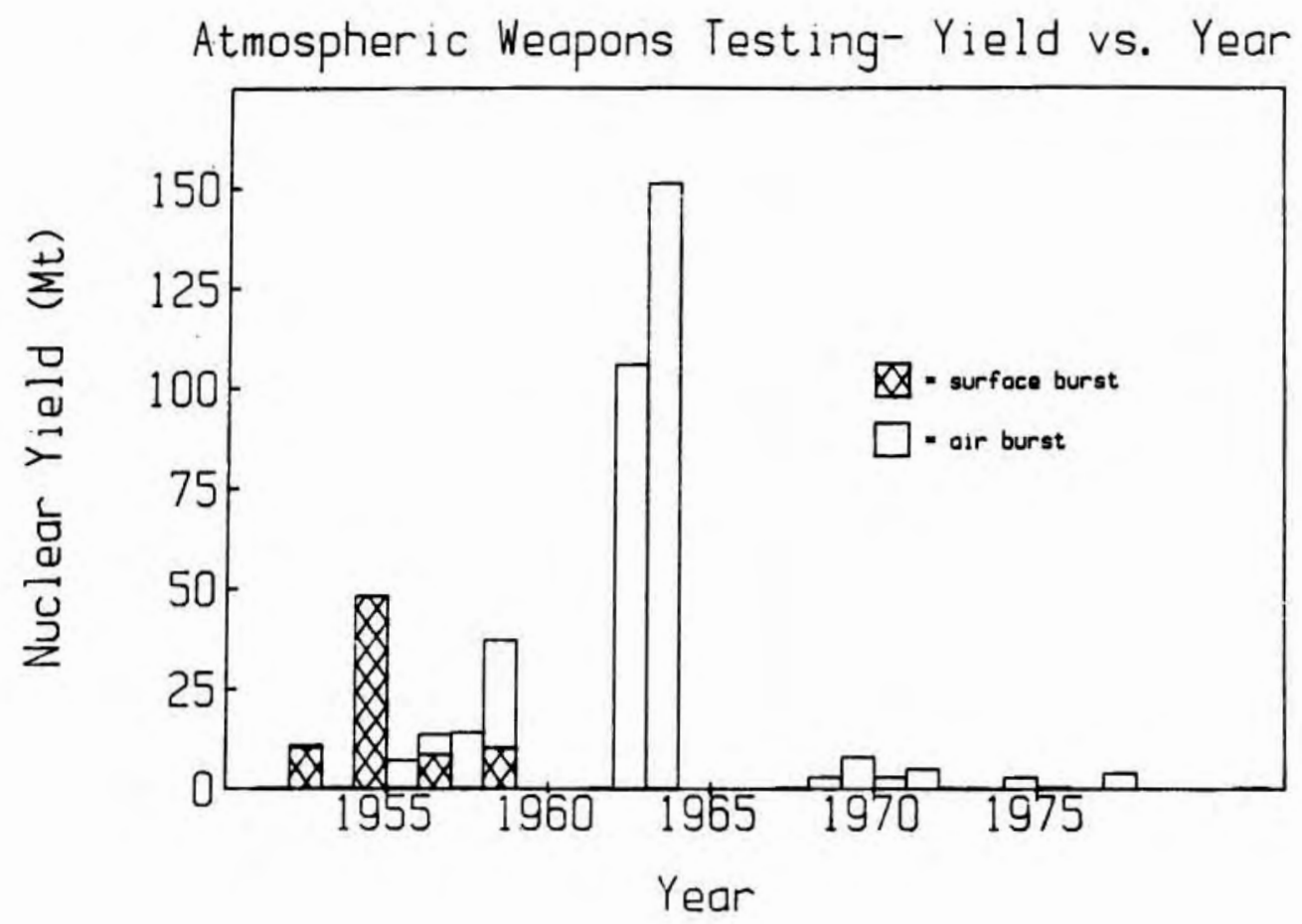

Fig. 1.5: Quarterly deposition of ${ }^{90} \mathrm{Sr}$ measured at New York City between 1954 and 1980. Figure redrawn from Environmental Measurement Laboratory (1980).

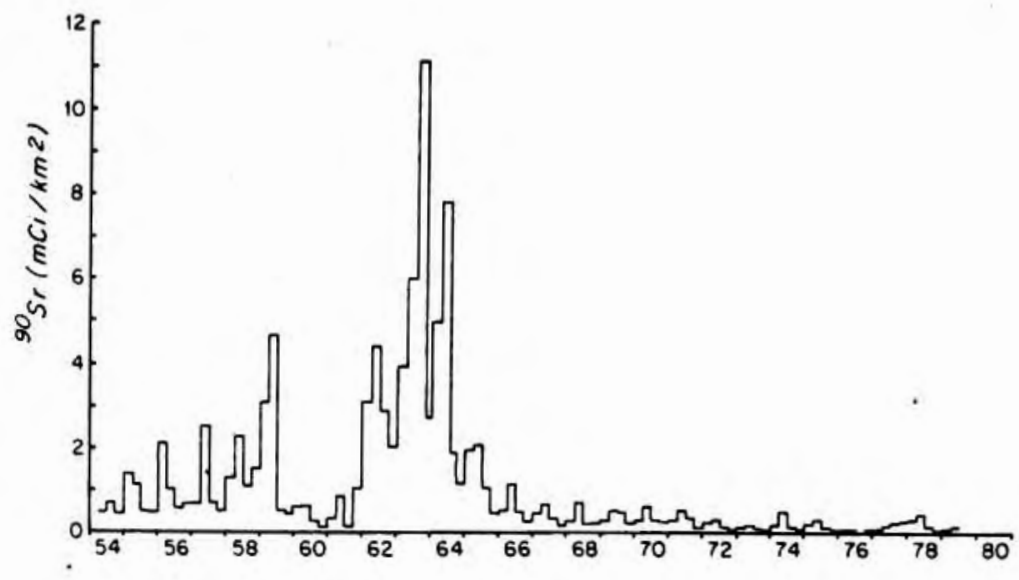


Table 1.2. Announced Atmospheric Nuclear Test Ylelds (kT) ${ }^{\text {(1) }}$

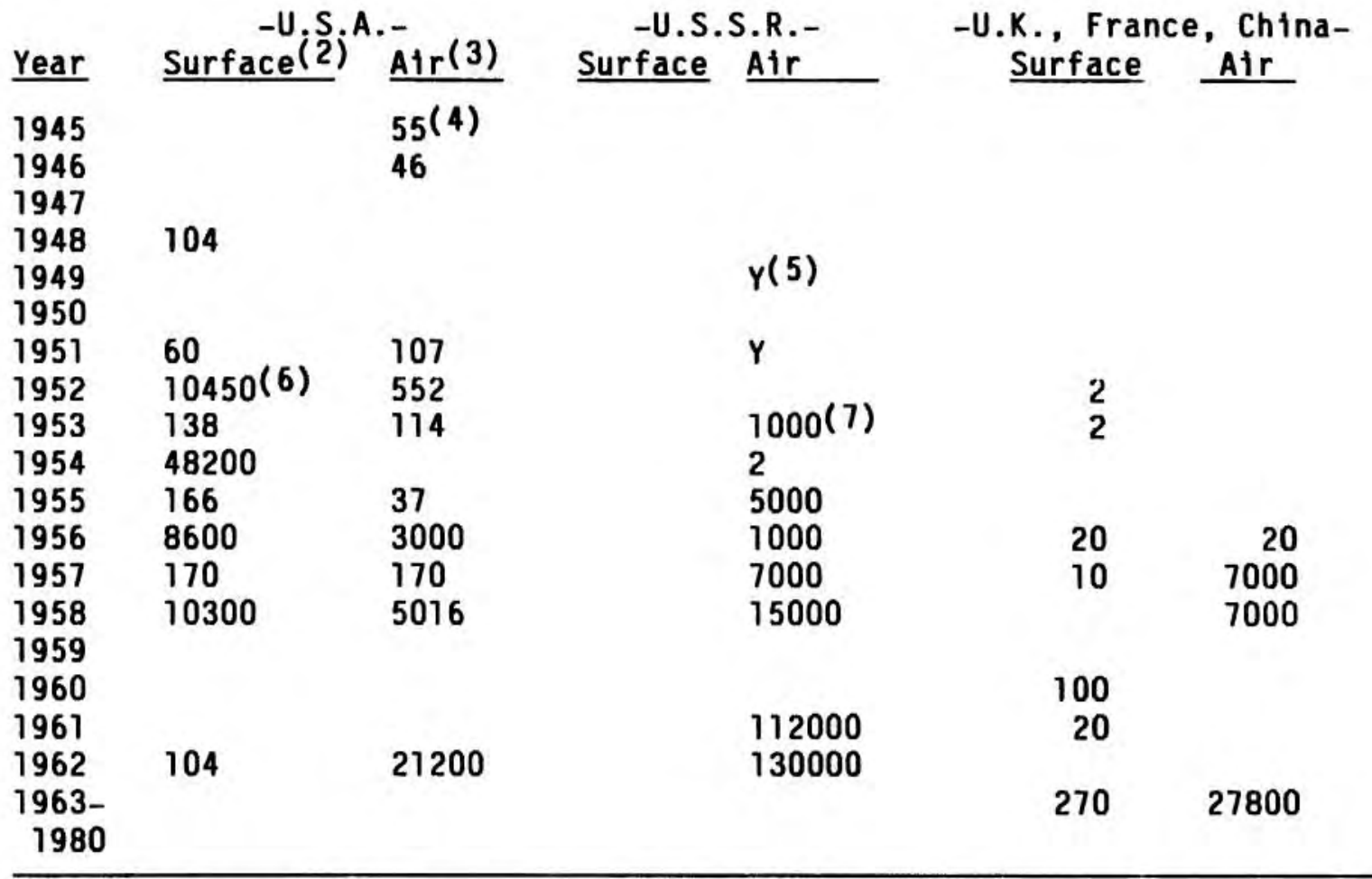

(1) Yields are listed in kilotons (kT) or the energy of a nuclear explosion that is equivalent to an exploston of 1,000 tons of TNT. These ylelds likely represent minimum values, since many test yields have never been reported or confirmed.

(2) Surface indicates those tests which are likely to produce considerable "close-in" or intermediate fallout due to the detonation of a nuclear bomb at or near the earth's surface. This includes all tower, barge, surface and low balloon shots (le. those detonated at $<500 \mathrm{ft}$. height).

(3) Air indicates shots less likely to produce "close-in" fallout. This includes all atmospheric, rocket, high altitude balloon and underwater tests.

(4) Includes first U.S. test ("Trinity") and the Hiroshima \& Nagasaki bombs.

(5) $Y$ indicates early low yleld U.S.S.R. test with unreported yield.

(6) First U.S. thermonuclear explosion (H-bomb)

(7) First U.S.S.R. thermonuclear explosion (likely yield at least $\simeq 1000 \mathrm{kt}$ ).

Refs.: Zander and Araskog, 1973; Perkins and Thomas, 1980; U.S. Dept. of Energy, 1982 
may have significantly different solubilities in the surface ocean than average global fallout debris. This difference in fallout particle solubility and reactivity will be discussed with relationship to my $240 \mathrm{Pu} /{ }^{239} \mathrm{Pu}$ ratio data in Chapter 6 .

The primary pathway for the injection of stratospheric fallout back into the troposphere is through the tropopause dicontinuity zone, which occurs predominantly in the spring at mid latitudes (Perkins and Thomas, 1980). The residence time of stratospheric fallout is approximately one year, while the residence time of tropospheric debris is much shorter on the order of days to weeks (Perkins and Thomas, 1980; Holloway and Hayes, 1982). Due to the predominance of testing sites in the Northern Hemisphere (Fig. 1.6), and due to the mid-latitudinal stratospheric injection process, the inventories of fallout 239,240 Pu vary with latitude, as shown in Figure 1.7. On a smaller scale, roughly $70 \mathrm{kCl}$ of close-in fallout have been deposited in the vicinity of the testing sites (Harley, 1980). The large surface based tests of the U.S. at the Marshall Islands in the Pacific are by far the largest source of close-in fallout and add a considerable inventory of "excess" Pu to the N. Pacific basin (Bowen et al., 1980). Other than weapons fallout, relatively minor releases of $\mathrm{Pu}$ to the environment have occurred, and these include (taken from Harley, 1980): 1) the accidental burn-up of the SNAP-9A navigational satellite in 1964 over the Indian Ocean (releasing $\simeq 17 \mathrm{kCl}$ of ${ }^{238} \mathrm{Pu}$ ), 2) the dispersal of weapons grade Pu from military alrplane mishaps in Palomares, Spain in 1966, and Thule, Greenland in 1968,3) slight leakages from nuclear reactor operations, weapons productions facilities, and nuclear waste disposal operations, and 4) the direct release of liquid radioactive wastes into the Irish Sea by the Sellafield fuel reprocessing plant in England (formerly known as Windscale). This last source is presently the world's largest source of Pu to the environment, with an estimated $14 \mathrm{kCi}$ of $239,240 \mathrm{Pu}$ having been released between 1957-1978 (Needler and Templeton, 1981). 
Fig. 1.6: Worldwide nuclear testing sites (from Zander and Araskog, 1973).

Test sites 1945 - 1972

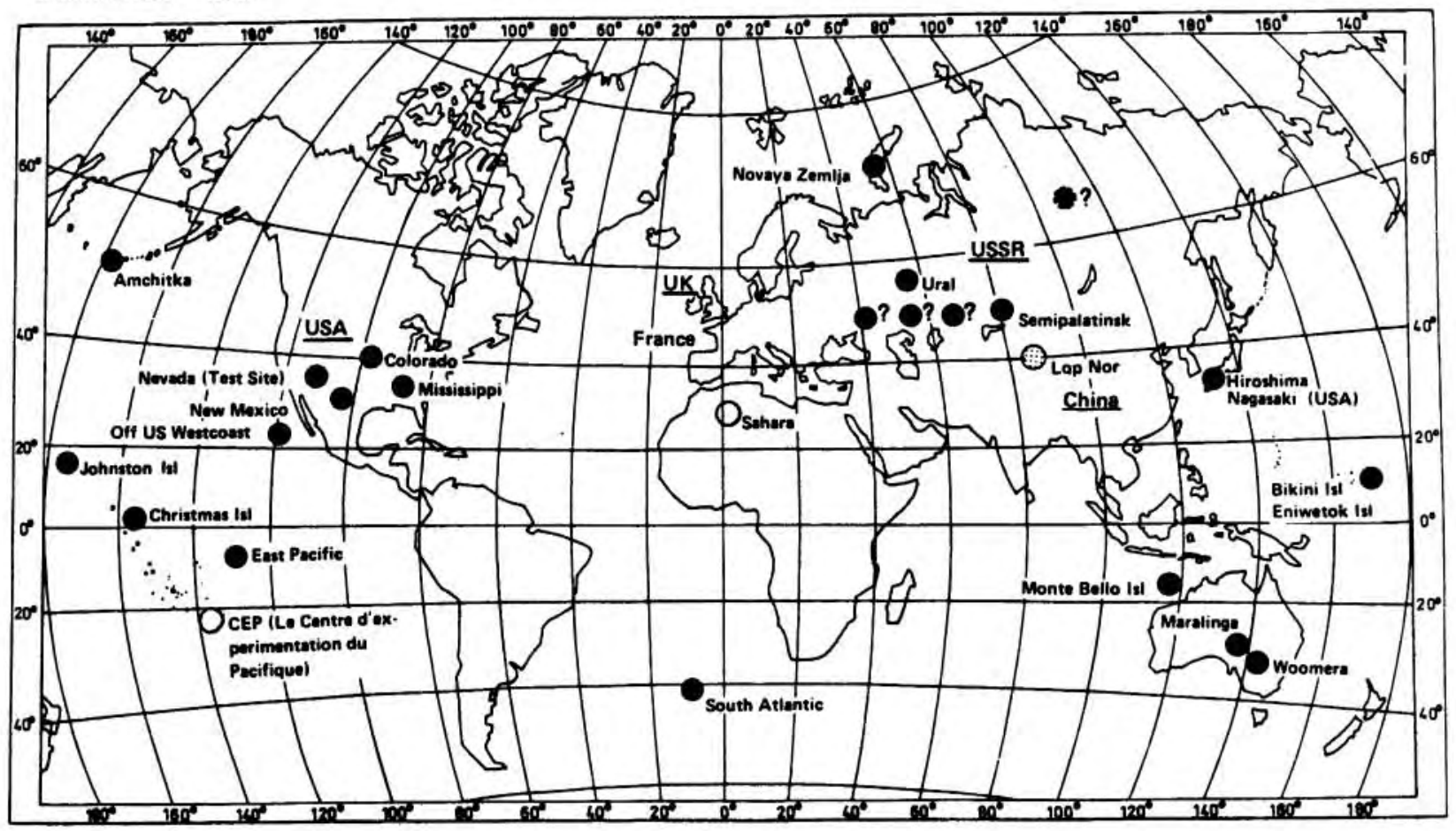

Fig. 1.7: Concentration of $239,240 \mathrm{Pu}$ as a function of latitude in integrated soll sample (from Perkins and Thomas, 1980).

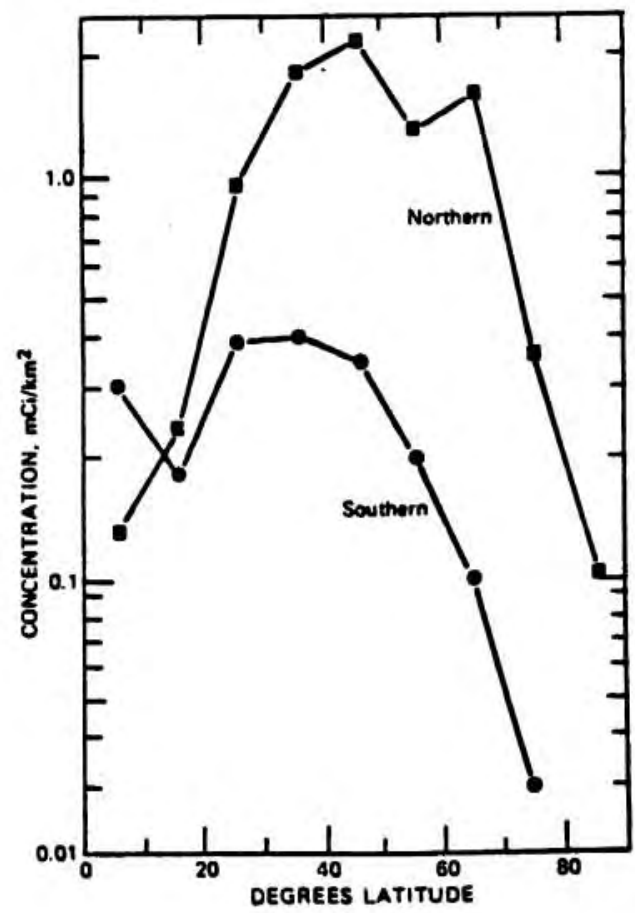




\section{AQUATIC CHEMISTRY OF PLUTONIUM}

The aquatic chemistry of $\mathrm{Pu}$ is complex since Pu can simultaniously exist in solution in four oxidation states (III, IV, V, VI) each with widely differing chemical properties (Taube, 1964; Milyukova et al., 1969; Cleveland, 1970; these references will be used for the following discussion, unless otherwise noted). This unique feature is due to three factors: 1) the tendency of Pu to disproportionate (Pu(IV) + $\mathrm{Pu}(\mathrm{V}) \leftrightharpoons \mathrm{Pu}(\mathrm{III})+\mathrm{Pu}(\mathrm{VI})), 2)$ the similar values of the Pu redox potentials, and 3 ) the slow rate of reactions involving the formation or rupture of $\mathrm{Pu}$-oxygen bonds (such as exist in $\mathrm{PuO}_{2}^{2+}$ and $\mathrm{PuO}_{2}^{+}$). In environmental studies the concentration of $\mathrm{Pu}$ in solution is so small (in the range of $10^{-18} \mathrm{M} / \mathrm{kg}$ ) that disproportionation becomes unlikely. Therefore, it is probable that Pu is present in natural samples in only one or two oxidation states, depending upon prevailing redox conditions and kinetic considerations.

Attempts have been made to derive physical-chemical models for Pu speciation in natural waters (Andelman and Rozze11, 1970; Bondietti and Sweeton, 1977; Cleveland, 1979; Aston, 1980; Allard et a1., 1980; Rai et al., 1980). There are two major problems with these models. First, the data used to derive the models are from laboratory experiments utilizing $\mathrm{Pu}$ at many orders-of-magnitude higher concentrations than those present in the natural environment. Secondly, the equilibrium constants used for complexation and hydrolysis of Pu are subject to large uncertainties and in some instances are not known at all. These features have led to widely differing predictions for the most abundant Pu species in natural waters (Aston, 1980; S1lver, 1983).

Recent advances in the measurement of Pu oxidation states in natural samples have been made (Nelson et al., 1984; Orlandini et al., 1986). In general, some mixture of reduced and oxidized dissolved Pu species is found in most freshwater and seawater systems. The reduced Pu species are more particle reactive than the oxidized Pu forms, and therefore changes in Pu redox state are important in considerations of Pu solubility and scavenging. In studies from the Irish Sea (Nelson and 
Lovett, 1978), the Mediterranean (Fukai et al., 1981), the N.W. Atlantic (Livingston et al., 1984), the Bikini and Enewetok lagoons in the Pacific (Noshkin and Wong, 1979), and in the $N$. Pacific Ocean (Nelson et al., 1984), anywhere from $50-90 \%$ of the ${ }^{239,240} \mathrm{Pu}$ is found in the oxidized $V$ or VI forms. The only data to show any systematic variability in $\mathrm{Pu}$ oxidation state are that of Nelson et al. (1984) in the Pacific, where the near bottom $239,240 \mathrm{Pu}$ samples are substantially more oxidized (90\%) than $239,240 \mathrm{Pu}$ throughout the remainder of the water column $(50 \pm 15 \%)$. Laboratory studies suggest that reactions at the mineral surface are effectively reducing the oxidized forms of Pu to the reduced forms (Sanchez, 1985; Keeney-Kennicutt and Morse, 1985).

It can be concluded that the oxidation state determinations which have been made on natural samples support the basic chemical models suggesting that reduced $\mathrm{Pu}$ is strongly associated with particles and that oxidized $\mathrm{Pu}$ is dominant in the dissolved phase in the oceans. However, storage effects, oxidation state tracer equilibration, and the kinetics of species re-equilibration during a selective extraction procedure may add some uncertainty to any of these oxidation state separation techniques. Also, the actual oxidation-state-determining mechanisms in the environment, either kinetic or equilibrium based, are not yet well understood.

The total particle reactivity of Pu has been described by the distribution coefficient, $K_{d}$, which is defined as the activity of $239,240 \mathrm{Pu}$ on the solids (dpm/ kg)/activity of $239,240 \mathrm{Pu}$ in solution $(\mathrm{dpm} / \mathrm{kg})$. Plutonium $\mathrm{K}_{d}$ 's range from $10^{4}-10^{6}$ in a wide variety of seawater and freshwater settings (Edgington, 1981). In general, higher distribution coefficients are found, if only the reduced Pu species are considered (Ne1son and Lovett, 1978, Sanchez, 1985). Interpretations of field and laboratory $K_{d}$ data may be complicated by differences in mineralogy and sediment type, competing natural ligands in solution, differences in suspended sediment concentration, the time needed for equilibration between the solids and solution, and the reversibility of adsorption which is assumed in the $K_{d}$ determination (Sholkovitz, 
1983).

The concentration of dissolved $239,240 \mathrm{Pu}$ has been shown to be affected by its complexation with inorganic and organic ligands. Elevated dissolved 239,240 Pu concentrations in Mono Lake (Simpson et a1., 1980, Anderson et a1., 1982) and Soap Lake (Sanchez et a 1., 1985) have been explained as being due to carbonate complexation in these highly alkaline lakes. This has been supported by laboratory adsorption studies and modelling (Sanchez, 1983) which show that carbonate can significantly inhibit Pu(IV) adsorption at alkalinity levels comparable to those measured at Soap Lake. Dissolved organic carbon (D.O.C.) has also been shown to have a controlling influence on $239,240 \mathrm{Pu}$ activity in solution in freshwaters (Nelson et al., 1985). These researchers found that the $K_{d}$ of $\mathrm{Pu}$ was inversely related to the ambient D.O.C. concentration in a wide variety of freshwaters. 
CHAPTER 2

The Non-destructive Analysis of ${ }^{210} \mathrm{~Pb},{ }^{234} \mathrm{Th}$ and ${ }^{226} \mathrm{Ra}$ by Gamma-ray Spectrometry

\section{INTRODUCTION}

The naturally occuring radionuclides $210_{\mathrm{Pb}}$ excess and ${ }^{234} \mathrm{Th}$ are commonly used to study mixing processes in marine sediments (Guinasso and Schink, 1975; Peng et a1., 1979; Benninger and Krishnaswami, 1981; DeMaster and Cochran, 1982; and references therein). In this thesis sediment mixing rates were desired (see Chapters 4 and 7 ) as well as sediment ${ }^{210} \mathrm{~Pb}^{\text {ex }}$ inventories (Chapter 5). Therefore, a non-destructive gamma-ray technique for the analysis of ${ }^{210} \mathrm{~Pb}^{\mathrm{ex}}$ and ${ }^{234} \mathrm{Th}$ was developed. technique is a modification of those described by Yokoyama \& Nguyen (1980) and Cutshall et al. (1983). Some of the features of this method include: 1) ${ }^{210} \mathrm{~Pb}^{\mathrm{ex}}$ and ${ }^{234}$ Th are measured non-destructively, so that subsequent analyses (in this case, ${ }^{239,240} \mathrm{Pu}$ and ${ }^{137} \mathrm{Cs}$ ) can be run on the exact same sediment material, and 2) this technique is much simpler than traditional $210 \mathrm{~Pb}^{\mathrm{ex}}$ and ${ }^{234} \mathrm{Th}$ alpha-counting procedures, while providing results with comparable accuracy.

\section{DETECTION TECHNIQUES}

The analysis of ${ }^{210} \mathrm{~Pb}$ traditionally involves sediment leaching or dissolution by strong acids followed by chemical clean-up procedures, sample plating, and the determination of the ${ }^{210} \mathrm{~Pb}$ daughter $\left({ }^{210} \mathrm{PO}\right)$ by alpha-counting (Thomson and Turekian, 1976; Lally, 1982). In addition, ${ }^{210} \mathrm{~Pb}^{\mathrm{ex}}$ is calculated from the difference between the total $210 \mathrm{~Pb}$ value and the ${ }^{210} \mathrm{~Pb}$ which is supported by ${ }^{226} \mathrm{Ra}$ in the core. ${ }^{226} \mathrm{Ra}$ determinations are therefore needed and are obtained either by assuming that the deep supported $210 \mathrm{~Pb}$ values are equivalent to ${ }^{226} \mathrm{Ra}$ throughout the core or by the ${ }^{222}$ Ra emination technique (Mathieu, 1977). The traditional ${ }^{234} \mathrm{Th}$ 
determination is similiar to ${ }^{210} \mathrm{~Pb}$ in that it involves sediment leaching or dissolution followed by chemical clean-up procedures, plating and beta-counting for ${ }^{234}$ Th (Lally, 1982).

The standard ${ }^{210} \mathrm{~Pb}^{\text {ex }}$ and ${ }^{234} \mathrm{Th}$ analytical techniques are all based upon the detection of a radionuclide or its daughter by their most common decay mode, i.e. alpha decay for ${ }^{210} \mathrm{~Pb}$ and beta decay for ${ }^{234} \mathrm{Th}$. Often with the alpha-decay process, a certain percent of the daughter nuclides are left in an excited energy state which then release their energy via gamma radiation of a known energy. These gamma-ray emmisions are used here to measure the parent activity. Since the gamma emmisions of ${ }^{210} \mathrm{~Pb}$ and ${ }^{234} \mathrm{Th}$ occur at a known energy and can be measured with high resolution, no chemical separation techniques need to be employed in the sample preparation steps. Also, since gamma-rays can travel relatively long distances through the sample (depending upon their energy), the samples need not be introduced as a thinly deposited source for detection. A recent breakthrough in gamma detector design (1.e., the intrinsic germanium detector) has allowed for the detection of low energy gamma rays $(<100 \mathrm{keV})$ in a region which includes the primary ${ }^{210} \mathrm{~Pb}(46.5 \mathrm{keV})$ and ${ }^{234}$ Th $(63.3 \mathrm{keV})$ gamma peaks.

The solid state detectors in use are all based upon the interaction of incoming gamma radiation with a semi-conductor material consisting of either a germanium crystal which has been lithium "drifted" ( $G e(L i) ' s$ ) or a pure germanium crystal alone (the intrinsic germanium, or planar detector). When a potential is applied to the $\mathrm{Ge}(\mathrm{Li})$ or planar detector crystal, incoming gamma-rays are detected in the so-called intrinsic volume of the crystal. This intrinsic volume is separated from the sample by a detector window, and in the case of the $\mathrm{Ge}(\mathrm{L} 1)^{\prime} \mathrm{s}$, by a relatively thick crystal layer which is insensitive to the incoming gamma radiation. Low energy gamma rays are unable to penetrate through this insensitive crystal volume and are not detected with the $\mathrm{Ge}(L i)$ design. One purpose of the lithium drifting in the $\mathrm{Ge}(L i)$ crystal is to neutralize any original acceptor impurities in the germanium crystal. The development of techniques for manufacturing 
pure Ge crystals removes these impurities and allows for the detection of the lower energy gamma rays due to the elimination of the insensitive volume associated with the $G(L I)$ design.

A comparison of the W.H.O.I. Ge(Li) and planar detector efficiencies vs. gamma energy can be seen in Figure 2.1. The W.H.O.I. planar detector is relatively thin $(7 \mathrm{~mm})$, and, therefore, the detector quickly becomes less efficient at energies greater than $100 \mathrm{keV}$, as the higher energy gamma rays simply pass through the crystal without interaction. The sharp drop-off in the detector efficiency of the W.H.O.I. planar detector at higher energies requites that both the planar and $\mathrm{Ge}(\mathrm{L} 1)$ detectors are used in order to cover the desired energy range: $\left({ }^{210} \mathrm{~Pb}\right.$ and ${ }^{234} \mathrm{Th}$ are measured on the planar detector at $46.5 \mathrm{keV}$ and $63.3 \mathrm{keV}$ respectively, while ${ }^{214} \mathrm{~Pb}$ and ${ }^{214} \mathrm{Bi}$ are measured on the $\mathrm{Ge}(\mathrm{Li})$ 's at $352 \mathrm{keV}$ and $609 \mathrm{keV}$ respectively). Pure germanium crystals, now avallable in increased thicknesses, can improve the planar detector efficiency at higher energies. Also, "well-type" crystal designs are now avallable in pure germanium which provide close to $4 \pi$ counting geometry and, therefore, very high counting efficiencies. These larger and more elaborate crystal designs become substantially more expensive as their size increases, and have higher background count rates as well. A comparison between a gamma-spectrum from the planar detector and the Ge(Li) detector at W.H.O.I. is provided in Figures $2.2 \mathrm{a}$ and $2.2 \mathrm{~b}$.

$\mathrm{Ge}(\mathrm{L} i)$ detectors must always be held at liquid $\mathrm{N}_{2}$ temperatures in order to maintain a constant pattern of Li drifting in the crystal. In contrast, the planar detector does not need to be maintained at these low temperatures to insure the crystal integrity, but they are still kept at liquid $\mathrm{N}_{2}$ temperatures during sample detection periods in order to improve detector resolution in general.

Both the $\mathrm{Ge}(\mathrm{L} 1)$ detectors and planar detectors benefit considerably from extensive lead shielding to reduce the amount of incoming background radiation to the detector. At W.H.O.I., roughly 4 inches of pre-bomb lead is used as shielding along with a inner cu liner which shields out low energy radiation which is constantly being 


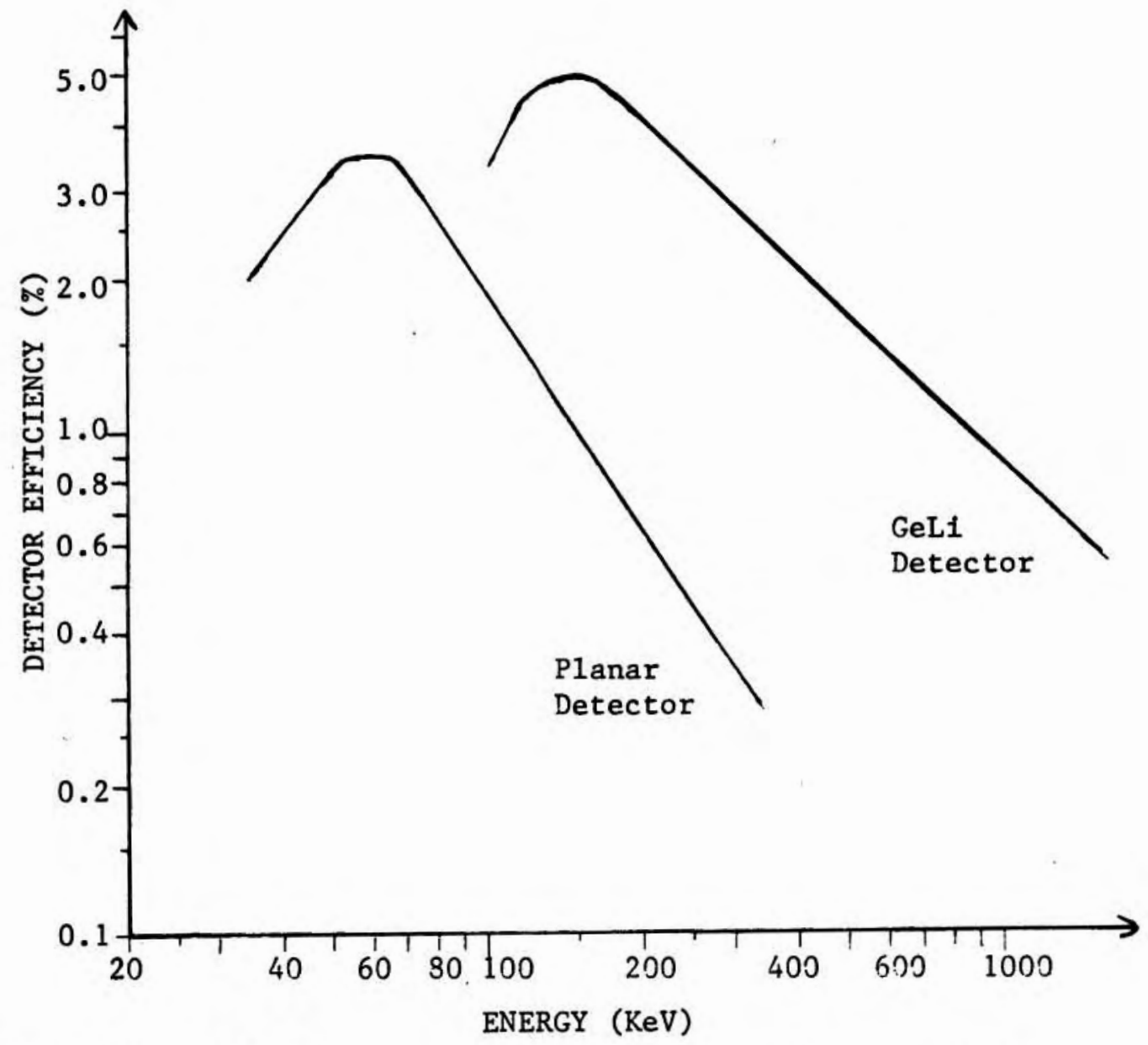

Fig. 2.1: Efficiency vs. Energy plot for a $50 \mathrm{gm}$ standard sediment sample in a $40 z$. counting jar. -note $\log -\log$ scale 
Fig. 2.2a and 2.2b: Gamma spectrum of standard sediment sample on the planar detector (2.2a) and $\mathrm{Ge}(\mathrm{L} 1)$ detector (2.2b).

$T I M E(L)=15094$

PSET $(L)=999999$

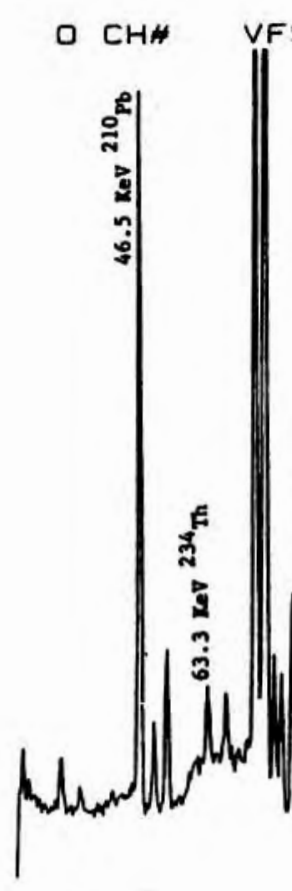

CLMX SAND STD 2OGM WAFER

4096

$C R T=(13-16)$

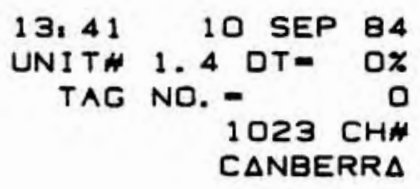

\section{TIME $(L)=576$ \\ PSET. (L) $=999999$}

O C!IH VFS: 16384

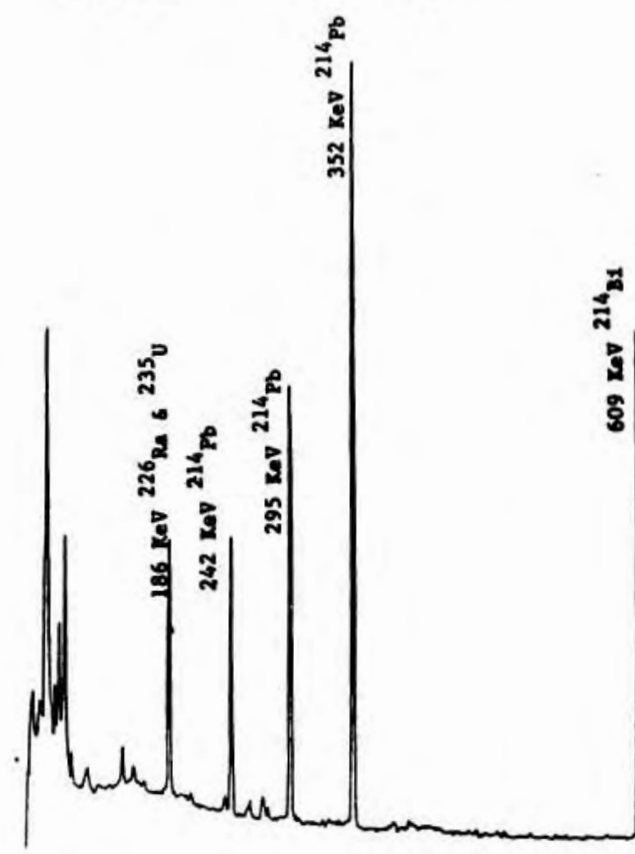

16:12 5 APR 84 UNITH 1.1 DT= $1 \%$ TAE NO. -

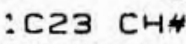


emmitted from the lead itself. There are no significant background peaks in the regions of the spectrum of interest to us, and, therefore, the peak count rate is simply the net count rate determined above the background count rate on either side of the peak channels.

\section{SAMPLE ANALYSES}

In order to determine ${ }^{210} \mathrm{~Pb}^{\text {ex }}$ or ${ }^{234} \mathrm{Th}$ on a given sediment sample, the samples are dried and ground and placed over the gamma-detector in an appropriate sample container. The sediment activity of a given isotope is calculated from the general equation:

$$
\mathrm{dpm} / \mathrm{g}=(\mathrm{cpm} \times \text { eff } \times \text { abs }) / \mathrm{g} \text { dry weight }
$$

where cpm, or counts per minute, is the net sample count rate above background detected by the gamma-detector for a given sample activity, geometry, etc., at a specific energy peak. Eff is the total detector collection efficiency at that energy determined by standards for a given detector set-up and sample configuration. Abs is the self-absorption factor for the energy of interest, which compensates for the relative difference in the absorption of low energy gamma-rays by the sample medium itself. Each of these components will be discussed in more detall below.

\section{A. Cpm (Counts Per Minute)}

$\mathrm{Cpm}$ or the measured count rate is a function of the particular detector design, the energy of interest, sample activity, background activity, and the sample geometry. A computer program called CPM.BAS was developed to assist in calculating the net count rate and the associated counting error for a given gamma peak (see Appendix I). In brief, the average count rate is determined on either side of the peak region. These two count rates are then averaged to determine the baseline or background count rate over the peak region itself. This background count rate is subtracted from the peak region count rate to determine the net cpm over the peak region energies. The one standard deviation counting error on any such calculation is proportional to the square root of the number of counts detected. This error is determined 
for both the baseline calculation and the peak region count rate, and the total error on the net $\mathrm{cpm}$ is calculated by taking the square root of the sum of the squares of the baseline and peak region errors.

With a given detector set-up it is the sample geometry (i.e. the sample size and form) which can most easily be altered to affect the net cpm that one measures. With most low energy gamma detection procedures, the sample is held in a thin walled container which is placed directly over the detector window. Within limits a larger sample size will produce a higher count rate. With the low energy gamma rays, however, an increase in the sample distance away from the detector window results in an increase in the number of gamma events which are attenuated by self absorption before being detected.

The first containers which were used in this study (on 83-Gyre-9 cores AK, BK, \& CK) were $4 \mathrm{oz}$. plastic screw top jars ( $\simeq 5 \mathrm{~cm}$ dia.). $50 \mathrm{~g}$ of dried and ground sediment could be sealed into these containers and packed to a constant height of $25 \mathrm{~mm}$ in the jar. This counting geometry was used on shelf and slope sediment samples with ${ }^{210} \mathrm{~Pb}$ activities of $1-40 \mathrm{dpm} / \mathrm{g}$ and ${ }^{234} \mathrm{Th}$ activities of $1-5 \mathrm{dpm} / \mathrm{g}$, and resulted in a 5-15\% counting error on a 1-2 day count. While successful, future sampling stratagies, geared towards obtaining finer depth resolution within the cores, provided less sample material for analyses. Furthermore, the low energy gamma rays of $210 \mathrm{~Pb}$ and ${ }^{234}$ Th were unlikely to have been very effectively collected given the $12.5 \mathrm{~mm}$ mean distance of the sample away from the detector window. A new sample procedure was therefore developed in order to improve on this existing sample geometry.

This new approach I have termed the "wafer" technique since the sample is pressed into a thin solid sediment wafer before counting. The essential steps are to first dry the sediment completely before grinding the sample very finely (in this case using a mechanical agate disk mill grinder). Then up to $20 \mathrm{~g}$ of the sediment is placed into a $2.5 \mathrm{~cm}$ diameter by $3.5 \mathrm{~cm}$ deep cylindrical dye of a hydraulic press (normally used for making X.R.F. pellets). The dye is pre-treated with TFE (teflon) spray which ensures that once pressed, the sediment wafer 
can be extruded easily. The sample is pressed under 40,000-50,000 pounds of pressure for $11 / 2$ to 2 minutes. The net result is that the sediment forms a thin solid wafer of constant thickness and geometry for a given sediment mass. Our sediment counting standards are formed in exactly the same manner (see following section). The wafers are subsequently sealed inside of a $5 \mathrm{~cm}$ diameter plastic petri dish, using silicon rubber cement to hold the dish shut and to minimize any handling problems.

Table 2.1 summarizes the effect which this wafer technique and other counting geometries have on the observed count rate of $210 \mathrm{~Pb}$. Two trends are seen in this table. First, the smallest, and therefore typically the thinnest samples, have the highest count rate when normalized to the total dpm per sample (this ranges by a factor of 3 ). Secondly, the wafer samples have a higher count rate than an equivalent mass of loosely packed sample due to their improved geometry. The conclusion is that even though a $10 \mathrm{~g}$ wafer is the most efficiently counted form, with this small sample mass, the net cpm per sample is smaller than with a larger loose sample. I have found that the $20 \mathrm{~g}$ sediment wafer is an attractive form to use, since the net cpm of a $20 \mathrm{~g}$ wafer is essentially identical to the net cpm of $50 \mathrm{~g}$ of loose sediment. Without using a very large diameter core, $20 \mathrm{~g}$ proves to be a much more reasonable size sample to collect if one is interested in 0.5 or $1 \mathrm{~cm}$ depth intervals in the top of a given core. The precise geometry that the wafer sample offers is certainly an additional bonus.

\section{B. Eff (efficiency)}

The efficiency is calculated by counting sediments with a known activity of a given radionuclide. In this case,

$$
\text { eff }=d p m \text { of standard/(cpm } \times \text { abs). }
$$

I use two sediment standards provided by the U.S. Environmental

Protection Agency labs in Las Vegas for calibrating our detectors. The "standard pitchblend ore" standard has a certified ${ }^{238} \mathrm{U}$ activity of $6.06 \times 10^{3} \mathrm{dpm} / \mathrm{g}$ (with a standard error of $0.4 \%$ ). Secular equilibrium can be assumed, and therefore the sample ${ }^{238} \mathrm{U},{ }^{210} \mathrm{~Pb}$, ${ }^{214} \mathrm{~Pb}$, and ${ }^{214} \mathrm{Bi}$ activities would be identical. The "climax sand 
Table 2.1. A Comparison of the Effects of Different Counting Geometries on the Detection of $210 \mathrm{~Pb}$ at $46.5 \mathrm{keV}$ with the W.H.O.I.

Planar Detector

\begin{tabular}{|c|c|c|c|c|c|c|}
\hline Sample & $\begin{array}{l}\text { gm } \\
\text { dry }\end{array}$ & & $\begin{array}{l}\text { rm- height } x \\
\text { diameter }\end{array}$ & $\begin{array}{l}210 \mathrm{pb} \\
\mathrm{dpm} / \mathrm{gm}\end{array}$ & $\begin{array}{l}\text { Relative* } \\
\text { cpm }\end{array}$ & $\begin{array}{l}\text { net } \\
\text { cpm }\end{array}$ \\
\hline AK4 & 10 & 1) & wafer- $7 x$ & $10.7+/-0.3$ & $3.1 \times 10^{-3}$ & 0.332 \\
\hline AK4 & 10 & 2) & 1oose $-\underset{50 \mathrm{~mm}}{5 x}$ & $10.7+/-0.3$ & $2.9 \times 10^{-3}$ & 0.309 \\
\hline AK4 & 15 & 3) & wafer- $\begin{array}{r}10 x \\
25 \mathrm{~mm}\end{array}$ & $10.7+/-0.3$ & $2.5 \times 10^{-3}$ & 0.407 \\
\hline LVE3 & 20 & 4) & 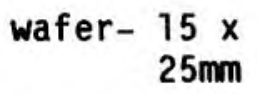 & $11.0+/-0.3$ & $2.3 \times 10^{-3}$ & 0.513 \\
\hline LVAT & 17 & 5) & $\begin{array}{r}100 \mathrm{se}-18 \times \\
30 \mathrm{~mm}\end{array}$ & $8.9+/-0.5$ & $2.0 \times 10^{-2}$ & 0.309 \\
\hline LVC2 & 35 & 6) & loose- $23 x$ & $9.1+/-1.0$ & $1.2 \times 10^{-3}$ & 0.398 \\
\hline AK4 & 50 & 7) & loose- $25 x$ & $10.7+/-0.3$ & $1.0 \times 10^{-3}$ & 0.552 \\
\hline
\end{tabular}

* = Relative cpm is the net counts per minute normalized to the total dpm per sample, 1.e. net $\mathrm{cpm} /(\mathrm{dpm} / \mathrm{gm} \times$ weight $)$. 
tailing" standard has a certified ${ }^{234} \mathrm{Th},{ }^{210} \mathrm{~Pb}$ and ${ }^{226} \mathrm{Ra}$ activity of $5.93 \times 10^{5} \mathrm{dpm} / \mathrm{g}, 6.66 \times 10^{5} \mathrm{dpm} / \mathrm{g}$, and $7.64 \times 10^{5} \mathrm{dpm} / \mathrm{g}$, respectively, as of May 1, 1976 (with a $4 \%$ standard error). This mine talling standard is therefore not in equilibrium and the current $210 \mathrm{~Pb}$ activity must be calculated assuming ingrowth of ${ }^{226} \mathrm{Ra}$ and $210 \mathrm{~Pb}$ decay. The current ${ }^{210} \mathrm{~Pb}$ activity as of December 1983 is $6.88 \times 10^{5} \mathrm{dpm} / \mathrm{g}$.

These EPA standards were counted overnight in the identical counting configuration as the samples. Efficiency calculations with both standards were in agreement within the counting errors (typically 1\%). The largest error in the efficiency calculation is determining the self absorption factor for these standards, which will be discussed in the following section.

C. Abs (self absorption):

The self absorption factor simply corrects for the relative attenuation of the low energy gamma radiation by the sample material itself. Different elements and minerals absorb gamma rays to significantly different extent (see Table 2.2). Differences between samples and/or the sample and standard mineralogy will affect the apparent count rate. As the gamma energy increases, the fraction of gamma rays which are attenuated decreases such that at energies greater than approximately $100 \mathrm{keV}$, there is essentially no need for this correction. The self absorption correction is made by counting samples with a hot ${ }^{210} \mathrm{~Pb}$ and ${ }^{234} \mathrm{Th}$ source placed over the sample such that the extent to which each sample affects the hot source attenuation can be taken into consideration.

The principles behind the self absorption factor calculation are taken from Cutshall et al., 1983. Three count rates are compared (see Figure 2.3): 1) the count rate of a hot ${ }^{210} \mathrm{~Pb}$ and ${ }^{234} \mathrm{Th}$ source over an empty sample container (= I), 2) the count rate of this hot source when placed over a real sample $(=T)$, and 3 ) the normally collected count rate of the sample alone $(=S)$. Given these definitions, the underlying equation for the transmition of gamma rays is:

$$
\text { (1) } T^{\prime}=I \exp (-\mu \rho x)
$$




\begin{tabular}{|c|c|}
\hline Mineral & Absorption Coefficient \\
\hline $\begin{array}{l}\text { Quartz } \\
\text { Feldspars } \\
\text { Albite } \\
\text { Anorthite } \\
\text { Orthoclase } \\
\text { Calcite } \\
\text { Dolomite } \\
\text { Hematite } \\
\text { Water }\end{array}$ & $\begin{array}{l}0.362 \\
0.348 \\
0.475 \\
0.453 \\
0.642 \\
0.649 \\
1.84 \\
0.235\end{array}$ \\
\hline
\end{tabular}

Reference: Cutshell et al., 1983.

Fig. 2.3: Self Absorption correction scheme.

$I=$ Count rate of hot source over empty container.

$T=$ Count rate of hot source over sample in container.

$S=$ Count rate of sample.
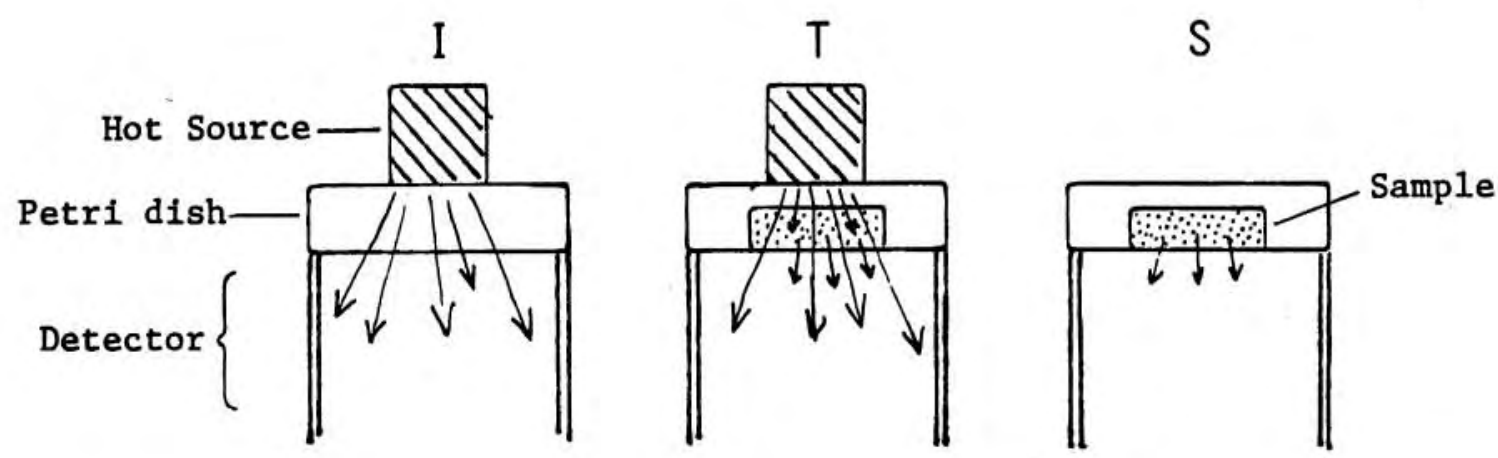
where $\mu$ is the total attenuation coefficient, $\rho$ is the sample density, $x$ is the path length, and $T^{\prime}$ is the count rate of the hot source alone (i.e. = T-S using the above notation). The necessary gamma self absorption equation is:

$$
\text { (2) } a b s=\mu \rho x / 1-\exp (-\mu \rho x) \text {. }
$$

From equation ( 1 ) one can calculate that:

$$
\text { (3) } \mu \rho X=-\ln \left(T^{\prime} / I\right) \text {. }
$$

Substituting equation (3) into (2) one obtains:

(4) abs $=\ln \left(T^{\prime} / I\right) /\left(\left(T^{\prime} / I\right)-1\right)$ or abs $=\ln ((T-S) / I) /(((T-S) / I)-1)$. In most cases, $T \gg S$, such that $T \simeq T^{\prime}$ given our hot source activity (I use a hot ${ }^{226}$ Ra source wafer and a uranyl nitrate hot source with count rates of $>100 \mathrm{cpm}$ at these energies). Our sediment samples need only be counted for $\mathbf{3 0}$ minutes under the hot source while the standards are counted overnight for these calculations. The standards need the longer counting intervals since the difference bewtween $T$ and $S$ is small and the longer count improves the statistics on the error of this difference. Selected abs factors calculated in the above manner at the energies of ${ }^{210} \mathrm{~Pb}$ and ${ }^{234} \mathrm{Th}$ are given in Table 2.3. As expected, as the gamma energy increases, this self absorption factor becomes less significant. Within a given core I have not found any real difference in the self absorption factor, and therefore the abs factor which I use for a specific core is determined from the results on 3 or 4 depths per core.

\section{OTHER FACTORS}

\section{A. $\mathrm{Rn}$ loss}

In order to estimate ${ }^{226}$ Ra activity within a given sample, ${ }^{214} \mathrm{~Pb}$ (at $352 \mathrm{keV}$ ) and ${ }^{214} \mathrm{Bi}$ (at $609 \mathrm{keV}$ ) are determined simultaneously on the $\mathrm{Ge}(\mathrm{L} i)$ detectors. These decay products of ${ }^{226} \mathrm{Ra}$ can only be in equilibrium with their parent if the intermediate gas ${ }^{222} \mathrm{Rn}$ does not escape from the sample (see decay chart, Fig. 2.4). Some ${ }^{222} \mathrm{Rn}$ gas can be expected to be lost during sample grinding procedures. Once the sample is sealed, given a couple 
Table 2.3. Self Absorption Factors (Abs) for $20 \mathrm{gm}$ Sample "Wafers"

\begin{tabular}{lcc} 
Sample & $\frac{46.5 \mathrm{KeV}}{2.35}$ & $\frac{63.3 \mathrm{KeV}}{1.52}$ \\
\hline P1tchblend std. & 1.66 & 1.43 \\
C11max Sand std. & & \\
Core D-2362m & 1.75 & 1.41 \\
$0-1 \mathrm{~cm}$ & 1.68 & 1.42 \\
$1-2 \mathrm{~cm}$ & 1.76 & 1.36 \\
$2-3 \mathrm{~cm}$ & 1.77 & 1.42 \\
$4-6 \mathrm{~cm}$ & 1.82 & 1.43 \\
$10-12 \mathrm{~cm}$ & 1.71 & 1.43 \\
$14-16 \mathrm{~cm}$ & & \\
& & 1.39 \\
Core E- 1275m & 1.73 & 1.42 \\
$0-1 \mathrm{~cm}$ & 1.73 & 1.37 \\
$3-4 \mathrm{~cm}$ & 1.71 & 1.39 \\
$10-12 \mathrm{~cm}$ & 1.71 & \\
$22-24 \mathrm{~cm}$ & & 1.37 \\
& & 1.36 \\
Core $\mathrm{F}-501 \mathrm{~m}$ & 1.64 & 1.38 \\
$0-1 \mathrm{~cm}$ & 1.64 & 1.39 \\
$3-4 \mathrm{~cm}$ & 1.64 & \\
$6-8 \mathrm{~cm}$ & 1.65 & \\
$12-14 \mathrm{~cm}$ & &
\end{tabular}


Fig. 2.4: Naturally occuring $238 \mathrm{U}$ decay series.

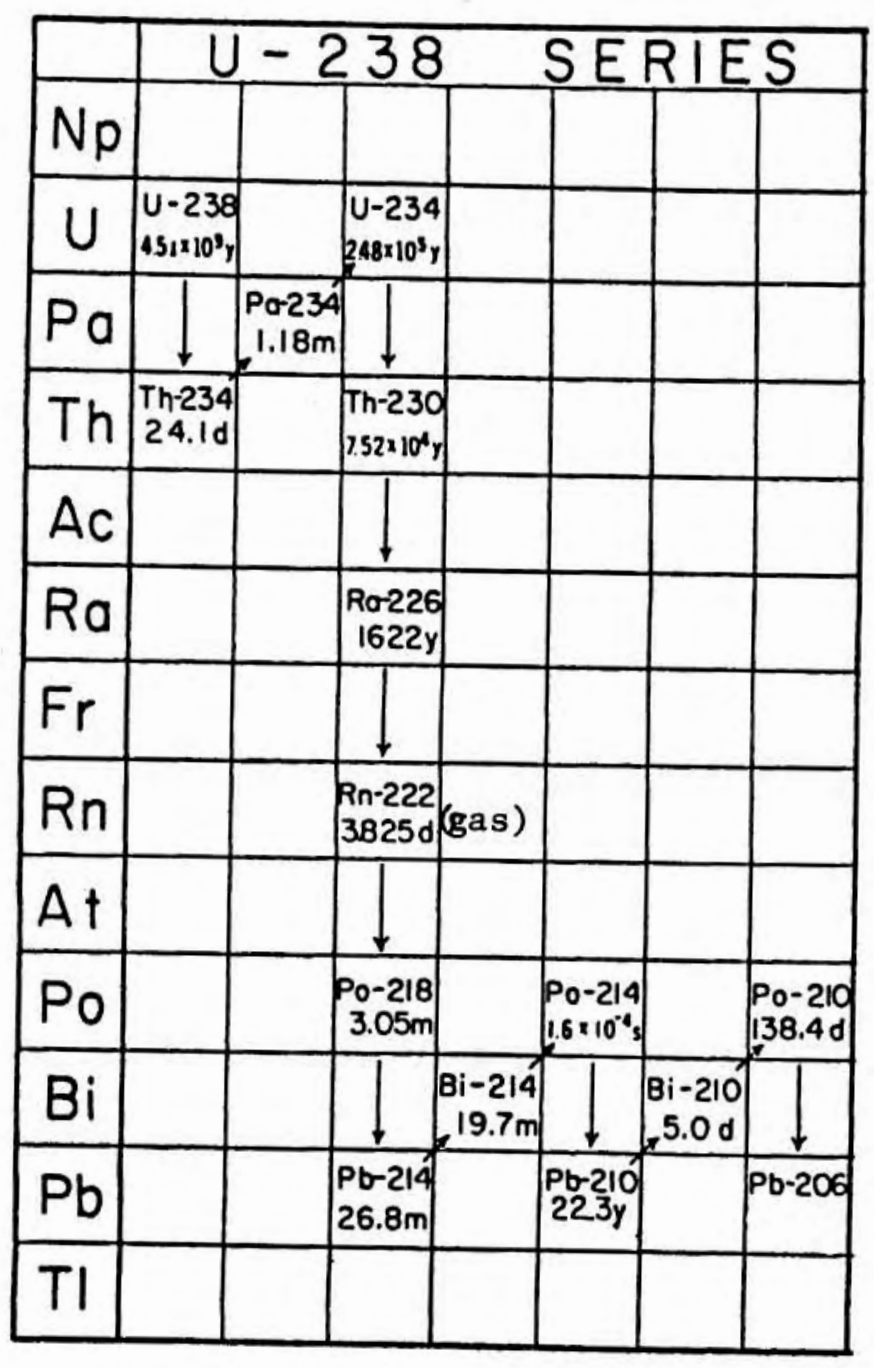


of weeks and the 3.8 day half $11 \mathrm{fe}$ of $\mathrm{Rn}$, equilibrium will once again be reached. I have measured ${ }^{214} \mathrm{~Pb}$ and ${ }^{214} \mathrm{BI}$ in samples without a cover in an attempt to access the possibility of Rn gas loses. I found no difference between the open or closed container sample count rates and conclude that $\mathrm{Rn}$ loses in general are minimal, at least with these samples which contain on average $1-2 \mathrm{dpm} / \mathrm{g}$ of the ${ }^{226} \mathrm{Ra}$ parent. This is supported by some earlier gamma-work by Kim and Burnett (1983) who found no evidence for significant ${ }^{222}$ Rn emination from a ground NBS phosphate rock standard.

B. Th decay:

Excess ${ }^{234} \mathrm{Th}$ is formed within the water column from its soluble parent, ${ }^{238} \mathrm{U}$. Given the 24.1 day half-1ife of Th and its rapid removal to marine sediments, the build-up of excess Th can only be seen in the most rapidly mixed upper layers at shallow sediment sites. ${ }^{234} \mathrm{Th}^{\mathrm{ex}}$ is determined by the difference between the measured ${ }^{234}$ Th activity, and the ${ }^{234}$ Th activity which is supported solely by ${ }^{238} U$ from within the sediments. In this study, the deep ${ }^{234}$ Th values below the ${ }^{234} \mathrm{Th}^{\text {ex }}$ activity in the core top, are used to correct for the supported Th activity. Only those cores with a very active benthic activity show any ${ }^{234} \mathrm{Th}^{\mathrm{ex}}$ at a11. Given the short ${ }^{234}$ Th half-1ife, the unsupported ${ }^{234}$ Th will decay quite rapidiy, such that the gamma measurements themselves must occur relatively soon after the core is collected (within about one month). The observed ${ }^{234} \mathrm{Th}^{\text {ex }}$ activities are all decay corrected to the date of core collection. I was only able to detect ${ }^{234} \mathrm{Th}^{\mathrm{ex}}$ in a few of the cores collected on the 83-Gyre-9 cruise which I was able to prepare and count soon after their collection.

\section{RESULTS}

The final ${ }^{210} \mathrm{~Pb},{ }^{226} \mathrm{Ra}$ and ${ }^{234} \mathrm{Th}$ results determined by this technique are reported in Appendix II. The data from this work will be discussed in Chapters 4,5 and 7 of this thesis. In general, total $210 \mathrm{~Pb}$ activities of $1-40 \mathrm{dpm} / \mathrm{g}$ were detected with a $5-10 \%$ error 
using a 1-2 day counting interval. ${ }^{234}$ Th activities ranged from 1-5 dpm/g and typically had a larger assoctated error than the ${ }^{210} \mathrm{~Pb}$ values from the same planar detector count $(10-20 \%) .{ }^{226} \mathrm{Ra}$ activities of $1-3 \mathrm{dpm} / \mathrm{g}$ were determined with a 5-10\% counting error for both ${ }^{214} \mathrm{~Pb}$ and ${ }^{214} \mathrm{Bi}$ on the $\mathrm{Ge}(\mathrm{Li})$ detectors over a 2 day counting interval. These ${ }^{210} \mathrm{~Pb}$ and ${ }^{226} \mathrm{Ra}$ data are well suited for the determination of sediment mixing rates and sediment inventories within all of the cores. Also, an intercalibration exercise was performed on a sediment sample analyzed for ${ }^{210} \mathrm{~Pb}$ and ${ }^{226} \mathrm{Ra}$ at W.H.O.I., Yale and Lamont by gamma detection procedures, and at Lamont by traditional alpha-counting procedures as well. All of the results were found to be identical within the counting precision (Anderson et al., 1986). 


\section{CHAPTER 3}

The Mass Spectrometric Analysis of Fallout ${ }^{239} \mathrm{Pu}$ and ${ }^{240} \mathrm{Pu}$

in Marine Samples

\section{INTRODUCTION}

Plutonium has been introduced to the oceans predominantly in the 1950's and early 1960's as fallout from the atmospheric nuclear weapons testing programs (Perkins and Thomas, 1980; Harley, 1980). Since this time, plutonium has been used by oceanographers as a geochemical tracer to study removal processes in the water column, and in understanding mixing processes in marine sediments (see Sholkovitz, 1983 for review). In general, geochemical researchers have measured fallout Pu by standard alpha-counting techniques. This results in the determination of $239,240 \mathrm{Pu}$, which represents the combined activity of the two most common fallout $\mathrm{Pu}$ isotopes, ${ }^{239} \mathrm{Pu}$ and ${ }^{240} \mathrm{Pu}$ (these isotopes being inseparable when $\mathrm{Pu}$ is determined by alpha-counting). An alternative $\mathrm{Pu}$ detection technique is thermal ionization mass spectrometry, which has been shown to be highly sensitive and capable of separating the ${ }^{239}$ and ${ }^{240} \mathrm{Pu}$ isotopes (Strebin and Robertson, 1977; Halverson, 1981; Perrin et a 1., 1985). We have applied a mass spectrometric technique for the determination of fallout $\mathrm{Pu}$ concentrations and isotopic ratios in sea water, ocean sediments, pore waters and sediment trap material. The optimal procedures used for the preparation and analyses of Pu by thermal ionization mass spectrometry in these samples will be presented.

\section{THERMAL IONIZATION MASS SPECTROMETRY}

Techniques for the analysis of Pu isotopes by thermal ionization mass spectrometry have been developed primarily within the U.S. national labs (Fasset and Kelly, 1984). With isotope dilution mass spectrometry, a Pu spike is added to the sample (in our case ${ }^{242} \mathrm{Pu}$ ), such that the concentrations of 239 and ${ }^{240} \mathrm{Pu}$ can be determined as 
well. The mass spectrometer (m.s.) used in this study is operated by E.I. DuPont de Nemours \& Co. at the Savannah River Laboratory (S.R.L.) in South Carolina. The instrument was designed and built similar to other mass spectrometers within the national labs, to fit the necessary requirements for trace level $\mathrm{Pu}$ isotopic analyses (Lagergren and Stoffels, 1970). A complete description of the m.s. is given by Halverson (1981), and is briefly summarized below.

The mass spectrometer is designed in a three stage arrangement consisting of two identical magnetic analyzers $\left(90^{\circ}, 30.5 \mathrm{~cm}\right.$ radius) in a "C"-configuration, followed by an electrostatic analyzer $\left(90^{\circ}\right.$, $30.5 \mathrm{~cm}$ radius) and a ion-mutiplier type detector. The source is a "canoe"-shaped single Re-ribbon. The instrument is interfaced with a PDP 11/34 computer for automated mass stepping (accomplished by sweeping the accelerating voltage) and data aquisition. The instrument is housed in a "Class 100" clean room facility where all of the filament fabrication and sample loading occurs. Samples can be loaded into the vacuum system five at a time. One of the filament positions is occupled by a uranium standard (NBS U standard U005) which can be repeatedly used at the start of a given run to align the beam by focusing of the ${ }^{235} U$ and ${ }^{238} U$ mass peaks. Up to four samples can then be analyzed within a period of two to three hours.

\section{A. Source and Loading}

The source filament arrangement is a critical component of any m.s. set up, since the ability to efficiently form Pu fons at the source determines to a large extent the overall detection efficiency (typically 0.1-1\% for these samples). The filament ribbon is made from a strip $(0.12 \mathrm{~cm}$ wide) of triple zone-refined Re which is folded into a $v$-shape. The ends of the ribbon are then pinched, and the ribbon is spot welded onto the tungsten posts of the fllament base forming a "canoe-shaped" source filament. The assembled fllaments are baked at $1500^{\circ} \mathrm{C}$ for 30 minutes under vacuum to ensure a clean source. The filaments are then ready to be carburized.

The effects of carburization on the lonization of Pu off $\mathrm{Re}$ 
fllaments have been well studied (Palmer et al., 1980a, 1980b; Kelly and Robertson, 1985). In general, carburization refers to the deposition of a carbon source onto a m.s. filament. The carbon which is deposited dissolves into the Re ribbon to form a solid solution. The work function of the carburized ribbon is thereby increased, resulting in an improvement in the efficiency of $P u$ ion production of $f$ of the m.s. filament (Palmer et al., 1980a; Kelly and Robertson, 1985). As a reducing agent, the carbon also serves to promote the production of $\mathrm{Pu}$ ions over $\mathrm{Pu}$ oxides, the latter being undesirable for m.s. analysis (Studier et al., 1962; Kelly and Robertson, 1985). Furthermore, the presence of carbon has been shown to counteract Pu diffusion on the filament surface, so that a point source for good ion optics is maintained (Smith et al., 1980).

At S.R.L. the carburization procedure is as follows: a current is run through a series of up to eight filaments which are held in a vacuum chamber ( $p<5 \times 10^{-6}$ torr.). The current is raised slowly until the temperature of the filaments reaches $\sim 1050^{\circ} \mathrm{C}$, as determined by an optical pyrometer. A valve on a trap containing xylene in a dry tce and alcohol bath is opened until the chamber pressure reaches $5 x$ $10^{-5}$ torr. This allows for leakage of $x y$ lene vapor into the chamber. The xylene vapor serves as the carbon source which is deposited onto the hot Re filaments. The extent of carburization is controlled by stopping the xylene flow after 30 minutes has elapsed. Once carburized, the fllaments are returned to room temperature and pressure after closing the valve to the $x y$ lene trap and reducing the current to zero. This carburization procedure has been sucessfully performed on filaments which are either loaded or unloaded, i.e. either with or without a sample being in place on the filament prior to carburization. We have not found any major difference in the observed ionization efficiency between these two options.

The actual sample is loaded onto the filament as two anion-exchange beads which are placed in the center of the filament trough. The resin bead technique was first described by Freeman et al. (1970), and first reported for the use in the determination of $U$ and Pu 
by m.s. by Walker et al. (1974). Plutonium samples loaded as resin beads have up to an order-of-magnitude increased ionization efficiency when compared to Pu samples loaded as solutions (Smith et al., 1980). We have also found that the bead technique provided higher ionization efficiencies than Pu samples which were electrodeposited onto single, flat Re ribbons, similar to the procedure described by Perrin et al. (1984), but we did not rigorously test this alternate procedure.

The advantages of the bead technique are several. The beads provide a good point source for the ion optics of the m.s.. Also, based upon a study which utilized the resin bead technique for the m.s. analysis of $U$, it appears that the resin beads provide a sample reservoir from which the $U$ (or $\mathrm{Pu}$ ) can slowly migrate to the filament/bead interface, evaporating and diffusing into the Re matrix (Smith et al., 1980). This provides for a stable Pu ion sample beam which allows for maximum $\mathrm{Pu}$ ionization over long periods of detection time.

To load the sample onto the beads at S.R.L., we first add 50-100 $\mu 1$ of $8 \mathrm{~N} \mathrm{HNO}_{3}$ to the bottom of a conical shaped Teflon beaker which contains the evaporated and purified Pu sample (see following sections for the Pu chemical clean-up procedures). We then add two pre-cleaned anion exchange beads (AG $1 \times 2,50-100$ mesh, Bio-Rad Labs) to the Pu sample solution. The beads are left in the solution overnight which allows ample time for the beads to quantitatively remove the Pu from the solution. The beads are then picked out of the nitric acid solution with a tungsten needle under a low powered microscope, and placed into the center of a prepared filament trough. Once both beads have been loaded, a drop of dilute collodion solution is used to secure the beads in place on the ribbon. Two beads are used to insure that if one bead fails to pick-up the Pu for any reason, or is lost during handling, the second bead can still provide an adequate sample signal. Once loaded, the samples are placed into a vacuum chamber where they undergo a slow preparatory heating procedure. This step is most often included in the standard m.s. thermal ionization procedures for Pu once a given m.s. run has begun. 
The advantage of performing this step outside of the m.s. is a considerable savings in valuable m.s. run time. The S.R.L. sample/preparatory procedure consists of raising the current through the filaments (up to eight at a time) under vacuum ( $p<5 \times 10^{-6}$ tor $r$ ) slowly until a temperature of $1250^{\circ} \mathrm{C}$ is reached, as determined by an optical pyrometer. The purpose of this heating step is to slowly decompose the sample bead at relatively low temperatures, which is needed before the ionization of the Pu sample of $f$ of the filament can occur. The filaments are kept at $1250^{\circ} \mathrm{C}$ for 45 minutes, and then slowly brought back to room temperature. Care must be taken to ensure that the temperature on the fllament is raised slowly, such that the bead or a fragment thereof does not fly off of the ribbon. Careful monitoring of the chamber pressure can usually detect such a loss.

\section{B. Detection}

The ion beam in the S.R.L. m.S. is measured in the pulse counting mode by a electron multiplier originally designed by Dietz (1965). The multiplier was constructed at S.R.L. and has a virtual 100\% detection efficiency along with essentially zero background (3-4 background counts per hour at a gain of $10^{8}$ ) (Halverson, 1981). In the pulse counting mode, the current collected by the multiplier is passed through a pulse height discriminator, whereby only pulses above a certain threshold voltage are accepted as actual sample ion pulses. In this fashion, background noise signals are eliminated, and with proper design $>99 \%$ of all true sample pulses exceed the threshhold voltage setting.

The standard filament temperature for optimal Pu ionization is $1350-1450^{\circ} \mathrm{C}$. The filament is brought up to this temperature while monitoring the ${ }^{242} \mathrm{Pu}$ mass peak for an ion beam signal. The ion source is tuned at the ${ }^{242}$ pu mass peak in order to align the beam for maximum detection by the ion multiplier. During a given sample run, the m.s. is programmed to scan the 239, 240, 242 and 243 Pu mass peaks, including \pm 0.2 mass units around each peak $\left({ }^{243} \mathrm{Pu}\right.$ is monitored to examine potential isobaric interferences from $\mathrm{Fe}$ and $\mathrm{Re}) .{ }^{236} \mathrm{Pu}$ 
and/or ${ }^{241} \mathrm{Pu}$ can also be examined if desired. The optimal counting times at each mass peak are determined by the computer to minimize the variances of the estimated isotopic composition. Repeated mass scans (up to 64, depending upon the sample size and the lon beam strength) are made, and the data are collected and reported as the atom percent of a given $\mathrm{Pu}$ isotope during the entire run. The reported atom percent error associated with each isotope is determined either from counting statistics from the square root of the total number of Pu ions detected at a given peak, or by the variability in the atom percent values obtained between individual mass scans, whichever is greater. If no counts were detected at a given mass peak, then a maximum atom percent ratio is calculated assuming that one count had been detected at that mass during the run. No corrections in our data have been made for isotopic fractionation, since this effect has been shown to be rather small for the $\mathrm{Pu}$ isotopes $(<<1 \%)$ relative to the errors seen in our actual sample analyses (1-10\%).

\section{PREPARATION AND PURIFICATION OF MARINE SAMPLES}

Prior to the m.s. analysis, Pu must be chemically separated and purified. The techniques used depend upon the initial sample type and are based primarily upon modifications of techniques used for the preparation and purification of marine samples for the detection of 239,240 Pu by alpha-counting (Wong, 1971; Livingston et al., 1975).

\section{A. Sample Preparation}

Prior to the Pu purification steps, all of the samples must be spiked and equilibrated with a ${ }^{242} \mathrm{Pu}$ tracer and brought up in a solution of $8 \mathrm{~N} \mathrm{HNO}_{3}$ before loading onto the first ion exchange column. These preparation procedures will be described below in some detall for each type of marine sample that has been analyzed.

a. Sediment preparation procedure

Typically 1-10 g (dry weight) of oceanic sediments proved sufficient for the m.s. analysis of fallout ${ }^{239} \mathrm{Pu}$ and ${ }^{240} \mathrm{Pu}$. An aliquot of dried sediment is placed into an acid cleaned $500 \mathrm{ml}$ beaker, 
and $100 \mathrm{ml}$ of $8 \mathrm{~N} \mathrm{HNO}_{3}$ (made with reagent grade $\mathrm{HNO}_{3}$ and de-tonized water) are carefully added along with $1 \mathrm{ml}$ of our standard ${ }^{242} \mathrm{Pu}$ tracer. The tracer contains a known quantity of ${ }^{242} \mathrm{Pu}(\simeq 0.2 \mathrm{pg})$ in dilute nitric acid, which has been weighed into an acid cleaned covered plastic container. The tracers are added to the sample using repeated (5x) rinses of the tracer vial with nitric acid to ensure quantitative transfer of the tracer. The beaker is then covered with a watchglass and heated gently to near bolling $\left(\approx 80^{\circ} \mathrm{C}\right)$ and left overnight with occasional stirring. This actd/sediment slurry is then filtered through an acid cleaned glass fiber filter set-up followed by repeated rinsings of the original sample container and the sediment slurry with $8 \mathrm{~N} \mathrm{HNO}_{3}$. The filtrate is collected in a $500 \mathrm{ml}$ beaker and is slowly evaporated down while the remaining solid residue is returned to the original beaker and re-leached in hot $8 \mathrm{~N} \mathrm{HNO}_{3}$ for 6-8 hours. The sediment slurry is filtered a second time, and this filtrate is added to the original sample solution. The combined filtrate is evaporated down until $50 \mathrm{ml}$ of what is now concentrated $\mathrm{HNO}_{3}$ remains. An equal volume of de-ionized water is added to the sample, thus forming $100 \mathrm{ml}$ of sample in $8 \mathrm{~N} \mathrm{HNO}_{3}$. One gram of $\mathrm{NaNO}_{2}$ is added to the sample which is then heated slightly $\left(10-15 \mathrm{~min}\right.$. at $\left.40^{\circ} \mathrm{C}\right)$ before the sample is ready to load onto the first ion exchange column. $\mathrm{NaNO}_{2}$ serves to fix the Pu in the nitric acid solution in the +4 oxidation state, resulting in the formation of the negatively charged Pu-hexanitrate complex which is strongly adsorbed onto the anion exchange column (Milyukova et al., 1969; Livingston et al., 1975).

\section{b. Seawater/pore water preparation procedure}

The typical sample size. we have been analyzing for $\mathrm{Pu}$ in seawater is 3-5 1iters, given seawater 239,240 Pu activites of $0.01-0.1 \mathrm{dpm} / 100 \mathrm{~kg}$. For pore waters the activity of Pu can be somewhat higher $(0.1-1 \mathrm{dpm} / 100 \mathrm{~kg})$, therefore the sample volume can be reduced to the order of 100's of ml's (see Buesseler and Sholkovitz, 1984 and Sholkovitz and Mann, 1984 for sampling procedures and pore water activities). Since the total $\mathrm{Pu}$ in these samples is extremely small $\left(\simeq 10^{-15} \mathrm{~g}\right)$, care must be taken to ensure that the sample is 
handled under conditions which ensure that no Pu bearing particles (1.e. natural sediments) can enter the solution. All of the handling procedures for the water samples are therefore performed in a clean room facility, and all glassware/Teflonware is stored in dilute acid baths prior to use.

Seawater and pore water samples are weighed into 2- or 6-1tter beakers, followed by the addition of our ${ }^{242} \mathrm{Pu}$ spike. The sample and spike are equilibrated for 36-48 hours while being slowly stirred. The Pu sample is collected by a co-precipitation step which involves the addition of $1 \mathrm{ml}$ of a pure Fe stock solution $\left(20 \mathrm{mg} / \mathrm{ml} \mathrm{Fe}\right.$ in $\left.1 \mathrm{~N} \mathrm{HNO}_{3}\right)$ followed by the adjustment of the $\mathrm{pH}$ to 9-10 by the addition of concentrated reagent grade $\mathrm{NH}_{4} \mathrm{OH}$. The $\mathrm{Fe}\left(\mathrm{OH}_{3}\right)$ precipitates that form are stirred for 1-2 hours and then allowed to settle overnight. The $\mathrm{Pu}$ (and other actinides, metals, etc.) are carried by the $\mathrm{Fe}$ hyrdoxides. The sample supernate is carefully siphoned off and the Fe precipitate slurry is collected in a $250 \mathrm{ml}$ centrifuge tube, with repeated rinsings of the sample beaker with $\mathrm{pH}=8 \mathrm{H}_{2} \mathrm{O}$ to quantitatively collect the Pu bearing precipitates. The sample is then spun at $20,000 \mathrm{rpm}$ for 30 minutes so that the overlying solution can simply be poured off of the sample precipitates. The $\mathrm{Fe}\left(\mathrm{OH}_{3}\right)$ is then dissolved in the centrifuge tube with $\cong 1-3 \mathrm{ml}$ of concentrated $\mathrm{HNO}_{3}$. $50 \mathrm{ml}$ of $8 \mathrm{~N} \mathrm{HNO}_{3}$ is added to the sample along with $0.5 \mathrm{~g}$ of $\mathrm{NaNO}_{2}$. The centrifige tube is then heated in a $40^{\circ} \mathrm{C}$ waterbath for 10-15 minutes, and the sample is now ready to run onto the prepared ion exchange column.

\section{c. Sediment trap sample preparation procedure}

5-10 mg samples of organic and inorganic settling particle debris which were collected by a sediment trap have been analyzed for $\mathrm{Pu}$ isotopes and concentration by m.s. The sediment trap samples are digested overnight under a heat lamp in a covered $30 \mathrm{ml}$ Teflon beaker with the addition of a mixture of $1 \mathrm{ml}$ each of reagent grade, concentrated $\mathrm{HF}, \mathrm{HCl}, \mathrm{HNO}_{3}$, and our ${ }^{242} \mathrm{Pu}$ spike. The sample is taken to dryness and transferred to a $100 \mathrm{ml}$ glass beaker with the addition of $3 \mathrm{ml}$ of aqua regia. A second aqua regia rinse is used to 
ensure a complete transfer, and the aqua regia solution is taken to dryness. $2 \mathrm{ml}$ of concentrated nitric acid is added, and the sample is evaporated to dryness. This nitric acid step is repeated a second time. After the final evaporation step, the sample is brought up in $50 \mathrm{ml}$ of $8 \mathrm{~N} \mathrm{HNO}_{3}$, along with $0.5 \mathrm{~g}$ of $\mathrm{NaNO}_{2}$. The sample is warmed to $40^{\circ} \mathrm{C}$ for $10-15$ minutes to prepare the sample for the initial ion exchange column.

\section{B. Plutonium Purification by Ion Exchange}

The purification of Pu from other actinides, metals and salts is accomplished by an ion exchange technique adapted from procedures described by Wong, 1971, Livingston et a1., 1975, and Perrin et al.., 1985. A clean Pu source is essential for trace level Pu m.s. analyses since the presence of other elements in the sample interfere not only with ionization and the general m.s. efficiency, but can also cause isobaric interferences at the Pu mass peaks (Perrin et al., 1985). The ion exchange procedures used will be discussed below for each type of marine sample analysed. In general, the procedures are similar for all samples, however the sediment samples require much more clean-up than do the water or sediment trap samples.

\section{a. Sediment ion exchange column \#1}

The first column used in the sediment purification procedure contains $20 \mathrm{ml}$ of wet resin (AG1-x8, 50-100 mesh, Bio-Rad Labs) in a $1.5 \mathrm{~cm}$ i.d. $\times 30 \mathrm{~cm}$ column. The column is equipped with a $250 \mathrm{ml}$ sample resevoir, glass wool plugs to contain the resin within the column, a stop-cock to control the flow rate, and a "goose neck" exit tube such that the resin cannot run dry if left unattended (see Fig. 3.1a). The column is pre-conditioned with $80 \mathrm{ml}$ of concentrated $\mathrm{HNO}_{3}$ followed by $100 \mathrm{ml}$ of a $8 \mathrm{~N} \mathrm{HNO}_{3}$ solution to which $1 \mathrm{~g}$ of $\mathrm{NaNO}_{2}$ has been added (the flow rate is kept at approximately $2 \mathrm{ml}$ per minute). All of the solutions used in this and the second sediment column are made up from reagent grade acids and de-ionized water.

The sample is added to the column resevoir, and allowed to flow through the column at a flow rate of $1 \mathrm{ml}$ per minute. The sample 

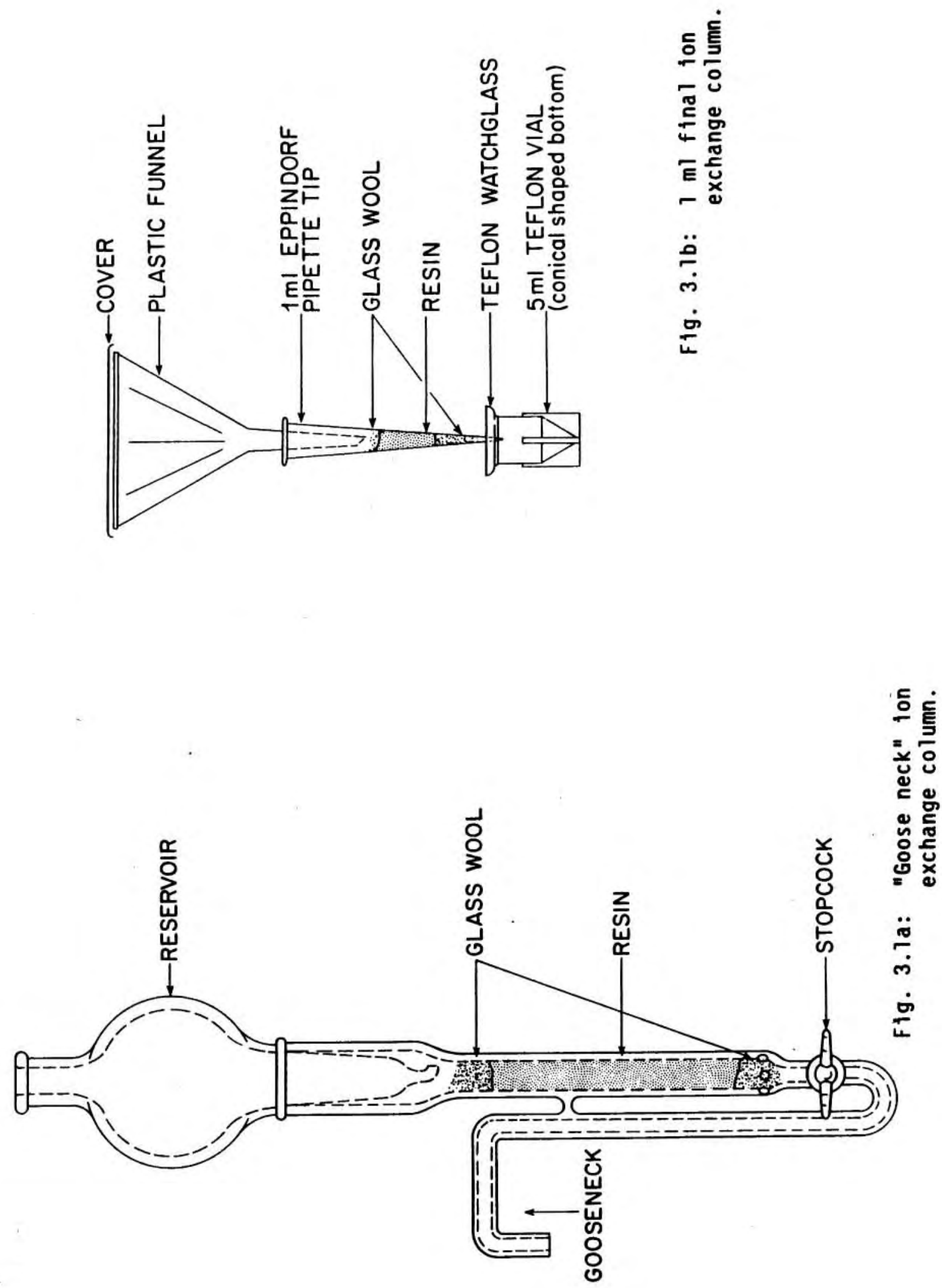
beaker is rinsed with $8 \mathrm{~N} \mathrm{HNO}_{3}$, and these washings - along with an additional $250 \mathrm{ml}$ of $8 \mathrm{~N} \mathrm{HNO}_{3}$ - are passed through the column (this step removes much of the $\mathrm{Fe}$ and $U$ from the sample, which pass through the column under these conditions). Next, $150 \mathrm{ml}$ of concentrated $\mathrm{HCl}$ are passed through the column at a fast flow rate $(2-4 \mathrm{ml} / \mathrm{min}$.) which serves to elute Th off the column. The Pu fraction is then collected by passing a solution of $150 \mathrm{ml}$ concentrated $\mathrm{HCl}$ with $7.5 \mathrm{ml}$ of $1 \mathrm{~N}$ $\mathrm{NH}_{4} \mathrm{I}$, through the column at a flow rate of $1 \mathrm{ml} / \mathrm{min}$. The $\mathrm{NH}_{4} \mathrm{I}$ reduces the $\mathrm{Pu}$ to the +3 oxidation state, which is no longer adsorbed to the column and is thereby eluted. The eluted Pu fraction is collected in a $250 \mathrm{ml}$ beaker and evaporated to dryness, using repeated treatments with aqua regia ( $2 x$ using $1 \mathrm{ml}$ of aqua regia) to destroy the remaining $\mathrm{NH}_{4} \mathrm{I}$, followed by evaporating to dryness in the presence of $\mathrm{HNO}_{3}$ ( $3 \times$ using $2 \mathrm{ml}$ of $\mathrm{HNO}_{3}$ ) to return the sample to the nitric acid form.

\section{b. Sediment column \#2}

The second fon exchange column used in the sediment procedure is similar to the first except that the volumes of acid and resin have now been greatly reduced. The eluted $\mathrm{Pu}$ sample from the previous column is brought up in $5 \mathrm{ml}$ of $8 \mathrm{~N} \mathrm{HNO}_{3}$, and $0.02 \mathrm{~g}$ of $\mathrm{NaNO}_{2}$ is added with slight heating. The fon exchange column is made with $2 \mathrm{ml}$ of resin (AG1-x8,100-200 mesh, Bio-Rad Labs) in a glass column with a $1.0 \mathrm{~cm} 1 . d . \times 2 \mathrm{~cm}$ height. The sample is loaded onto the column with a glass pipette (acid cleaned) in order to ensure that no sample solution is lost. Once loaded onto the column, the flow rate is maintained at roughly $1 \mathrm{ml} / \mathrm{min}$. due to the geometry of the column and the fine mesh resin which is used. The sample is followed by $10 \mathrm{ml}$ of $8 \mathrm{~N} \mathrm{HNO}_{3}$ which is used to rinse the beaker, followed by $20 \mathrm{ml}$ of $8 \mathrm{~N}$ $\mathrm{HNO}_{3}$ as a general column wash. After the nitric acid is eluted, $25 \mathrm{ml}$ of concentrated $\mathrm{HCl}$ is passed through the column. Finally, the $\mathrm{Pu}$ is collected in a $50 \mathrm{ml}$ beaker by passing a solution made up of $1.5 \mathrm{ml}$ of $1 \mathrm{~N} \mathrm{NH}_{4} \mathrm{I}$ in $30 \mathrm{ml}$ of concentrated $\mathrm{HCl}$ through the column at a flow rate of $1 \mathrm{ml} / \mathrm{min}$.

This final Pu eluate is evaporated to dryness, and as with the 
first column, the $\mathrm{NH}_{4} \mathrm{I}$ is destroyed by the addition of aqua regia $(2 x)$, between repeated evaporations to dryness. The sample is finally brought to dryness $(2 \mathrm{x})$ with the addition of $1 \mathrm{ml}$ of concentrated $\mathrm{HCl}$.

\section{c. Sediment column \#3}

The final Pu ion exchange column is similar for all samples, and serves to achleve the added clean-up necessary for trace level Pu analysis by m.s. The column work is performed in a separate positive pressure clean-room, where the room air is continuously filtered through a large HEPA filter clean-air bench. All of the acids used in these steps are high purity grade, to ensure that the final Pu elutate is obtained free from any interfering contaminants (Seastar double sub-boiling distilled concentrated $\mathrm{HNO}_{3}$ and $\mathrm{HCl}$; EM Reagents "Suprapur" high purity $47 \% \mathrm{HBr}$ ). The glassware/Teflonware is all hot acid leached ( $4 \mathrm{~N} \mathrm{HCl}$ ) and stored in $\mathrm{N} \mathrm{HCl}$ baths prior to use. The water which is used is distilled and de-ionized through a Milli-Q purification system. The following procedures are based on those of Larsen and 0ldham, 1974 and Perrin et al., 1985.

The sample from the previous column is brought-up in $1 \mathrm{ml}$ of freshly prepared $\mathrm{HCl} / \mathrm{H}_{2} \mathrm{O}_{2}$ solution ( $10 \mathrm{ml}$ concentrated $\mathrm{HCl}$ with one drop $30 \% \mathrm{H}_{2} \mathrm{O}_{2}$ added). The sample is warmed silightly $\left(\approx 40^{\circ} \mathrm{C}\right)$ for 60 minutes before loading onto the column.

The column itself is prepared in an acid cleaned, disposable $1 \mathrm{ml}$ Eppindorf pipette tip (see Fig. 3.1b). A plug of hot acid-leached and de-ionized water-rinsed glass wool is pressed into the tip of the column. The resin used is AGMP-1, 20-50 mesh (B10-Rad Labs) which has been hot acid ( $4 \mathrm{~N} \mathrm{HC1)-leached} \mathrm{and} \mathrm{repeatedly} \mathrm{rinsed} \mathrm{with} \mathrm{the}$ de-ionized water and stored as a slurry in de-ionized water. The resin slurry is added to the column with a disposable plastic pipette such that a resin bed volume of $1 \mathrm{ml}$ is obtained $(2.5 \mathrm{~cm}$ height). A second glass wool plug is placed on top of the column and a $10 \mathrm{ml}$ plastic funnel is pushed into the column top to serve as the sample and rinse solution resevoir. This resevoir is covered by a plastic top. The column is pre-conditioned with 2-3 $\mathrm{ml}$ of the $\mathrm{HCl} / \mathrm{H}_{2} \mathrm{O}_{2}$ solution, and the column flow rate is controlled simply by the column design, in 
particular by the density and packing of the initial glass wool plug.

The sample is loaded onto the column with a plastic, disposable $3 \mathrm{ml}$ pipette. This is followed by $2 \mathrm{ml}$ of the $\mathrm{HCl}_{2} / \mathrm{H}_{2} \mathrm{O}_{2}$ solution which is used to rinse the original sample container before adding the solution to the resevoir. The $\mathrm{HCl}$ solution is followed by a $2 \mathrm{ml}$ wash of $8 \mathrm{~N} \mathrm{HNO}_{3}$. Pu is eluted with $3 \mathrm{ml}$ of concentrated $\mathrm{HBr}$, which are collected directly in a $5 \mathrm{ml}$ screw top, conical shaped Teflon vial. The vial is covered by a Teflon watchglass with holes which permit the column tip to reach just inside the covered vial (see Fig. 3.1b). Once the $\mathrm{HBr}$ elutant is collected, the sample is placed under a heat lamp and the $\mathrm{HBr}$ solution is evaporated. When only a few drops of the $\mathrm{HBr}$ solution remain, 6-8 drops of concentrated $\mathrm{HNO}_{3}$ are added to destroy any traces of $\mathrm{HBr}$. The solution is evaporated to dryness, sealed with the threaded Tefion top and is now ready to be transported to the m.s. facility for loading and analysis. A summary of the sediment ion exchange purification prodcedures is provided in Fig. 3.2a.

\section{d. Seawater, pore water and sediment trap sample column \#1} The first ion exchange column for these samples is designed similar to the initial sediment column except that the resin bed volume has been reduced to $10 \mathrm{ml}$. We use $10 \mathrm{ml}$ of wet resin (AG)-x8, 50-100 mesh, Bio-Rad Labs) in a 1.0 1.d. $\times 20 \mathrm{~cm}$ tall "goose-neck" column equipped with a $125 \mathrm{ml}$ sample resevoir and a stop-cock to adjust the flow rate. The column is pre-conditioned with $50 \mathrm{ml}$ of $8 \mathrm{~N} \mathrm{HNO}{ }_{3}^{\text {to }}$ which $0.5 \mathrm{~g}$ of $\mathrm{NaNO}_{2}$ has been added (flow rate is $2 \mathrm{ml} / \mathrm{min}$ ). All of the acids used in this column are reagent grade, and as required, are diluted with "Milli-Q" de-ionized water.

The sample is poured into the column resevoir and passed through the column at a flow rate of $1 \mathrm{ml} / \mathrm{min}$. This is followed by three $5 \mathrm{ml}$ $8 \mathrm{~N} \mathrm{HNO}_{3}$ rinses of the original sample centrifuge tube container and then a $150 \mathrm{ml}$ column wash with $8 \mathrm{~N} \mathrm{HNO}_{3}$ at a flow of $1 \mathrm{ml} / \mathrm{min}$. Next, $150 \mathrm{ml}$ of concentrated $\mathrm{HCl}$ is passed through at a faster flow rate of $2 \mathrm{ml} / \mathrm{min}$. The Pu fraction is then eluted at a flow rate of $1 \mathrm{ml} / \mathrm{minute}$ with $75 \mathrm{ml}$ of concentrated $\mathrm{HCl}$ to which $6 \mathrm{ml}$ of $1 \mathrm{~N} \mathrm{NH}_{4} \mathrm{I}$ solution has been added. This Pu fraction is collected in a $100 \mathrm{ml}$ beaker, and 

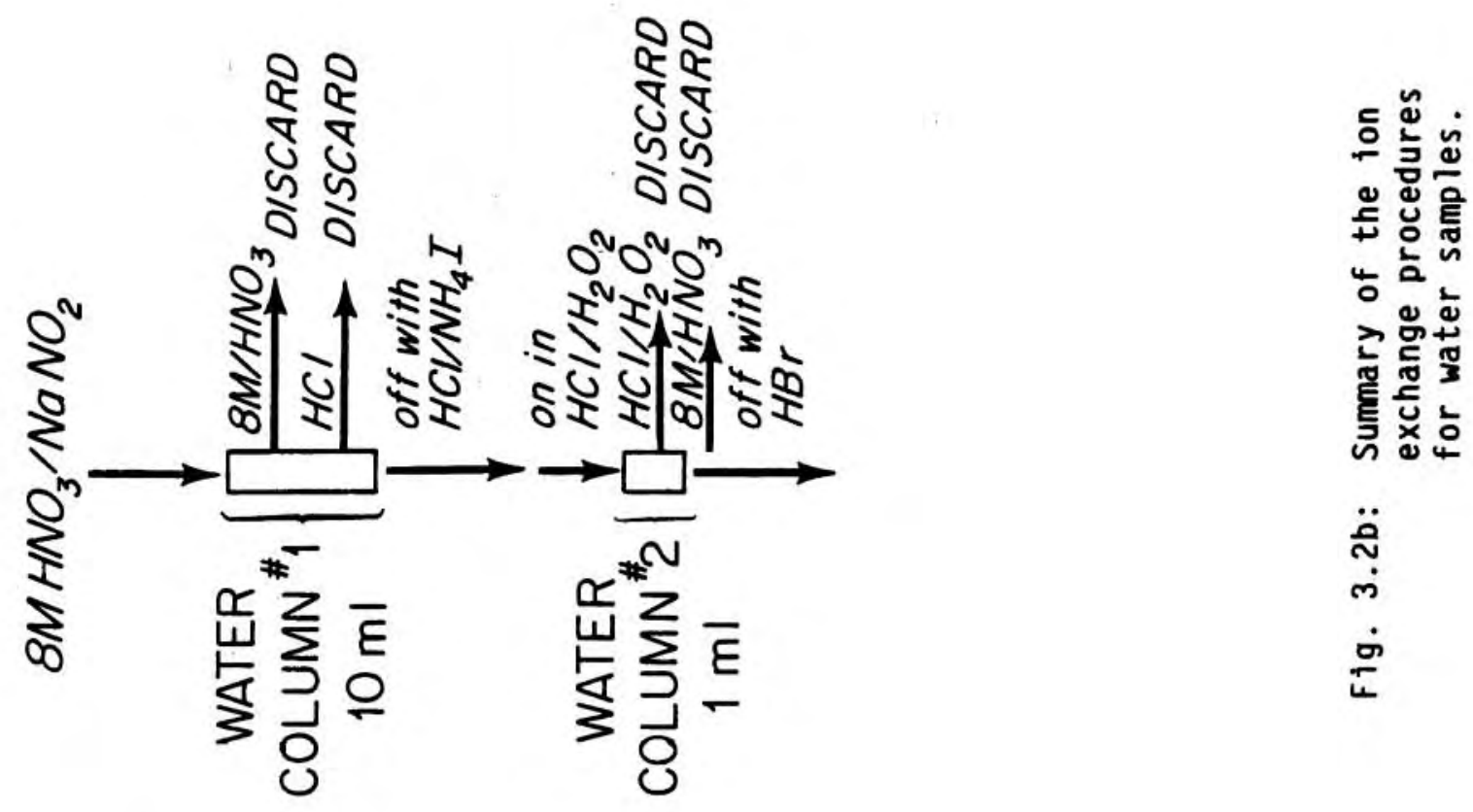

0

>

등 옹

हᄐํํㅇํㄴ

ํํำ

i

훈

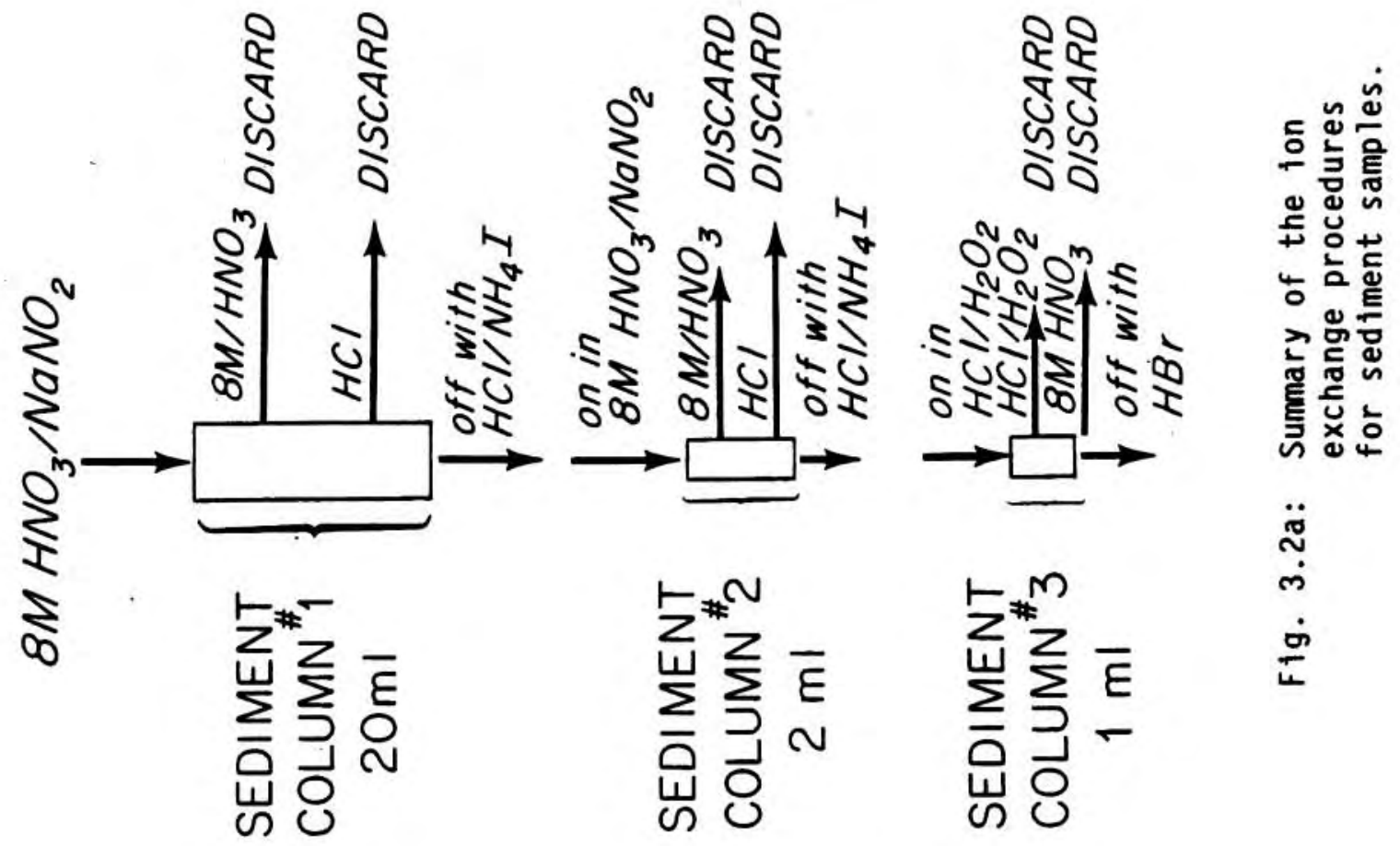


evaporated slowly to dryness. Two treaments with $1 \mathrm{ml}$ of aqua regia are used to destroy the remaining $\mathrm{NH}_{4} \mathrm{I}$. The sample is prepared for the following column by evaporating the solution to dryness ( $3 x$ ) with the addition of 1-2 $\mathrm{ml}$ of concentrated $\mathrm{HCl}$.

e. Seawater, pore water and sediment trap sample column \#2 Only two clean up columns are used for these samples, the second ion exchange column being identical to the final sediment column \#3 described previously (1.e. a $1 \mathrm{ml}$ AGMP resin column; sample on as concentrated $\mathrm{HCl} / \mathrm{H}_{2} \mathrm{O}_{2}$, off with $\mathrm{HBr}$ and into $5 \mathrm{ml}$ Teflon vials with evaporation to dryness). A summary of the water and sediment trap ion exchange procedures is given in $\mathrm{Fig}$. $3.2 \mathrm{~b}$.

\section{RESULTS AND DISCUSSION}
A. $\frac{{ }^{242} \mathrm{Pu} \text { Tracer }}{\text { The }{ }^{242} \mathrm{Pu} \text { tra }}$

iN $\mathrm{HNO}_{3}$ from a dilution of the NBS ${ }^{242} \mathrm{Pu}$ standard 4334-B. This standard has been routinely used in our labs as a yield monitor for Pu determinations by alpha counting. It is important to check for other Pu isotopes in our standard $1 \mathrm{ml}$ aliquot of the ${ }^{242} \mathrm{Pu}$ spike. Table 3.1 shows the results of two separate m.s. analyses of this spike. The ${ }^{239} \mathrm{Pu}$ and ${ }^{240} \mathrm{Pu}$ concentrations are so low that only an upper limit on the atom percent of these isotopes can be calculated assuming that one count of ${ }^{239} \mathrm{Pu}$ or ${ }^{240} \mathrm{Pu}$ is detected in the ${ }^{242} \mathrm{Pu}$ spike (see Table 3.1). We conclude that our ${ }^{242} \mathrm{Pu}$ spike is indeed free of any other Pu isotope contaminants.

The concentration of the ${ }^{242} \mathrm{Pu}$ m.s. standard was checked by intercalibration with a known quantity of a ${ }^{239} \mathrm{Pu}$ spike provided by the E.P.A. Labs in Las Vegas, Nevada U.S.A.. Two samples consisting of $200 \mathrm{ml}$ of our ${ }^{242} \mathrm{Pu}$ standard solution ( $\simeq 0.4 \mathrm{dpm}{ }^{242} \mathrm{Pu}$ each) were spiked with $0.4 \mathrm{dpm}$ of the EPA ${ }^{239} \mathrm{Pu}$ solution and alpha-counted. Also, an aliquot of one of these samples (1/100th of the sample by volume) was analyzed directly by the S.R.L. m.s. to obtain an atom ratio of ${ }^{239} \mathrm{Pu} /{ }^{242} \mathrm{Pu}$ as well. The ${ }^{242} \mathrm{Pu}$ concentration of our 


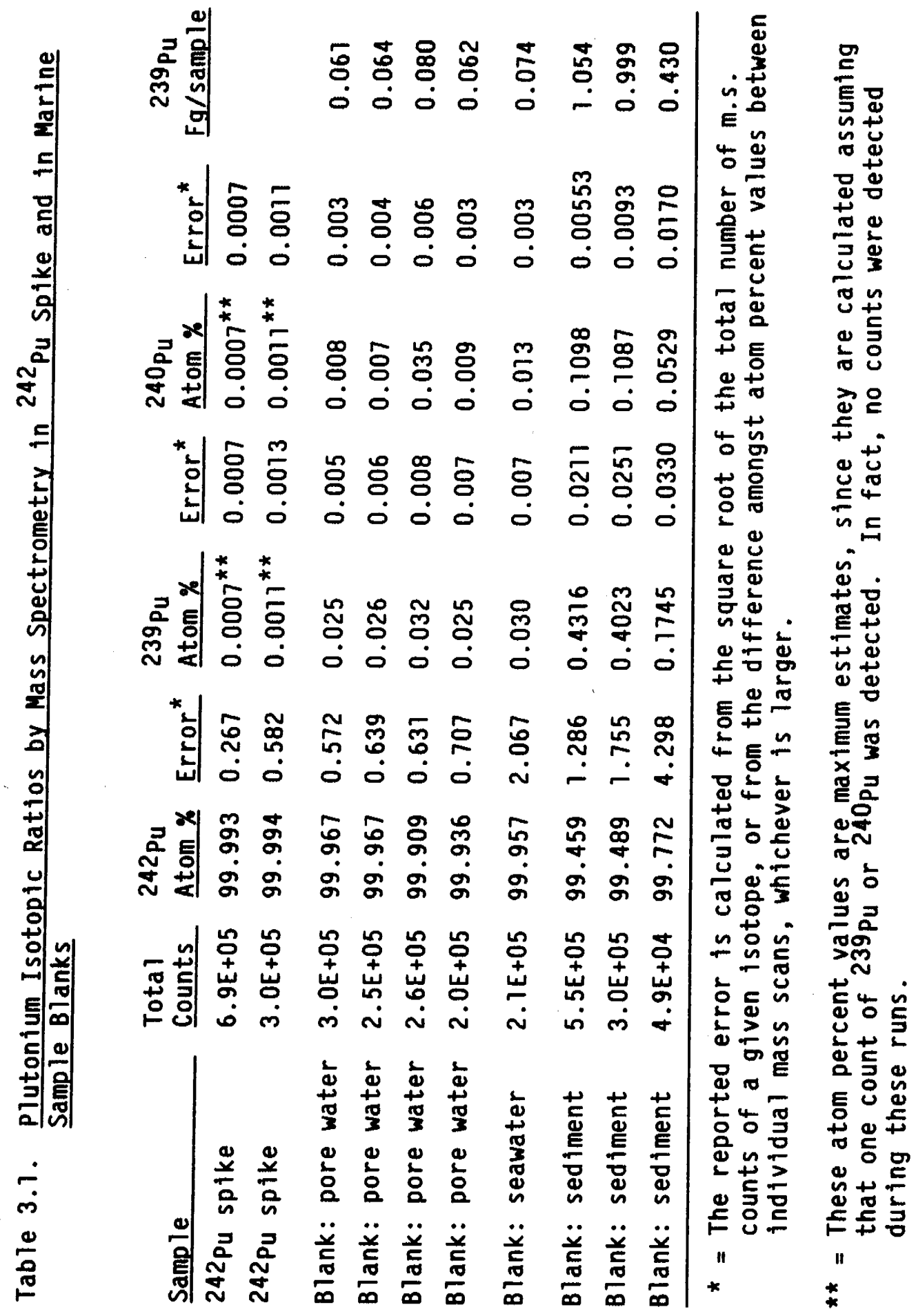


spike is determined assuming that the quantity of added ${ }^{239} \mathrm{Pu}$ is precisely known. The results of the ${ }^{239} \mathrm{Pu} /{ }^{242} \mathrm{Pu}$ ratios determined by alpha-counting and by m.s. agree within the counting precision ( $\pm 2.7 \%$ for a-counting and $\pm 1.6 \%$ for m.s.). The calibrated ${ }^{242} \mathrm{Pu}$ concentration of our spike was determined from these three analyses to be $0.239 \pm 0.003 \mathrm{pg}{ }^{242} \mathrm{Pu} / \mathrm{g}$ solution. In practice, $1 \mathrm{~g}$ aliquots of this ${ }^{242} \mathrm{Pu}$ tracer solution are welghed into acid cleaned vials and used for isotope dilution m.s. determinations of fallout ${ }^{239} \mathrm{Pu}$ and $240 \mathrm{Pu}$ concentrations in our samples.

\section{B. Blanks}

Procedural blanks for the m.s. technique are given in

Table 3.1. Essentially, these blanks are determined by running a ${ }^{242} \mathrm{Pu}$ splke through all of the associated preparation and purification procedures described previously for the sediment and water samples. The sediment sample blank is significantly higher than that of the water samples, which is likely due to the additional handiing and reagents needed in the sediment analytical technique. A blank correction of $0.8 \times 10^{-3} \mathrm{pg}{ }^{239} \mathrm{Pu} / \mathrm{sample}$ has been applied to our sediment data. This correction is relatively insignificant given the levels of ${ }^{239} \mathrm{Pu}$ measured in our samples, and represents $<1 \%$ of the total mass of ${ }^{239} \mathrm{Pu}$ in most of these sediment samples. As expected, the blanks for the seawater and pore water samples are identical due to the similar handling procedures used on these samples. The observed blank for these samples averaged $6.8 \times 10^{-5} \mathrm{pg}{ }^{239} \mathrm{Pu} / \mathrm{sample}$ (see Table 3.1). Some of the deeper pore water samples had ${ }^{239} \mathrm{Pu}$ concentrations at this blank level, and represent zero Pu levels, or more accurately, levels of $\mathrm{Pu}<6.8 \times 10^{-5} \mathrm{pg}{ }^{239} \mathrm{Pu} / \mathrm{sample}$. In practice, samples with ${ }^{239} \mathrm{Pu}$ concentrations less than $<0.5-1 \times 10^{-3}$ pg ${ }^{239} \mathrm{Pu} / \mathrm{sample}$ (or 10-15 times the blank), proved difficult to extract statistically meaningful Pu data from, due to the limited number of $\mathrm{Pu}$ lons detected. Though a sediment trap blank was not measured, the two sediment trap samples have been corrected by this same Pu water procedural blank, due to the similarity in handling 
procedures between these sample types.

C. Sample Results

Results for an assortment of marine samples are given as atom percent values, 240/239 $\mathrm{Pu}$ isotopic ratios, and as $\mathrm{Pu}$ concentrations in Table 3.2. Complete results and their interpretations will be presented elsewhere (Chapter 6, this thesis). The Pu determinations by m.s. agree well with alpha-counting determinations of Pu on larger quantities of the same sample (see Table 3.2). Also, repeated analyses of the same seawater sample by m.s. have provided consistent Pu ratios and concentrations within the analytical precision (see seawater sample "QCW" in Table 3.2). Intercalibration exercises have been run between the Savannah River Laboratory and other m.s. facilities at Los Alamos and Scripps and provide excellent agreement between labs in the determination of ${ }^{240} \mathrm{Pu} /{ }^{239} \mathrm{Pu}$ ratios (Koide et al., 1985). As discussed with regards to our water blank, the absolute detection capability is approximately $0.5-1 \times 10^{-3} \mathrm{dpm} 239,240 \mathrm{Pu}$ per sample (given a ${ }^{240} \mathrm{Pu} /{ }^{239} \mathrm{Pu}$ ratio of 0.18 ), or $0.5-1 \times 10^{-15} \mathrm{~g}$ of ${ }^{239} \mathrm{Pu}$ per sample.

As far as the analysis of environmental marine samples is concerned, it must be remembered that the specific activity of Pu spans seven orders-of-magnitude on a weight basis, when one is dealing with sediment trap, sediment, pore water, and seawater samples (see insert, Fig. 3.3). If typical collected sample weights for each of these sample types are compared to the range of Pu activities found, several factors become clear (Fig. 3.3). For all of these sample types, some combination of relatively high activity and/or large sample mass can provide ample Pu above the detection limit of this m.s. technique. This is easiest to obtain for sediments, where most samples have considerable activity, and where multi-gram sampling is common and straight-forward. It must be remembered however, that even in sediments, deep in a given core one will reach a point where zero Pu tracer is present, since this isotope has only recently been introduced into the environment. Pre-bomb samples of any type should have essentially blank signals. The pore water samples prove most difficult 


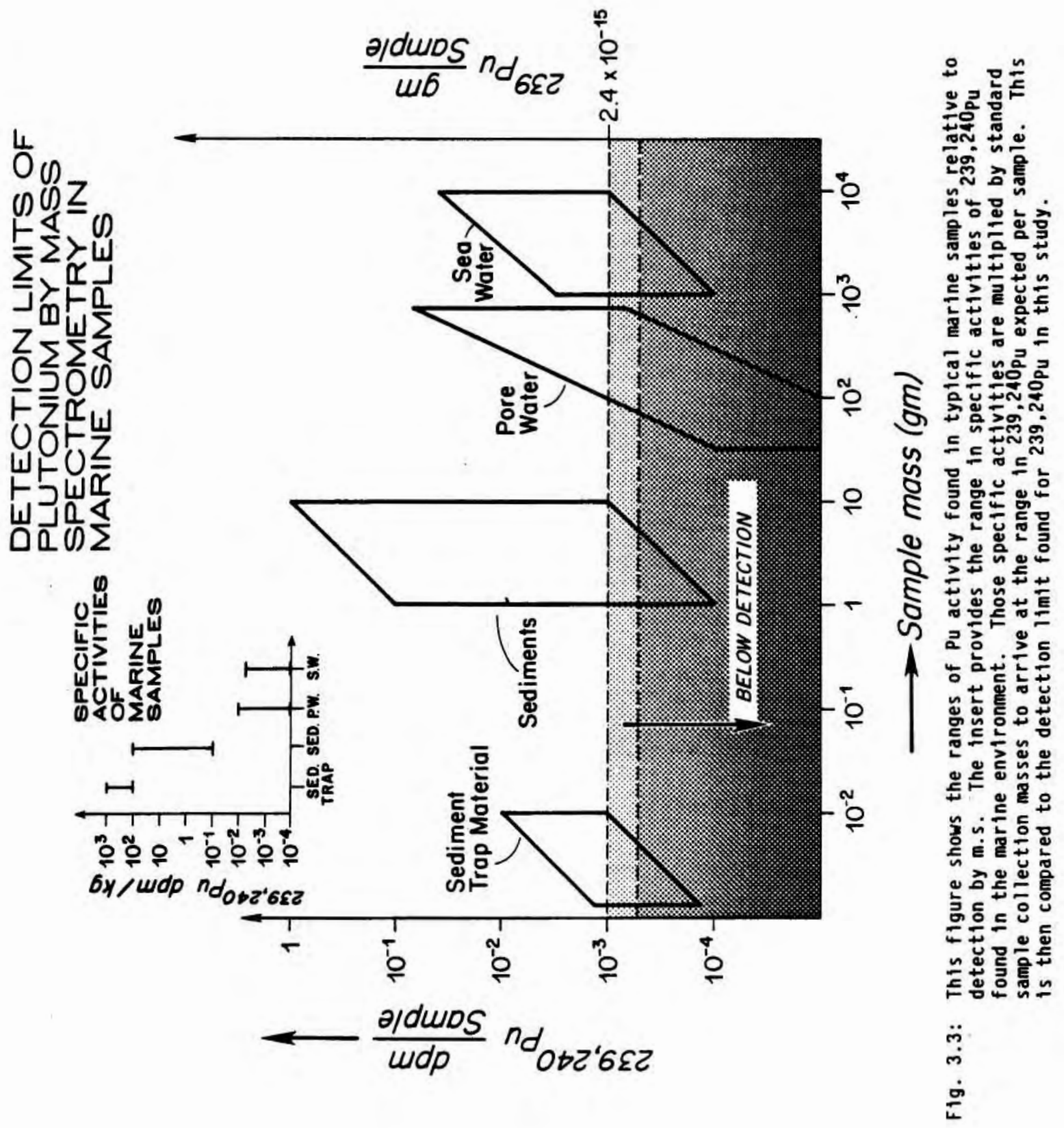


Table 3.2. Selected Plutontum Analyses by Mass Spectrometry in N. Atlantic Marine Samples (with Comparisons to Alpha-counting)

\section{Sample}

Sediments

SEEP LVA $: 0-1.5 \mathrm{~cm}$

SEEP LVEIA:0-1 cm

SEEP LVE2A:2-3cm

SEEP LVE8:14-16cm

SEEP LVFIA:0-1 cm

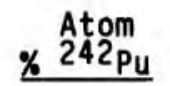

\begin{tabular}{l} 
Atom \\
\% $239 \mathrm{pu}_{\mathrm{u}}$ \\
\hline
\end{tabular}

Atom
$240 \mathrm{Pu}$

Rat10

239/242 \begin{tabular}{l} 
\pm error \\
$239 / 242$ \\
\hline
\end{tabular}

Rat10

240/239 \pm error $\underline{240 / 239}$

\section{Pore water}

SEEP LVEI:0-2cm

92.667

21.102

97.571

6.224

68.125

1.0884

10.7699

0.0672

3.2284

0.0016

0.175

0.008

99.951

2.127

0.3020

0.0218

98.217

0.042

0.0067

0.0004

0.0187

0.158

0.002

1.513

0.2707

0.0154

0.0005

0.142

0.009

0.00003

0.159

0.029

0.0003

0.179

0.005

SEEP LVE2: $2-4 \mathrm{~cm}$

94.094

4.997

0.8934

98.659

1.115

0.2051

0.0531

0.0006

0.179

0.007

97.788

1.859

0.3489

0.0190

0.0004

0.184

0.044

SEEP LVFI:0-2cm

2.078

0.3722

0.9455

0.0213

0.0561

0.0005

0.0025

0.179

0.180

0.008

EN CMME -4 3985m

93.764

5.262

0.163

0.0295

0.148

0.0266

0.1937

0.0409

0.0958

0.0184

0.0016

0.0015

0.0019

0.00096

0.00003

0.000045

0.181

0.0001

0.180

0.000025

0.211

0.192

0.011

0.011

0.018

SEEP STA-F: $454 \mathrm{~m}$

99.885

$0.0958-0$


Table 3.2.: (Continued)

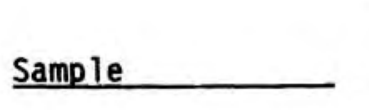

Sediments

SEEP LVAl:0-1.5cm

SEEP LVEIA:0-1 cm

SEEP LVE2A:2-3cm

SEEP LVE8:14-16cm

SEEP LVF1A:0-1 cm

Pore water

SEEP LVEI :0-2cm

SEEP LVE2:2-4cm

SEEP LVF 1:0-2cm

Sediment trap materertal

SEEP \#4 1200m 0.0047

EN CMME-4 3985m

0.0086

Seawater

Sargasso Sea surf. 1300

Sargasso Sea surf. 1400

SEEP STA-D:1700m 1000

SEEP STA-F:454m $\quad 1000$
Sample $\quad \begin{aligned} & \text { Detection-- Su } \\ & \text { Pumle }\end{aligned}$

wt. (gm) dpm/sample 239,240Pu

(dpm/kg) .

$114.76+5.90$

$59.92 \pm 0.78$

$35.49 \pm 2.39$

$0.70 \pm 0.14$

$26.23 \pm 0.89$

$(\mathrm{dpm} / 100 \mathrm{~kg})$

$0.567 \pm 0.007$

$0.122 \pm 0.012$

$0.181 \pm 0.004$

$$
\text { (dpm/gm) }
$$

$0.244 \pm 0.012$

$0.355 \pm 0.030$

$(\mathrm{dpm} / 100 \mathrm{~kg})$
0.0018
0.0018
0.0010
0.0013

----Alpha Detection---Sample wt. (gm) $239,240 \mathrm{Pu}$

(dpm/kg)

$\begin{array}{rr}15 & 107.1 \pm 4.9 \\ 15 & 62.7 \pm 3.5 \\ 15 & 36.2 \pm 2.2 \\ 15 & 0.8 \pm 0.4 \\ 15 & 27.4 \pm 2.1\end{array}$
$0.138+0.009$
$0.129 \mp 0.009$
55000
$0.13+0.03$
$0.099 \pm 0.009$
55000
$0.13 \pm 0.03$
$0.124 \pm 0.007$
55000
$0.10 \pm 0.01$
$0.13 \pm 0.01$ 
to run, since Pu activities are extremely low, and since the volumes of sample which can be collected are rather small. The range in pore water sample mass used in Figure 3.3 is $50-900 \mathrm{~g}$, which is still rather large, requiring considerable effort to collect given the avallable sampling techniques. Again, since the total Pu signal in these marine cores is often concentrated in the upper most $\mathrm{cm}$ 's, the pore water Pu signal is only above detection in shallow and relatively large samples. Seawater samples can be as low in Pu activity as the pore waters, however here much larger water volumes can be easily collected. Thermal ionization mass spectrometry provides a number of advantages for environmental studies of Pu. The increased sensitivity of the m.s. detection technique allows for the determination of Pu on liter quantities of seawater in contrast to the 50-100 1iter water samples used for alpha-counting analyses. These smaller volumes are much more practical to obtain, and provide a real savings in terms of the costs and effort needed not only in sampling, but also in the sample preparation and purification steps. In addition, the gain in isotopic information which the m.s. provides has been shown to be a valuable indicator of the source(s) of fallout $\mathrm{Pu}$ at a given site (Scott et al., 1983; Koide et al., 1985; Buesseler et al., 1985;

Chapter 6, this thesis). The isotopic ratio of ${ }^{240} \mathrm{Pu} /{ }^{239} \mathrm{Pu}$ can also potentially be used to trace the relative significance of reactor vs. fallout $\mathrm{Pu}$ at a given site, or to trace releases of $\mathrm{Pu}$ in nuclear waste disposal operations.

\section{v. CONCLUSIONS}

1. Thermal ionization mass spectrometry provides an extremely sensitive technique for the detection of $\mathrm{Pu}$ in marine samples. This technique is orders-of-magnitude more sensitive than alpha-counting detection techniques. This is a valuable feature in environmental studies where Pu concentrations are extremely small.

2. The chemical preparation and purification procedures for the analysis of Pu by m.s. are similar to those used for alpha-counting, with some additional attention needed to maintain clean sample 
conditions and low blanks.

3. The Savannah River Laboratory m.s. facility can analyze 8 Pu samples within a period of roughly 8 hours. This is considerably faster than the detection times needed for alpha-counting. The inherent problem with alpha-counting is that the long half-lives of alpha-decay for ${ }^{239} \mathrm{Pu}(24,390 \mathrm{yrs})$ and ${ }^{240} \mathrm{Pu}(6,620 \mathrm{yrs})$ combined with the low abundances of these isotopes in the environment simply result in extremely few alpha-decay events during the course of a given counting interval.

4. The isotopic ratio of ${ }^{240} \mathrm{Pu} /{ }^{239} \mathrm{Pu}$ can be accurately determined by $m . s$. This can provide valuable additional information concerning the source of $\mathrm{Pu}$ in a given sample. 
$-62-$ 
CHAPTER 4

\section{A Pore Water Study of Plutonium in Shelf, Slope, and}

\section{Deep-Sea Sediments}

\section{INTRODUCTION}

This chapter will focus on the unresolved question of $\mathrm{Pu}$ remobilization from and within marine sediments (see Sholkovitz (1983) for review). Traditionally, evidence for or against Pu mobility has been inferred from water column studies (Bowen et a1., 1980; Santschi et a1., 1980), sediment distributions (Koide et a1., 1975; Livingston and Bowen, 1979; Carpenter and Beasley, 1981; Cochran, 1985; Stordal at a1., 1985; Sayles and Livingston, 1985) and laboratory studies (Sholkovitz at a1., 1983; Santsch1 et a1., 1983; Higgo and Rees, 1986). However, these studies are not conclusive. For instance, early evidence of downcore decreases in the ${ }^{239,240} \mathrm{Pu} /{ }^{137} \mathrm{Cs}$ ratio in coastal sediments has been used to argue both for (Livingston and Bowen, 1979) and against (Edgington 1981; Carpenter and Beasley, 1981) Pu mobility in sediments. While pore water studies are known to provide the most sensitive indication of diagenetic mobility (Emerson, 1976; Froelich et a1., 1979; Berner, 1976, 1980), pore water Pu studies have been limited due to the extremely low concentration of fallout $239,240 \mathrm{Pu}$ expected in natural pore waters $\left(\simeq 10^{-18} \mathrm{moles} / \mathrm{kg}\right)$ (Edgington, 1981; Sholkovitz, 1983).

The advantages in obtaining $239,240 \mathrm{Pu}$ pore water data are seen in the study of Sholkovitz and Mann (1984). They were able to measure both ${ }^{239,240} \mathrm{Pu}$ and ${ }^{137} \mathrm{Cs}$ in the solid phase and large volume $(1-3.4 \mathrm{~kg})$ pore water samples at the same Buzzards Bay site studied by Livingston and Bowen (1979). Their data show evidence for the diffusive transport of ${ }^{137} \mathrm{Cs}$ relative to $239,240 \mathrm{Pu}$ and can account for the decreasing solid phase ${ }^{239,240} \mathrm{Pu} /{ }^{137} \mathrm{Cs}$ ratio with depth in the core. They found that the exchange of $\mathrm{Pu}$ between the solids and the pore waters was roughly constant throughout the core with a 
distribution coefficient $\left(K_{d}\right)$ of $3-12 \times 10^{4}\left(K_{d}=(d p m / k g\right.$ solids)/(dpm/kg solution)). Their ${ }^{239,240} \mathrm{Pu}$ pore water data remain the most conclusive evidence against significant Pu remobilization at a shallow reducing marine site.

Data on $239,240 \mathrm{Pu}$ pore water chemistry under more oxidizing conditions and in different sediment types are lacking. Enhanced Pu mobility in deep-sea sediments has recently been suggested based upon comparisons in the solid phase between fallout ${ }^{239,240} \mathrm{Pu}$ and the naturally occuring tracer ${ }^{210} \mathrm{~Pb}$ (Cochran, 1985; Stordal at al., 1985; Sayles and Livingston, 1985). In these studies both the penetration of $239,240 \mathrm{Pu}$ below ${ }^{210} \mathrm{~Pb}^{\text {ex }}$ at depth in a core and discrepencies in the solid phase ${ }^{239,240} \mathrm{Pu}$ and $210 \mathrm{~Pb}^{\mathrm{ex}} \mathrm{mixing}$ rates are used to argue for Pu mobility. Cochran (1985) estimates that a Pu $K_{d}$ of $\simeq 10^{2}$ would be needed to support the solid phase $239,240 \mathrm{Pu}$ data in his deep-sea cores (MANOP). Pore water ${ }^{239,240} \mathrm{Pu}$ data from the deep sea are needed to test this hypothesis.

The chief objective of this work is to compare Pu pore water distributions from a variety of locations which differ in their geochemical settings but which have received relatively similar inputs of $239,240 \mathrm{Pu}$ from atmospheric fallout. To this end, samples have been obtained from a transect of seven cores ranging from reducing muds on the U.S. continental shelf to sub-oxic and oxic cores in carbonate-rich sediments in the deep Northwest Atlantic. At these sites $239,240 \mathrm{Pu}$ distributions in the solid and pore water phases will be examined in light of ancillary pore water measurements ( $\mathrm{Fe}, \mathrm{Mn}$, D.0.C., alkalinity, $\mathrm{SO}_{4}^{2-}, \mathrm{NO}_{3}^{-}$) and solid phase $210 \mathrm{~Pb}^{\text {ex }}$ and ${ }^{137}$ Cs results. Both traditional alpha-counting detection techniques and a newly developed mass spectrometric (m.s.) technique (see Chapter 3, this thesis) have been used to detect $239,240 \mathrm{Pu}$ in the pore waters and sediments at these sites. These data extend considerably our knowledge of the diagenetic chemistry of Pu beyond coastal sites where the only previous pore water $239,240 \mathrm{Pu}$ data exist (Heatherington, 1978; Nelson and Lovett, 1981; Sholkovitz and Mann, 1984). 


\section{SAMPLING}

Sediment and pore water samples were collected from box cores taken at seven sites during three cruises in water depths ranging from 90-5000 $\mathrm{m}$ between Woods Hole and Bermuda in the Northwest Atlantic (Fig. 4.1). Core locations, sampling dates, cruise numbers, and water depths are given in Table 4.1. Sediment cores were collected with a $50 \times 50 \mathrm{~cm}^{2}$ single spade box corer, and only those cores with a level and visually undisturbed surface layer were sampled. Sholkovitz and Mann (1984) describe in more detall the strategy needed to collect large volumes of pore water. Briefly, this involves replacing one side of the box core with an assembly of $2 \mathrm{~cm}$ wide horizontal plates which can be removed individually to allow sequential $2 \mathrm{~cm}$ slices to be made from the entire box core surface. Each section of mud is then loaded into centrifuge bottles for pore water extraction and subsequent flitration. All handiing steps need to include precautions to avoid atmospheric (1.e. $\mathrm{O}_{2}$ ) contamination of sub-oxic muds and their included pore waters (Troup et al., 1974), and extensive changes in temperature should be avoided (Manglesdorf et a1., 1969; Bischoff et a1., 1970). As this procedure becomes unmanageable at sea, a storage technique was devised to preserve entire box cores for up to five days at ambient temperatures and under anoxic conditions before they are processed upon our return to shore based facilities.

The core handling and storage procedures begin immediately once the box core reaches the ship's deck where overlying waters are carefully siphoned off the core and a temperature probe is placed in the mud. The core is covered initially with a plastic top and freon gas is used to purge the overlying head space. The box core is then lifted onto a cradle where the coring tripod and triggering mechanisms of the box corer can be removed. The remaining $50 \times 50 \mathrm{~cm}$ stainless steel box, containing the sediment core with the spade in place, is secured. This entire core is then covered by an insulating box which is filled with ice to maintain the in-situ core temperatures $\left(\simeq 5^{\circ} \mathrm{C}\right)$. A more permanent top is sealed over the core and the overlying $5-10 \mathrm{~cm}$ 
FIGURE 4.1: Map Showing the Location of Box Cores A through H

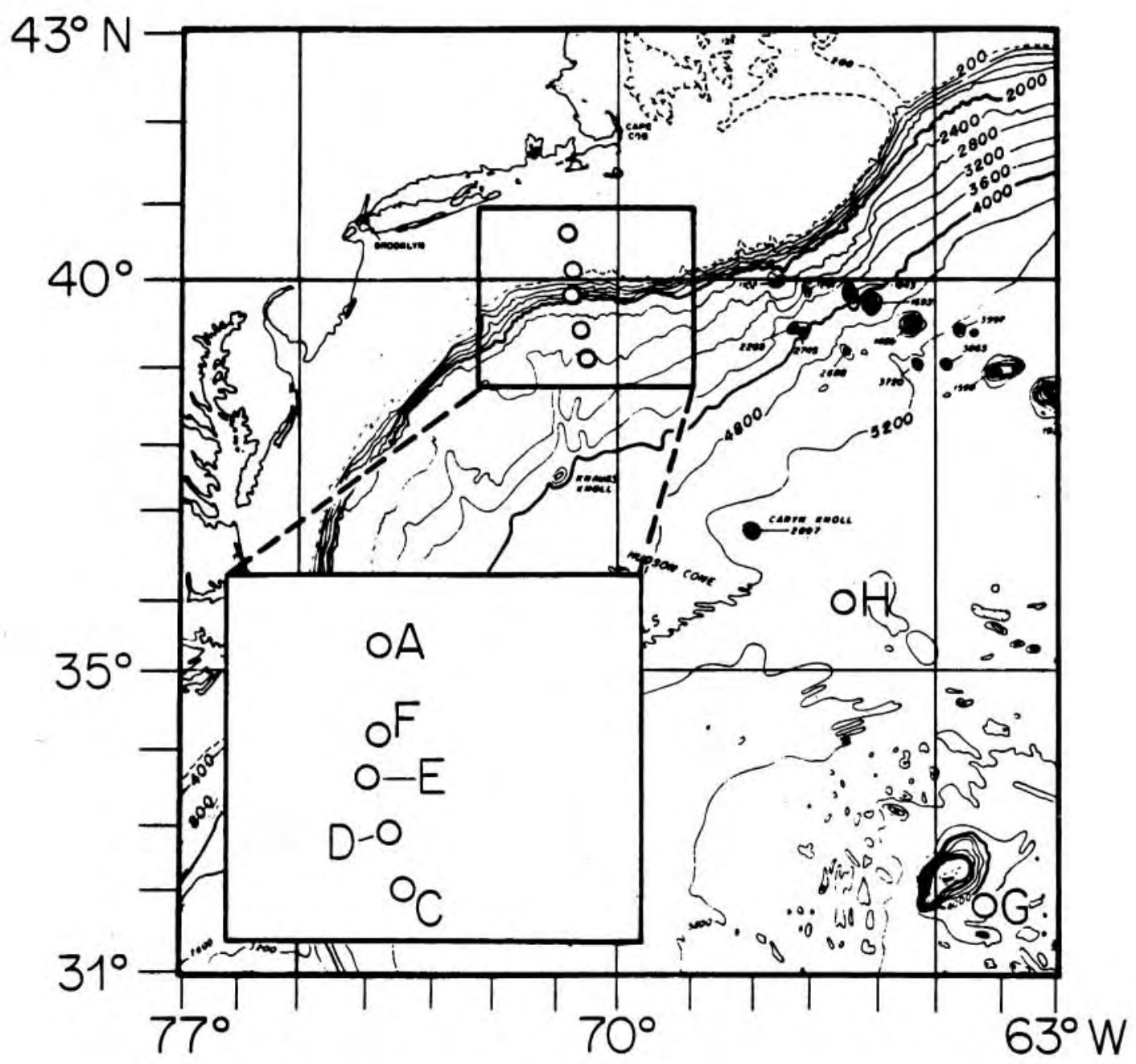


TABLE 4.1: Location of Pore Water Sampling Sites and Date of Collection

\begin{tabular}{|c|c|c|c|c|c|}
\hline Depth & Core & Cruise & Date & $\underline{\text { Latitude }}$ & Longitude \\
\hline $\begin{array}{l}90 \mathrm{~m} \\
501 \mathrm{~m} \\
1275 \mathrm{~m} \\
2362 \mathrm{~m} \\
2700 \mathrm{~m} \\
4469 \mathrm{~m} \\
4990 \mathrm{~m}\end{array}$ & $\begin{array}{l}\mathbf{A} \\
\mathbf{F} \\
\mathbf{E} \\
\mathbf{D} \\
\mathbf{C} \\
\mathbf{G} \\
\mathbf{H}\end{array}$ & $\begin{array}{l}83-\text { GYRE-9 } \\
\text { OCEANUS- } 152 \\
\text { OCEANUS- } 152 \\
\text { OCEANUS- } 152 \\
\text { 83-GYRE-9 } \\
\text { OCEANUS- } 173 \\
\text { OCEANUS- } 173\end{array}$ & $\begin{array}{l}7 / 28 / 83 \\
4 / 30 / 84 \\
4 / 29 / 84 \\
4 / 29 / 84 \\
7 / 31 / 83 \\
12 / 4 / 85 \\
12 / 8 / 85\end{array}$ & $\begin{array}{ll}40 & 28.11 \mathrm{~N} \\
39 & 55.11 \mathrm{~N} \\
39 & 48.11 \mathrm{~N} \\
39 & 35.01 \mathrm{~N} \\
39 & 10.31 \mathrm{~N} \\
31 & 54.11 \mathrm{~N} \\
36 & 27.91 \mathrm{~N}\end{array}$ & $\begin{array}{ll}70 & 54.1^{\prime} w \\
70 & 54.2^{\prime} w \\
70 & 56.3^{\prime} w \\
70 & 56.8^{\prime} w \\
70 & 43.8^{\prime} w \\
64 & 17.8^{\prime} w \\
66 & 33.6^{\prime} w\end{array}$ \\
\hline
\end{tabular}


broken-up and hot acid leached $\left(8 \mathrm{~N} \mathrm{HNO}_{3}\right.$ ) in the presence of a ${ }^{242} \mathrm{Pu}$ and stable Cs spike, followed by standard ion exchange purification procedures for ${ }^{239,240} \mathrm{Pu}$ and ${ }^{137} \mathrm{Cs}$ (Wong, 1971; Livingston et al., 1975). ${ }^{137}$ Cs is collected as a chloroplatinate precipitate and detected with low background beta detectors (Noshkin and De Agazio, 1966). 239,240 $\mathrm{Pu}$ is electroplated onto stainless steel planchets and alpha-counted (Wong, 1971; Livingston et a1., 1975). The reported errors for all of the radioisotopic data are the propigated one standard deviation counting errors from the radiometric analyses.

The first pore water samples analyzed for ${ }^{239,240} \mathrm{Pu}$ were from cores $A(90 \mathrm{~m})$ and $C(2700 \mathrm{~m})$. These large volume pore water samples $(0.8-3.3 \mathrm{~kg})$ were processed by standard alpha-counting procedures (see Sholkovitz and Mann (1984) for details). Alpha-counting intervals of up to eight weeks per sample on our low background si-surface barrier detectors were needed to obtain statistically significant results. Even with such long counting intervals, the activities of $239,240 \mathrm{Pu}$ in the pore waters were at or below detection in three of the four samples from core $C$, and in the deepest sample from core $A$. An increase in the sensitivity for detecting $239,240_{\mathrm{Pu}}$ was therefore needed if reliable deep-sea pore water $239,240 \mathrm{Pu}$ data were to be obtained.

During the course of this project, a m.s. technique was developed for low level Pu analyses (Chapter 3, this thesis). The m.s. technique was used to measure $239,240 \mathrm{Pu}$ in the remaining pore waters (cores D through $H$ ), and on replicates of some of the sediment samples and pore waters which had previously been analyzed by alpha-counting (Table 4.A provides information on the analytical technique and sample sizes used for the pore water analyses). Using isotope dilution m.s., ${ }^{239,240} \mathrm{Pu}$ activities can be determined down to the $10^{-4} \mathrm{dpm} 239,240 \mathrm{pu}$ per sample level. The m.s. $239,240 \mathrm{Pu}$ technique is similar to alpha-counting in the sample preparation and clean-up steps, with additional attention being paid to ensure complete Pu purification and low blanks. The pore water procedural blank was found to be constant $(n=5)$ at $1.0 \times 10^{-5} \mathrm{dpm} 239,240 \mathrm{Pu}$ per sample, and the pore water 
239,240 $\mathrm{Pu}$ data in Table 4.A are corrected for this blank. In only four cases is this correction larger than $25 \%$ of the total reported 239,240 Pu activity (Table 4.A).

In contrast to alpha-counting, the m.s. technique provides a separate determination of the ${ }^{239} \mathrm{Pu}$ and ${ }^{240} \mathrm{Pu}$ isotopes. The m.s. data presented in this chapter have been converted into $239,240 \mathrm{Pu}$ activities in order to compare them directly with Pu activity data reported in the literature and determined by alpha-counting. A complete discussion of the m.s. technique and ${ }^{240} \mathrm{Pu} /{ }^{239} \mathrm{Pu}$ ratio data appears in Chapters 3 and 6 of this thesis.

\section{RESULTS AND DISCUSSION}

\section{A. Geochemical setting}

While the input of fallout $\mathrm{Pu}$ to cores $\mathrm{A}$ through $\mathrm{H}$ has been similar, a contrasting range of geochemical settings exists along this transect. Transitions between sediment types and redox environments need to be elucidated in order to interpret downcore and between core variability in the pore water $239,240 \mathrm{Pu}$ data. These ancillary data are important since the solubility of pore water $239,240 \mathrm{Pu}$ may vary as a function of the sediment mineralogy (Duursma and Gross, 1971; Aston et al., 1985), complexation reactions with organic or inorganic 1igands (Anderson at al., 1982; Sanchez, 1983; Nelson et al., 1985; Higgo and Rees, 1986), in conjunction with the redox cycles of $\mathrm{Fe}$ and Mn (Sholkovitz et al., 1982; Buesseler et al., 1985), or as a result of direct redox transformations of Pu itself (Nelson and Lovett, 1978 and 1981; Sanchez et a 1., 1985; Keeney-Kennicutt and Morse, 1985).

The sediment mineralogy along this transect varies sytematically depending upon the relative abundance of land vs. biogenic derived sediment sources at a site and sediment redistribution processes within the ocean. Solid phase aluminum and carbonate data are provided in Table 4.B. The grain size data discussed below are from extensive survey work in this region (Hathaway, 1971, 1972; M111iman, 1972) and from qualitative observations of sediment texture in these cores. 
The shallowest core $(A, 90 \mathrm{~m})$ lies in a region known appropriately as the "Mud Patch" since the sediments here are predominantly silty and clayey muds, with only trace amounts of blogenic carbonate or silica. The core at $501 \mathrm{~m}(\mathrm{~F})$ is somewhat sandier than core A (lower water contents; sandy texture) possibly due to the increased erosion of fine-grained sediments at the shelf-slope break. The slope core $E$ $(1275 \mathrm{~m})$ consists of muddy sediments which have been diluted with $\simeq 10 \%$ carbonate by weight. $\mathrm{CaCO}_{3}$ is the dominant biogenic phase which is generated in this region due to the formation of calcite tests by the planktonic foraminifera (Tucholke, 1984). Cores D (2362), C $(2700 \mathrm{~m}), H(4990 \mathrm{~m})$, and $G(4469 \mathrm{~m})$ are more enriched in these carbonate phases, which average 25, 27, 30, and $60 \%$ by weight of the sediment respectively (Table 4.B).

Along with this transition from shallow muds to deep-sea carbonate-rich sediments, there is a gradual transition in the redox characteristics of the cores as well. The redox transitions are ultimately driven by the flux of organic matter to the sediments. This flux is highest in the coastal waters, decreasing away from shore in this region. As is now well documented, the degradation of organic matter in marine sediments is coupled to the sequential utilization of oxidants in the order of highest to lowest energy producers per mole of organic carbon which is oxidized. That is, the consumption of $\mathrm{O}_{2}$ is followed by denitrification, which is followed by $\mathrm{Mn}$ (IV) reduction, $\mathrm{Fe}$ (III) reduction and potentially $\mathrm{SO}_{4}^{2-}$ reduction (Froelich et al., 1979; Emerson et a1., 1980; Berner, 1980). Within a given core, one can expect to find progressively more reducing conditions deeper in the sediments. Moreover, along the transect a transition is expected from highly reducing sediments in the coastal sites out to more oxic conditions in the deep-sea sediments.

As an indicator of redox state, I have focused on the determination of pore water $M n$ (II) and $F e($ II) which reflects $M n$ (IV) and $\mathrm{Fe}$ (III) reduction as outlined in the above sequence. In the most reducing core (A) I have also measured pore water $\mathrm{SO}_{4}^{2-}$, while in the oxic deep-sea sites $\mathrm{G}$ and $\mathrm{H}$, pore water $\mathrm{NO}_{3}^{-}$data were obtained 
(Table 4.B).

The pore water Mn and Fe data in Table 4.B (and shown later in Figure 4.3) support a gradual transition from oxidizing to reducing sediments along this transect. For example, the deep-sea cores $\mathbf{G}$ $(4469 \mathrm{~m})$ and $H(4990 \mathrm{~m})$ are found to have undetectable $\mathrm{Mn}$ and $\mathrm{Fe}$ $(<1 \mu M / 1)$ throughout their pore waters, consistent with the highly oxidizing nature of these sites. Pore water $\mathrm{NO}_{3}^{-}$data place denitrification within the sediments at core $G$ (with a subsurface $\mathrm{NO}_{3}^{-}$maximun at $7 \mathrm{~cm}$ ) and at the sediment/water interface for core H. At $2700 \mathrm{~m}$ (core C), pore water Mn and Fe are undetectable in the upper $5 \mathrm{~cm}$ of the core. Below $5 \mathrm{~cm}$ in core $\mathrm{C}$, pore water Mn concentrations rapidly increase to over $40 \mu \mathrm{M} / 1$ by $15 \mathrm{~cm}$ and remain high between $15-25 \mathrm{~cm}$. Pore water Fe in core $C$ remains less than $3 \mu \mathrm{M} / 1$ at all depths below $5 \mathrm{~cm}$. Hence, core $\mathrm{C}$ exhibits a downcore shift from sub-oxic conditions in the top $5 \mathrm{~cm}$ to $M$ n reducing but not strongly $\mathrm{Fe}$ reducing conditions in the $10-25 \mathrm{~cm}$ depth zone. As the data are examined from the shallower sites, the zone of Mn and Fe reduction gradually shifts upwards within the cores so that by core $A$ $(90 \mathrm{~m})$, pore water $M \mathrm{n}$ is highest in the $0-1.5 \mathrm{~cm}$ sample $(42 \mu \mathrm{M} / 1)$ with a pore water $\mathrm{Fe}$ maximum $(37 \mu \mathrm{M} / \mathrm{L})$ at $2.5 \mathrm{~cm}$. In a highly reducing core such as $A$, evidence extsts for the removal of pore water Mn and Fe below $5 \mathrm{~cm}$, possibly due to the formation of less soluble carbonate and sulfide phases (Elderfield et a1., 1981; Pedersen and Price, 1982). The pore water $\mathrm{SO}_{4}^{2-}$ concentrations at core $\mathrm{A}$ are constant with depth (Table 4.B).

In summary, the pore water $M n$ and Fe data indicate a well defined set of redox conditions along this transect. Conditions range from oxic and sub-oxic in the deep-sea sediments to progressively more reducing on the slope and shelf. Within any given core there is a transition to more reducing conditions with increasing depth in the sediments.

In cores C $(2700 \mathrm{~m}), D(2362 \mathrm{~m}), E(1275 \mathrm{~m})$, and $F(501 \mathrm{~m})$ solid phase Mn data can be used to examine the long term stablility of the above described redox conditions (Froelich et al., 1979). In these 
cores the net result of the upward diffusion of soluble $\mathrm{Mn}$ (II) and its reaction with downward diffusing $\mathrm{O}_{2}$ are seen in the solid phase Mn profile where a peak in solid $\mathrm{MnO}_{2}$ exists just above the pore water $M n$ (II) gradient (Table 4.B). The steepest pore water Mn gradients, and hence the largest diffusive $M n$ (II) fluxes, are matched by the largest increase in solid phase $M n$ in core C $(2700 \mathrm{~m})$. If I calculate the diffusive Mn flux upwards in cores $C, D, E$ and $F$ and compare this to the observed solid phase enrichment in $\mathrm{Mn}$, an indication of the long term stability of the redox setting is obtained. This calculation (neglecting advection) leads to an estimate of 50-150 years over which the diffusion of Mn and the precipitation of Mn oxides must have been occuring at these sites ( $t=$ Mn solid "excess" inventory/Mn(II) flux; where the excess Mn solid phase inventory is taken from the data in Table 4.B; the pore water Mn(II) flux is calculated from:

$$
f l u x=\phi^{m} D_{b}^{i}[d C / d x] \text {, }
$$

with $\phi=0.7, \mathrm{~m}=2.5, \mathrm{D}_{\mathrm{b}}^{i}=2 \times 10^{-6} \mathrm{~cm} / \mathrm{sec}$, and $\mathrm{dc} / \mathrm{dx}$ is taken from the $\mathrm{Mn}^{2+}$ pore water profiles at cores C, D, and $\mathrm{E}$ ( $\mathrm{LI}$ and Gregory, 1974; Berner, 1980; Ullman and Aller, 1982)). This calculation suggests that there has been no major change in the sediment redox properties since the introduction of fallout $239,240 \mathrm{Pu}$ to these sediments during the past 30 years.

Finally, it is of interest to examine the ancillary pore water D.O.C. and alkalinity data (Table 4.B). While the D.0.C. data are somewhat scattered, some general trends are evident. In the shallower cores $(90 \mathrm{~m}$ and $501 \mathrm{~m})$, D.O.C. values are relatively low in the upper $0-2 \mathrm{~cm}(\simeq 10 \mathrm{mgC} / 1)$ and increase to a subsurface maximum of $44 \mathrm{mgC} / 1$ at $12.5 \mathrm{~cm}$ in core $A$ and $25 \mathrm{mgC} / 1$ at $5 \mathrm{~cm}$ in core $F$. Below these maximum D.O.C. concentrations there is a gradual dropoff in D.O.C. concentration with depth in these cores. This pattern contrasts with D.0.C. data from $E(1275 \mathrm{~m}), D(2362 \mathrm{~m})$ and $C(2700 \mathrm{~m})$, where the highest D.O.C. concentrations are in the upper $0-2 \mathrm{~cm}$ of the core (30-35 mgC/1) decreasing rapidly to values in the $10-20 \mathrm{mgC} / 1$ range (with some scatter) in the deeper samples. No D.O.C. data were collected for the deep-sea cores $G$ and $H$ for comparison. 
The alkalinity data show no consistent trends except that the shallower cores $A$ and $F$ appear to have generally higher alkalinity values than the other sites. Analytical difficulties with different Gran titration procedures in the lab between cruises does not instill confidence in these data.

B. Sedimentary $239,240 \mathrm{Pu}, 210_{\mathrm{Pb}}$ ex and ${ }^{137} \mathrm{Cs}$

$$
\text { The solid phase profiles of } 239,240 \mathrm{Pu}, 210 \mathrm{~Pb} \text { ex and }
$$

${ }^{137} \mathrm{Cs}$ are shown in Figure 4.2 and reported in Table 4.A. A major feature of the solid phase results are the generally similar distributions of these three tracers Fig. 4.2). Also, there is a decrease in the depth of tracer penetration along the transect. The shallowest core $(\mathrm{A}, 90 \mathrm{~m})$ exhibits detectable ${ }^{239,240} \mathrm{Pu}$ and $21 \mathrm{~Pb}^{\text {ex }}$ down to at least $35 \mathrm{~cm}$. In cores $\mathrm{F}(501 \mathrm{~m}), \mathrm{E}(1275 \mathrm{~m}), \mathrm{D}$ $(2362 \mathrm{~m})$ and $C(2700 \mathrm{~m})$ the tracer penetration depths are all found to be similar and 1 le between 10 and $15 \mathrm{~cm}$. In the deep-sea cores $G$ $(4469 \mathrm{~m})$ and $H(4990)$ these tracers are only found in the top $8 \mathrm{~cm}$ of the core. These tracer distributions are consistent with a trend from more rapid and deeper benthic mixing at the shelf site, towards decreased benthic mixing in the slope cores and the least intense benthic mixing at the deep-sea sites. It is likely that this reflects a change in benthic macrofauna community structure and density with increasing water depth (Rowe et al., 1974).

Previous studies have used a comparison between the depths of penetration of $239,240 \mathrm{Pu}$ and $210 \mathrm{~Pb}$ as evidence in arguments supporting enhanced Pu mobility in the sediments (Cochran, 1985; Stordal et a1., 1985; Sayles and Livingston, 1985). For instance, Cochran (1985), Stordal et al. (1985) and Sayles and Livingston (1985) all argue that $239,240 \mathrm{Pu}$ is present deeper than $210 \mathrm{~Pb}$ ex in at least some of their cores. The assumption is that given the 22.3 year half-life of $210 \mathrm{~Pb}$, zero ${ }^{210} \mathrm{pb}^{\text {ex }}$ values should be reached at an age and depth equivalent to about 100 years (1.e. $\simeq 5$ half-lives), whereas fallout $239,240 \mathrm{Pu}$ should only be present in post-fallout samples (1.e. 25-40 years before present). This is not entirely 
F1g. 4.2: Sol1d Phase ${ }^{239,240} \mathrm{Pu},{ }^{210}{ }_{\mathrm{Pb}}$ ex and ${ }^{137} \mathrm{Cs}$ Profiles

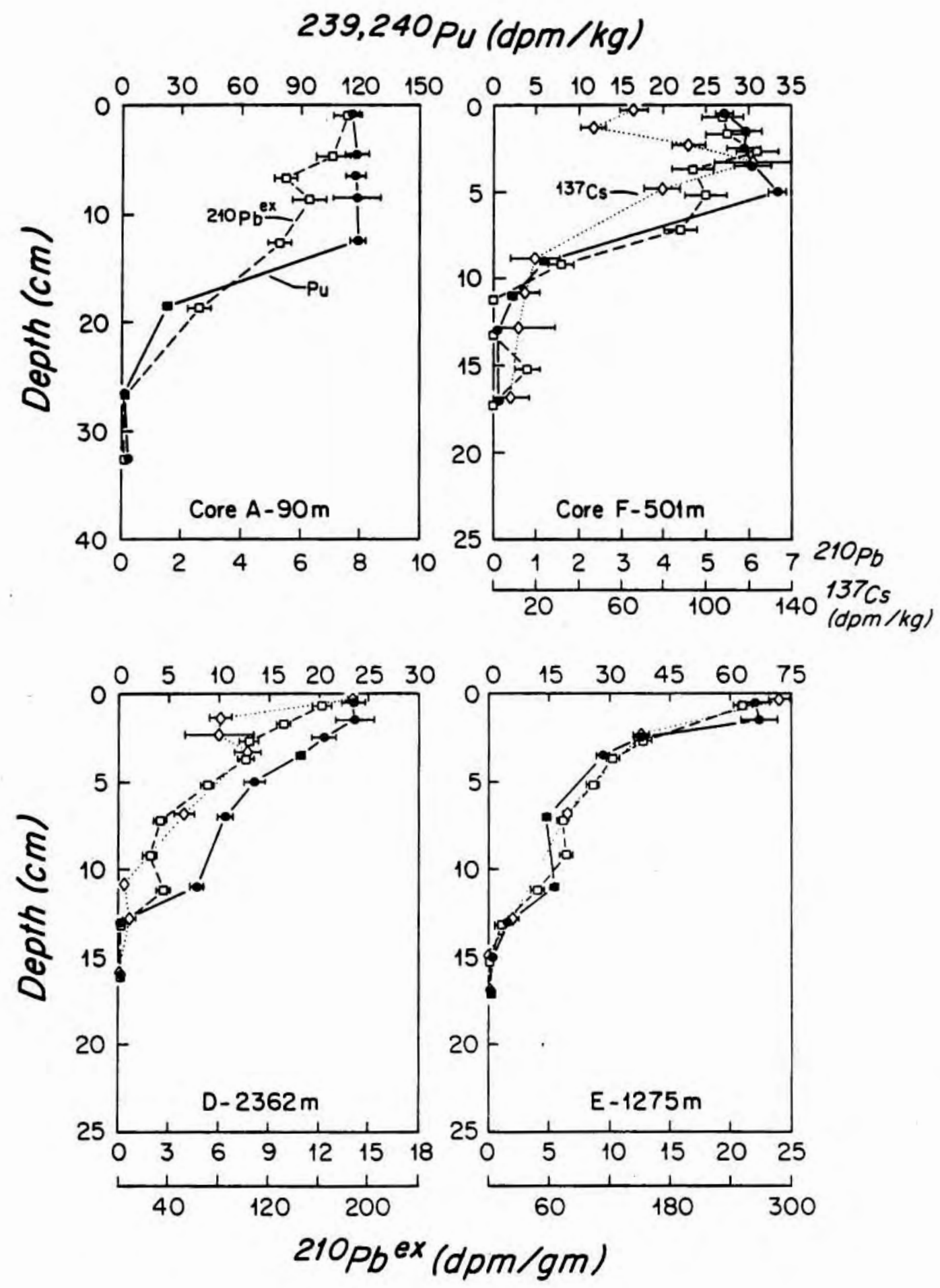


Fig. 4.2 (Cont'd.)

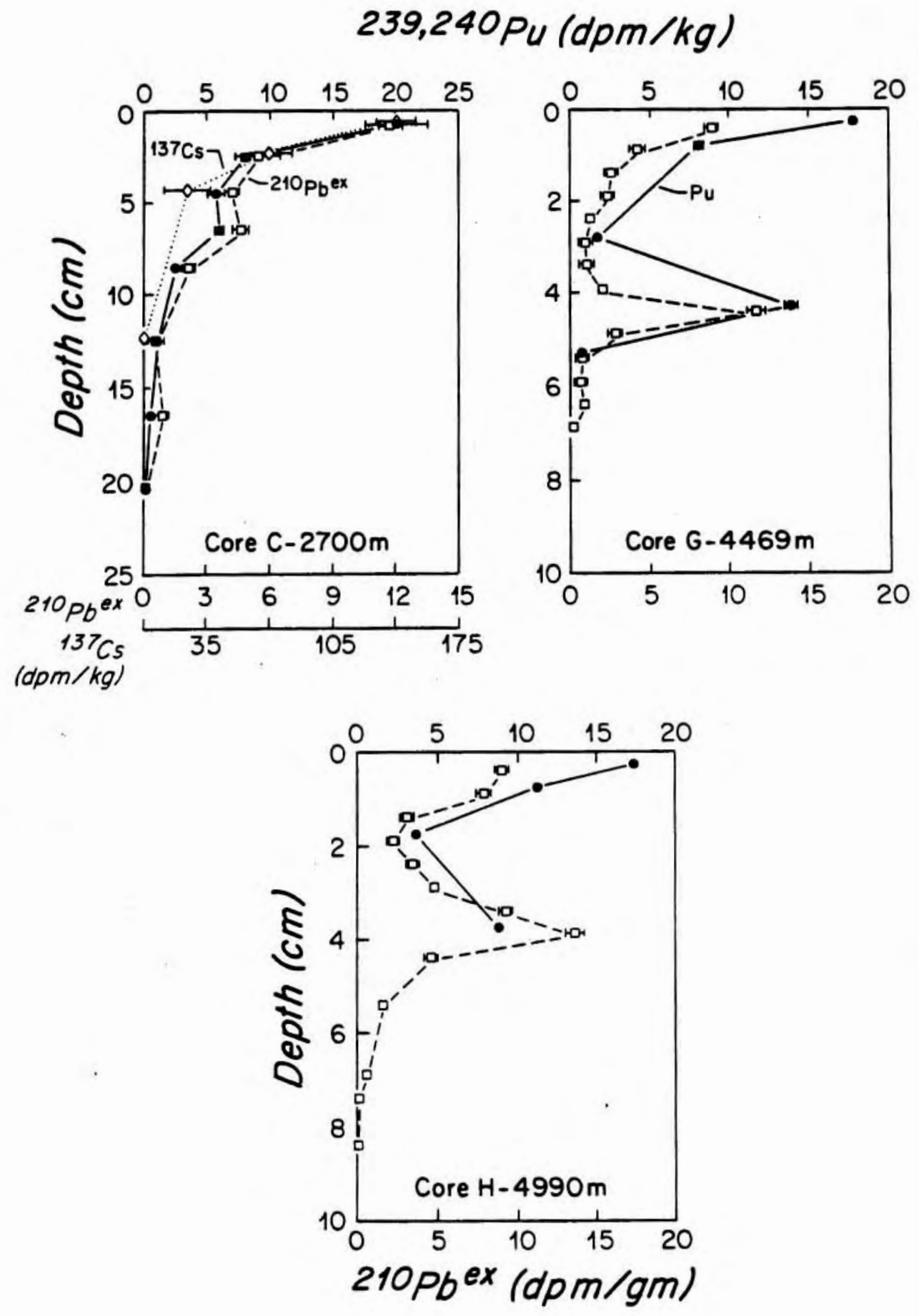


correct since ${ }^{239,240} \mathrm{Pu}$ may reach the same depth as ${ }^{210} \mathrm{~Pb}$ ex over time if sediment mixing is rapid (Anderson et a 1., 1986). In general though, the presence of fallout ${ }^{239,240} \mathrm{Pu}$ below ${ }^{210} \mathrm{~Pb}^{\mathrm{ex}}$ in the solid phase at this time would argue for enhanced $239,240 \mathrm{Pu}$ mobility in the pore waters or its preferential transport by a selective particle mixing process (Cochran, 1985; Stordal et a1., 1985) since $210 \mathrm{~Pb}$ immobility has been assumed given the ${ }^{210} \mathrm{~Pb}^{\text {ex }}$ pore water work of Cochran and Krishnaswami (1980).

In a similar manner, the depth of penetration of $239,240 \mathrm{Pu}$ relative to ${ }^{210} \mathrm{~Pb}^{\text {ex }}$ can be examined along my transect for evidence of Pu mobility. In all of my cores the penetration depths of $239,240 \mathrm{Pu}$ and ${ }^{210} \mathrm{~Pb}^{\text {ex }}$ in the sediments are identical within the counting errors. In cores $A, D$, and $F$ it can be seen that there are samples deep in these cores where $210_{\mathrm{Pb}}$ ex values cannot be determined above $0.3 \mathrm{dpm} / \mathrm{g}$, while the $239,240 \mathrm{Pu}$ signal is sti11 detectable in the sediments (Table 4.A). To conclude that this represents a real separation between these two tracers and hence evidence for Pu mobility is not within the accuracy of the data set (see following discussion).

There are two main problems when comparing solid phase $239,240 \mathrm{Pu}$ and $210 \mathrm{~Pb}^{\text {ex }}$ data which make the results insensitive indicators of Pu mobility. First, in many previous studies - such as in Stordal et a). (1985) and in some of the Sayles and Livingston (1985) data $239,240 \mathrm{Pu}$ and ${ }^{210} \mathrm{~Pb}^{\text {ex }}$ activities were not determined on the same sediment sample. This is a serious problem in that considerable spatial variability can exist in benthic sediment mixing within a given region or even within a given core (Cochran, 1985; DeMaster et al., 1985; Anderson et a1., 1986). Therefore, direct comparisons amongst tracers in terms of their penetration and mixing rates between closely spaced samples can cause an apparent discrepency which is an artifact of the real spatial variability in benthic processes.

A second problem mentioned above with respect to my data set (and any other) is the sensitivity in determining the absolute depth of zero $210_{\mathrm{Pb}}$ ex activities at depth in a core relative to zero $239,240 \mathrm{Pu}$ 
activities. While relatively small $239,240 \mathrm{Pu}$ activities $(<0.5$ $\mathrm{dpm} / \mathrm{kg}$ ) can be reliably determined above zero fallout $239,240 \mathrm{Pu}$ activities deep in a core, the detection of sma $11{ }^{210} \mathrm{~Pb}^{\mathrm{ex}}$ activities above the supported $210 \mathrm{~Pb}$ values is inherently prone to large errors. Simply stated, the error on the determination of a small value $\left({ }^{210} \mathrm{~Pb}^{\mathrm{ex}}\right)$, from the difference between two much larger values (total $210 \mathrm{~Pb}$ minus supported $210 \mathrm{~Pb}$ ) is subject to considerable statistical uncertainty. This problem is particulary difficult in the Pacific deep-sea samples of Cochran (1985) where supported ${ }^{210} \mathrm{~Pb}$ values are high and variable, $15-90 \mathrm{dpm} / \mathrm{g}$, and the determination of $210_{\mathrm{Pb}}{ }^{\mathrm{ex}}$ values of less than a few $\mathrm{dpm} / \mathrm{g}$ is subject to a large error. In a later section data from a core in Cochran (1985) will be used as a test case to lllustrate this effect.

Detailed modeling of the $239,240 \mathrm{Pu}$ and $210 \mathrm{~Pb}^{\mathrm{ex}}$ sediment profiles in order to estimate sediment mixing coefficients has been presented elsewhere for cores A, F, E, D, and C (Anderson et a1., 1986; Chpt. 7, this thesis). In summary, there is no statistical difference between sediment mixing rates determined by steady-state $210_{\mathrm{Pb}}$ ex eddy-diffusive benthic mixing models (Goldberg and Koide, 1962; Nozaki et a1., 1977; Peng et a1., 1979; Krishnaswami et a1., 1980; DeMaster and Cochran, 1982; Chpt. 7, this thesis) and those determined by $239,240 \mathrm{Pu}$, either assuming a pulse input for $\mathrm{Pu}$ to the sediments (Cochran, 1985, and references therein) or by using a numerical model which utilizes the nuclear weapons fallout input curve to determine 239,240 Pu fluxes to the sediments (Anderson et al., 1986). At $90 \mathrm{~m}$ (core A) in the "Mud Patch" region, sediment mixing rates average $1.5 \mathrm{~cm}^{2} /$ year. The remaining cores from $501 \mathrm{~m}$ out to $2700 \mathrm{~m}$ have sediment $\mathrm{mixing}$ rates which average $0.5 \mathrm{~cm}^{2} /$ year (ranging from $0.14-1.0 \mathrm{~cm}^{2}$ /year) with no systematic variability between depths. The sub-surface peaks in both ${ }^{239,240} \mathrm{Pu}$ and $210_{\mathrm{Pb}}{ }^{\text {ex }}$ in the deep-sea cores $G$ and $H$ are a distinct and somewhat unusual feature which prohibit the application of a simple diffusive mixing model at these sites. In both of these cores, activities of $239,240 \mathrm{Pu}$ and $210_{\mathrm{Pb}}$ ex which are similar to those at the sediment interface are 
found in a sub-surface peak centered at $3-4 \mathrm{~cm}$ in core $\mathrm{H}$ and at 4-4.5 cm in core $G$ (Fig. 4.2). These peaks would be much less obvious If larger sediment sampling intervals (i.e. $2 \mathrm{~cm}$ ) had been analyzed. These very sharp subsurface peaks may be caused by the selective feeding and defecation depths of a population of benthic organisms (conveyor belt species (Benninger et al., 1979; Aller, 1982), by physical mass transport processes (Yingst and Aller, 1982; Chanton et al., 1983; Knebel, 1984), or as postulated recently, by the preferential accumulation and redistribution of these tracers in sterecomes of deep-sea rhizpopods (Swinbanks and Skirayama, 1986). This last possiblility seems least likely based upon what is known of the benthic communities in this region (Grassle, 1986). The $210 \mathrm{~Pb}^{\text {ex }}$ sediment inventories in cores $\mathrm{G}$ and $\mathrm{H}, 10.8$ and 14.2 $\mathrm{dpm} / \mathrm{cm}^{2}$, respectively, are similar to other inventory data from this region (Buesseler et al., 1985). The ${ }^{210} \mathrm{~Pb}^{\text {ex }}$ inventories also agree with annual sediment trap $210 \mathrm{~Pb}$ fluxes measured above core $G$, If a steady-state input for ${ }^{210} \mathrm{~Pb}$ is assumed (Bacon et al., 1985). Because of this balance between the measured and expected inventories of $210 \mathrm{pb}$, the process which is responsible for creating the sharp subsurface tracer peak cannot have added substantial tracer rich sediment to this site. This argument would rule out physical transport processes such as slumping or turbidity flows as a possible mechanism for creating the subsuface peaks, unless an earlier loss of core top sediment was followed by an equivalent addition of tracer rich surface sediment to both sites. Since these samples were taken from a $10 \mathrm{~cm}$ diameter sediment subcore it also seems unlikely that a feature this strong could be produced by the accidental sampling of a single recent worm burrow. Alternatively, the sub-surface peaks could be formed by the redistribution of surface, tracer-rich sediment to depth by benthic conveyor belt species. The community of benthic fauna responsible for this peak are unknown and were not seen upon inspection of the cores. Previous researchers have suggested that $239,240 \mathrm{Pu}$ and $210 \mathrm{~Pb}^{\text {ex }}$ are mixed with different rates in the sediments (Cochran, 1985; Stordal et al., 1985). Sayles and Livingston (1985) have also 
suggested that $239,240 \mathrm{Pu}$ sediment mixing rates increase at depth in their cores. To account for their model data all three of these studies concluded that ${ }^{239,240} \mathrm{Pu}$ was somehow moblle relative to $210 \mathrm{~Pb}^{\text {ex }}$ in the sediments. There are, however, many inherent errors associated with determining sediment mixing rates, such that apparent deviations between the mixing coefficients calculated from ${ }^{239,240} \mathrm{Pu}$ and $210_{\mathrm{Pb}}$ ex mixing models cannot be interpreted as being a reliable indicator of Pu mobility or preferential mixing. Some of the model errors which require further attention include: a) assumptions concerning the input flux of $239,240 \mathrm{Pu}$ to the sediments, since recent data from sediment traps and ${ }^{240} \mathrm{Pu} /{ }^{239} \mathrm{Pu}$ ratios in Atlantic cores suggest a more complex $\mathrm{Pu}$ input than is included in the models (Buesseler and Sholkovitz, 1986; Chapters 6 and 7, this thes is), b) potential uncertainties in fitting a complex time-dependent curve to limited sediment data as discussed by officer and Lynch (1982, 1983) and Lynch and officer (1984), c) the non-diffusive nature of mixing (Aller, 1982), d) the assumption of constant ${ }^{210} \mathrm{~Pb}$ fluxes, when sediment trap data suggest at least seasonal and possibly some inter-annual variability in these fluxes (Bacon et al., 1985), and e) evidence for enhanced mixing due to tracer penetration in solution in evacuated burrows (Aller, 1982, 1984). While model derived sediment mixing rates can be useful parameters for quantifying average benthic mixing processes, they are not sensitive indicators of $239,240 \mathrm{Pu}$ mobility. This will be demonstrated later using the MANOP data of Cochran (1985) as a case study.

${ }^{137}$ Cs solid phase data were obtained for cores F, E, D and C and are provided in Table 4.A and Figure 4.2. As stated previously, the activity of ${ }^{137} \mathrm{Cs}$ tends to follow the other solid phase mixing tracers. The ${ }^{239,240} \mathrm{Pu} /{ }^{137} \mathrm{Cs}$ ratios in the sediments range between 0.15-0.40 and show no systematic downcore variability. This is in general agreement with previous studies of $239,240 \mathrm{Pu}$ and ${ }^{137} \mathrm{Cs}$ in all but the most reducing sites (Livingston and Bowen, 1979; Carpenter and Beasley, 1981). Only shallow and highly reducing cores show evidence for a decrease in the solid phase ${ }^{239,240} \mathrm{Pu} /{ }^{137} \mathrm{Cs}$ with 
depth in a core (Livingston and Bowen, 1979; Sholkovitz and Mann, 1984).

\section{Pore water $239,240 \mathrm{Pu}$}

Pore water ${ }^{239,240} \mathrm{Pu}$ data are given in Table 4.A, and are compared directly to the solid phase $239,240 \mathrm{Pu}$ and $\mathrm{Fe}$ and $\mathrm{Mn}$ pore water profiles in Figure 4.3. These are the first reported data on pore water $239,240 \mathrm{Pu}$ from sites other than coastal seas and embayments (Heatherington, 1978; Nelson and Lovett, 1981; Sholkovitz and Mann, 1984). $239,240 \mathrm{Pu}$ activities of up to $0.75 \mathrm{dpm} / 100 \mathrm{~kg}$ are found in the pore waters with the highest activities occuring in the near-surface samples or in the case of core $F(501 \mathrm{~m})$, in a subsurface pore water $239,240 \mathrm{Pu}$ maximum at $2-4 \mathrm{~cm}$. The near-surface pore water $239,240 \mathrm{Pu}$ activities always exceed the near bottom water $239,240 \mathrm{Pu}$ activities (these average $<0.1 \mathrm{dpm} / 100 \mathrm{~kg}$ - see Fig. 4.3). The pore water $239,240 \mathrm{Pu}$ activities decrease with depth in the cores following the distribution of solid phase ${ }^{239,240} \mathrm{Pu}$. There is also no obvious or consistent relationship between the pore water $239,240 \mathrm{Pu}$ proftles and the pore water distributions of $\mathrm{Fe}, \mathrm{Mn}$, or D.O.C.

The main feature of the entire data set is a fairly consistent relationship between pore water $239,240 \mathrm{Pu}$ and the corresponding solid phase $239,240 \mathrm{Pu}$ activities. This relationship can be described by the dimensionless distribution coefficient, $K_{d}$, which is operationally defined as the ratio of ${ }^{239,240} \mathrm{Pu}$ in the solid phase (dpm/kg) to $239,240 \mathrm{Pu}$ in the pore solution $(\mathrm{dpm} / \mathrm{kg})$. The calculated $K_{d}$ 's along this entire transect range from $0.2-23 \times 10^{4}$ (Table $4 . A$ and Fig. 4.3), which is within the range of previously reported values from laboratory and fleld studies $\left(10^{3}-10^{5}\right.$ : Edgington, 1981; Sholkovitz, 1983).

A general trend in the $K_{d}$ data is an apparent decrease in $K_{d}$ values between the shallower and deeper stations. The mean $K_{d}$ values (using all of the $K_{d}$ data with an associated error of $<25 \%$ ) in the deeper cores at $2700 \mathrm{~m}, 4460 \mathrm{~m}$, and $4990 \mathrm{~m}$ are $0.61,0.44$, and $0.32 x$ $10^{4}$, respectively. This is significantly lower than the mean $k_{d}$ values within the shallower cores, which average 2.0, 2.0, 6.4 and 12 $\times 10^{4}$ at $90 \mathrm{~m}, 501 \mathrm{~m}, 1275 \mathrm{~m}$ and $2362 \mathrm{~m}$, respectively. 
Figure 4.3: Pore Water and Solid Phase 239,240 Pu Profiles, Pu Distribution Coeffictents, and Pore Water $\mathrm{Fe}$ and $\mathrm{Mn}$ ( or $\mathrm{NO}_{3}$ ) Data
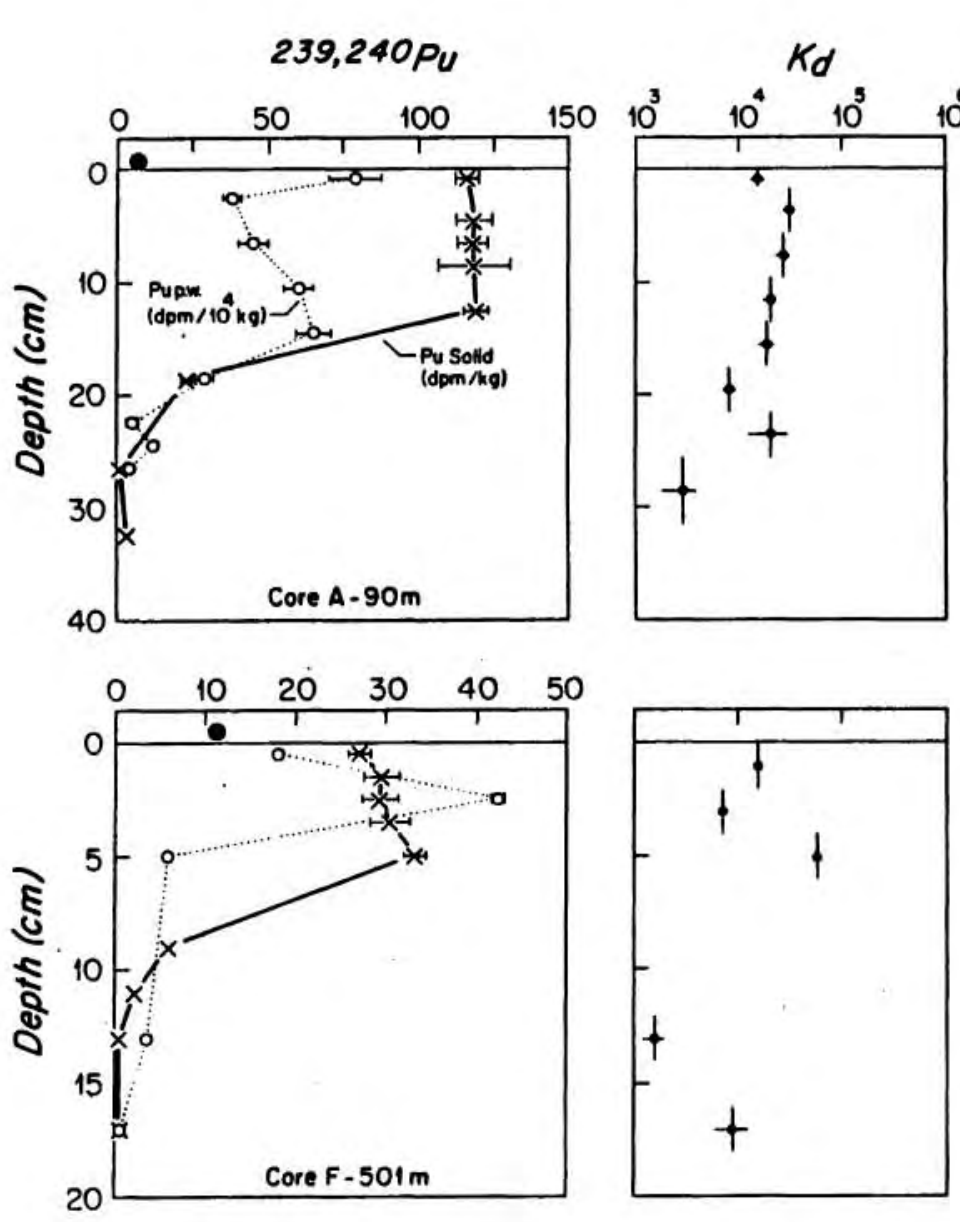

Pore Water

Fe \& $M n(\mu M / l)$
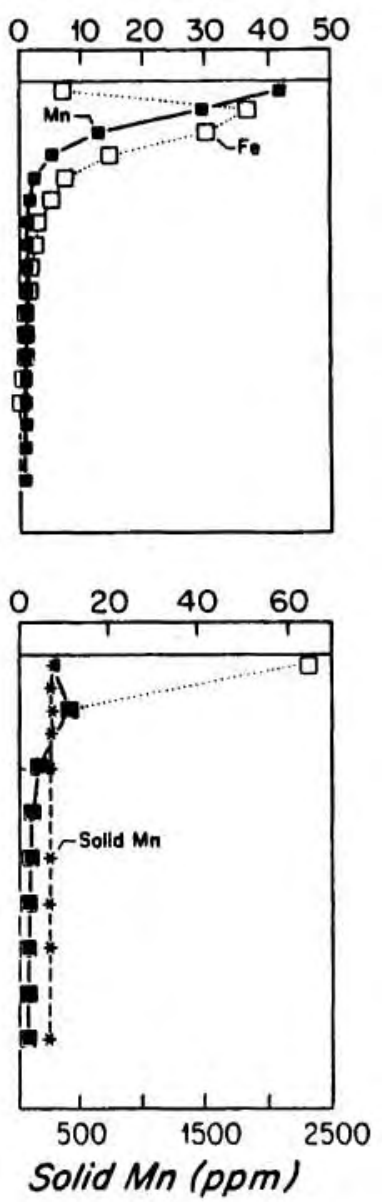

For each core, I have plotted the solid phase ( $\left.x^{\prime} s\right)$ and pore water (open circles) $239,240 \mathrm{Pu}$ data in the left hand figure. The solid circle above zero $\mathrm{cm}$, represents the overlying water $239,240 \mathrm{Pu}$ activity at these sites (Livingston, 1986). If the associated one standard deviation error on the $239,240 \mathrm{Pu}$ activity determination is larger than the symbol, than the error bars are plotted as well.

The center figure for each core depicts the distribution coefficlent ( $K_{d}=d p m$ on solids/dpm in solution) for each part where a $K_{d}$ calculation could be made. The error bars represent the propagated error on the $K_{d}$ calculation (in the horizontal direction) and the depth interval represented by the pore water sample (in the vertical direction). Note the log scale.

The righthand figure for each core shows the pore water and solid phase data used to examine the redox characteristics at each site, as discussed in the text. 
Fig. 4.3 (Cont'd.)
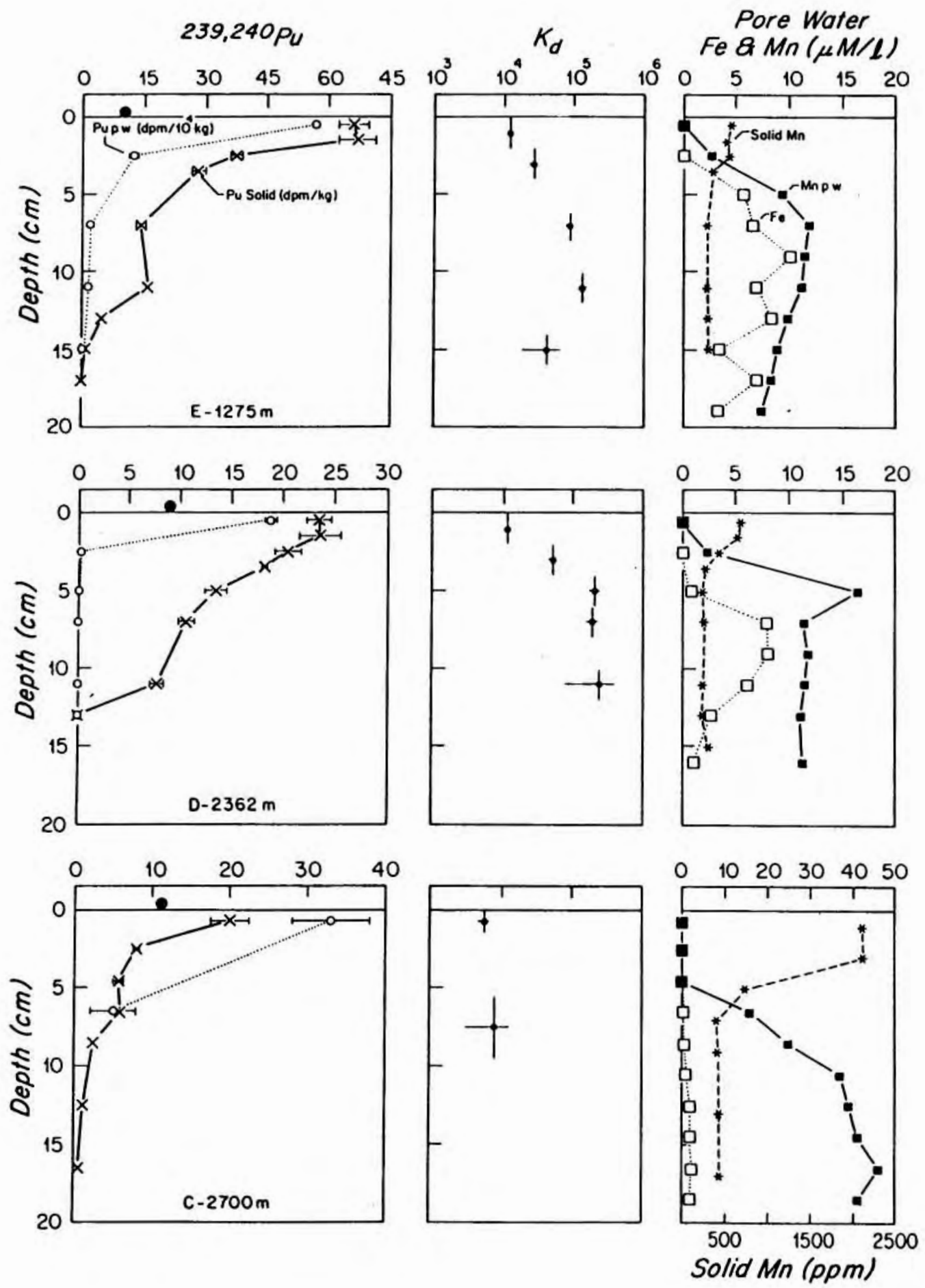
Fig. 4.3 (Cont'd.)
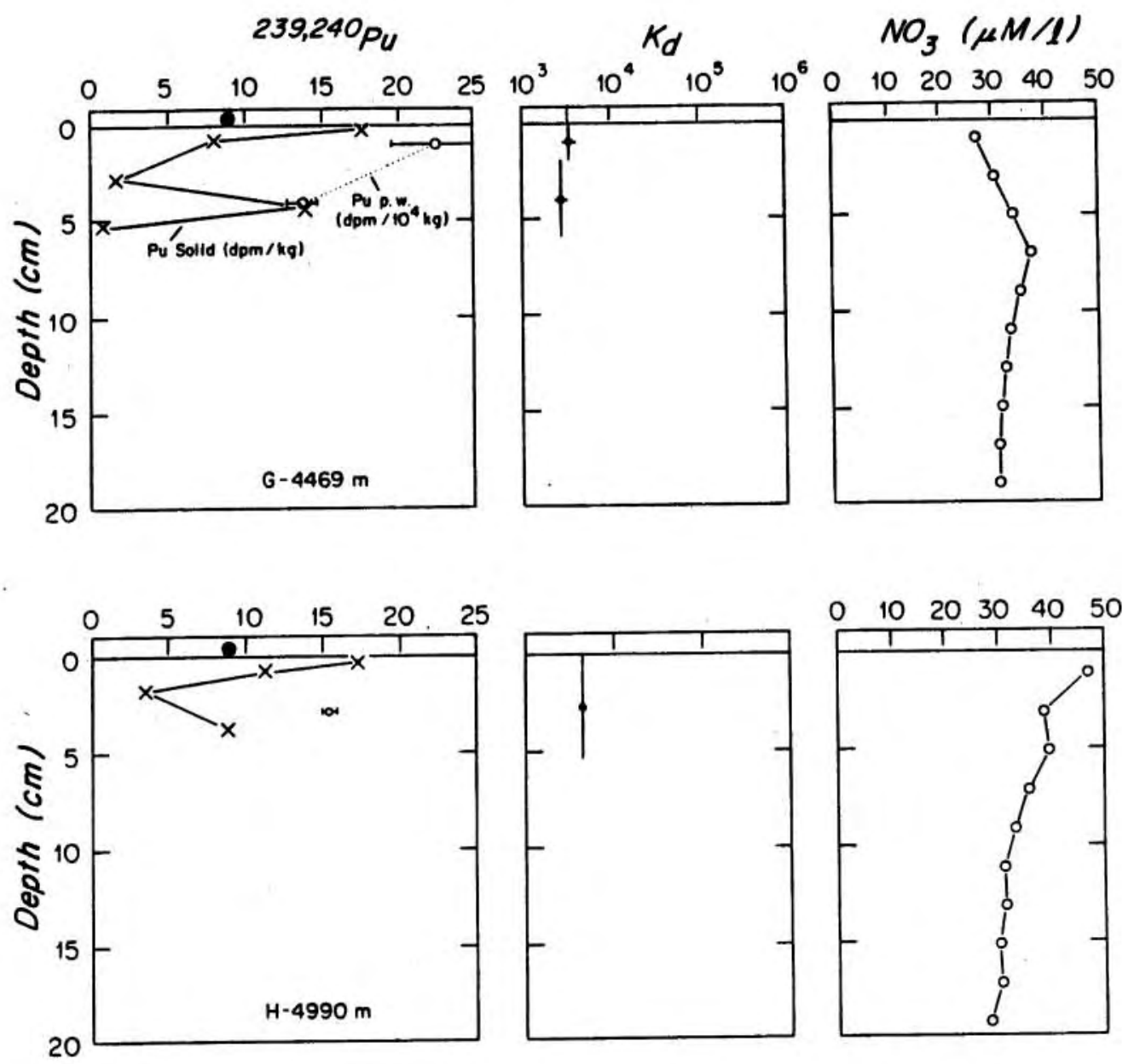
In addition to this trend of decreasing $K_{d}$ values with increasing core depth, there is significant within core variability in the $K_{d}$ values. These downcore shifts in the $K_{d}$ data can be seen in Figure 4.3, which includes the assoclated error on the $K_{d}$ calculation. In core $A(90 \mathrm{~m})$ there is a maximum in the $K_{d}$ values at $2.5 \mathrm{~cm}$, followed by a gradual decrease in $K_{d}$ with depth. At $501 \mathrm{~m}$ the $K_{d}$ data are scattered with no discernable trend and a wide range of $K_{d}$ values $\left(0.2-7 \times 10^{4}\right)$. At slope sites $(1275 \mathrm{~m}$ and $2362 \mathrm{~m}) \mathrm{K}_{\mathrm{d}}$ values are just above $10^{4}$ at the sediment/water interface and increase to values around $1-2 \times 10^{5}$ at $5-10 \mathrm{~cm}$ in the core. In the deeper cores insufficient data are avallable to discuss the downcore $K$ trends. It should be remembered that with a $K_{d}$ value of $10^{5}$, as the solid phase activities approach $1 \mathrm{dpm} / \mathrm{kg}$ the pore water activities will approach the detection 1 imit. Therefore, the $K_{d}$ values deep in cores $E$ and $D$ of $1-2 \times 10^{5}$ do have considerable uncertainty due to the extremely low pore water ${ }^{239,240} \mathrm{Pu}$ activities. On the other hand, if $239,240 \mathrm{Pu}$ was somehow enhanced in solution deep in these cores, $a K_{d}$ of $10^{3}$ or $10^{4}$ would be readily observable in the pore water data.

These $239,240 \mathrm{Pu}$ pore water data can be compared to the work of Sholkovitz and Mann (1984) who have the only other reliable pore water $239,240 \mathrm{Pu}$ data in marine sediments. In their study, the pore water $239,240 \mathrm{Pu}$ distributions followed the solid phase profiles with an associated $K_{d}$ of $3-12 \times 10^{4}$. These data are from one site in a highly reducing coastal embayment (Buzzards Bay, Massachusetts), and the $K_{d}$ 's are well within the ranges of my shallower cores A, F, E, and D. Pore water $239,240 \mathrm{Pu}$ has been determined at one other site in sediments from the Irish Sea which were contaminated by nuclear fuel reprosessing wastes (Heatherington, 1978; Nelson and Lovett, 1981). The $K$ data from these studies are slightly higher than my values and the Buzzards Bay values. This difference cannot be elaborated upon since the Irish Sea studies may contain artifacts due to the oxidation of $\mathrm{Fe}$ (II) from the reducing sediments during pore water extraction and flitration under atmospheric $\mathrm{O}_{2}$ conditions (Sholkovitz, 1983).

Given the ancillary geochemical data, one would like to be able to suggest possible mechanisms which could account for the trends in the 
pore water $239,240 \mathrm{Pu}$ activity. Possible mechanisms of interest include redox related processes, variability in the sediment type, and complexation reactions with $\mathrm{Pu}$ in solution. With respect to redox processes, either direct oxidation/reduction transitions of $\mathrm{Pu}$ or reactions involving the co-precipitation or solubilization of $\mathrm{Pu}$ in conjunction with the Fe and Mn cycles could be important. If the latter is significant, one would expect ${ }^{239}, 240$ Pu activities to be enhanced in solution (1.e. lower $K_{d}{ }^{\prime} s$ ) in zones with soluble $F e(I I)$ and $M n(I I)$ in the pore water and depleted in zones of $\mathrm{Mn}$ and $\mathrm{Fe}$ oxidation and hence removal from solution. The data trend in the opposite direction as seen in cores $E(1275 \mathrm{~m})$ and $D(2362 \mathrm{~m})$ where $P u K_{d}$ maxima at depth occur in zones of high pore water $M n(I I)$ and $\mathrm{Fe}(\mathrm{II})$ concentrations. In addition, Pu $K_{d}$ 's are lowest in cores $G$ and $H$ which show no detectable $\mathrm{Mn}$ (II) or $\mathrm{Fe}$ (II) concentrations in solution throughout the core.

Direct redox transformations of Pu are an alternative process which could be important in controlling Pu solubility since it is widely accepted that Pu can exist in solution simultaneously in a combination of the III, IV, V, or VI oxidation states and the lower oxidation states (III and IV) are known to be relatively more particle reactive (Taube, 1964; Milyukova et a1., 1969; Cleveland, 1979; Nelson et a1., 1985). Indeed, laboratory experiments have shown that the $K_{d}$ 's of tracer level Pu in the $V$ and VI oxidation state are one to two orders of magnitude lower than the $K_{d}$ 's of $\mathrm{Pu}$ in the more reduced oxidation states (Nelson and Orlandini, 1979; Sanchez at al., 1985; Higgo et a1, 1985; Keeney-Kennicutt and Morse, 1985). In a limited data set from the Atlantic water column (Livingston et a 1., 1984), the deep water Pu is found to be $90 \%$ in the more oxidized $V$ and VI states. The observed increase in the $P_{u} K_{d}$ values with depth in the cores at $1275 \mathrm{~m}$ and $2362 \mathrm{~m}$ would be expected if they reflected a down core shift to more reducing and hence more particle reactive Pu species. Estimates of the Eh conditions necessary to enact this change in Pu oxidation state in the natural environment are subject to considerable error but are similar to redox potentials necessary to drive the redox cycles of $\mathrm{Mn}$ and Fe (Cleveland, 1970 and 1979). A shift in Pu redox speciation would also be consistent with the data from cores $G$ and $H$ which indicates 
decreased $K_{d}$ 's in the more oxidizing deep-sea cores. However, a redox controlling mechanism does not work for all of the data. In the most reducing cores $(A, 90 \mathrm{~m}$; and $F, 501 \mathrm{~m})$ lower $P u K_{d}$ 's are found relative to cores $E(1275 \mathrm{~m})$ and $D(2362 \mathrm{~m})$; this trend is opposite to what one would expect if the reduced species of Pu were dominant at the more reducing sites.

Another factor which can potentially alter the distribution of Pu between solution and the solid phase is simply a change in the sediment type since variability in Pu uptake with different sediments has been shown (Duursma and Gross, 1971; Aston et a1., 1985). Solid phase aluminum data (Table 4.B) represent clay contents and do not appear to be related to either the $K$ variability within a core or the decreasing $K_{d}$ values in the deep-sea cores. The $\mathrm{CaCO}_{3}$ data in Table 4.B can be examined for evidence of the dilution of clays by biogenic carbonate phases. The general shift in $\mathrm{Pu} \mathrm{K}_{d}$ 's to lower values at increasing water depths is only partially consistent with the increased carbonate content of the deeper samples, which ranges from trace amounts on the shelf, $10 \%$ at core $E(1275 \mathrm{~m}), 25-30 \%$ at cores D (2362 m, C (2700 m), and $H(4990 \mathrm{~m})$, and up to $60 \%$ at core $G(4469 \mathrm{~m})$. The complexation of $\mathrm{Pu}$ by carbonates has been argued in other studies to be effective in maintaining elevated Pu activites in solution (Sanchez, 1983; Anderson et al., 1982; Higgo and Rees, 1986). Specifically, the study of Higgo and Rees suggests that at high sediment to solution ratios such as in marine pore solutions, the distribution ratio of Pu with carbonates can be as low as $1-4 \times 10^{2}$; low $K_{d}$ values are not seen with other sediment types or at low solid to solution ratios (below $\approx 20 \mathrm{~g}$ sediment/1 solution). Higgo and Rees suggest that a Pu-carbonate complex in solution is responsible for this apparent increase in Pu solubility. This mechanism is consistent with the lower $K_{d}$ in the carbonate-rich deep-sea core $G$, but does not explain an equally low $K_{d}$ at the $30 \%$ carbonate core $H$ at $4990 \mathrm{~m}$.

I also have analyzed one pore water Pu sample from a carbonate ooze ( $80 \% \mathrm{CaCO}_{3}$-MANOP site $\mathrm{C}$ in the Pacific (Cochran, 1985)), and the $K_{d}$ there is $0.1 \times 10^{4}$ (at $7.9-10.2 \mathrm{~cm}$ ) - the lowest value to date. Unfortunately the sample was stored under refrigeration without control 
over atmospheric contamination prior to pore water extractions (Cochran, 1986 - personnal communication). No other data are presently available from deep-sea pore waters from either carbonate-rich or carbonate-poor sediments which would allow for more extensive comparisons and interpretations.

If carbonate complexation does play an important role in determining the general Pu $K_{d}$ shift between these cores, then the precipitation of $\mathrm{CaCO}_{3}$ upon depressurization during core retrieval could certainly bias these results. For example, in a comparison between pore waters collected by an in-situ probe and those extracted from a box core, Toole et al. (1984) found a decrease in the deep-sea pore water uranium concentration by up to $40 \%$ in the box core samples. If the shift for Pu upon depressurization were similar, my calculated $K_{d}$ 's would be too high by a factor of two in the deep-sea cores. This artifact would work to increase the difference I have found between the deep-sea and shallow water K 's.

Pu solubility in a variety of settings has been suggested to be modulated by complexation with D.O.C. (Nelson et al., 1985). The general decrease with depth in D.O.C. In the top few $\mathrm{cm}$ 's of cores $E$ and $D$ is perhaps consistent with the increasing $\mathrm{Pu} K_{d}$ 's at these sites but the D.O.C. data cannot explain the major variability seen in the $K_{d}$ data which is the decreasing $K_{d}$ values in the deep-sea cores.

A final factor of interest in these $N$. Atlantic pore water data arises from ${ }^{240} \mathrm{Pu} /{ }^{239} \mathrm{Pu}$ ratio determinations on these same pore water and sediment samples (these data are discussed in more detail in Chapter 6). There is a disequilibrium between the solids and the pore waters in the Pu isotopic signature. This reflects the input of Pu to the sediments from two sources. The major source of $\mathrm{Pu}$ is global stratospheric fallout, the bulk of which remains in the water column today (Livingston and Buesseler, 1985). The second source is tropospheric surface debris from the Nevada test site which carries $\mathrm{Pu}$ in an unreactive form which is rapidiy deposited to marine sediments. The spatial distribution of the Nevada debris has been shown to include the Gulf of Mexico (Scott et a 1., 1983) and much of the N. Atlantic (Buesseler and Sholkovitz, 
1985; Chapter 6, this thesis). The data indicate that Pu carried by Nevada test debris is not participating in the general solid/solution exchange reactions. The Pu $K_{d}$ 's should perhaps be recalculated relative to Pu from the stratospheric fallout source alone. The percent of Nevada fallout in sediments varies as a function of the total sediment inventories such that in the deep Northwest Atlantic (cores $G$ and $H$ ) where Pu sediment inventories are low, the Nevada solid phase component represents just over $40 \%$ of the total solid phase $239,240 \mathrm{Pu}$ activity (Chapter 6, this thesis). Therefore, if this unreactive fraction of the solid phase $239,240 \mathrm{Pu}$ is subtracted from the soltd phase activity in the $K_{d}$ calculation, the $K_{d}$ 's in the deep-sea cores would decrease by 50\%; at the shallower cores this effect would be less important, and the $K_{d}$ 's would be $30 \%, 15 \%$, or $<5 \%$ lower at cores $C, D$ or $E$, and $F$ or $A$, respectively.

The main conclusion from this pore water $239,240 \mathrm{Pu}$ data set is that the primary factor controlling Pu solubility in the pore waters is the concentration of $239,240 \mathrm{Pu}$ in the solid phase. A secondary feature is the shift to lower $K_{d}$ 's with increasing water depth; however, the processes responsible for the shift to lower $K_{d}$ 's cannot be determined with certainty. This $K_{d}$ variability will be important in any discussion of Pu diffusion rates since a two order of magnitude change in the Pu $K_{d}$ from shallow to deep-sea cores would result in increased Pu mobility in the deep-sea sediments (see following model calculations). It should be emphasized that these Pu $K_{d}$ 's are operationally determined by the analysis of solid phase and pore water Pu. Depressurization effects on pore water Pu solubility and the existance of at least two distinct Pu-bearing phases in the solids (stratospheric vs. Nevada fallout Pu - see Chapter 6) could produce an artifact in the deeper cores which would tend to overestimate the true Pu $K_{d}$.

\section{PORE WATER 239,240 PU FLUXES}

Estimates of potential Pu remobilization rates can be made using a simple diffusive flux calculation based upon the observed pore water 
239,240 Pu gradients. The calculation is similar to that used to model Mn(II) fluxes in a previous section in that advection and horizontal processes are neglected, and the data used in the calculation at each site are provided in Table 4.2. The calculated $239,240 \mathrm{Pu}$ fluxes across the sediment/water interface vary from $0.3-24 \times 10^{-5} \mathrm{dpm} 239,240 \mathrm{Pu} / \mathrm{cm}^{2}$ year. It can be concluded that since its introduction less than 30 years ago, 11ttle $239,240 \mathrm{Pu}$ has been lost to the overlying seawater due to diffusive fluxes out of the sediment at my study sites ( 30 years $x$ $0.3-24 \times 10^{-5} \mathrm{dpm} / \mathrm{cm}^{2}$ year $=0.9-72 \times 10^{-4} \mathrm{dpm} / \mathrm{cm}^{2}$ ).

When the flux at each site is compared to the total sediment $239,240 \mathrm{Pu}$ inventory (which varies from $>1 \mathrm{dpm} / \mathrm{cm}^{2}$ in the shallowest cores to $<0.05 \mathrm{dpm} / \mathrm{cm}^{2}$ in the deep-sea cores), one sees that in the shallower cores $(A, F, E$, and $D)$, it would take $10^{3}-10^{4}$ years to remobilize the present $239,240 \mathrm{Pu}$ inventory, while in the deep-sea cores $\left(C, H\right.$, and $G$ ) it would take less than $10^{3}$ years. This is due to the low sediment $239,240 \mathrm{Pu}$ inventories in the deep-sea cores and their relatively sharp pore water gradients; these gradients are maintained by the low $K_{d}$ 's and hence relatively high pore water activities in the deep-sea cores as discussed previously. This calculation is certainly an oversimplification of the true rate of Pu remobilization on the long time scale for several reasons. First, the Pu sediment gradient - and hence the Pu pore water gradient at the sediment/water interface - will be altered as benthic sediment mixing continues to mix the Pu deeper into the sediments. The Pu diffusive fluxes would have been greatest in the past when the bulk of the Pu was less deeply mixed, and the diffusive fluxes will decrease with time. Also, on the $10^{3}$ year time scale, the continued flux of $\mathrm{Pu}$ to the sediments and burial by sedimentation cannot be ignored.

\section{TEST CASE: MANOP SITE C}

The $239,240 \mathrm{Pu}$ and $210 \mathrm{~Pb}$ ex data of Cochran (1985) at MANOP site C are given in Table 4.3, and will be used as a test case to examine the potential effects of Pu diffusion in the pore waters. This study 
Table 4.2: 239,240 Pu Diffusive Flux Calculations.

\begin{tabular}{|c|c|c|c|c|c|c|}
\hline $\begin{array}{l}\text { Station/ } \\
\text { Depth }\end{array}$ & $\Phi$ & m & $d C / d z$ & $\begin{array}{l}\text { Flux } \times 10^{-5} \\
\text { dpm/cm } 2 y r)\end{array}$ & $\begin{array}{c}\text { Inv. } \\
\left(\mathrm{dpm} / \mathrm{cm}^{2}\right)\end{array}$ & $\begin{array}{l}\text { Time } \\
\left(10^{3} \text { yr }\right)\end{array}$ \\
\hline $\begin{array}{l}A \\
90 m\end{array}$ & 0.73 & 3 & $\frac{79-7.2 \mathrm{dpm} / 10^{7} \mathrm{~cm}^{3}}{0.75 \mathrm{~cm}}$ & $12-24$ & 1.24 & $5.5-11$ \\
\hline $\begin{array}{l}F \\
501 m\end{array}$ & 0.50 & 2 & $\frac{42-11 \mathrm{dpm} / 10^{7} \mathrm{~cm}^{3}}{3 \mathrm{~cm}}$ & $0.8-1.6$ & 0.27 & $0.15-0.3$ \\
\hline $\begin{array}{l}E \\
1275 m\end{array}$ & 0.76 & 2.5 & $\frac{57-11 \mathrm{dpm} / 10^{7} \mathrm{~cm}^{3}}{1 \mathrm{~cm}}$ & $7-14$ & 0.22 & $1.5-3$ \\
\hline $\begin{array}{l}D \\
2362 m\end{array}$ & 0.76 & 2.5 & $\frac{19-8.3 \mathrm{dpm} / 10^{7} \mathrm{~cm}^{3}}{1 \mathrm{~cm}}$ & $1.7-3.4$ & 0.13 & $4-8$ \\
\hline $\begin{array}{l}\text { C } \\
2700 m\end{array}$ & 0.77 & 2.5 & $\frac{33-8.5 \mathrm{dpm} / 10^{7} \mathrm{~cm}^{3}}{0.75 \mathrm{~cm}}$ & 5.4-11 & 0.029 & $0.3-0.6$ \\
\hline $\begin{array}{l}\text { G } \\
4460 m\end{array}$ & 0.80 & 2.5 & $\frac{23-8 \mathrm{dpm} / 10^{7} \mathrm{~cm}^{3}}{1 \mathrm{~cm}}$ & $2.7-5.4$ & 0.026 & $0.5-1$ \\
\hline $\begin{array}{l}H \\
4990 m\end{array}$ & 0.69 & 2.5 & $\frac{15-8 \mathrm{dpm} / 10^{7} \mathrm{~cm}^{3}}{3 \mathrm{~cm}}$ & $0.29-0.58$ & 0.043 & $0.75-1.5$ \\
\hline
\end{tabular}

Flux $=d^{m_{D}}{ }_{b}^{1}(d c / d z)$; where $d=a v g$. porosity in sediments specific to the gradients used; $m=2$ to 3 depending upon sediment type (UIlman \& Aller, 1982); (dC/dz) is taken from the data in Table $4 . A ; D_{b}^{1}=1-2 \times 10^{-6} \mathrm{~cm}^{2}$; sec., assuming analogy with Th and $U$ diffusion coefficients at $0^{\circ} \mathrm{C}$ from Li and Gregory $(1974) ; 239,240 \mathrm{Pu}$ solid phase inventory data taken from this work and Buesseler et a1. (1985); Time = Inv./Flux. 
Table 4.3: MANOP Site C Data.

Core MBC-3 (4423m collected $\left.12 / 10 / 8201^{\circ} 01.6^{\prime} \mathrm{N}, 138^{\circ} 56.1^{\prime} \mathrm{W}\right)$

\begin{tabular}{|c|c|c|c|c|c|}
\hline $\begin{array}{l}\text { Depth } \\
(\mathrm{cm})\end{array}$ & $\begin{array}{l}\text { Dry Bulk } \\
\text { Density }\end{array}$ & $\begin{array}{r}239,240 \mathrm{Pu} \\
(\mathrm{dpm} / \mathrm{kg})\end{array}$ & $\begin{array}{l}210_{\mathrm{Pb}} \text { tota } 1 \\
(\mathrm{dpm} / \mathrm{g}) \\
\end{array}$ & $\begin{array}{r}{ }^{226} \mathrm{Ra} \\
(\mathrm{dpm} / \mathrm{g}) \\
\end{array}$ & $\begin{array}{l}210 \mathrm{~Pb}^{\mathrm{ex}} \\
(\mathrm{dpm} / \mathrm{g})\end{array}$ \\
\hline $\begin{array}{c}0-1.5 \\
1.5-3.5 \\
3.5-7.5 \\
5.7-7.9 \\
7.9-10.2 \\
10.2-12.2\end{array}$ & $\begin{array}{l}0.382 \\
0.434 \\
0.476 \\
0.506 \\
0.539 \\
0.576\end{array}$ & $\begin{array}{r}25.9 \pm 1.7 \\
13.7 \pm 0.9 \\
8.5 \pm 0.6 \\
6.3 \pm 0.5 \\
3.2 \pm 0.4 \\
4.0 \pm 0.5\end{array}$ & $\begin{array}{l}26.1 \pm 1.4 \\
22.4 \pm 1.2 \\
19.6 \pm 0.7 \\
18.0 \pm 0.6 \\
14.7 \pm 0.5 \\
15.9 \pm 0.5\end{array}$ & $\begin{array}{l}15.1 \pm 0.8 \\
13.6 \pm 0.7 \\
17.4 \pm 0.9 \\
17.1 \pm 0.9 \\
14.2 \pm 0.7 \\
15.5 \pm 0.8\end{array}$ & $\begin{array}{r}11.1 \pm 1.6 \\
8.9 \pm 1.4 \\
2.2 \pm 1.1 \\
0.9 \pm 1.1 \\
0.5 \pm 0.9 \\
0.5 \pm 0.9\end{array}$ \\
\hline
\end{tabular}

Data from Cochran (1985).

Dry bulk density = grams dry, salt-free sediment $/ \mathrm{cm}^{3}$ wet sediment. Activities as dpm per mass dry, salt-free sediment. 
provides high quality data from a deep-sea site which has been interpreted to indicate possible Pu mobility and where I now have an estimate of the $\mathrm{Pu} K_{\mathrm{d}}$. In this core the surface ${ }^{210} \mathrm{~Pb}^{\text {ex }}$ activity is $11 \mathrm{dpm} / \mathrm{g}$ dropping off to $2.2 \pm 1.1$ and $0.9 \pm 1.1 \mathrm{dpm} / \mathrm{g}$ by 4.6 and $6.8 \mathrm{~cm}$, respectively. The error of $1.1 \mathrm{dpm} / \mathrm{g}$ on the $210 \mathrm{~Pb}$ activities is $10 \%$ of the interface activity and is obtained by propagating the counting errors from the total ${ }^{210} \mathrm{~Pb}$ values $(\simeq 19 \pm 0.7 \mathrm{dpm} / \mathrm{g})$ and the ${ }^{226} \mathrm{Ra}$ values $(\simeq 17 \pm 0.9 \mathrm{dpm} / \mathrm{g})$. As is typical for radiochemical studies, the reported errors are the one standard deviation, or $68 \%$ confidence limits around the mean activity. This error places a lower 1 imit of $\simeq 1 \mathrm{dpm} / \mathrm{g}$ (or 2 $\mathrm{dpm} / \mathrm{g}$ if $95 \%$. or two standard deviation confidence limits are desired) on the ${ }^{210} \mathrm{~Pb}^{\mathrm{ex}}$ determinations. In comparison, the solid phase ${ }^{239,240} \mathrm{Pu}$ activity is $26 \mathrm{dpm} / \mathrm{kg}$ at the interface dropping off to $8.5 \pm 0.6$ and $6.3 \pm 0.5 \mathrm{dpm} / \mathrm{g}$ by 4.6 and $8.6 \mathrm{~cm}$, respectively. Below these depths detectable 239,240 Pu activities are still evident $(3-4 \mathrm{dpm} / \mathrm{kg}$, or $10-15 \%$ of the interface value) down to at least $11.2 \mathrm{~cm}$. These deep $239,240 \mathrm{Pu}$ are well above the detection limits for solid phase $239,240 \mathrm{Pu}$. The comparison between ${ }^{210} \mathrm{~Pb}$ ex and ${ }^{239,240} \mathrm{Pu}$ penetration depths is, therefore, clearly limited by the ability to detect small $210 \mathrm{~Pb}$ activities. To interpret these data as supporting deep Pu mobility is unwarranted. The $K_{d}$ for $P u$ in this carbonate-rich deep-sea core is $1 \times 10^{3}$ and is at the low end of the $K_{d}$ values I have found. Two questions will be addressed: 1) how well can the calculated downward $239,240 \mathrm{Pu}$ diffusive fluxes account for apparent excess solid phase 239,240 pu below $5.7 \mathrm{~cm}$ and 2) what effect would pore water diffusion have on a simple sediment mixing model by increasing Pu transport relative to $210 \mathrm{~Pb}$ ? To answer the first question one needs to add up the solid phase $239,240 \mathrm{Pu}$ inventory below $5.7 \mathrm{~cm}$ (1.e. below the lowest "detectable" $210_{\mathrm{Pb}} \mathrm{ex}$ ) and compare it to a calculation of potential downcore $239,240 \mathrm{Pu}$ diffusion fluxes. This deep "excess" $239,240 \mathrm{Pu}$ inventory can be calculated from the data in Table 4.3 to be $0.016 \mathrm{dpm} / \mathrm{cm}^{2}$. With a $K_{d}$ of $1 \times 10^{3}$, I calculate a pore water gradient of $1 \times 10^{-6} \mathrm{dpm} / \mathrm{cm}^{2}$ (between 4.6 and $6.8 \mathrm{~cm}$ ), and a corresponding downcore pore water ${ }^{239,240} \mathrm{Pu}$ flux of $2.5 \times 10^{-5} \mathrm{dpm} / \mathrm{cm}^{2}$ year (using the equation in Table 4.2 and $d=0.7, m=2.5$, and $D_{b}^{1}=$ 
$2 \times 10^{-6} \mathrm{~cm}^{2} / \mathrm{sec}$ ). If this flux had existed for 30 years, (an overestimate since the $\mathrm{Pu}$ has not been mixed down to $6 \mathrm{~cm}$ since its introduction 30 years ago), then the flux could account for the transport of $7.5 \times$ $10^{-4} \mathrm{dpm} / \mathrm{cm}^{2}$ of $239,240 \mathrm{Pu}$ to depths below $5.7 \mathrm{~cm}$; this represents less than $5 \%$ of the observed solid phase enrichment. It is obvious that diffusive transport alone cannot account for the "apparent" excess $239,240 \mathrm{Pu}$ found in the solid phase profile below $5.7 \mathrm{~cm}$.

To look at the second question, the enhancement of total mixing rates, the sediment mixing rate first needs to be calculated ignoring any diffusive transport of ${ }^{239,240} \mathrm{Pu}$ in the pore waters. I have used a "pulse input" model for Pu as done by Cochran (1985) and others (Anderson et al., 1986; Lapique et al., 1986) to calculate an apparent sediment mixing rate. The solution to the Pu pulse input model, assuming negligible sedimentation ( $=1.8 \mathrm{~cm} / 10^{3}$ year; Kadko, 1981), constant porosity and constant mixing rates over the mixed zone is of the form:

$$
A=A_{0} \exp \left(-z^{2} / 4 D_{b} t\right),
$$

where $A$ and $A_{0}$ are the activities of solid phase $239,240 \mathrm{Pu}$ at depth and at the interface repectively; $z$ is the depth in $\mathrm{cm}$; $t$ is the time since the Pu input in years (30 years is used here (1952-1982), but 25 or less years could be used with little change); and $D_{b}$, the sediment mixing coefficient is calculated from a best fit line to an exponentially decreasing curve through the data points. I arrive at an apparent sediment mixing rate of $0.21^{2} \mathrm{~cm} /$ year with a $90 \%$ confidence range of 0.15 to $0.33 \mathrm{~cm}^{2} /$ year for the MANOP $C$ core. This is well within the range of values determined from the steady-state diffusive model for $210_{\mathrm{Pb}}{ }^{\mathrm{ex}}$ at this site (Cochran reports a $\mathrm{D}_{\mathrm{b}}$ of $0.08-0.47$ from ${ }^{210} \mathrm{~Pb}^{\mathrm{ex}}$ data). This Pu pulse model $D_{b}$ is actually $40 \%$ higher than the value reported by Cochran (1985) for the same 239,240 Pu data. This difference is due to the fact that in my curve fitting procedures, the best fit line is not necessarily forced through the uppermost $239,240 \mathrm{Pu}$ value, as done by Cochran (see discussion in Chapter 7). If I include the effects of molecular diffusion in the pore waters with rapid and reversible exchange off the solids with a $K_{d}$ of $1 \times 10^{3}$, the total diffusion coefficient due to the pore water transport becomes $D_{p . w .}=\left(\phi^{m_{D_{b}}}\right) / 1+K_{d}$, or 
$0.026 \mathrm{~cm}^{2} /$ year (Berner, 1976). This diffusion rate is $12 \%$ of the sediment mixing rate, and the combined rate of diffusive transport would be $0.21+0.026=0.236 \mathrm{~cm}^{2} /$ year. The calculated solid phase profile using this enhanced mixing rate is shown in Figure 4.4 to be indistinguishable from the mean rate of $0.21 \mathrm{~cm}^{2} /$ year used previously. Even if the $\mathrm{K}_{\mathrm{d}}$ were $10^{2}$ (1.e. $D_{p . w .}=0.26+D_{b}=0.21$ or $0.47 \mathrm{~cm}^{2} /$ year), the calculated total mixing profile would be only slightly outside of the $90 \%$ confidence limits of the model case where no Pu pore water diffusion is assumed (Fig. 4.4). In shallower cores with higher sediment mixing rates and higher $K_{d}{ }^{\prime} s$ the effects of pore water Pu diffusion on Pu mixing rates would be much smaller. These calculations view diffusion as one dimensional process and neglect the possibility of Pu migration horizontally in open burrows. If $\mathrm{Pu}$ is behaving analogous to other particle reactive species such as ${ }^{234} \mathrm{Th}$ or ${ }^{210} \mathrm{~Pb}$, then diffusion via open burrows in the horizontal dimension would only be significant at extremely high burrow densities (Aller, 1984). The main conclusion is that no evidence for enhanced Pu mobility can be seen in any of the solid phase models, confirming the need for pore water data in estimates of $\mathrm{Pu}$ fluxes and diagenesis.

\section{SUMMARY}

Pu pore water chemistry was examined along a transect of seven cores from the Northwest Atlantic between Woods Hole and Bermuda. These cores exhibit a systematic transition between highly reducing muddy sediments on the shelf to carbonate-rich, sub-oxic, and oxic sediments in the deep-sea. These redox conditions appear to be stable, as evidenced by the close correspondence between present day pore water Mn(II) fluxes and solid phase Mn enrichments in the slope and upper-rise cores,

Evidence for Pu remobilization was sought from solid phase $239,240 \mathrm{Pu},{ }^{210} \mathrm{~Pb}$ ex ${ }^{137} \mathrm{Cs}$ data, and from direct pore water ${ }^{239,240} \mathrm{Pu}$ determinations. From this data I conclude: 
Figure 4.4: MANOP Site C Mixing Models

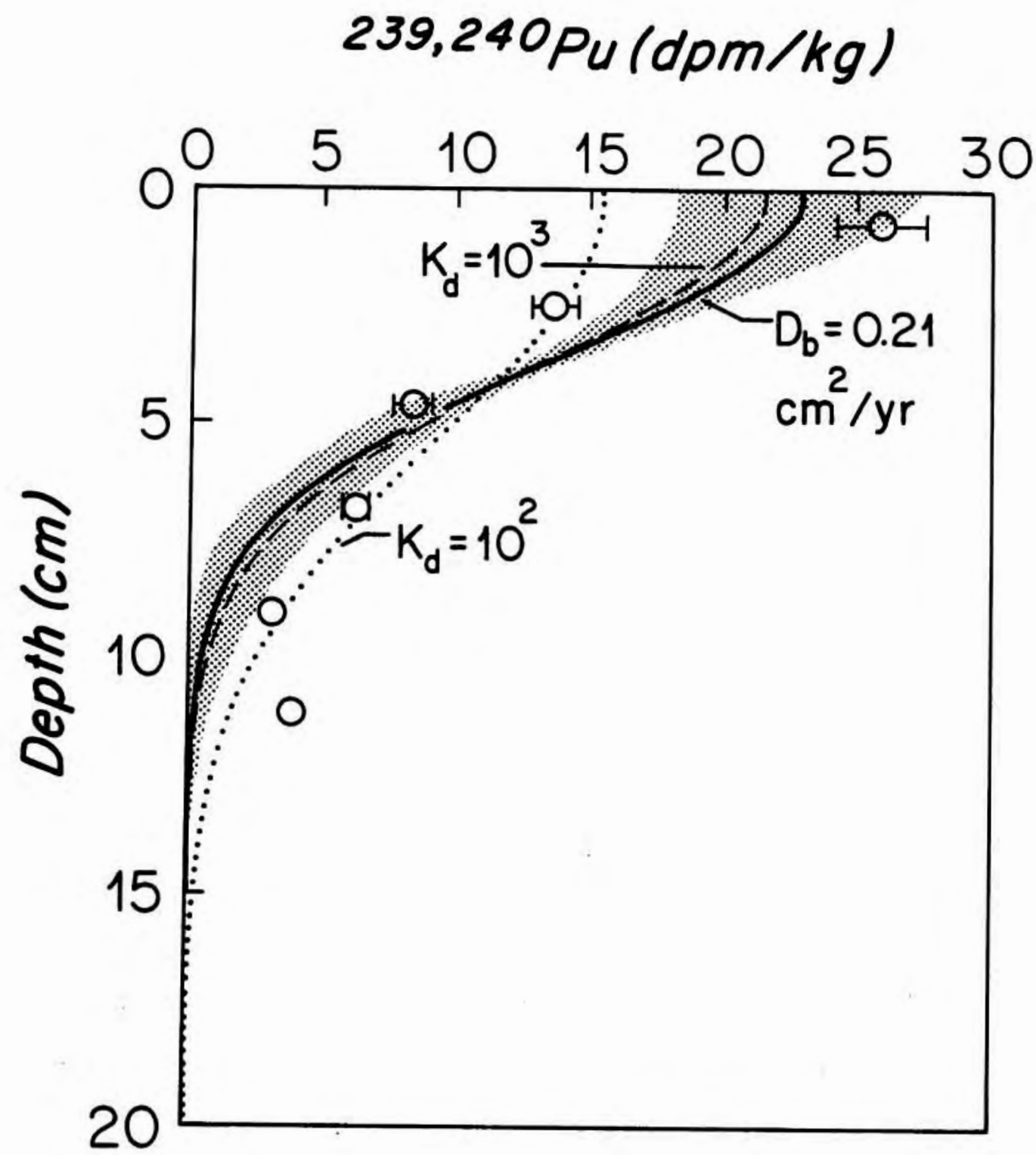

Data points for solid phase Pu are shown as open circles. The best fit mixing line is given as a heavy solid line $\left(D_{b}=0.21\right)$ with the $90 \%$ confidence limits for $D_{b}$ represented by the shaded area. The enhanced mixing due to molecular diffusion with a $P u K_{d}$ of $10^{3}$ and $10^{2}$ is shown as the dashed and dotted ilnes, respectively. See text for model details. 
1) The solid phase $239,240 \mathrm{Pu},{ }^{210} \mathrm{~Pb}$ ex , and ${ }^{137} \mathrm{Cs}$ results from the entire transect do not suggest that any of these tracers are preferentially mobile within the cores. Solid phase $239,240 \mathrm{Pu}$ and ${ }^{210} \mathrm{~Pb}$ ex are distributed to the same depths at the same mixing rates within the errors of the data.

2) Pore water $239,240 \mathrm{Pu}$ activities determined in shelf, slope, and deep-sea cores are elevated over typical bottom water activities at the sediment/water interface and decrease below detection as the solid phase activities drop off with depth in the core.

3) The pore water $239,240 \mathrm{Pu}$ distributions can be represented by an apparent exchange between the solids and the pore solutions with an operationally determined distribution coefficient, $K_{d}$ in the range of $0.2-23 \times 10^{4}$.

4) Along this transect there is a decrease in the average $k_{d}$ values between shallow and deep sites with $K_{d}$ 's of $10^{4}-10^{5}$ in the sheif and slope cores to $K_{d}$ values of $0.3-0.6 \times 10^{4}$ in the deep-sea cores. No single mechanism was found which could account for this shift in Pu solubility.

5) Flux calculations suggest that since tts introduction a relatively insignificant amount of $239,240 \mathrm{Pu}$ has been remobilized out of the sediments from these sites $\left(0.3-24 \times 10^{-5} \mathrm{dpm} 239,240 \mathrm{Pu} / \mathrm{cm}^{2}\right.$ year).

6) Data from MANOP site $C$ are used to demonstrate that solid phase data are insensitive indicators of Pu mobility, efther through comparisons of solid phase $239,240 \mathrm{Pu}$ and $210 \mathrm{~Pb}^{\text {ex }}$ penetration depths or through the modeling of apparent mixing rates.

7) The two order-of-magnitude variation in Pu pore water solubility in natural marine systems is important in long-term predictive models of Pu migration such as used in evaluating nuclear waste disposal options. 


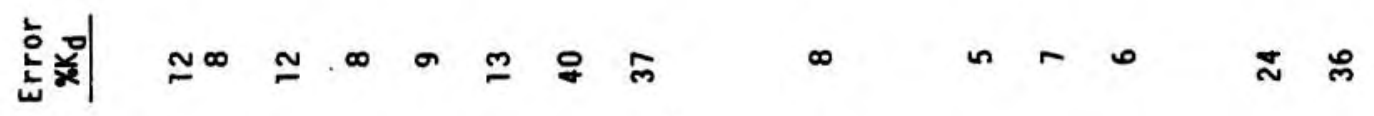

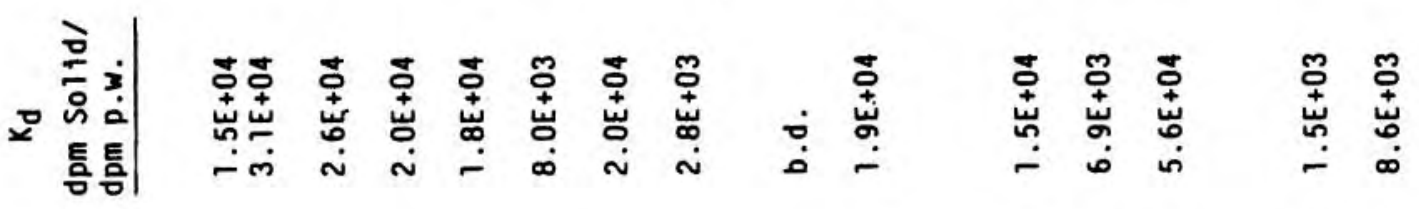

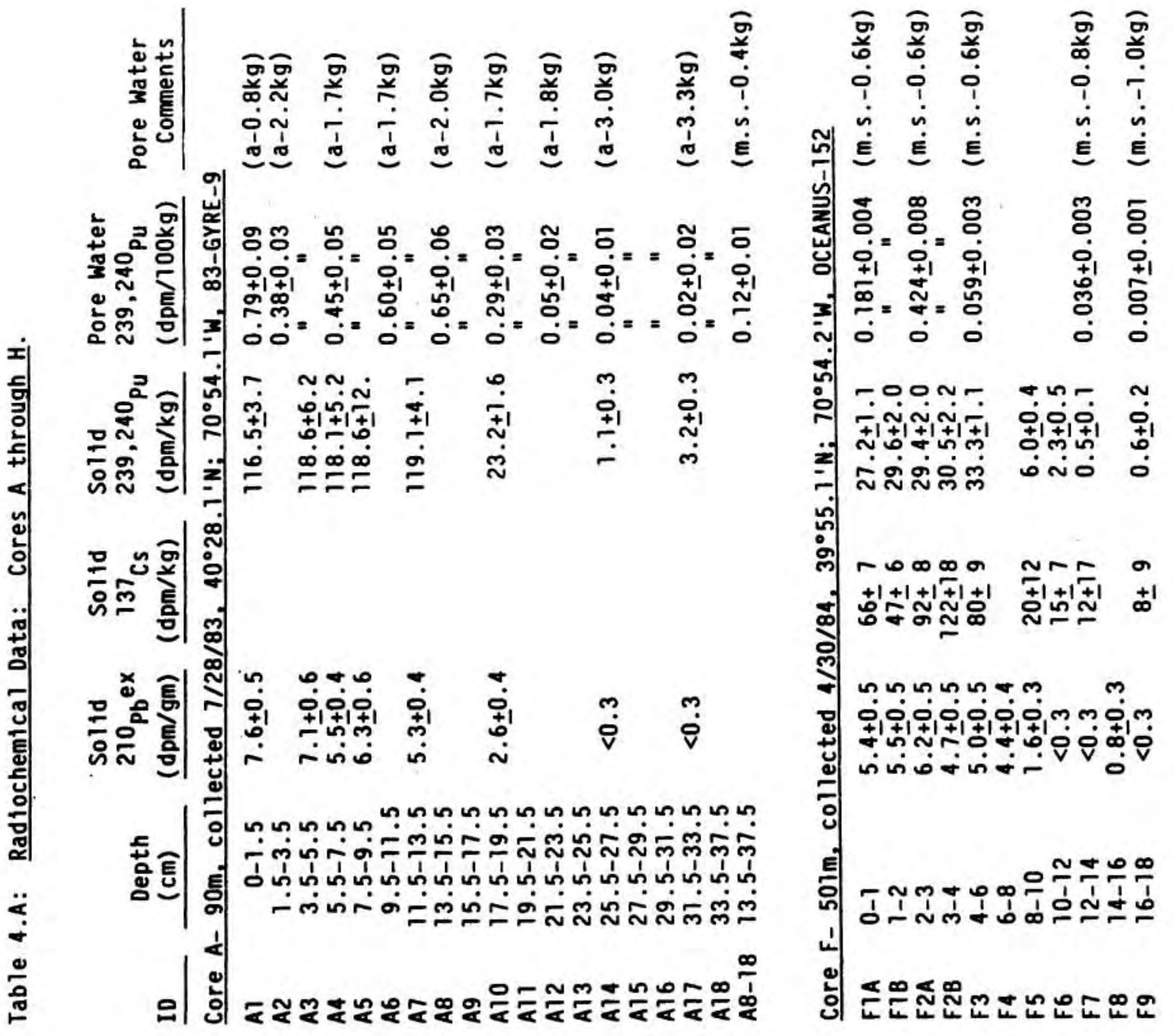




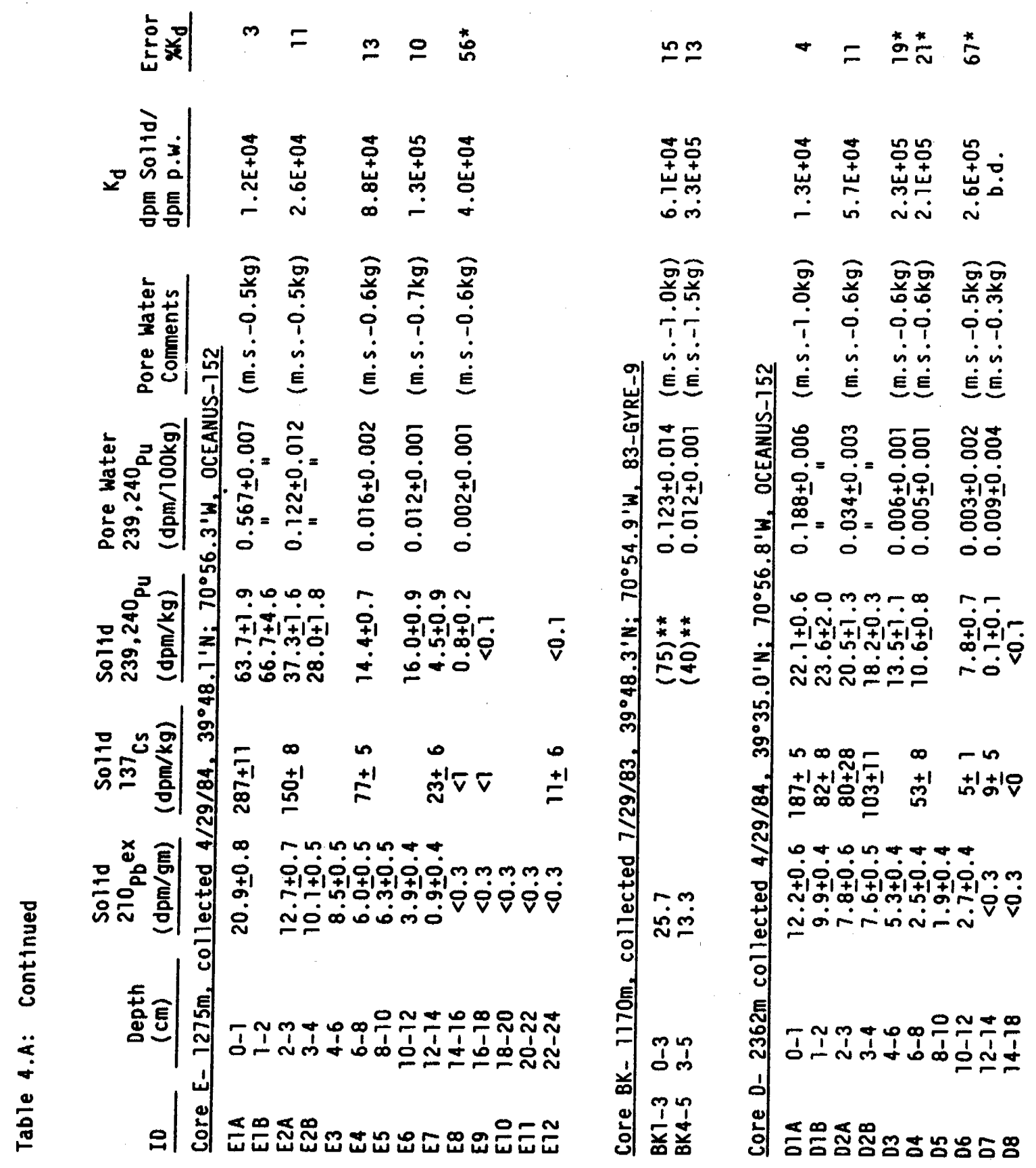




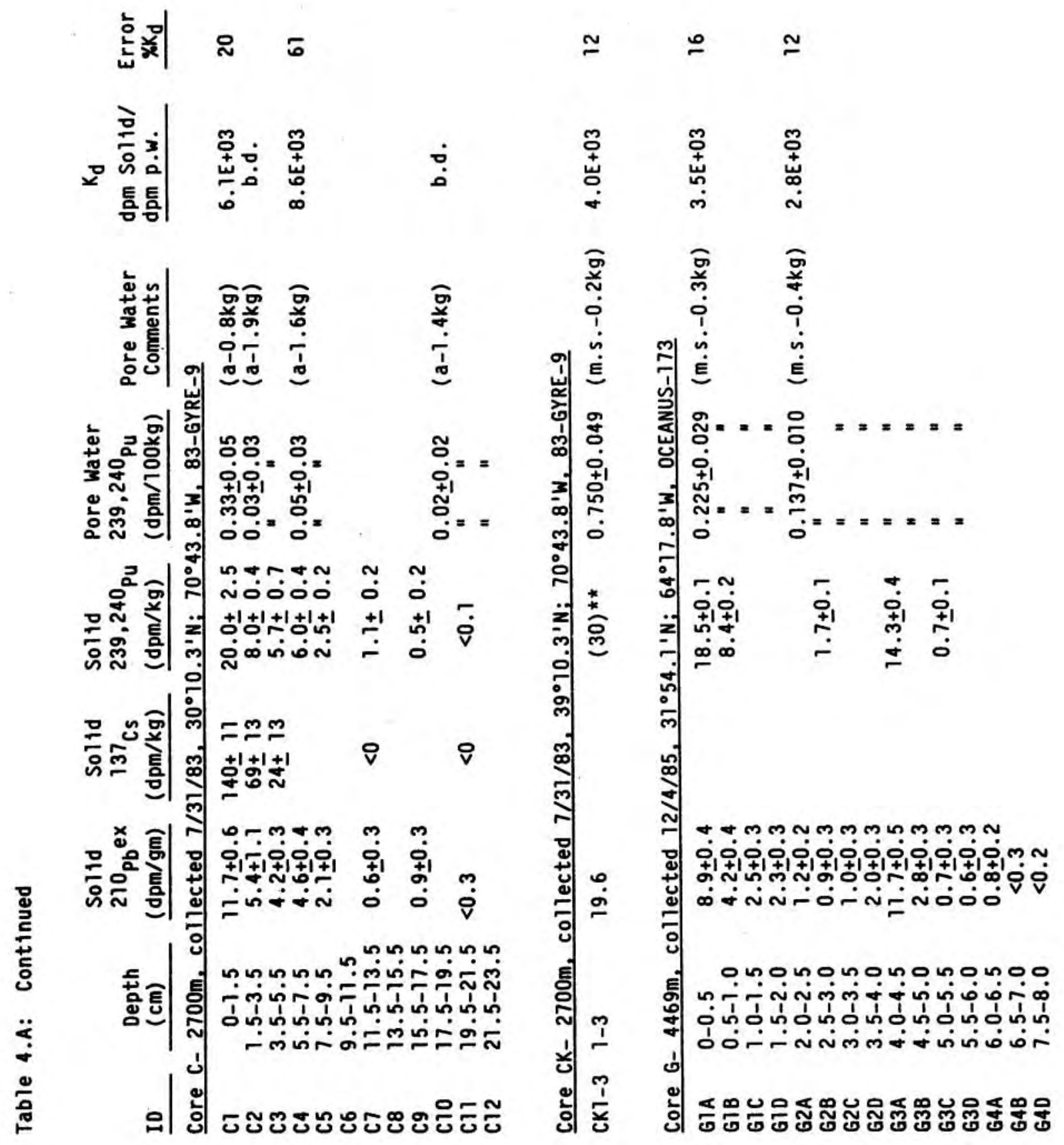




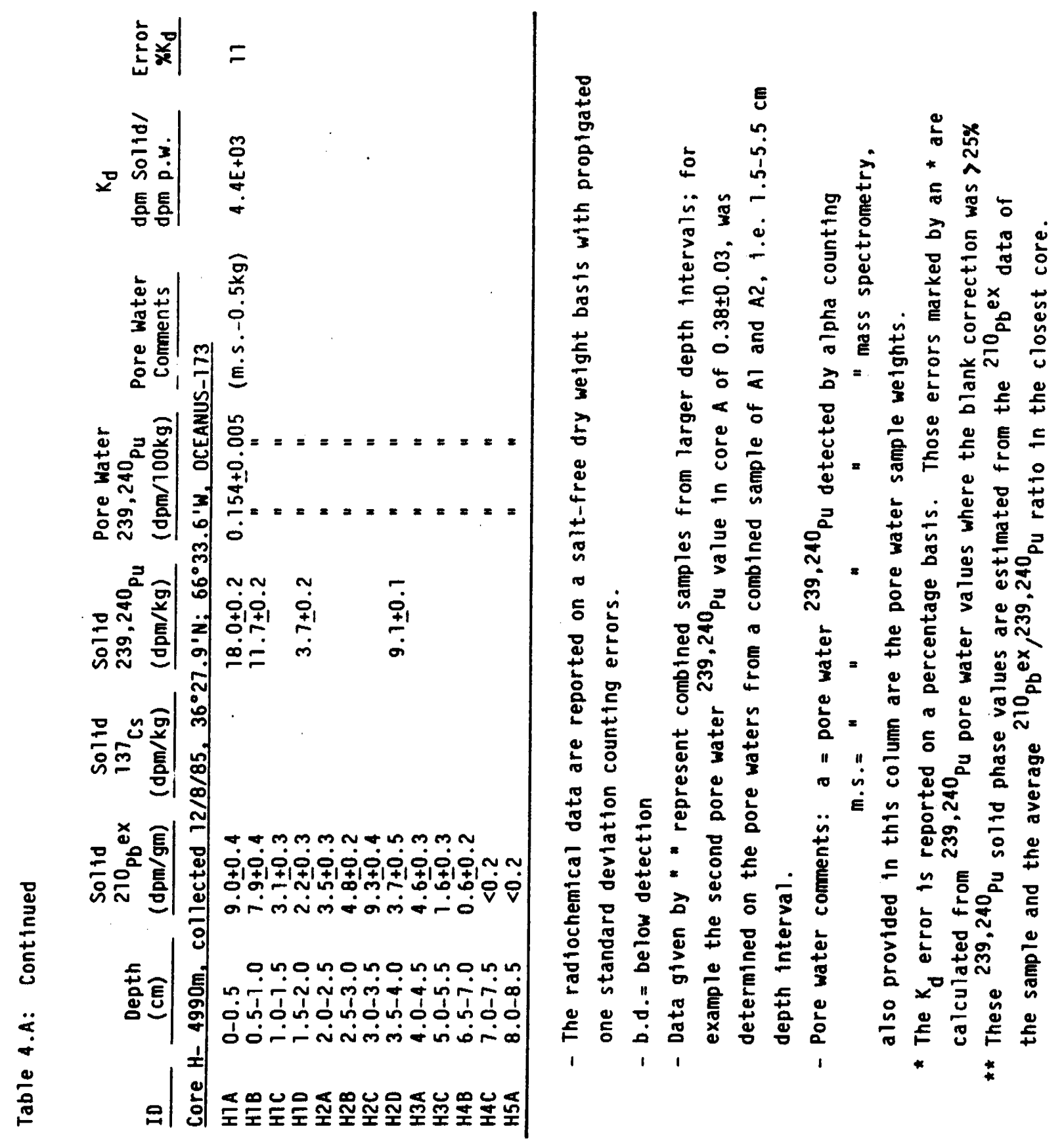




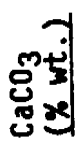

$$
\stackrel{\circ}{\circ}
$$<smiles>[CH]C</smiles>

$=\frac{1}{3}$

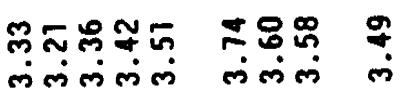

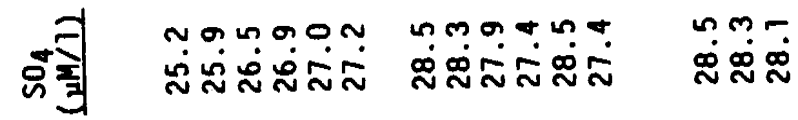

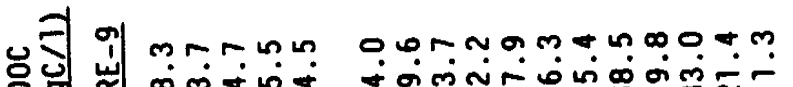
๓ i习习

Nomm

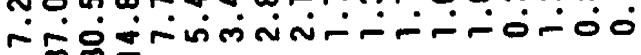

$$
\text { ஸिक्षக }
$$

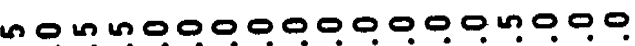

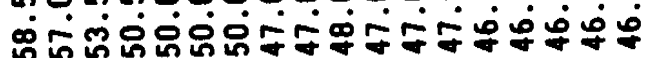

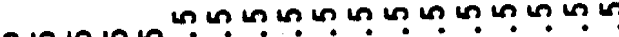

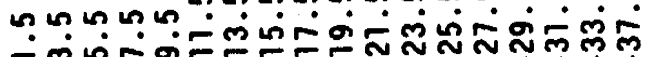

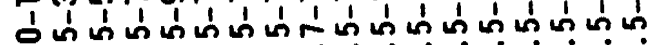

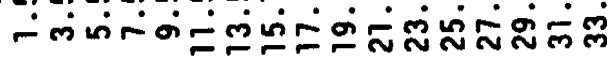

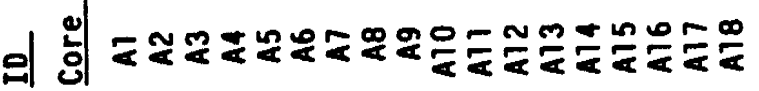

or orogono

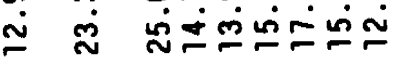

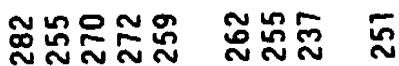
$\because \because$ ஜ

- $m \infty \div \div \div \%$ ம

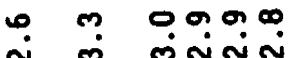
$m+r n+\infty n \infty m \infty$

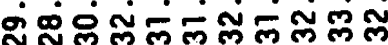

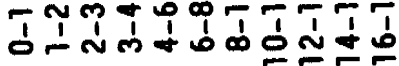

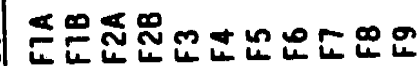




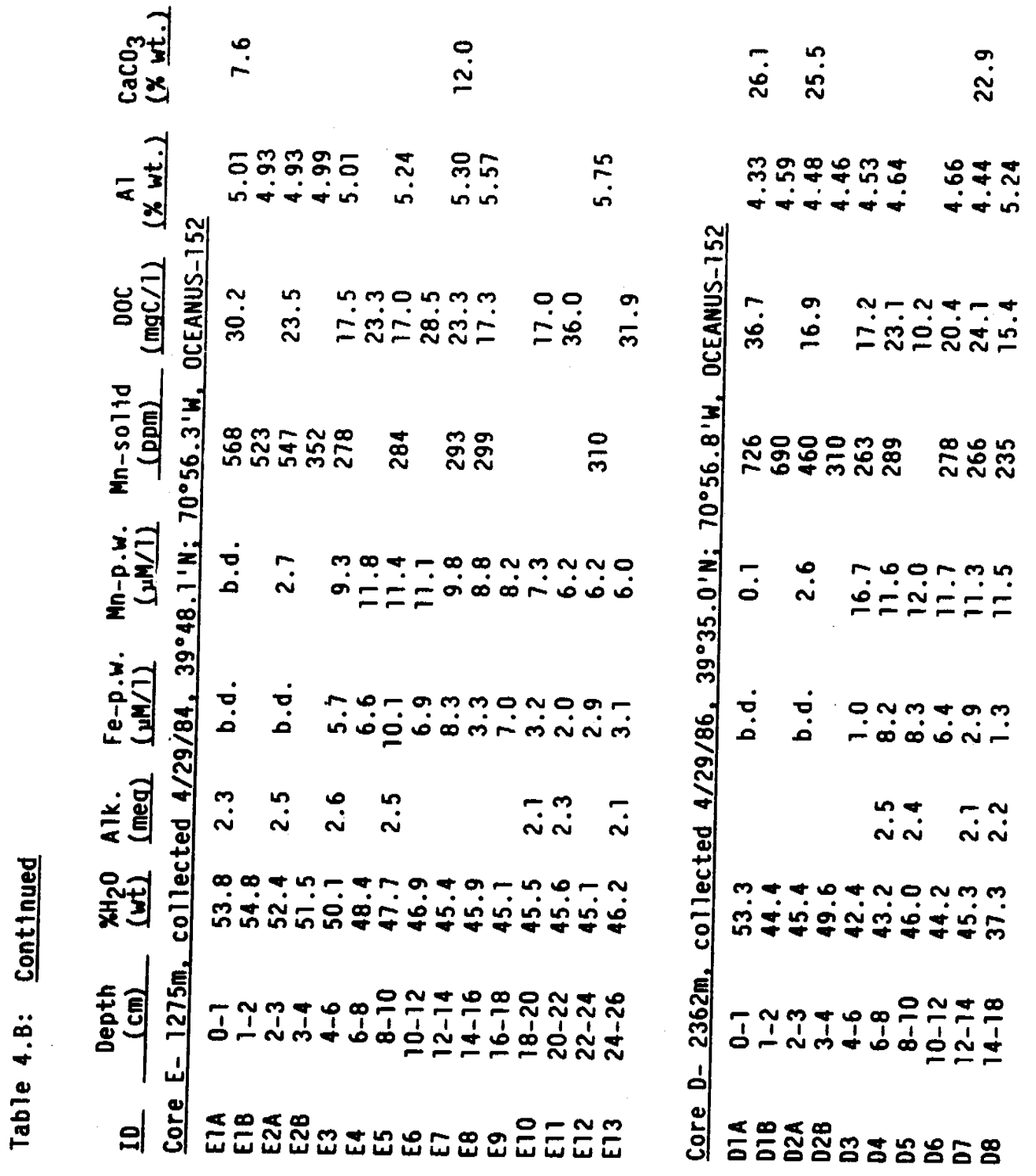


疋

ลำ

กั

กิ

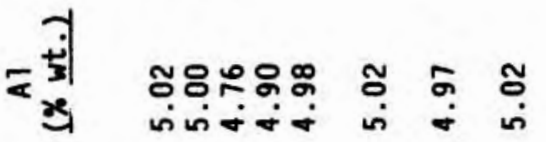

$\tilde{n}==\stackrel{\tilde{n}}{n}==$

$\underset{\dot{m}}{\dot{0}}=\frac{\infty}{i}$

ธำำ

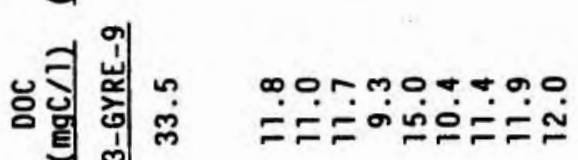

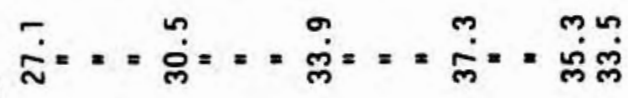

을 형

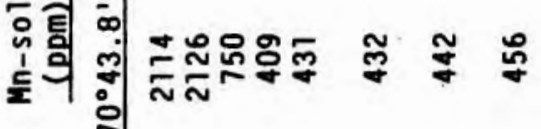

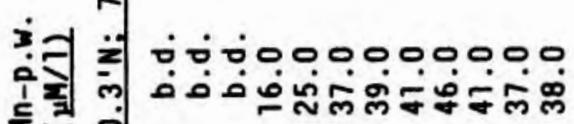

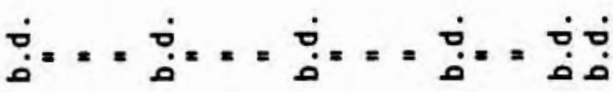

;교

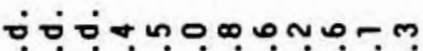

\&

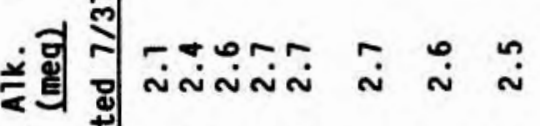

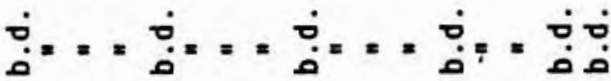

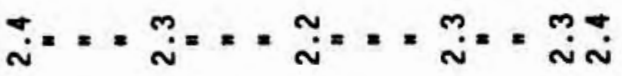

of 0 ononogono no 0

?.

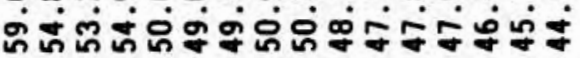

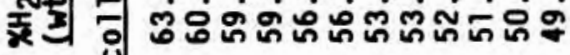
击目

nomonomono no noo

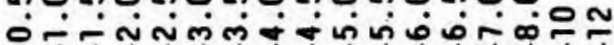

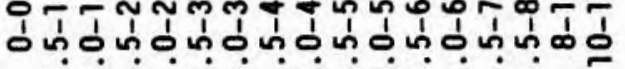

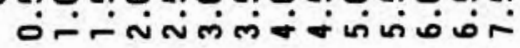

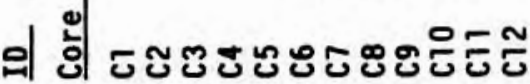




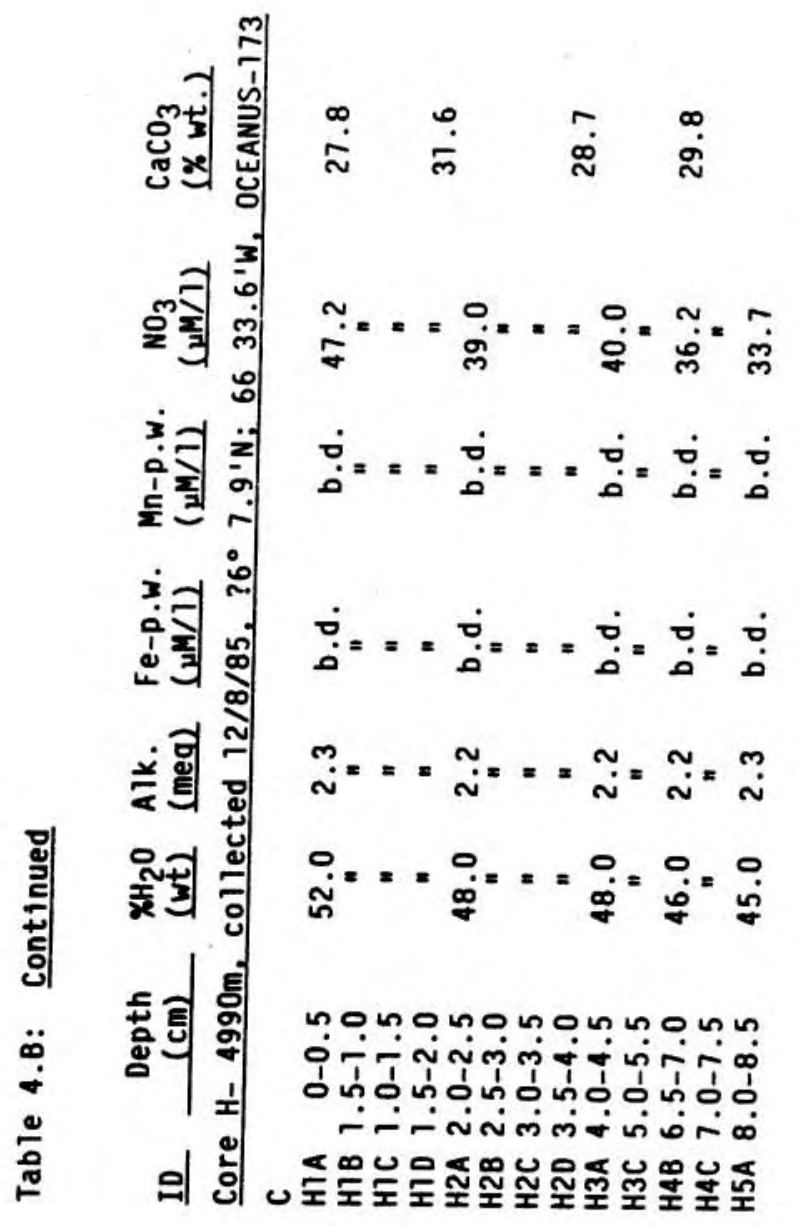




\title{
CHAPTER 5
}

Earth and Planetary Science Letters, $76(1985 / 86) 10-22$

Elsevier Science Publishers B.V., Amsterdam - Printed in The Netherlands

\section{${ }^{239,240} \mathrm{Pu}$ and excess ${ }^{210} \mathrm{~Pb}$ inventories along the shelf and slope of the northeast U.S.A.}

\author{
Ken O. Buesseler, Hugh D. Livingston and Edward R. Sholkovitz \\ Woods Hole Oceanographic Institution, Woods Hole, MA 02543 (U.S.A.)
}

Received April 2, 1985; revised version received August 29. 1985

\begin{abstract}
Sedimentary $\mathrm{Pu}$ and excess ${ }^{210} \mathrm{~Pb}$ inventory data are examined from a large number of sites along the U.S. North Atlantic shelf and slope. From these data, an estimate can be made of the magnitude and location of $\mathrm{Pu}$ and ${ }^{210} \mathrm{~Pb}$ accumulation in this region. A major feature of the data is a decrease in the $\mathrm{Pu}$ and ${ }^{210} \mathrm{~Pb}$ inventories with water depth, which appears to reflect a decrease in the net scavenging of these elements off-shore. When $\mathrm{Pu}$ and ${ }^{210} \mathrm{~Pb}$ inventories are summed over water depths less than $\mathbf{4 0 0 0} \mathrm{m}$ in the North Atlantic shelf and slope region, the sediments can account for $24 \pm 8 \%$ of the expected $\mathrm{Pu}$ and $83 \pm 15 \%$ of the expected ${ }^{210} \mathrm{~Pb}$ inputs. At water depths greater than $4000 \mathrm{~m}$ in this region, we find a greater deficiency in the measured inventories of both ${ }^{210} \mathrm{~Pb}$ and $\mathrm{Pu}$, which cannot be accounted for in the shallower sediments. This suggests that the northwest Atlantic continental margin is not a major site of $\mathrm{Pu}$ or ${ }^{210} \mathrm{~Pb}$ removal and storage, when compared to atmospheric, in situ, and lateral inputs of these radionuclides.
\end{abstract}

\section{Introduction}

In this study, a large suite of sedimentary ${ }^{239.240} \mathrm{Pu}$ and excess ${ }^{210} \mathrm{~Pb}$ inventory data are examined from the continental margin region off of the northeast U.S.A. Inventories of plutonium and ${ }^{210} \mathrm{~Pb}$ will reflect their source functions [1-3], removal efficiencies $[4,5]$, and lateral transport in water and particles $[6,7]$. Comparisons between ${ }^{239.240} \mathrm{Pu}$ and ${ }^{210} \mathrm{~Pb}^{\mathrm{ex}}$ are of interest since both isotopes are supplied predominantly by atmospheric delivery to coastal waters, and since both $\mathrm{Pu}$ and ${ }^{210} \mathrm{~Pb}$ are used to study recent accumulation and mixing processes in marine sediments [8-12].

No large-scale compilations of $\mathrm{Pu}$ and ${ }^{210} \mathrm{~Pb}$ inventories along the North Atlantic shelf and slope region (NASS region) have been published. Previous work in this area has focused on ${ }^{239.240} \mathrm{Pu}$ and $/{ }^{210}{ }^{21 b^{e x}}$ inventories in only a few cores at a limited number of sites along the Atlantic continental margin [13--15]. The examination of a larger data set will allow for a significant improvement in our understanding of the fluxes and budgets of these two radionuclides of geochemical interest.
The main objective of this study is to examine the inventory data on hand, in order to understand the magnitude and location of $\mathrm{Pu}$ and ${ }^{210} \mathrm{~Pb}$ deposition along the North Atlantic continental margin. We first compare $\mathrm{Pu}$ and ${ }^{210} \mathrm{~Pb}$ sedimentary inventories to their expected fallout supply, considering only vertical removal processes within the NASS region. This leads to an immediate subdivision of the NASS region into areas of either net accumulation or net depletion of these two radionuclides. Two major questions are considered: (1) what factors and mechanisms appear to be controlling the incorporation of $\mathrm{Pu}$ and ${ }^{210} \mathrm{~Pb}$ into the sediments, and (2) how do the inventories in any given area affect the budget of $\mathrm{Pu}$ or ${ }^{210} \mathrm{~Pb}$ in the NASS region in toto. Later sections test the model of Bacon et al. $[16,17]$, which suggests that lateral fluxes of ${ }^{210} \mathrm{~Pb}$ to the West Atlantic ocean margin are significant. We also compare the NASS region to other sites along the west coast of the U.S.A. $[7,8,18]$, where similar inventory data exist.

For this discussion, the NASS region is defined as the entire sediment/water system running from the coast at Cape Hatteras to Nova Scotia. This region is bounded at the seaward edge by a straight line running roughly parallel to the continental margin (see Fig. 1 for location and boundaries). 


\section{Methods}

The analytical techniques for the detection and measurement of ${ }^{239.240} \mathrm{Pu}$ and ${ }^{210} \mathrm{~Pb}^{\mathrm{ex}}$ are provided in the original references cited. In this text, plutonium, $\mathrm{Pu}$ or ${ }^{239.240} \mathrm{Pu}$, represents the combined activity of ${ }^{239} \mathrm{Pu}$ and ${ }^{240} \mathrm{Pu}$, which are inseparable using alpha counting techniques [19]. ${ }^{210} \mathrm{~Pb}$ is determined from the activity of its daughter nuclide, ${ }^{210}$ Po [10], ore more recently by non-destructive low-energy gamma counting [20]. ${ }^{226} \mathrm{Ra}$, a long-lived parent of ${ }^{210} \mathrm{~Pb}$, is determined by a standard ${ }^{222} \mathrm{Rn}$ emanation technique [21], or by low-energy gamma counting [22]. ${ }^{226} \mathrm{Ra}$ is needed to correct the total ${ }^{210} \mathrm{~Pb}$ activity for that fraction of the activity which is supported by sedimentary ${ }^{226} \mathrm{Ra}$, ie. excess ${ }^{210} \mathrm{~Pb}\left(={ }^{210} \mathrm{~Pb}\right.$ ex $)$ is ${ }^{210} \mathrm{~Pb}$ derived from atmospheric and water-column sources only.
Tabel 1 compiles the radionuclide data and also provides information on the methods of core collection and the year of sample collection. An important consideration in estimates of sediment inventory is the possibility of the physical loss of core top material during sampling. This would certainly reduce the measured $\mathrm{Pu}$ and ${ }^{210} \mathrm{~Pb}$ inventories, perhaps accounting for some of the spread in the data, and the lower than average inventories at any given depth. We have no reason to assume that this effect is significant relative to real spatial variability at any given site in this region. It appears from the consistent trends of isotope inventories discussed below, that no systematic bias has been introduced due to the different analytical techniques used by various laboratories, the range of sampling devices employed, or the date of core collection.

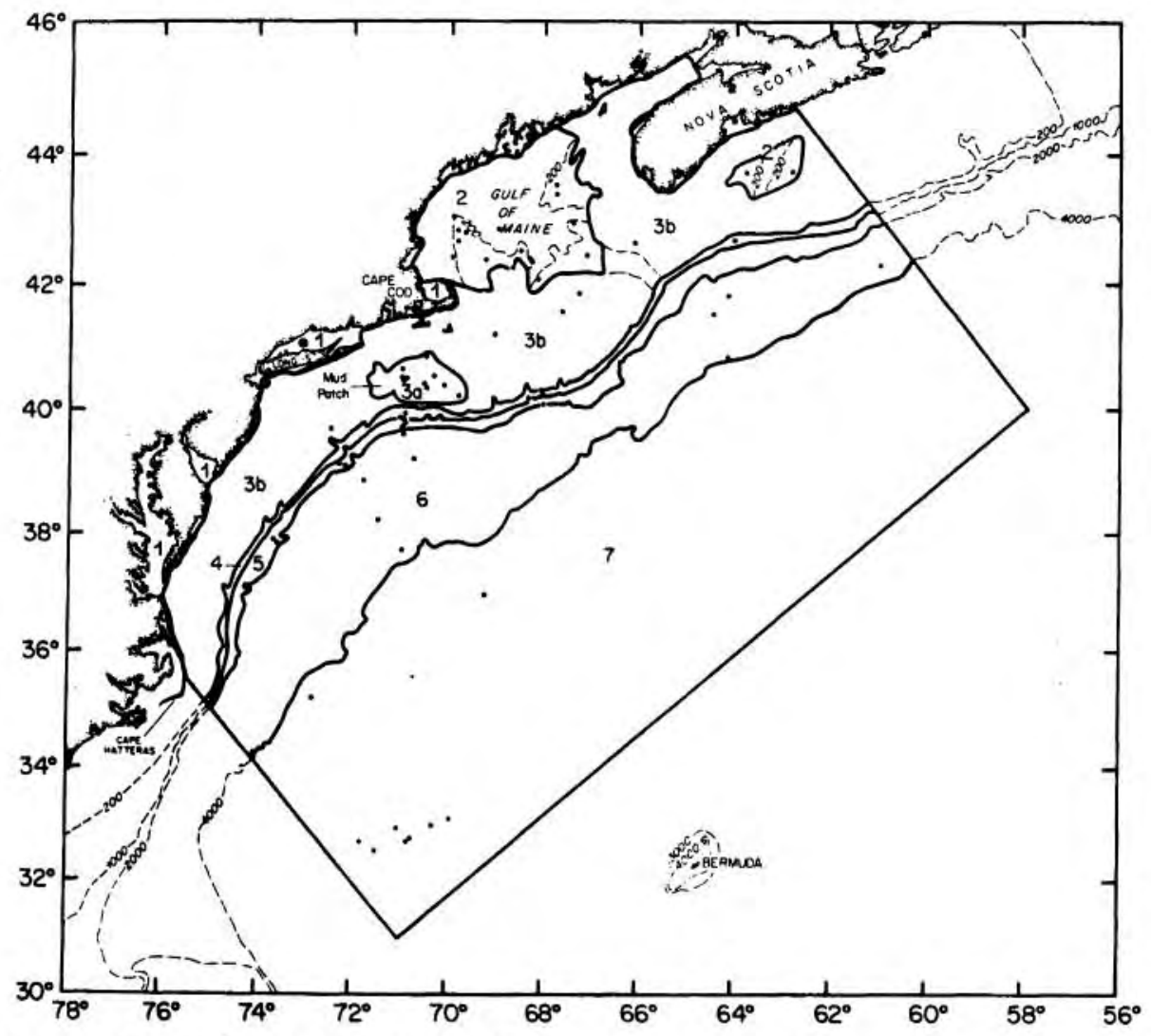

Fig. 1. Map showing the location of the North Atlantic shelf and slope region (NASS region). Points on this map indicate core locations from the data listed in Table 1 . The boundaries shown, and the numbered subdivisions refer to areas of similar Pu and ${ }^{210} \mathrm{~Pb}^{\mathrm{ex}}$ inventories, as discussed in the text, and used in Tables. 1 and 2. 


\section{Sources}

Both ${ }^{239.240} \mathrm{Pu}$ and ${ }^{210} \mathrm{~Pb}$ are supplied predominantly by atmospheric deposition in coastal waters off of the northeast U.S.A. ${ }^{239.240} \mathrm{Pu}$ has been introduced into the environment as stratospheric fallout resulting from atmospheric nuclear weapons testing, the bulk of which occurred in the late 1950 's and early 1960's. Since its introduction, there has been negligible decay of the long-lived $\mathrm{Pu}$ isotopes $\left({ }^{239} \mathrm{Pu} t_{1 / 2}=24,110\right.$ years, ${ }^{240} \mathrm{Pu} t_{1 / 2}$ $=6560$ years). The total inventory of ${ }^{239.240} \mathrm{Pu}$ delivered to the NASS region due to weapons fallout is $2.0 \pm 0.6 \mathrm{mCi} / \mathrm{km}^{2}$ [1]. This inventory figure is obtained from a large set of $\mathrm{Pu}$ soil data (17 sites) collected in the $30-50^{\circ} \mathrm{N}$ latitude band. We have chosen the mean of these data, 2.0 $\mathrm{mCi} / \mathrm{km}^{2}$, as the expected fallout delivered inventory of $\mathrm{Pu}$ for the entire NASS region in our subsequent calculations.

Atmospheric ${ }^{210} \mathrm{~Pb}$ fluxes result from the emanation of ${ }^{222} \mathrm{Rn}$ gas on land. ${ }^{222} \mathrm{Rn}$ rapidly decays via a series of short-lived decay products to ${ }^{210} \mathrm{~Pb}$, which quickly becomes associated with aerosol particles. Similar to $\mathrm{Pu}$, these aerosol particles enter the surface oceans via wet or dry deposition [2]. A second source of excess ${ }^{210} \mathrm{~Pb}$ is in situ production in the water column from ${ }^{226} \mathrm{Ra}$. In terms of the inventory calculations considered below, this source will be shown to be significant only at water depths greater than approximately $4000 \mathrm{~m}$. The expected inventory of ${ }^{210} \mathrm{~Pb}^{\mathrm{ex}}$ from atmospheric delivery alone is $25 \mathrm{dpm} / \mathrm{cm}^{2}$ [23]. This figure is the mean inventory of a series of soil samples collected throughout the eastern U.S.A. (soil inventories ranged from 19 to $29 \mathrm{dpm} / \mathrm{cm}^{2}$ [23]). This translates into an expected ${ }^{210} \mathrm{~Pb}$ flux of $0.8 \mathrm{dpm} / \mathrm{cm}^{2} / \mathrm{yr}$, given the mean life of ${ }^{210} \mathrm{~Pb}$, which is 32 years. Direct measurements of the atmospheric ${ }^{210} \mathrm{~Pb}$ flux in Bermuda [24] yields a ${ }^{210} \mathrm{~Pb}$ delivery rate of $0.7 \mathrm{dpm} / \mathrm{cm}^{2} \mathrm{yr}$, which is within the range of this eastern U.S.A. data set. For the purposes of our calculations below, we use $25 \mathrm{dpm} / \mathrm{cm}^{2}$ as the expected inventory of ${ }^{210} \mathrm{~Pb}^{\text {ex }}$ due to atmospheric delivery at all sites throughout the NASS region.

\section{Results}

Sedimentary inventories of ${ }^{239.240} \mathrm{Pu}$ and ${ }^{210} \mathrm{~Pb}^{\text {ex }}$ are presented for more than 100 cores in Table 1 , and the sampling locations are shown in Fig. 1. The radionuclide inventory and water depths have been used to separate 8 distinct regions within the NASS area (see Fig. 1 and Table 2). Within each region some basic trends are evident, which will be discussed below, region by region.

1. Coastal bays and inlets. Sedimentary inventories of $\mathrm{Pu}$ and ${ }^{210} \mathrm{~Pb}$ are generally higher than can be expected from their atmospheric delivery in this region. The range of data between sites, however, is quite large. $\mathrm{Pu}$ inventories are found between 1.1 and $4.3 \mathrm{mCi} / \mathrm{km}^{2}$, and ${ }^{210} \mathrm{~Pb}^{\mathrm{ex}}$ inventories range from 9 to $78 \mathrm{dpm} / \mathrm{cm}^{2}$. In general, this region characteristically tends to accumulate higher than fallout expected inventories for both $\mathrm{Pu}$ and ${ }^{210} \mathrm{~Pb}^{\mathrm{ex}}$, in areas with fine-grained sediments and intense biological reworking. Within the sediments of the entire NASS region, $-9 \%$ of the $\mathrm{Pu}$ and $\sim 2 \%$ of the ${ }^{210} \mathrm{~Pb}^{\mathrm{ex}}$ found in the sediments is stored within this area (calculated from the measured inventory in a region/total NASS measured inventory; data from Table $2 \mathrm{~A}$ and $\mathrm{B}$ ).

2. Gulf of Maine / Nova Scotian basins. There are a number of cores from the Gulf of Maine and Nova Scotian shelf which are not particularly sandy (less than 50\% sand) and which do accumulate some sedimentary $\mathrm{Pu}$ and ${ }^{210} \mathrm{~Pb}$. The boundary of this region was chosen to include continental shelf basins (shown in Fig. 1) and Gulf of Maine sediments which contain appreciably ${ }^{210} \mathrm{~Pb}$ and $\mathrm{Pu}$ in the surface sediments $[13,25]$. These basins and shallow sediments tend to have average sedimentary inventories for $\mathrm{Pu}$ and ${ }^{210} \mathrm{~Pb}^{\text {ex }}$ of approximately $0.9 \mathrm{mCi} / \mathrm{km}^{2}$ and $25 \mathrm{dpm} / \mathrm{cm}^{2}$ respectively. The inventories are significantly lower than expected from atmospheric delivery alone for $\mathrm{Pu}$, and roughly equal to delivery for ${ }^{210} \mathrm{~Pb}^{\mathrm{ex}}$. When corrected for the area of this region, we find that $\sim 17 \%$ of the total measured $\mathrm{Pu}$ and $\sim 6 \%$ of the measured ${ }^{210} \mathrm{~Pb}^{\mathrm{ex}}$ is found within the sediments of this region.

3a. Shelf-fine-grained deposits. A major feature of the continental shelf south of Cape Cod is the Mud Patch $[14,26]$. This is a relatively small region of fine-grained sediment. The sedimentary inventories found here for $\mathrm{Pu}$ range up to $5.6 \mathrm{mCi} / \mathrm{km}^{2}$. and for ${ }^{210} \mathrm{~Pb}^{\text {ex }}$ range up as high as $94 \mathrm{dpm} / \mathrm{cm}^{2}$. 
TABLE 1

Northwest Atlantic continental margin core summary

\begin{tabular}{|c|c|c|c|c|c|c|c|c|c|}
\hline \multirow[t]{2}{*}{ I.D. } & \multirow[t]{2}{*}{$z(\mathrm{~m})$} & \multirow{2}{*}{$\begin{array}{l}\mathrm{Pu} \\
(\mathrm{mCi} / \mathrm{km})\end{array}$} & \multirow{2}{*}{$\begin{array}{l}{ }^{210} \mathrm{~Pb}^{\mathrm{ex}} \\
\left(\mathrm{dpm} / \mathrm{cm}^{2}\right)\end{array}$} & \multirow[t]{2}{*}{ Ref. } & \multirow[t]{2}{*}{ Year } & \multirow[t]{2}{*}{ Type } & \multirow[t]{2}{*}{ Area $^{b}$} & \multicolumn{2}{|c|}{ Location } \\
\hline & & & & & & & & lat.N & long.W \\
\hline \multicolumn{10}{|l|}{ 83-G-9: } \\
\hline AK & 78 & & 80 & [43] & 1983 & BC & $3 a$ & $40^{\circ} 28^{\prime}$ & $70^{\circ} 55^{\prime}$ \\
\hline BK & 1250 & & 91 & & & BC & 4 & $39^{\circ} 48^{\prime}$ & $70^{\circ} 55^{\prime}$ \\
\hline CK & 2700 & & 48 & & & BC & 6 & $39^{\circ} 10^{\prime}$ & $70^{\circ} 44^{\prime}$ \\
\hline LVA & 78 & 5.6 & 76 & & & BC & $3 a$ & $40^{\circ} 28^{\prime}$ & $70^{\circ} 55^{\prime}$ \\
\hline LVC & 2700 & 0.13 & 21 & & & BC & 6 & $39^{\circ} 10^{\prime}$ & $70^{\circ} 44^{\prime}$ \\
\hline \multicolumn{10}{|l|}{ Oc-152: } \\
\hline LVD & 2300 & 0.57 & 48 & [43] & 1984 & BC & 6 & $39^{\circ} 35^{\prime}$ & $70^{\circ} 57^{\prime}$ \\
\hline LVE & 1200 & 1.0 & 72 & & & BC & 5 & $39^{\circ} 48^{\prime}$ & $70^{\circ} 56^{\prime}$ \\
\hline LVF & 500 & 1.2 & so & & & BC & 4 & $39^{\circ} 55^{\prime}$ & $70^{\circ} 54^{\prime}$ \\
\hline \multicolumn{10}{|l|}{ Oc-86: } \\
\hline C & 4525 & 0.12 & & [15] & 1981 & TR & 7 & $36^{\circ} 56^{\prime}$ & $69^{\circ} 13^{\prime}$ \\
\hline D & 3950 & 0.41 & 33 & & & $\mathrm{TR} / \mathrm{W}$ & 6 & $37^{\circ} 39^{\prime}$ & $70^{\circ} 59^{\prime}$ \\
\hline E & 2975 & 0.25 & 29 & & & $\mathrm{TR} / \mathrm{W}$ & 6 & $38^{\circ} 13^{\prime}$ & $71^{\circ} 30^{\prime}$ \\
\hline $\mathbf{F}$ & 2600 & 0.30 & 44 & & & $\mathrm{TR} / \mathrm{W}$ & 6 & $38^{\circ} 51^{\prime}$ & $71^{\circ} 49^{\prime}$ \\
\hline G & 1935 & 0.36 & 36 & & & $\mathrm{TR} / \mathrm{W}$ & 5 & $39^{\circ} 02^{\prime}$ & $72^{\circ} 11^{\prime}$ \\
\hline $\mathbf{H}$ & 1170 & 0.59 & 64 & & & $\mathrm{TR} / \mathrm{W}$ & 5 & $39^{\circ} 05^{\prime}$ & $72^{\circ} 19^{\prime}$ \\
\hline \multicolumn{10}{|l|}{ EN 69: } \\
\hline loc BB & 5350 & 0.12 & 24 & {$[34,44]$} & 1981 & BC & 7 & $33^{\circ} 03^{\prime}$ & $69^{\circ} 54^{\prime}$ \\
\hline HH & 5317 & 0.08 & 17 & & & BC & 7 & $32^{\circ} 39^{\prime}$ & $71^{\circ} 47^{\prime}$ \\
\hline II & 5387 & 0.11 & 22 & & & BC & 7 & $32^{\circ} 31^{\prime}$ & $71^{\circ} 28^{\prime}$ \\
\hline$T$ & 5410 & 0.11 & 18 & & & BC & 7 & $32^{\circ} 57^{\prime}$ & $70^{\circ} 18^{\prime}$ \\
\hline \multicolumn{10}{|l|}{ EN 53: } \\
\hline $\operatorname{loc} \mathrm{H}$ & 5400 & 0.06 & 11 & {$[34,44]$} & 1980 & BC & 7 & $32^{\circ} 55^{\prime}$ & $71^{\circ} 00^{\prime}$ \\
\hline I & 5346 & 0.18 & 29 & & & BC & 7 & $32^{\circ} 45^{\prime}$ & $70^{\circ} 43^{\prime}$ \\
\hline J & 5400 & 0.11 & 21 & & & BC & 7 & $32^{\circ} 43^{\prime}$ & $70^{\circ} 48^{\prime}$ \\
\hline \multicolumn{10}{|l|}{ A-II-86: } \\
\hline 3 & 255 & 0.63 & & [13] & 1975 & $21 \mathrm{~cm}$ & 2 & $42^{\circ} 51^{\prime}$ & $69^{\circ} 51^{\prime}$ \\
\hline 4 & 255 & 0.22 & & & & $21 \mathrm{~cm}$ & 2 & $42^{\circ} 41^{\prime}$ & $69^{\circ} 50^{\prime}$ \\
\hline 6 & 224 & 1.06 & & & & $21 \mathrm{~cm}$ & 2 & $42^{\circ} 25^{\prime}$ & $69^{\circ} 57^{\prime}$ \\
\hline 7 & 247 & 0.60 & & & & $21 \mathrm{~cm}$ & 2 & $42^{\circ} 22^{\prime}$ & $69^{\circ} 16^{\prime}$ \\
\hline \multicolumn{10}{|l|}{ A-II-86: } \\
\hline 1 & 264 & 0.31 & 12.6 & [44] & 1975 & $21 \mathrm{~cm}$ & 2 & $42^{\circ} 47^{\prime}$ & $69^{\circ} 41^{\prime}$ \\
\hline 15 & 1370 & 0.16 & & & & $21 \mathrm{~cm}$ & 5 & $37^{\circ} 53^{\prime}$ & $73^{\circ} 38^{\prime}$ \\
\hline 16 & 2100 & 0.13 est & & & & $21 \mathrm{~cm}$ & 6 & $37^{\circ} 48^{\prime}$ & $73^{\circ} 34^{\prime}$ \\
\hline 2 & 207 & 0.61 & 14.3 & & & $21 \mathrm{~cm}$ & 2 & $43^{\circ} 01^{\prime}$ & $69^{\circ} 57^{\prime}$ \\
\hline 20 & 620 & 1.0 est & & & & $21 \mathrm{~cm}$ & 4 & $36^{\circ} 03^{\prime}$ & $74^{\circ} 45^{\prime}$ \\
\hline 22 & 4230 & 0.08 & & & & $21 \mathrm{~cm}$ & 7 & $35^{\circ} 08^{\prime}$ & $72^{\circ} 51^{\prime}$ \\
\hline 11 . & 227 & 1.76 & & & & $21 \mathrm{~cm}$ & $3 a$ & $39^{\circ} 40^{\prime}$ & $72^{\circ} 28^{\prime}$ \\
\hline \multicolumn{10}{|l|}{ A-II-85: } \\
\hline 5 & 760 & 1.3 & & [13] & 1974 & $21 \mathrm{~cm}$ & 4 & $40^{\circ} 17^{\prime}$ & $68^{\circ} 04^{\prime}$ \\
\hline 6 & 1060 & 0.2 & & & & $21 \mathrm{~cm}$ & 5 & $40^{\circ} 14^{\prime}$ & $68^{\circ} 02^{\prime}$ \\
\hline 8 & 2080 & 0.8 & & & & $21 \mathrm{~cm}$ & 5 & $40^{\circ} 07^{\prime}$ & $68^{\circ} 01^{\prime}$ \\
\hline 4507E & 91 & & 94 & [14 & & VB & $3 a$ & $40^{\circ} 11^{\prime}$ & $69^{\circ} 47^{\prime}$ \\
\hline $4508 \mathrm{~A}$ & 82 & & 63 & & & VB & $3 a$ & $40^{\circ} 22^{\prime}$ & $70^{\circ} 07^{\prime}$ \\
\hline $5421 B$ & 31 & & 0 & & & VB & $3 b$ & $41^{\circ} 33^{\prime}$ & $67^{\circ} 40^{\prime}$ \\
\hline 4527D & 54 & & 58 & & & VB & $3 a$ & $40^{\circ} 51^{\prime}$ & $70^{\circ} 31^{\prime}$ \\
\hline 4712 & 81 & & 74 & & & VB & $3 a$ & $40^{\circ} 30^{\prime}$ & $71^{\circ} 00^{\prime}$ \\
\hline 4714 & 83 & & 51 & & & VB & $3 a$ & $40^{\circ} 21^{\prime}$ & $70^{\circ} 31^{\prime}$ \\
\hline
\end{tabular}


TABLE 1 (continued)

\begin{tabular}{|c|c|c|c|c|c|c|c|c|c|}
\hline \multirow[t]{2}{*}{ I.D. } & \multirow[t]{2}{*}{$z(\mathrm{~m})$} & \multirow{2}{*}{$\begin{array}{l}\mathrm{Pu} \\
(\mathrm{mCi} / \mathrm{km})\end{array}$} & \multirow{2}{*}{$\begin{array}{l}{ }^{210} \mathrm{~Pb}^{\mathrm{ex}} \\
\left(\mathrm{dpm} / \mathrm{cm}^{2}\right)\end{array}$} & \multirow[t]{2}{*}{ Ref. } & \multirow[t]{2}{*}{ Year } & \multirow[t]{2}{*}{ Type" } & \multirow[t]{2}{*}{ Area $^{b}$} & \multicolumn{2}{|l|}{ Location } \\
\hline & & & & & & & & lat.N & long.W \\
\hline \multicolumn{10}{|l|}{$\overline{\text { Oc 81: }}$} \\
\hline 4757 & 67 & & 68 & [45] & & VB & $3 a$ & $40^{\circ} 30^{\prime}$ & $70^{\circ} 19^{\prime}$ \\
\hline 7772 & 630 & & 86 & & & VB & 4 & $40^{\circ} 09^{\prime}$ & $68^{\circ} 20^{\prime}$ \\
\hline $\mathrm{Kn}$ 61:1 & 75 & 3.2 est & & {$[45]$} & & & $3 \mathbf{a}$ & $40^{\circ} 24^{\prime}$ & $70^{\circ} 30^{\prime}$ \\
\hline Buzz, Bay:ERS & 16 & 4.3 & & [46] & 1982 & BC & 1 & $41^{\circ} 32^{\prime}$ & $70^{\circ} 44^{\prime}$ \\
\hline \multicolumn{10}{|l|}{ Buzz. Bay: } \\
\hline 4 & 16 & 1.5 & & [13] & 1964 & $21 \mathrm{~cm}$ & 1 & $41^{\circ} 29^{\prime}$ & $70^{\circ} 52^{\prime}$ \\
\hline 5 & 16 & 1.5 & & & 1964 & $21 \mathrm{~cm}$ & 1 & $41^{\circ} 29^{\prime}$ & $70^{\circ} 52^{\prime}$ \\
\hline 8 & 12 & 2.5 & & & 1970 & $21 \mathrm{~cm}$ & 1 & $41^{\circ} 34^{\prime}$ & $70^{\circ} 43^{\prime}$ \\
\hline 11 & 16 & 2.4 & & & 1972 & $21 \mathrm{~cm}$ & 1 & $41^{\circ} 29^{\prime}$ & $70^{\circ} 52^{\prime}$ \\
\hline 12 & 16 & 1.2 & & & 1973 & $21 \mathrm{~cm}$ & 1 & $41^{\circ} 32^{\prime}$ & $70^{\circ} 44^{\prime}$ \\
\hline 13 & 16 & 2.0 & & & 1973 & $21 \mathrm{~cm}$ & 1 & $41^{\circ} 28^{\prime}$ & $70^{\circ} 52^{\prime}$ \\
\hline 15 & 17 & 1.6 & & & 1973 & $21 \mathrm{~cm}$ & 1 & $41^{\circ} 28^{\prime}$ & $70^{\circ} 51^{\prime}$ \\
\hline 16 & 16 & 1.1 & & & 1973 & $21 \mathrm{~cm}$ & 1 & $41^{\circ} 28^{\prime}$ & $70^{\circ} 52^{\prime}$ \\
\hline 17 & 16 & 2.4 & & & 1973 & $21 \mathrm{~cm}$ & 1 & $41^{\circ} 28^{\prime}$ & $70^{\circ} 52^{\prime}$ \\
\hline 20 & 16 & 1.6 & & & 1974 & $21 \mathrm{~cm}$ & 1 & $41^{\circ} 28^{\prime}$ & $70^{\circ} 52^{\prime}$ \\
\hline \multicolumn{10}{|l|}{ Gayhead: } \\
\hline 20 & 32 & 2.9 & & & 1974 & $21 \mathrm{~cm}$ & 1 & $41^{\circ} 18^{\prime}$ & $70^{\circ} 52^{\prime}$ \\
\hline 23 & 32 & 4.5 & & & 1975 & $21 \mathrm{~cm}$ & 1 & $41^{\circ} 18^{\prime}$ & $70^{\circ} 52^{\prime}$ \\
\hline \multicolumn{10}{|l|}{ KN 69: } \\
\hline T-2 & 265 & 0.45 & & {$[44]$} & 1977 & TR & 2 & $42^{\circ} 31^{\prime}$ & $69^{\circ} 27^{\prime}$ \\
\hline $\mathrm{T}-3$ & 240 & 0.83 & & & & TR & 2 & $42^{\circ} 22^{\prime}$ & $69^{\circ} 16^{\prime}$ \\
\hline BC6 & 240 & & 10.2 & & & BC & 2 & $42^{\circ} 22^{\prime}$ & $69^{\circ} 16^{\prime}$ \\
\hline$T-4$ & 272 & 2.06 & & & & TR & 2 & $43^{\circ} 21^{\prime}$ & $67^{\circ} 45^{\prime}$ \\
\hline BC7 & 272 & 1.42 & 9.7 & & & BC & 2 & $43^{\circ} 21^{\prime}$ & $67^{\circ} 45^{\prime}$ \\
\hline T-5 & 225 & 0.79 & & & & TR & 2 & $42^{\circ} 04^{\prime}$ & $68^{\circ} 10^{\prime}$ \\
\hline BC9 & 225 & 0.86 & 12.3 & & & BC & 2 & $42^{\circ} 04^{\prime}$ & $68^{\circ} 10^{\prime}$ \\
\hline$T-6$ & 365 & 1.02 & & & & TR & 2 & $42^{\circ} 25^{\prime}$ & $67^{\circ} 09^{\prime}$ \\
\hline T-8 & 4160 & 0.18 & & & & TR & 7 & $40^{\circ} 50^{\prime}$ & $64^{\circ} 11^{\prime}$ \\
\hline BC11 & 4160 & 0.19 & & & & BC & 7 & $40^{\circ} 50^{\prime}$ & $64^{\circ} 11^{\prime}$ \\
\hline T-9 & 3205 & 0.13 & & & & TR & 6 & $41^{\circ} 30^{\prime}$ & $64^{\circ} 30^{\prime}$ \\
\hline BC12 & 3205 & 0.31 & & & & BC & 6 & $41^{\circ} 30^{\prime}$ & $64^{\circ} 30^{\prime}$ \\
\hline T-27 & 2520 & 0.16 & & & & TR & 6 & $41^{\circ} 44^{\prime}$ & $64^{\circ} 07^{\prime}$ \\
\hline $\mathrm{T}-11$ & 890 & 0.61 & & & & TR & 4 & $42^{\circ} 40^{\prime}$ & $64^{\circ} 01^{\prime}$ \\
\hline BC13 & 890 & 0.82 & & & & BC & 4 & $42^{\circ} 40^{\prime}$ & $64^{\circ} 01^{\prime}$ \\
\hline T-12 & 240 & 0.81 & & & & TR & 2 & $43^{\circ} 42^{\prime}$ & $63^{\circ} 45^{\prime}$ \\
\hline T-13 & 190 & 1.38 & & & & TR & 2 & $44^{\circ} 12^{\prime}$ & $64^{\circ} 00^{\prime}$ \\
\hline$T-15$ & 210 & 0.63 & & & & TR & 2 & $43^{\circ} 43^{\prime}$ & $62^{\circ} 48^{\prime}$ \\
\hline$T-16$ & 3302 & 0.17 & & & & TR & 6 & $42^{\circ} 13^{\prime}$ & $60^{\circ} 58^{\prime}$ \\
\hline SBC-1 & 69 & 4.2 & 58 & [5] & 1978 & $21 \mathrm{~cm}$ & $3 a$ & $40^{\circ} 38^{\prime}$ & $71^{\circ} 00^{\prime}$ \\
\hline-5 & 87 & 3.9 & 76 & & & $21 \mathrm{~cm}$ & $3 a$ & $40^{\circ} 28^{\prime}$ & $70^{\circ} 58^{\prime}$ \\
\hline-2 & 850 & 0.41 & 75 & & & $21 \mathrm{~cm}$ & 4 & $39^{\circ} 50^{\prime}$ & $71^{\circ} 05^{\prime}$ \\
\hline HBC-3 & 1800 & 0.23 & 80 & & & $21 \mathrm{~cm}$ & 5 & $39^{\circ} 44^{\prime}$ & $71^{\circ} 02^{\prime}$ \\
\hline Nar-6 & 10 & 2.7 & 21 & & & & 1 & & \\
\hline Nar-7 & 10 & 1.8 & 15 & & & & 1 & & \\
\hline B5 & 192 & & 20 & {$[25]$} & 1980 & BC & 2 & $43^{\circ} 15^{\prime}$ & $68^{\circ} 40^{\prime}$ \\
\hline B6 & 184 & & 34 & & & BC & 2 & $42^{\circ} 50^{\prime}$ & $69^{\circ} 00^{\prime}$ \\
\hline B7 & 289 & & 34 & & & BC & 2 & $42^{\circ} 20^{\prime}$ & $69^{\circ} 20^{\prime}$ \\
\hline B9 & 250 & & 46 & & & BC & 2 & $43^{\circ} 30^{\prime}$ & $67^{\circ} 45^{\prime}$ \\
\hline B10 & 259 & & 60 & & & BC & 2 & $42^{\circ} 55^{\prime}$ & $67^{\circ} 25^{\prime}$ \\
\hline
\end{tabular}


TABLE 1 (continued)

\begin{tabular}{|c|c|c|c|c|c|c|c|c|c|}
\hline \multirow[t]{2}{*}{ I.D. } & \multirow[t]{2}{*}{$z(\mathrm{~m})$} & \multirow{2}{*}{$\begin{array}{l}\mathrm{Pu} \\
(\mathrm{mCi} / \mathrm{km})\end{array}$} & \multirow{2}{*}{$\begin{array}{l}{ }^{210} \mathrm{~Pb}^{\mathrm{ex}} \\
\left(\mathrm{dpm} / \mathrm{cm}^{2}\right)\end{array}$} & \multirow[t]{2}{*}{ Ref. } & \multirow[t]{2}{*}{ Year } & \multirow[t]{2}{*}{ Type " } & \multirow[t]{2}{*}{ Area $^{\mathrm{h}}$} & \multicolumn{2}{|c|}{ Location } \\
\hline & & & & & & & & lat. $\mathrm{N}$ & long.W \\
\hline Q8 & 65 & & 0 & & & S & $3 b$ & $42^{\circ} 35^{\prime}$ & $66^{\circ} 05^{\prime}$ \\
\hline Q19 & 98 & & 0 & & & $\mathbf{S}$ & $3 b$ & $41^{\circ} 10^{\prime}$ & $69^{\circ} 05^{\prime}$ \\
\hline E79 & 51 & & 0 & & & $\mathbf{S}$ & $3 b$ & $41^{\circ} 50^{\prime}$ & $67^{\circ} 20^{\prime}$ \\
\hline DEEP & 34 & & 78 & [47] & 1975 & BC & 1 & $41^{\circ} 03^{\prime}$ & $72^{\circ} 35^{\prime}$ \\
\hline TTM1 & & & 63 & & & & 1 & & \\
\hline TTM2 & & & 46 & & & & 1 & & \\
\hline FOAM & 8 & & 45 & & & BC & 1 & $42^{\circ} 15^{\prime}$ & $72^{\circ} 45^{\prime}$ \\
\hline NWC & 15 & & 9 & & , & BC & 1 & $41^{\circ} 10^{\prime}$ & $72^{\circ} 56^{\prime}$ \\
\hline BX6 & 36 & 13.5 & 90 & [10] & 1975 & BC & $3 a$ & $40^{\circ} 24^{\prime}$ & $73^{\circ} 47^{\prime}$ \\
\hline BX8 & 48 & & 140 & & & BC & $3 a$ & $40^{\circ} 20^{\prime}$ & $73^{\circ} 47^{\prime}$ \\
\hline BX9 & 38 & 16.7 & 127 & & & BC & $3 a$ & $40^{\circ} 20^{\prime}$ & $73^{\circ} 49^{\prime}$ \\
\hline BX10 & 62 & 25.2 & 114 & & & BC & $3 a$ & $40^{\circ} 13^{\prime}$ & $73^{\circ} 45^{\prime}$ \\
\hline BX30 & 86 & & 88 & & & BC & $3 a$ & $40^{\circ} 03^{\prime}$ & $73^{\circ} 27^{\prime}$ \\
\hline BX18 & 20 & & 53 & & & BC & $3 a$ & $40^{\circ} 33^{\prime}$ & $73^{\circ} 25^{\prime}$ \\
\hline
\end{tabular}

- Type (type of sampling device): $\mathrm{BC}=$ box core, $21 \mathrm{~cm}=21 \mathrm{~cm}$ dia. sphincter corer, $\mathrm{TR}=$ tripod mounted $21 \mathrm{~cm}$ corer, $\mathrm{W}=6.5 \mathrm{~cm}$ dia. core from WHIMP sampler, VB = vibracorer, $\mathrm{S}=$ surface grab.

b $1=$ shallow, coastal bays and inlets. $2=$ Gulf of Maine/Nova Scotian basins, $3 \mathrm{a}=$ shelf - Mud Patch, $3 \mathrm{~b}=$ shelf - sandy, $4=200-1000 \mathrm{~m}, 5=1000-2000 \mathrm{~m}, 6=2000-4000 \mathrm{~m}, 7=4000-6000 \mathrm{~m}$.

There are also fine-grained shelf deposits in the NASS region near major river mouths, such as in the inner New York Bight area. Benninger and Krishnaswami [10] report significantly elevated $\mathrm{Pu}$ and ${ }^{210} \mathrm{~Pb}^{\text {ex }}$ inventories relative to atmospheric delivery in this region (4-9 times higher than expected). Even though the inventories found by Benninger and Krishnaswami are somewhat higher than found at the Mud Patch, especially for Pu, these two areas of shallow and muddy shelf sediments are combined into one region for the purposes of discussion within this paper. The boundary of the Mud Patch region is taken from sediment texture studies [27] and its area $\left(1.1 \times 10^{4}\right.$ $\mathrm{km}^{2}$ ) is enlarged to include a rough estimate of the area of other shelf sites with high $\mathrm{Pu}$ and ${ }^{210} \mathrm{~Pb}$ sediment inventories (such as the inner New York Bight). We find $\sim 27 \%$ of the sedimentary $\mathrm{Pu}$ and $-3 \%$ of the ${ }^{210} \mathrm{~Pb}^{\mathrm{ex}}$ of the entire NASS region stored in these shelf sediments.

3b. Shelf-sandy deposits. The largest area of the continental shelf is covered with highly sandy deposits which do not accumulate significant $\mathrm{Pu}$ or ${ }^{210} \mathrm{~Pb}$. Since this region covers $20 \%$ of the total NASS area, it becomes a major factor in determining the total budget of these radionuclides. Sediment texture surveys of this area are extensive [27] and have been used to define this region's boundaries. The number of published $\mathrm{Pu}$ and ${ }^{210} \mathrm{~Pb}^{\mathrm{ex}}$ inventory analyses in this region is small though, generally due to zero sediment inventories and difficulties in coring. Despite the limited number of analyses in this region, one can show that even if this area contained on average a few percent of the expected $\mathrm{Pu}$ and ${ }^{210} \mathrm{~Pb}$ inventories, the budgets to be discussed subsequently would not be significantly altered. The atmospherically delivered input of $\mathrm{Pu}$ and ${ }^{210} \mathrm{~Pb}$ over this region must be exported laterally to other sites of net accumulation.

4. 200-1000 $\mathrm{m}$ region. This region is confined to a narrow band at the shelf-slope break between 200 and $1000 \mathrm{~m}$ water depth. At the shelf-slope break, the gradient of the off-shore slope changes from less than $1^{\circ}$ on the shelf to roughly $2-6^{\circ}[28]$. The sediments in this region are silty and clayey muds [27]. The sediment $\mathrm{Pu}$ inventory averages 0.9 $\mathrm{mCi} / \mathrm{km}^{2}$, which is less than expected from fallout alone, and less than the Mud Patch region on the shallower shelf. In contrast, sedimentary ${ }^{210} \mathrm{~Pb}^{\text {ex }}$ inventories remain high $\left(76 \mathrm{dpm} / \mathrm{cm}^{2}\right)$, and are similar to those of the Mud Patch. These sediments contain $\sim 6 \%$ of the sedimentary $\mathrm{Pu}$ and also $\sim 6 \%$ of the sedimentary ${ }^{210} \mathrm{~Pb}^{\text {ex }}$ measured in the entire NASS region. 
TABLE 2A

Total Pu sediment inventories for the North Atlantic shelf and slope region

\begin{tabular}{|c|c|c|c|c|c|c|c|}
\hline Regions * & Description & $\begin{array}{l}\mathrm{km}^{2} \\
\times 10^{4}\end{array}$ & $\begin{array}{l}\text { Measured } \mathrm{Pu}^{\mathrm{b}} \\
\mathrm{mCi} / \mathrm{km}^{2} \pm \text { s.d. }\end{array}$ & $n^{\mathrm{c}}$ & $\begin{array}{l}\text { Ci Pu } \\
\text { measured }\end{array}$ & $\begin{array}{l}\mathrm{Ci} \mathrm{Pu} \\
\text { expected }\end{array}$ & $\frac{\text { Pu measured }}{\text { Pu expected }}$ \\
\hline 1 & $\begin{array}{l}\text { Coastal bays } \\
\text { and inlets }\end{array}$ & 1.4 & $2.3 \pm 1.0$ & 15 & $32 \pm 14$ & 28 & $115 \%$ \\
\hline 2 & Gulf of Maine/Nova Scotian basins & 7.0 & $0.9 \pm 0.5$ & 16 & $63 \pm 35$ & 140 & $45 \%$ \\
\hline $3 \mathbf{a}$ & $\begin{array}{l}\text { Shelf-fine- } \\
\text { grained deposits }\end{array}$ & 1.1 & $9.3 \pm 8.4$ & 7 & $102 \pm 92$ & 22 & $460 \%$ \\
\hline $3 \mathbf{b}$ & $\begin{array}{l}\text { Shelf-sandy } \\
\text { deposits }\end{array}$ & 26 & Ø & & $\varnothing$ & 520 & $0 \%$ \\
\hline 4 & $200-1000 \mathrm{~m}$ & 2.4 & $0.9 \pm 0.3$ & 6 & $22 \pm 7$ & 48 & $45 \%$ \\
\hline 5 & $1000-2000 \mathrm{~m}$ & 4.3 & $0.5 \pm 0.3$ & 7 & $22 \pm 13$ & 86 & $25 \%$ \\
\hline 6 & $2000-4000 \mathrm{~m}$ & 23 & $0.3 \pm 0.1$ & 9 & $69 \pm 23$ & 460 & $15 \%$ \\
\hline 7 & $4000-6000 \mathrm{~m}$ & 65 & $0.1 \pm 0.04$ & 11 & $65 \pm 26$ & 1300 & $5 \%$ \\
\hline
\end{tabular}

Regions 1-7: NASS total Ci Pu measured $=375+106$

NASS total $\mathrm{Ci}$ Pu expected $=2604$

Total measured $\mathrm{Pu} /$ total expected $\mathrm{Pu}=14 \pm 4 \%$

Regions I-6: Ci Pu measured $=310 \pm 103$

Ci Pu expected $=1304$

Measured $\mathrm{Pu} /$ expected $\mathrm{Pu}=24 \pm 8 \%$

TABLE 2B

Total ${ }^{210} \mathrm{~Pb}^{\mathrm{cx}}$ sediment inventories for the North Atlantic shelf and slope region

\begin{tabular}{|c|c|c|c|c|c|c|c|}
\hline$\overline{\text { Regions }}^{\text {a }}$ & Description & $\begin{array}{l}\text { Measured }{ }^{210} \mathrm{~Pb}^{\mathrm{ex} \mathrm{b}} \\
\mathrm{dpm} / \mathrm{cm}^{2} \pm \mathrm{s} . \mathrm{d}\end{array}$ & $n^{\mathrm{c}}$ & $\begin{array}{l}\mathrm{dpm}{ }^{210} \mathrm{~Pb}^{\mathrm{ex}} \\
\text { measured } \\
\times 10^{15}\end{array}$ & $\begin{array}{l}\text { dpm }{ }^{210} \mathrm{~Pb}^{\mathrm{ex}} \\
\text { atmos. }^{\prime} \\
\times 10^{15}\end{array}$ & $\begin{array}{l}\mathrm{dpm}{ }^{210} \mathrm{~Pb}^{\mathrm{ex} 8} \\
\text { in-situ prod. } \\
\times 10^{15}\end{array}$ & $\frac{{ }^{210} \mathrm{~Pb}^{\mathrm{ex}} \text { measured }}{{ }^{210} \mathrm{~Pb}^{\mathrm{ex}} \text { atmos. + in-situ }}$ \\
\hline 1 & $\begin{array}{l}\text { Coastal Bays } \\
\text { and inlets }\end{array}$ & $40 \pm 26$ & 7 & $5.6 \pm 3.6$ & 3.5 & - & $160 \%$ \\
\hline 2 & $\begin{array}{l}\text { Gulf of Maine/ } \\
\text { Nova Scotian basins }\end{array}$ & $25 \pm 18$ & 10 & $18 \pm 13$ & 18 & 0.2 & $100 \%$ \\
\hline $3 a$ & $\begin{array}{l}\text { Shelf-fine- } \\
\text { grained deposits }\end{array}$ & $82 \pm 26$ & 16 & $9.0 \pm 2.9$ & 2.8 & 0.03 & $320 \%$ \\
\hline $3 b$ & $\begin{array}{l}\text { Shelf-sandy } \\
\text { deposits }\end{array}$ & $\varnothing$ & 4 & $\varnothing$ & 65 & 0.8 & $0 \%$ \\
\hline 4 & $200-1000 \mathrm{~m}$ & $76 \pm 18$ & 4 & $18 \pm 4$ & 6.0 & 0.6 & $275 \%$ \\
\hline 5 & $1000-2000 \mathrm{~m}$ & $63 \pm 19$ & 4 & $27 \pm 8$ & 11 & 2.6 & $200 \%$ \\
\hline 6 & $2000-4000 \mathrm{~m}$ & $37 \pm 11$ & 6 & $85 \pm 25$ & 58 & 28 & $100 \%$ \\
\hline 7 & $4000-6000 \mathrm{~m}$ & $20 \pm 6$ & 5 & $130 \pm 40$ & 160 & 130 & $45 \%$ \\
\hline
\end{tabular}

Regions 1-7: NASS total $\mathrm{dpm}^{210} \mathrm{~Pb}^{\mathrm{ex}}$ measured $\times 10^{15}=292 \pm 50$

NASS total dpm ${ }^{210} \mathrm{~Pb}^{\text {ex }}$ expected (atmos. + in situ) $\times 10^{15}=486$

Total measured ${ }^{210} \mathrm{~Pb}^{\text {ex }} /$ total expected ${ }^{210} \mathrm{~Pb}^{\text {ex }}=60 \pm 10 \%$

Regions 1-6: $\mathrm{dpm}{ }^{210} \mathrm{~Pb}^{\text {ex }}$ measured $\times 10^{15}=162 \pm 30$

dpm ${ }^{210} \mathrm{~Pb}^{\text {ex }}$ expected $\times 10^{15}=196$

Measured ${ }^{210} \mathrm{~Pb}^{\text {ex }} /$ expected ${ }^{210} \mathrm{~Pb}^{e x}=83 \pm 15 \%$

a See Fig. 1 for NASS area and regions.

b Reported as mean \pm sample standard deviation.

c Number of cores used to calculate inventories.

d Measured inventory $\times$ area.

- Based upon $2.0 \mathrm{mCi} / \mathrm{km}^{2} \times$ area

I Based upon $25 \mathrm{dpm} / \mathrm{cm}^{2} \times$ area

${ }_{8}$ Calculated from ${ }^{226} \mathrm{Ra}\left(\mathrm{dpm} / \mathrm{cm}^{3}\right) \times z(\mathrm{~cm})={ }^{210} \mathrm{~Pb}\left(\mathrm{dpm} / \mathrm{cm}^{3}\right) \times z(\mathrm{~cm})-{ }^{210} \mathrm{~Pb}$ removal $\left(\mathrm{dpm} / \mathrm{cm}^{2}\right)$ using ${ }^{226} \mathrm{Ra}=10 \mathrm{dpm} / 10^{5}$ $\mathrm{cm}^{3}$ (from GEOSECS Atlantic data average), ${ }^{210} \mathrm{~Pb}=6 \mathrm{dpm} / 10^{5} \mathrm{~cm}^{3}$ (from Bacon [39]) and adjusted for the average depth and area of each region. 
5. 1000-2000 $m$ region. In this region, Pu inventories decrease further to approximately 0.5 $\mathrm{mCi} / \mathrm{km}^{2}$, while ${ }^{210} \mathrm{~Pb}^{\mathrm{ex}}$ drops only slightly to 63 $\mathrm{dpm} / \mathrm{cm}^{2}$. This region covers only a narrow band of area within the NASS since the slope is still rather steep in this region. The measured sediment inventories when corrected for this area account for $\sim 6 \%$ of the total Pu and almost $10 \%$ of the total ${ }^{210} \mathrm{~Pb}^{\mathrm{ex}}$ stored in the NASS region sediments.

6. 2000-4000 $\mathrm{m}$ region. The gradient in the slope becomes less steep in this region. Pu inventories in this relatively wide band of sediments are very low, approximately $0.3 \mathrm{mCi} / \mathrm{km}^{2} .{ }^{210} \mathrm{~Pb}^{\mathrm{ex}}$ inventories drop off to values a bit higher than that expected from atmospheric delivery and vertical deposition alone $\left(37 \pm 11 \mathrm{dpm} / \mathrm{cm}^{2}\right)$. Since this area is large, we find that $\sim 18 \%$ of the total $\mathrm{Pu}$ and $\sim 30 \%$ of the total ${ }^{210} \mathrm{~Pb}^{\text {ex }}$ measured in the NASS area sediments are stored in this region.

7. 4000-6000 $\mathrm{m}$ region. This region includes deep sea cores on the continental rise and abyssal plain where $\mathrm{Pu}$ inventories are extremely low (0.1 $\mathrm{mCi} / \mathrm{km}^{2}$ ), and where ${ }^{210} \mathrm{~Pb}^{\mathrm{ex}}$ inventories (mean $=20 \mathrm{dpm} / \mathrm{cm}^{2}$ ) fall just below the assumed atmospheric delivery of ${ }^{210} \mathrm{~Pb}$. In this large area, we find $\sim 20 \%$ of the total Pu and $\sim 43 \%$ of the total ${ }^{210} \mathrm{~Pb}^{\text {ex }}$ in the sediments of the entire NASS region.

\section{Discussion}

\subsection{Sediment inventory vs. water depth}

When sediment inventories of $\mathrm{Pu}$ and ${ }^{210} \mathrm{~Pb}^{\mathrm{ex}}$ are plotted vs. water depth (Fig. 2), some basic features become apparent. Ignoring the sandy shelf and the Gulf of Maine sediments, the major trend is decreasing inventories of both $\mathrm{Pu}$ and ${ }^{210} \mathrm{~Pb}$ with increasing water depth. $\mathrm{Pu}$ and ${ }^{210} \mathrm{~Pb}$, however, show very different depth-dependent distributions. Pu inventories are high relative to fallout only in shallow, muddy sediments such as at the Mud Patch. Pu inventories drop off quickly to less than half the fallout value at depths of only a few hundred meters. A more gradual decrease in the sedimentary Pu inventory is seen between 500 and $6000 \mathrm{~m}$. In contrast to $\mathrm{Pu},{ }^{210} \mathrm{~Pb}^{\mathrm{ex}}$ inventories remain high in all cores from water depths of less than $2000 \mathrm{~m}$. At depths greater than $2000 \mathrm{~m},{ }^{210} \mathrm{~Pb}$ inventories drop slowly, reaching atmospheric values at $3000-4000 \mathrm{~m}$, and values less than fallout only at greater depths.

In general, the trends in Fig. 2 appear to be reflecting a decrease in the net scavenging of both $\mathrm{Pu}$ and ${ }^{210} \mathrm{~Pb}^{\mathrm{ex}}$ with increasing water depth. Also, the differences between the $\mathrm{Pu}$ and ${ }^{210} \mathrm{~Pb}^{\text {ex }}$ depthdependent inventory patterns in Fig. 2 suggests that ${ }^{210} \mathrm{~Pb}$ is more efficiently removed from the water column than $\mathrm{Pu}$ at water depths greater than $200 \mathrm{~m}$. The differences between the $\mathrm{Pu}$ and ${ }^{210} \mathrm{~Pb}$ inventory patterns, however, are complicated by Pu's recent introduction into the marine environment. While the naturally occurring radionuclide ${ }^{210} \mathrm{~Pb}$ may be considered to be in steady-state with respect to its delivery and removal over the time scale of its mean life ( 32 years), this is certainly not the case for Pu. The data plotted in Fig. 2 for $\mathrm{Pu}$ represent inventories that will tend to increase with time, if present-day removal of Pu continues, and its release from sediments remains negligible. It is clear, however, that the regions of strongest $\mathrm{Pu}$ and ${ }^{210} \mathrm{~Pb}$ accumulation are the coastal bays, the Mud Patch, and the upper slope (200-2000 m). Mechanism(s) of $\mathrm{Pu}$ and ${ }^{210} \mathrm{~Pb}$ removal must exist which result in the observed patterns of enhanced removal over shallow vs. deep ocean sediments.

In shallow regions, the resuspension of finegrained material can act to enhance the scavenging of particle reactive elements. This resuspension effect can be controlled by either biological or physical processes. Biological sediment mixing processes have been proposed to modulate the removal of a number of elements, including $\mathrm{Pu}$ and ${ }^{210} \mathrm{~Pb}$, in coastal environments $[5,8]$. Benthic faunal mixing can cause an increase in the erodibility of surface sediments [29]. Also, benthic macrofauna can directly inject particles into the overlying water during feeding and defecation $[29,30]$. In the Mud Patch region, the physical action of water storms has been shown to produce suspended sediment concentrations of $5-10 \mathrm{mg} / \mathrm{l}$ [26].

Both biological and physical resuspension processes are most effective in regions of easily erodible fine-grained sediments. In addition, finegrained sediments have a relatively larger surface area on a volume basis and should, therefore, be more reactive than coarser-grained sands $[30,31]$. 


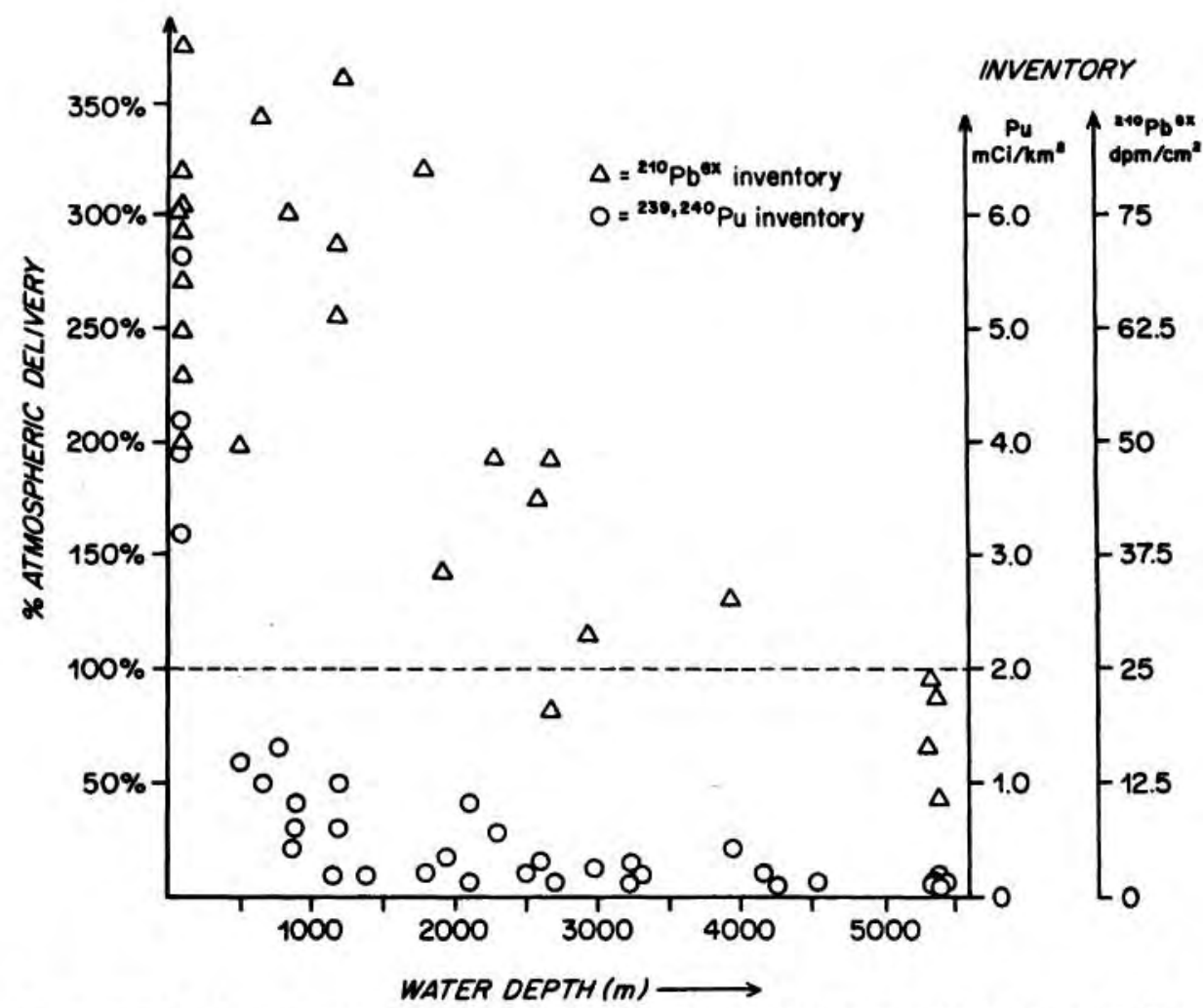

Fig. 2. Plot of the measured sediment inventory vs. water depth for the muddy shelf, slope and deep cores (regions 3a, 4-7). Triangles represent ${ }^{210} \mathrm{~Pb}^{\mathrm{ex}}$ inventory data while circles represent $\mathrm{Pu}$ data. Both ${ }^{210} \mathrm{~Pb}^{\mathrm{ex}}$ and $\mathrm{Pu}$ inventories are normalized to the expected atmospheric on the left axis. The actual corresponding inventories are given on the right axis in $\mathrm{mCi} / \mathrm{km}^{2}$ for Pu, and in dpm/ $\mathrm{cm}^{2}$ for ${ }^{210} \mathrm{~Pb}^{e x}$. (Data from the New York Bight [10] has been excluded, and would lie in the range of $400-900 \%$ of atmospheric delivery.)

Several investigators have reported that radionuclides are more concentrated in fine-grained sediments compared with coarse grained sands $[4,18,32]$. Indeed the sandy shelf sediments do store little or no $\mathrm{Pu}$ and ${ }^{210} \mathrm{~Pb}$, while the silty Mud Patch has higher inventories. When the data are examined closely, however, a simple correlation between inventories and grain size is not seen, even within a given depth range and locality. This can be seen, for example, in the data of Bothner et al. [14] for ${ }^{210} \mathrm{~Pb}$ in a suite of cores from the Mud Patch area. In this study, ${ }^{210} \mathrm{~Pb}^{\mathrm{ex}}$ inventories ranged from 51 to $94 \mathrm{dpm} / \mathrm{cm}^{2}$, while the fine-grained silt fraction constituted a range of $20-80 \%$ of the total sample, unrelated to the inventory data. Brower [25] also found no correlation between sediment surface area and ${ }^{210} \mathrm{~Pb}$ inventories for a large number of Gulf of Maine cores.

Bacon et al. [16] have suggested that the re- moval of ${ }^{210} \mathrm{~Pb}$ may be enhanced near the sediment-water interface by the oxidative precipitation of $\mathrm{Mn}$ and $\mathrm{Fe}$ oxides. At present it is not possible to distinguish this process from the effects of benthic mixing and resuspension, discussed earlier. Both of these mechanisms are most intense in shallow muddy sediments, decreasing with depth, and have little effect when deep waters are reached.

In deeper waters there will be a decrease in the effectiveness of boundary scavenging processes. Biological removal and transport of $\mathrm{Pu}$ as ${ }^{210} \mathrm{~Pb}$ via fecal pellet production is likely to become increasingly important in the open ocean. Collections of rapidly sinking large biogenic particles have recently been used to measure the fluxes of $\mathrm{Pu}$ and ${ }^{210} \mathrm{~Pb}$ at a site near Bermuda $\left(32^{\circ} \mathrm{N}, 64^{\circ} \mathrm{W}\right)$ at a water depth of $4000 \mathrm{~m}$ [33]. These fluxes were obtained from 3 years of samples collected bi- 
monthly from a single trap at $3200 \mathrm{~m}$. This study reports a Pu flux of $2.5 \times 10^{-3} \mathrm{mCi} / \mathrm{km}^{2} \mathrm{yr}$. If this is representative of the annual $\mathrm{Pu}$ flux to the sediments since its introduction (approximately 20 years), then it can account for roughly one-half of the average $\mathrm{Pu}$ inventory $\left(0.11 \mathrm{mCi} / \mathrm{km}^{2}\right)$ found in 7 cores west of Bermuda (in Table 1 EN 53 and EN 69 cores). At this same site, an additional 0.35 $\mathrm{mCi} / \mathrm{km}^{2}$ of $\mathrm{Pu}$ is present in the deep water column (> $3200 \mathrm{~m}$ [34]) which must have similarly been supplied by rapidly sinking particles. The present-day trap flux, if constant over the last 20 years, can therefore be shown to account for only $11 \%$ of the combined sediment and deep-sea Pu inventory. This evidence can be used to argue for substantially elevated Pu fluxes in the past, most likely following the years of the highest weapons testing inputs (the late 1950's/early 1960's [3]).

Bacon et al. [33] also measured ${ }^{210} \mathrm{~Pb}$ sediment trap fluxes of $0.5 \mathrm{dpm} / \mathrm{cm}^{2} \mathrm{yr}$ at the same Bermuda site. They calculated that the measured trap flux could only account for roughly $30 \%$ of the total expected ${ }^{210} \mathrm{~Pb}$ flux, based upon atmospheric inputs and in-situ production calculations. When based upon sediment ${ }^{210} \mathrm{~Pb}^{\text {ex }}$ inventory data however, the observed flux appears able to account to approximately $80 \%$ of the sediment inventory (flux $X$ mean life $=16 \mathrm{dpm} / \mathrm{cm}^{2}$; mean inventory of ${ }^{210} \mathrm{~Pb}^{\mathrm{ex}}=20 \mathrm{dpm} / \mathrm{cm}^{2}$ at the EN 53 and EN 69 sites). It appears that the relatively low deep-sea ${ }^{210} \mathrm{~Pb}^{\text {ex }}$ inventories can be approximately balanced by the trap collected flux of ${ }^{210} \mathrm{~Pb}$, while both the fluxes and inventories remain lower than one would predict based upon input calculations. These calculations are tenuous, though, since a large number of assumptions must be made concerning trap and inventory measurements, and the actual long-term depositional flux and the inventories at any given site.

Rowe and Gardner [35] deployed 4 sediment traps during one summer in water depths of $2000-3500 \mathrm{~m}$ in the NASS slope region. They reported total trap fluxes by weight and found roughly an order of magnitude larger fluxes than at the Bermuda site of Bacon et al. [33]. This difference may reflect an increase in the productivity (and hence fecal pellet formation) between slope waters and open ocean sites. This comparison is limited, however, by such factors as the physical differences in the traps deployed, the deployment durations and the depth of deployment above the seafloor.

\subsection{Total storage of $P u$ and ${ }^{210} P b^{e x}$ in the NASS sediments}

The total sedimentary inventories of $\mathrm{Pu}$ and ${ }^{210} \mathrm{~Pb}^{\mathrm{ex}}$ have been calculated for each region of the NASS region in Table 2 . The average inventory within a given region has been multiplied by its area. These total inventories for each region have been summed, and then compared to the expected inventory, assuming atmospheric supply, in situ ${ }^{210} \mathrm{~Pb}$ production, and vertical deposition only (see Table 2). These calculations use all of the data in Table 1, and the reported errors are based upon the sample standard deviation about the mean of the measured inventory data. We feel that the conclusions reached in the following discussion would hold even if the associated errors are in fact somewhat larger than this estimate.

A main feature of the Pu inventory data from the NASS region in toto, is an apparent deficiency in the sediments of Pu ( $24 \pm 8 \%$ of that delivered). This sedimentary inventory deficiency is not too surprising for $\mathrm{Pu}$, since a considerable fraction of $\mathrm{Pu}$ is still found in the watercolumn itself. This is seen in the Central North Pacific [36], where less than 3\% of the total water and sediment Pu inventory is in the sediments. Data for the deep Atlantic [34], provides a similar conclusion, with $95 \%$ of the inventory still remaining in the water column. In effect, $\mathrm{Pu}$ is remaining for longer periods of time in the water column than was originally expected [37]. A removal time of 840 years for $\mathrm{Pu}$ in the ocean can be estimated given the total $\mathrm{Pu}$ water column inventory of $2.1 \mathrm{mCi} / \mathrm{km}^{2}$ at the EN 53 site and assuming a constant flux of $2.5 \times 10^{-3}$ $\mathrm{nCi} / \mathrm{km}^{2} \mathrm{yr}$ as seen at the Bermuda site [33]. This is within a factor of two of the 400-year residence time one can calculate from the Pacific Pu trap and inventory data of Livingston and Anderson [38].

The NASS total ${ }^{210} \mathrm{~Pb}$ inventory calculations indicate that this region is accumulating $60 \pm 10 \%$ of the ${ }^{210} \mathrm{~Pb}$ which enters this area via atmospheric delivery of is produced by in-situ decay of ${ }^{226} \mathrm{Ra}$ in the water column (see Table 2). It should be noted, however, that the in-situ production calculation for ${ }^{210} \mathrm{~Pb}$ is strongly a function of the water depth 
and the area of the deep NASS region. $80 \%$ of the expected in-situ production of ${ }^{210} \mathrm{~Pb}$ would be expected to occur in region 7 (depths greater than $4000 \mathrm{~m}$ ) given the NASS boundaries in Fig. 1. When we look at the shelf and slope region less than $4000 \mathrm{~m}$, we find a closer balance between ${ }^{210} \mathrm{~Pb}$ inventories and inputs. ${ }^{210} \mathrm{~Pb}$ inputs from atmospheric sources $\left(1.6 \times 10^{17} \mathrm{dpm}\right)$ and in-situ production $\left(0.3 \times 10^{17} \mathrm{dpm}\right)$ at depths less than $4000 \mathrm{~m}$ within the NASS region are roughly equal to the measured ${ }^{210} \mathrm{~Pb}$ inventory in this area $(1.6 \pm$ $0.3 \times 10^{17} \mathrm{dpm}$ ). The deficiency of ${ }^{210} \mathrm{~Pb}$ in the deep NASS sediments $(>4000 \mathrm{~m})$ cannot be accounted for in the shelf and slope sediments of the northeast U.S.A. continental margin. Thus if low ${ }^{210} \mathrm{~Pb}$ inventories are a general feature of the entire deep Atlantic, as the present data tend to indicate, then a sink for this "missing" ${ }^{210} \mathrm{~Pb}$ must exist to balance the inputs. One of the possible candidates for intense ${ }^{210} \mathrm{~Pb}$ scavenging and removal is the eastern side of the Atlantic ocean. This would be similar to the enhanced removal of $\mathrm{Pu}$ and ${ }^{210} \mathrm{~Pb}$ seen along the eastern Pacific margins $[7,8,11]$, which is discussed in a following section.

Bacon et al. [16] initially proposed a lateral and boundary scavenging model for ${ }^{210} \mathrm{~Pb}$, which would be expected to increase ${ }^{210} \mathrm{~Pb}$ fluxes into the continental margin regions. This lateral transport mechanism was proposed to account for the wide spread ${ }^{210} \mathrm{~Pb} /{ }^{226} \mathrm{Ra}$ disequilibrium in the deep sea, and the ${ }^{210} \mathrm{~Pb} /{ }^{226} \mathrm{Ra}$ activity ratio, which was shown to increase with increasing distance from the seafloor in both vertical and horizontal directions. The magnitude of such a lateral ${ }^{210} \mathrm{~Pb}$ flux was calculated in a model by Spencer et al. [17] to be on the order of $0.4 \times 10^{10} \mathrm{dpm} / \mathrm{yr}$ m at the western Atlantic boundary $\left(15-30^{\circ} \mathrm{N}\right)$. If we take this model flux, multiplied by the length of the deep NASS boundary $\left(1.5 \times 10^{6} \mathrm{~m}\right)$, one calculates an additional ${ }^{210} \mathrm{~Pb}^{\mathrm{ex}}$ flux of $6 \times 10^{15} \mathrm{dpm} / \mathrm{yr}$ into the NASS region. This is roughly half of the expected atmospherically delivered supply of ${ }^{210} \mathrm{~Pb}$ (area NASS $\left(1.3 \times 10^{16} \mathrm{~cm}^{2}\right) \times$ atmospheric flux $\left.\left(0.8 \mathrm{dpm} / \mathrm{cm}^{2} \mathrm{yr}\right)=1.0 \times 10^{16} \mathrm{dpm} / \mathrm{yr}\right)$. It is clear from our total inventory calculations that there is no evidence for such a large lateral flux into the NASS region. More recent ${ }^{210} \mathrm{~Pb}$ water-column work in the NASS region [39] confirms that there is not a strong lateral gradient in ${ }^{210} \mathrm{~Pb}$ in this region which would result from an intense margin scavenging process. The model lateral ${ }^{210} \mathrm{~Pb}$ flux of Spencer et al. does not hold for this region.

\subsection{A comparison between East and West Coast sites}

An interesting comparison can be made between the NASS region and the Washington state shelf-slope region where a relatively large sink for laterally transported ${ }^{210} \mathrm{~Pb}$ and $\mathrm{Pu}$ does appear to exist $[7,8,11]$. In the Washington continental shelf and slope region, ${ }^{210} \mathrm{~Pb}$ and $\mathrm{Pu}$ inventories are several times fallout expected inputs $[7,8]$, and no large sandy areas equivalent to the Atlantic continental shelf occur. At this west coast site, strong upwelling and the lateral transport of ${ }^{210} \mathrm{~Pb}$ may explain the high sedimentary inventories observed $[7,8]$. Calculated residence times for water over the Washington shelf and slope are on the order of 0.01 year and 0.1 year, tespectively [7]. This is in contrast to the mid-Atlantic shelf waters, which have a residence time on the order of 1 year [40-42]. It appears then that the large ${ }^{210} \mathrm{~Pb}$ inventories at the U.S.A. West Coast site are due to the increased advective supply of ${ }^{210} \mathrm{~Pb}$ along eastern basin boundaries, and its removal from the water column. The total ${ }^{210} \mathrm{~Pb}^{\text {ex }}$ inventory of the West Coast site is large and may prove sufficient in balancing lateral fluxes of ${ }^{210} \mathrm{~Pb}$ from the interior of the Pacific, but this has yet to be comprehensively shown.

\section{Summary and conclusions}

A major feature of the $\mathrm{Pu}$ and ${ }^{210} \mathrm{~Pb}^{\mathrm{ex}}$ distributions in the North Atlantic shelf and slope region sediments is high inventories in the coastal bays, the Mud Patch region, and for ${ }^{210} \mathrm{~Pb}^{\mathrm{ex}}$, also on the upper slope (200-2000 m). This is consistent with the hypothesis that increased scavenging of $\mathrm{Pu}$ and ${ }^{210} \mathrm{~Pb}$ occurs over shallow and highly bioturbated sediments, with storage of these elements in regions of fine-grained sediment deposition. Off the shelf, $\mathrm{Pu}$ inventories decrease rapidly, while ${ }^{210} \mathrm{~Pb}^{\text {ex }}$ inventories remain high. This may be due both to the shorter residence time of ${ }^{210} \mathrm{~Pb}$ compared to $\mathrm{Pu}$ with respect to water column removal, and to comparisons between "steady-state" ${ }^{210} \mathrm{~Pb}$ inventories and the more recently introduced $\mathrm{Pu}$. Inventories of $\mathrm{Pu}$ and ${ }^{210} \mathrm{~Pb}$ continue to drop at greater 
depths across the slope as the dominant removal process likely becomes incorporation into particles generated in situ (either fast sinking large biogenic particles or smaller slowly sinking particles).

Inventory calculations of $\mathrm{Pu}$ and ${ }^{210} \mathrm{~Pb}^{\mathrm{ex}}$ in the NASS region $(<4000 \mathrm{~m})$ indicate that the sediments can account for about $24 \pm 8 \%$ of the supplied $\mathrm{Pu}$, and roughly $83 \pm 15 \%$ of the supplied ${ }^{210} \mathrm{~Pb}^{\mathrm{ex}}$. At depths greater than $4000 \mathrm{~m}$ we find significantly more depletion in $\mathrm{Pu}$ and ${ }^{210} \mathrm{~Pb}^{\mathrm{ex}}$ in the sediments. This inventory data also argues against strong lateral ${ }^{210} \mathrm{~Pb}$ fluxes into the NASS region. In general, the Atlantic shelf/slope margin is not a major site for $\mathrm{Pu}$ or ${ }^{210} \mathrm{~Pb}$ storage relative to other coastal margin sites.

\section{Acknowledgements}

We would like to thank M. Bothner, C. Brower, $M$. Bacon and $\mathrm{K}$. Turekian for allowing us to use their data. We thank the Education Office of the Massachusetts Institute of Technology-Woods Hole Oceanographic Institution Joint Program for supporting KOB during his work on this project. Other support came from the U.S. Department of Energy under contracts DE-AC02-83ER60172, DE-AC02-81EV10694 and earlier contracts, and from Sandia Laboratories under contract 15-1034 and earlier contracts. This is contribution No. 5912 from the Woods Hole Oceanographic Institution.

\section{References}

1 E.P. Hardy, P.W. Krey and H.L. Volchok, Global inventory and distribution of fallout plutonium, Nature 241, 444-445, 1973.

2 K.K. Turekian, Y. Nozaki and L.K. Benninger, Geochemistry of atmospheric radon and radon products, Annu. Rev. Earth Sci. 5, 227-255, 1977.

3 R.W. Perkins and C.W. Thomas, Worldwide fallout. in: Transuranic Elements in the Environment, W.C. Hanson ed., 1980.

4 E.K. Duursma and M.G. Gross, Marine sediments and radioactivity, in: Radioactivity in the Marine Environment, pp. 147-160, National Academy of Sciences, 1971

5 P.H. Santschi, Y.-H. Li, J. Bell, R. Trier and K. Kawtaluk, $\mathrm{Pu}$ in coastal marine environments, Earth Planet. Sci. Lett. $51,248-265,1980$.

6 L.K. Benninger, R.C. Aller, J.K. Cochran and K.K. Turekian, Effects of biological sediment mixing on the ${ }^{210} \mathrm{~Pb}$ chronology and trace metal distribution in a Long Island Sound sediment core, Earth Planet. Sci. Lett. 43. 241-259, 1979.
7 R. Carpenter, J.T. Bennett and M.L. Peterson, ${ }^{210} \mathrm{~Pb}$ activities in and fluxes to sediments of the Washington continental slope and shelf, Geochim. Cosmochim. Acta 45. 1155-1172, 1981.

8 T.M. Beasley, R. Carpenter and C.D. Jennings, Plutonium, ${ }^{241} \mathrm{Am}$ and ${ }^{137} \mathrm{Cs}$ ratios, inventories and vertical profiles in Washington and Oregon continental sheif sediments, Geochim. Cosmochim. Acta 46, 1931-1946, 1982.

9 J.P. Chanton, C.S. Martens and G.W. Kipphut, Lead-210 sediment geochronology in a changing coastal environment. Geochim. Cosmochim. Acta 47, 1791-1804, 1983.

10 L.K. Benninger and S. Krishnaswami, Sedimentary processes in the inner New York Bight: evidence from excess ${ }^{210} \mathrm{~Pb}$ and ${ }^{239.240} \mathrm{Pu}$, Earth Planet. Sci. Lett. 53, 158-174, 1981.

11 R. Carpenter, M.L. Peterson and J.T. Bennett, ${ }^{210} \mathrm{~Pb}$-derived sediment accumulation and mixing rates for the Washington continental slope, Mar. Geol. 48, 135-164. 1982.

12 J.K. Cochran, Particle mixing rates at MANOP sites in the eastern equatorial Pacific: evidence from ${ }^{210} \mathrm{~Pb},{ }^{239.240} \mathrm{Pu}$. and ${ }^{137} \mathrm{Cs}$ distributions, Geochim. Cosmochim. Acta 49. $1195-1210,1985$.

13 H.D. Livingston and V.T. Bowen, Pu and ${ }^{137} \mathrm{Cs}$ in coastal sediments. Earth Planet. Sci. Lett. 43, 29-45, 1979.

14 M.H. Bothner, E.C. Spiker, P.P. Johnson, R.R. Rendigs and PJ. Aruscavage, Geochemical evidence for modern sediment accumulation on the continental shelf off southern New England. J. Sediment. Petrol. 51, 281-292, 1981.

15 F.L. Sayles and H.D. Livingston, The distribution of ${ }^{239.240} \mathrm{Pu},{ }^{137} \mathrm{Cs}$, and ${ }^{55} \mathrm{Fe}$ in continental margin sediments: relation to sedimentary redox environment, in: Proc. 4th Annu. Int. Ocean Disposal Symp., Plymouth, U.K., in press, 1985.

16 M.P. Bacon, D.W. Spencer and P.G. Brewer, ${ }^{210} \mathrm{~Pb} /{ }^{226} \mathrm{Ra}$ and ${ }^{210} \mathrm{Po} /{ }^{210} \mathrm{~Pb}$ disequilibria in seawater and suspended particulate matter, Earth Planet. Sci. Lett. 32, 277-296, 1976.

17 D.W. Spencer, M.P. Bacon and P.G. Brewer, Models of the distribution of ${ }^{210} \mathrm{~Pb}$ in a section across the North equatorial Atlantic ocean. J. Mar. Res. 39, 119-138, 1981.

18 C.A. Nittrouer, R.W. Sternberg, R. Carpenter and J.T. Bennett. The use of ${ }^{210} \mathrm{~Pb}$ geochronology as a sedimentological tool: application to the Washington continental shelf. Mar. Geol. 31, 297-316, 1979.

19 H.D. Livingston, D.R. Mann and V.T. Bowen, Analytical procedures for transuranic elements in seawater and marine sediments, in: Analytical Methods in Oceanography, T.R.P. Gibbs, ed., Am. Chem. Soc. Adv. Chem. Ser. 147, 124. 1975.

20 N.H. Cutshall, I.L. Larsen and C.R. Olsen, Direct analysis of ${ }^{210} \mathrm{~Pb}$ in sediment samples: self-absorption corrections, Nucl. Instrum. Methods 206, 309-312, 1983.

21 G.G. Mathieu, ${ }^{222} \mathrm{Rn}$ and ${ }^{226} \mathrm{Ra}$ technique of analysis, Prog. Rep. ERDA Contract Ey 76-S-02-2185, 1977.

22 Y. Yakoyama and H.-V. Nguyen. Direct and non-destructive dating of marine sediments, manganese nodules, and corals by high resolution gamma-ray spectrometry, in: Isotope Marine Chemistry, E.D. Goldberg, Y. Horibe and I. Saruhashi, eds., pp. 259-289, Geochem. Res. Assoc., Tokyo. 1980. 
23 K.K. Turekian, personal communication.

24 K.K. Turekian, L.K. Benninger and E.P. Dion, ${ }^{7} \mathrm{Be}$ and ${ }^{210} \mathrm{~Pb}$ total depositional fluxes at New Haven, Connecticut and at Bermuda, J. Geophys. Res. 88, 5411-5415, 1983.

$25 \mathrm{C}$. Brower, ${ }^{210} \mathrm{~Pb}$ in the sediment of the Gulf of Maine, M.S. Thesis, University of Maine, 1984.

26 D.C. Twichell et al., Morphology and processes associated with the accumulation of the fine-grained sediment deposit on the southern New England shelf, J. Sediment. Petrol. 51. 269-280, 1981.

$27 \mathrm{~J}$. Schlee, Atlantic continental shelf and slope of the United States-sediment texture of the northeastern part, U.S. Geol. Surv. Prof. Pap. 529-L, 1973.

28 H.J. Knebel, Sedimentary processes on the Atlantic continental slope of the United States, Mar. Geol. 61, 43-74, 1984.

29 D.C. Rhoads, J.Y. Yingst and W.J. Ullman, Seafloor stability in central Long Island Sound, I. Temporal changes in erodibility of fine-grained sediments, in: Estuarine Interactions, M.L. Wiley ed., pp. 221-244, Academic Press, New York, N.Y., 1978.

30 R.C. Aller, The effects of macrobenthos on chemical properties of marine sediment and overlying water, in: Animal-Sediment Relations, P.L. McCall and M.J.S. Teuesz, eds., pp. 53-101, Plenum Press, New York, N.Y., 1982.

31 W. Stumm and J. Morgan, Aquatic Chemistry, 2nd ed., J. Wiley and Sons, New York, N.Y., 1981.

32 W.L. Templeton and A. Preston, Transport and distribution of radioactive effluents in coastal and estuarine waters of the United Kingdom, in: Disposal of Radioactive Wastes into Seas, Oceans, and Surface Waters, pp, 267-289, IAEA, Vienna, 1966.

33 M.P. Bacon, C.-A. Huh, A.P. Fleer and W.G. Deuser, Seasonality in the flux of natural radionuclides and plutonium in the deep Sargasso Sea, Deep-Sea Res. 32, 273-286, 1985.

34 H.D. Livingston and D.L. Schneider, 1983 Annual Status Report-Radiochemical studies in support of the low level waste ocean disposal program, WHOI Report prepared for Sandia National Laboratories, 1984.

35 G.T. Rowe and W.D. Gardner, Sedimentation rates in the slope water of the northwest Atlantic Ocean and the northern Gulf of Mexico, Deep-Sea Res. 37, 581-600, 1979.

36 V.T. Bowen, V.E. Noshkin, H.D. Livingston and H.L. Volchok, Fallout radionuclides in the Pacific Ocean: vertical and horizontal distributions, largely from GEOSECS stations, Earth Planet. Sci. Lett. 49, 411-434, 1980.

37 V.T. Bowen, Transuranic elements in marine environments, Health Safety Lab. Rep. HASL-291, I-58, 1975.

38 H.D. Livingston and R.F. Anderson, Large particle transport of plutonium and other fallout radionuclides to the deep ocean, Nature 303, 228-231, 1983.

39 M.P. Bacon, Am. Geophys. Union, Spring Meeting, presentation and personal communication.

$40 \mathrm{~N}$. Garfield, A box model study of the middle Atlantic Bight, M.S. Thesis, University of Delaware, 1978.

41 Y.H. Li, H.W. Feely and P.H. Santschi. ${ }^{228} \mathrm{Th}-{ }^{228} \mathrm{Ra}$ radioactive disequilibrium in the New York Bight and its implication for coastal pollution, Earth Planet. Sci. Lett. 42, 13-26, 1979.

42 R.C. Beardsley, W.C. Boicourt and D.V. Hansen, Physical oceanography of the Middle Atlantic Bight, Limnol. Oceanogr. Spec. Symp. 2, 20-34, 1976.

43 K.O. Buesseler and E.R. Sholkovitz, unpublished Pu and ${ }^{210} \mathrm{~Pb}^{\mathrm{ex}}$ inventory data.

44 H.D. Livingston, unpublished $\mathrm{Pu}$ and ${ }^{210} \mathrm{~Pb}^{e x}$ inventory data.

45 M.H. Bothner, unpublished ${ }^{210} \mathrm{~Pb}^{e x}$ data.

46 E.R. Sholkovitz and D.R. Mann, The pore water chemistry of ${ }^{239.240} \mathrm{Pu}$ and ${ }^{137} \mathrm{Cs}$ in sediments of Buzzards Bay, Massachusetts, Geochim. Cosmochim. Acta 48, 1107-1114, 1984.

47 K.K. Turekian, J.K. Cochran, L.K. Benninger and R.C. Aller. The sources and sinks of nuclides in Long Island Sound, in: Advances in Geophysics, Vol. 22. Estuarine Physics and Chemistry: Studies in Long Island Sound, pp. 129-164, 1980. 
$-120-$ 


\section{CHAPTER 6}

The Geochemistry of Fallout Plutonium in the North Atlantic:

$24 \mathrm{Pu}_{\mathrm{Pu}}{ }^{239} \mathrm{Pu}$ Ratios and Their Significance

\section{INTRODUCTION}

The major source of fallout plutonium to the marine environment is atmospheric nuclear weapons testing which occurred during the 1950's and early 1960's (Perkins and Thomas, 1980; Harley, 1980). In fallout, the dominant $\mathrm{Pu}$ isotopes are ${ }^{239} \mathrm{Pu}$ and ${ }^{240} \mathrm{Pu}$, the combined activities of which have been traditionally measured by alpha-counting techniques (written as $239,240 \mathrm{Pu}$ ). By employing a mass spectrometric (m.s.) technique I have been able to separately determine the concentrations of ${ }^{239} \mathrm{Pu}$ and ${ }^{240} \mathrm{Pu}$ in marine sediments, pore waters, sea water and sediment trap samples from the North Atlantic. With the ${ }^{240} \mathrm{Pu} /{ }^{239} \mathrm{Pu}$ ratio data, fallout from specific nuclear testing sites can be identified. An important finding is that the solubility and reactivity of $\mathrm{Pu}$ from different fallout sources are not necessarily identical, as previously assumed. This evidence for the input of different Pu fallout types with differing geochemistries will have important bearing on: a) the use of $\mathrm{Pu}$ as a geochemical tracer to study present day scavenging and removal processes in the water column, b) the use of $\mathrm{Pu}$ as a tracer in sediment mixing and accumulation studies where the input function of $\mathrm{Pu}$ to the sediments must be known, and $\mathrm{c}$ ) the interpretation of previous water column $239,240 \mathrm{Pu}$ activity data in the Pacific (Bowen et al., 1980) where subsurface and near-bottom activity maxima exist for Pu.

In this study, a systematic decrease in the ${ }^{240} \mathrm{Pu} /{ }^{239} \mathrm{Pu}$ ratio in sediments is found with increasing water depth along a transect of cores between Woods Hole and Bermuda. The ${ }^{240} \mathrm{Pu} /{ }^{239} \mathrm{Pu}$ ratios range from $\simeq 0.18$ on the shelf to $\simeq 0.10$ at $5000 \mathrm{~m}$. A model will be presented which can account for the range of ${ }^{240} \mathrm{Pu} /{ }^{239} \mathrm{Pu}$ ratios found in this and other similar studies (Noshkin and Gatrousis, 1974; 
Scott et al., 1983). In this model, I propose that there have been at least two distinct sources of fallout Pu to this region. The major source of $\mathrm{Pu}$ is global stratospheric fallout which is characterized by a ${ }^{240} \mathrm{Pu} /{ }^{239} \mathrm{Pu}$ ratio of 0.18 . The second source of fallout $\mathrm{Pu}$ is characterized by a much lower ${ }^{240} \mathrm{Pu} /{ }^{239} \mathrm{Pu}$ ratio, and relative to global fallout, must have been more efficiently deposited to deep-sea sediments.

I will first present some background information on the various sources and characteristics of fallout $\mathrm{Pu}$, and previous studies in this area. Then I will focus on my results in order to examine the relationship between the geochemistry of $\mathrm{Pu}$ and the specific sources of fallout Pu at any given site. While the discussions presented here pertain to the behavior and sources of fallout $\mathrm{Pu}$ to the North Atlantic, the significance of similar processes in the Pacific will be considered.

\section{BACKGROUND}

A. Fallout Data

I will use ${ }^{240} \mathrm{Pu} /{ }^{239} \mathrm{Pu}$ data from the North Atlantic to distinguish between two classes of fallout debris - global or stratospheric fallout versus tropospheric fallout from the Nevada Test Site. It is therefore important to first define what is meant by stratospheric and tropospheric fallout and then to examine briefly the input history of $\mathrm{Pu}$ in terms of the ${ }^{240} \mathrm{Pu} /{ }^{239} \mathrm{Pu}$ isotopic ratios observed in the fallout record.

Global or stratospheric fallout refers to very small sized fallout particles $(\simeq 1 \mu \mathrm{m}$ or less in diameter - Joseph et al., 1971) which received sufficient height to become entrained in the stratosphere. This fallout debris has a residence time in the atmosphere on the order of one year (Joseph et a1., 1971; Perkins and Thomas, 1980). This is the most abundant type of fallout, accounting for $>80 \%$ of the total fallout radioactivity distributed worldwide (Harley, 1980). Both large and small yield nuclear tests conducted at high altitudes and large 
yleld surface based nuclear tests have produced considerable stratospheric fallout.

Tropospheric fallout refers to fallout debris which is retained within the troposphere either as larger fallout particles which are deposited rapidly within the vicinity of the nuclear testing site (so-called close-in fallout) or smaller fallout particles which do not reach stratospheric altitudes and are deposited within the hemisphere of injection in the days to weeks following a particular testing event (so-called intermediate fallout) (Joseph et a 1., 1971; Holloway and Hayes, 1982). Any nuclear test that is conducted at or just above the ground (1.e. surface based) will generate at least some tropospheric fallout. The largest source of tropospheric fallout was U.S. surface based testing of large yield thermonuclear bombs ( $H$-bombs) at the Marsha11 Islands $\left(\simeq 11^{\circ} \mathrm{N} \simeq 165^{\circ} \mathrm{E}\right.$ ) (Joseph et a1., 1971; Perkins and Thomas, 1980; D.0.E., 1982). Testing at the Marshall Islands resulted in the local deposition of roughly the same inventory of Pu to the North Pacific basin as Pu from global fallout (Bowen et al., 1980). An additional source of tropospheric fallout of interest to my work in the North Atlantic is the Nevada Test Site where over 35 surface based small yield nuclear tests were conducted between 1951 and 1958 (D.0.E., 1982; Hicks and Baar, 1984).

To distinguish between stratospheric fallout and tropospheric fallout from the Nevada Test Site, a review is needed of the factors which determine the ${ }^{240} \mathrm{Pu} /{ }^{239} \mathrm{Pu}$ ratio in fallout. In general, differences in weapons design appear to account for much of the variability seen in the historical ${ }^{240} \mathrm{Pu} /{ }^{239} \mathrm{Pu}$ record (Cameron, 1959; Perkins and Thomas, 1980; Kolde et a1., 1985). Within any given design or series of tests, a larger nuclear yield produces greater neutron fluxes resulting in the enhanced production of the higher masses

of Pu. The U.S. nuclear testing program dominated the early atmospheric fallout record in terms of total fallout yields (Zander and Araskog, 1973; Perkins and Thomas, 1980; D.O.E., 1982). In the early 1950's, stratospheric fallout was characterized by a ${ }^{240} \mathrm{Pu} /{ }^{239} \mathrm{Pu}$ ratio of $>0.30$ dropping off to the 0.21-0.26 range in the mid-1950's based upon ice 
core records in the Antarctic and Greenland ice sheets (Koide et al., 1985). This is supported by a ${ }^{240} \mathrm{Pu} /{ }^{239} \mathrm{Pu}$ ratio of 0.35 in a 1953 aerosol sample collected over the U.S., and a 0.21 ratio in a similar sample from 1955 (Krey, 1985). Also, Noshkin (1978) has reported an average ${ }^{240} \mathrm{Pu} /{ }^{239} \mathrm{Pu}$ ratio of 0.31 from the soil and vegetation on the Bikint atoll in the Marshall Islands. Specifically, the U.S. "Mike" shot in 1952 at Enewetak produced a fallout ${ }^{240} \mathrm{Pu} /{ }^{239} \mathrm{Pu}$ ratio of 0.36 (Diamond et a 1., 1960) and remained a unique (Cameron, 1959) and relatively large source of high ratio fallout Pu until further U.S. testing in 1954 (Perkins and Thomas, 1980; D.0.E., 1982). Later atmospheric nuclear testing programs in the early 1960's were dominated by the large yield Soviet tests. These U.S.S.R. tests are responsible for the bulk of the stratospheric fallout $P u$ in the environment accounting for $\simeq 75 \%$ of the total worldwide fallout yields (calculated from the total yield data in D.0.E. (1982)). The average $240 \mathrm{Pu} /{ }^{239} \mathrm{Pu}$ ratio of this material is 0.18 (Perkins and Thomas, 1980). This is supported by the ice core data which show ${ }^{240} \mathrm{Pu} /{ }^{239} \mathrm{Pu}$ ratios averaging 0.18 during the 1960-1966 period (ranging form 0.16-0.22, Koide et a1., 1985). Also, an average ratio of $0.178 \pm 0.009$ is found in aerosol samples collected between 1957 and 1967 at $35^{\circ} \mathrm{N}$ (recalculated from HASL-273 (1973)) using data from over 100 filtered aerosol particulate samples with a precision of $<10 \%$ on the measured ${ }^{240} \mathrm{Pu} /{ }^{239} \mathrm{Pu}$ ratio. This is identical to the average integrated sol1 $240 \mathrm{Pu} /{ }^{239} \mathrm{Pu}$ ratio of $0.176 \pm 0.014$ found at over 50 sites from $33^{\circ} \mathrm{S}$ to $71^{\circ} \mathrm{N}$ (Krey et a1., 1976). It is apparent that the 0.18 value from the soll study is strongly influenced by the dominance of the U.S.S.R. high yield tests in the total fallout record. Similar to other previous discussions of Pu fallout (Hardy et a1., 1972; Perkins and Thomas, 1980; Beasley et a1., 1981; Scott et a1., 1983), I will use $0.18 \pm 0.01$ as the characteristic isotopic signature of average stratospheric fallout $\mathrm{Pu}$ arriving to the North Atlantic.

As mentioned previously, an additional source of Pu to the Northern Hemisphere is tropospheric fallout from the Nevada Test site. The Nevada fallout is characterized by an average ${ }^{240} \mathrm{Pu} /{ }^{239} \mathrm{Pu}$ ratio of 
0.035. This value is the weighted mean ${ }^{240} \mathrm{Pu} /{ }^{239} \mathrm{Pu}$ ratio of fallout from all tower and surface tests conducted in Nevada ( $n=36$; calculated from the data in Hicks and Barr, 1984) and it agrees well with previous estimate of this ratio (Krey et a1., 1976; Perkins and Thomas, 1980; Krey, 1983; Hicks and Baar, 1984). Fallout from surface based testing at Nevada would have traveled with the prevalling winds in an eastwardly direction (Clark, 1954). The behavior of fallout $\mathrm{Pu}$ in the oceans from this source will be a major focus of attention in following discussions.

\section{B. Previous Studies}

The first study to use $\mathrm{Pu}$ isotopic data to understand the blogeochemistry of fallout $\mathrm{Pu}$ in the oceans is that of Noshkin and Gatrousis (1974). They found ${ }^{240} \mathrm{Pu} /{ }^{239} \mathrm{Pu}$ atom ratios ranging from 0.11 to 0.24 in six sediment samples and in 3 biological samples from the North and South Atlantic. This range in Pu isotopic composition is quite surprising given the ${ }^{240} \mathrm{Pu} /{ }^{239} \mathrm{Pu}$ ratio of 0.18 found in worldwide fallout. Noshkin and Gatrousis suggested that the fractionation of fallout material upon deposition to the ocean may lead to this wide range of $\mathrm{Pu}$ isotopic values.

Scott et a1. (1983), report the only other ${ }^{240} \mathrm{Pu} /{ }^{239} \mathrm{Pu}$ data from marine sediments. They found a systematic decrease in the ${ }^{240} \mathrm{Pu} /{ }^{239} \mathrm{Pu}$ ratio from 0.18 in cores at the mouth of the Mississippi river to values below 0.10 in the deep abyssal plain sediments $(3500 \mathrm{~m})$ in the Gulf of Mexico. They attributed the lower ${ }^{240} \mathrm{Pu} /{ }^{239} \mathrm{Pu}$ values (relative to the global fallout average of 0.18 ) to either a separation of ${ }^{239} \mathrm{Pu}$ from $240 \mathrm{Pu}$ during transit to the sea floor, or to a unique source (possibly the Nevada Test Site) of low ratio Pu.

\section{I. SAMPLING}

Sediment samples analyzed for ${ }^{240} \mathrm{Pu} /{ }^{239} \mathrm{Pu}$ ratios were obtained primarily from three sources. The major analytical effort was spent on a series of seven box cores (cores $A$ through $H$ ) from a transect between Woods Hole and Bermuda (Fig. 6.1). At these sites, sediment profiles of both $239,240 \mathrm{Pu}$ activity and ${ }^{240} \mathrm{Pu} /{ }^{239} \mathrm{Pu}$ ratio data were obtained. 
Figure 6.1: Sampling Location Map.

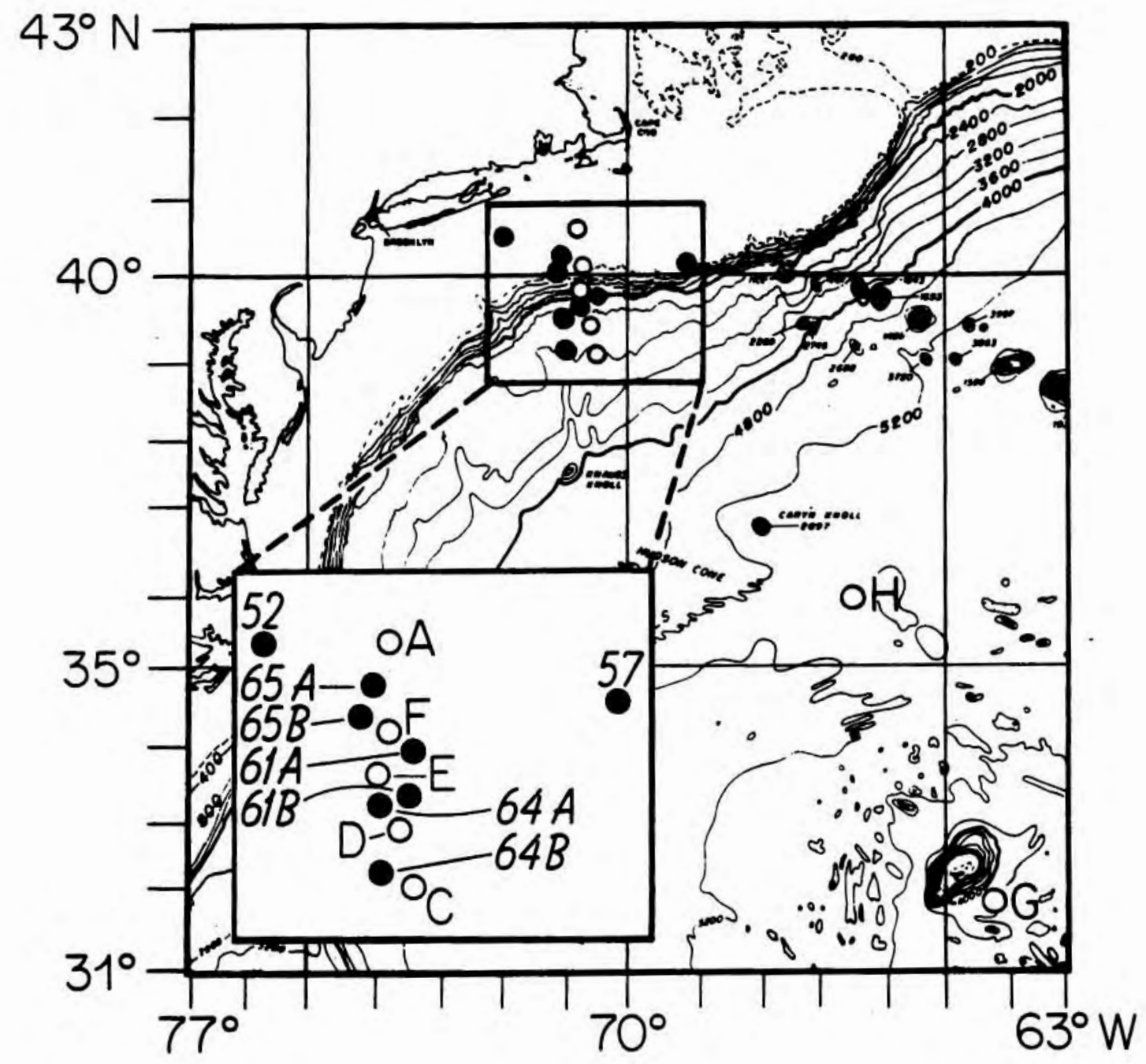

Sites A through $H$ are box cores collected in 1983-1985. Sites numbered 52 through 65b (see insert) are surface samples collected in the 1950's and $1960^{\prime} \mathrm{s}$. 
Sediment samples were collected from box cores which were retrieved with visually undisturbed and level surfaces. The cores were subsampled for solid phase analyses with a 6 or $10 \mathrm{~cm}$ diameter subcoring device in 0.5-1.0 cm depth intervals over the upper $4-6 \mathrm{~cm}$ of the core and in $2 \mathrm{~cm}$ depth intervals throughout the remainder of the core. The $239,240 \mathrm{Pu}$ activity proftles from these cores have been examined for evidence of Pu diagenesis in Chapter 4 of this thesis and used to determine sediment mixing rates in Chapter 7 and Anderson et al. (1986).

In order to follow the historical sequence of Pu inputs to this region, a set of archived sediment samples collected in the 1950's and early 1960's were analyzed. These archived samples are mainly surface grab samples or dredge samples from a U.S.G.S./W.H.O.I. survey of the eastern U.S. continental margin. A complete description of the sediment samples from this entire survey is provided in Hathaway (1971), and pertinent data for this study are provided in Table 6.1. The locations of these 1950's and 1960's samples are given in Figure 6.1.

Finally, surface sediment samples from a wide range of locations in the Atlantic were analyzed for Pu isotopes (sample locations are given in Table 6.1). These samples were analyzed to examine the spatial extent of tropospheric fallout Pu from the Nevada Test Site.

The pore water samples which were analyzed by mass spectrometry are from cores $F(501 \mathrm{~m}), E(1275 \mathrm{~m}), D(2362 \mathrm{~m}), \mathrm{C}(2700 \mathrm{~m}), \mathrm{G}(4469 \mathrm{~m})$, and $H(4990 \mathrm{~m})$ (Fig. 6.1). The collection and extraction of pore waters from these samples is described in detail in Chapter 4 of this thesis. Chapter 4 also discusses the interpretation of the pore water activity profiles with respect to Pu diagenesis, while in this chapter I will focus on the pore water ${ }^{240} \mathrm{Pu} /{ }^{239} \mathrm{Pu}$ data alone. Five Atlantic seawater and two Atlantic sediment trap samples were also analyzed for $\mathrm{Pu}$ isotopes by m.s. and their sampling locations will be discussed in the text.

\section{ANALYTICAL TECHNIQUES}

This chapter focuses on ${ }^{240} \mathrm{Pu} /{ }^{239} \mathrm{Pu}$ atom ratio data which are 
Table 6.1. Sampling Locations and Date of Collection

Depth Core ID Cruise or I.D. Date Latitude Longitude Woods Hole to Bermuda transect: sediment profiles and pore waters-

$\begin{array}{llllll}90 \mathrm{~m} & \text { A } & \text { 83-Gyre-9 } & 7 / 28 / 83 & 40^{\circ} 28.1^{\prime} \mathrm{N} & 70^{\circ} 54.1^{\prime} \mathrm{W} \\ 501 \mathrm{~m} & \text { F } & \text { Oceanus-152 } & 4 / 30 / 84 & 39^{\circ} 55.1^{\prime} \mathrm{N} & 70^{\circ} 54.1^{\prime} \mathrm{W} \\ 501 \mathrm{~m} & \text { F } & \text { Dceanus-152 } & 4 / 30 / 84 & 39^{\circ} 55.1^{\prime} \mathrm{N} & 70^{\circ} 54.2^{\prime} \mathrm{W} \\ 1275 \mathrm{~m} & \text { E } & \text { Oceanus-152 } & 4 / 29 / 84 & 39^{\circ} 48.1^{\prime} \mathrm{N} & 70^{\circ} 56.3^{\prime} \mathrm{W} \\ 2362 \mathrm{~m} & \text { D } & \text { Oceanus-152 } & 4 / 29 / 84 & 39^{\circ} 35.0^{\prime} \mathrm{N} & 70^{\circ} 56.8^{\prime} \mathrm{W} \\ 2700 \mathrm{~m} & \text { C } & \text { 83-Gyre-9 } & 7 / 31 / 83 & 39^{\circ} 10.3^{\prime} \mathrm{N} & 70^{\circ} 43.8^{\prime} \mathrm{W} \\ 4469 \mathrm{~m} & \text { G } & \text { Oceanus-173 } & 12 / 4 / 85 & 31^{\circ} 54.1^{\prime} \mathrm{N} & 64^{\circ} 17.8^{\prime} \mathrm{W} \\ 4990 \mathrm{~m} & \text { H } & \text { Oceanus-173 } & 12 / 8 / 85 & 36^{\circ} 27.9^{\prime} \mathrm{N} & 66^{\circ} 33.6^{\prime} \mathrm{W}\end{array}$

Archived sediments: surface grab \& dredge samples-

\begin{tabular}{|c|c|c|c|c|c|}
\hline $93 \mathrm{~m}$ & $65 a$ & $\# 2507$ & 1965 & $40^{\circ} 20^{\prime} \mathrm{N}$ & $71^{\circ} 00^{\prime} h$ \\
\hline $125 m$ & 52 & Atlantis -179 & 1952 & $40^{\circ} 50^{\prime} \mathrm{N}$ & $72^{\circ} \mathrm{O}^{\prime} \mathrm{W}$ \\
\hline $200 \mathrm{~m}$ & 57 & \#W031 & 1957 & $40^{\circ} 10^{\prime} \mathrm{N}$ & $69^{\circ} 05^{\prime} \mathrm{h}$ \\
\hline $458 \mathrm{~m}$ & $65 b$ & $\# 2511$ & 1965 & $39^{\circ} 58^{\prime} \mathrm{N}$ & $71^{\circ} 00^{\prime} \mathrm{h}$ \\
\hline $1500 \mathrm{~m}$ & b1a & \#E004 & 1961 & $39^{\circ} 47^{\prime} \mathrm{N}$ & $70^{\circ} 45^{\prime} \mathrm{h}$ \\
\hline $2086 \mathrm{~m}$ & $61 \mathrm{~b}$ & \#E005 & 1961 & $39^{\circ} 42^{\prime} \mathrm{N}$ & $70^{\circ} 39^{\prime} \mathrm{h}$ \\
\hline $2335 \mathrm{~m}$ & $64 a$ & $\# 2136$ & 1964 & $39^{\circ} 37^{\prime} \mathrm{N}$ & $70^{\circ} 52^{\prime} \mathrm{W}$ \\
\hline 2722 & $64 b$ & \#2135 & 1964 & $39^{\circ} 11^{\prime} \mathrm{N}$ & $71^{\circ} 05^{\prime} \mathrm{W}$ \\
\hline
\end{tabular}

Atlantic deep-sea: surface sediments from box cores-

$\begin{array}{llllll}3046 \mathrm{~m} & \text { BX49 } & 10549 \# 5 B X & 1984 & 00^{\circ} 02.9^{\prime} \mathrm{S} & 16^{\circ} 07.4^{\prime} \mathrm{W} \\ 4655 \mathrm{~m} & \text { BX52 } & 10552 \# 9 B X & 1984 & 19^{\circ} 27.3^{\prime} \mathrm{N} & 29^{\circ} 53.6^{\prime} \mathrm{W} \\ 5145 \mathrm{~m} & \text { BX39 } & 11139 \# 8 B X & 1984 & 31^{\circ} 25.4^{\prime} \mathrm{N} & 25^{\circ} 12.2^{\prime} \mathrm{W} \\ 4360 \mathrm{~m} & \text { BX47 } & 11147 \# 5 B X & 1984 & 49^{\circ} 40.8^{\prime} \mathrm{N} & 14^{\circ} 38.6^{\prime} \mathrm{W} \\ 5613 \mathrm{~m} & \text { BX64 } & 10164 \# 5 B X & 1984 & 26^{\circ} 04.9^{\prime} \mathrm{N} & 60^{\circ} 24.7^{\prime} \mathrm{W} \\ 4990 \mathrm{~m} & \text { Kn } & \text { Kn54/15 } & 1976 & 45^{\circ} 36.9^{\prime} \mathrm{N} & 12^{\circ} 34.3^{\prime} \mathrm{W} \\ 5400 \mathrm{~m} & \text { EnJ } & \text { En53/2-LOCJ } & 1980 & 32^{\circ} 43.3^{\prime} \mathrm{N} & 70^{\circ} 47.6^{\prime} \mathrm{W} \\ 4810 & \text { AII } & \text { AII/49 } & 1969 & 39^{\circ} 02^{\prime} \mathrm{N} & 42^{\circ} 36^{\prime} \mathrm{W} \\ 2900 \mathrm{~m} & \text { Med } & \text { AII/93 } & 1976 & 34^{\circ} 01.3^{\prime} \mathrm{N} & 28^{\circ} 59.8^{\prime} \mathrm{E}\end{array}$


obtained by a mass spectrometric technique developed to measure low level Pu concentrations and isotope ratios in marine samples (for details see Chapter 3 of this thesis). The advantages of the m.s. technique over traditional alpha-counting procedures for Pu are twofold. First, when $\mathrm{Pu}$ is determined by alpha-counting, ${ }^{239} \mathrm{Pu}$ and ${ }^{240} \mathrm{Pu}$ remain inseparable due to the similar alpha energies of these isotopes. With m.s. in contrast, these fsotopes are easily separated. In addition, due to the long half-lives of ${ }^{239} \mathrm{Pu}\left(24,400 \mathrm{yrs}\right.$ ) and ${ }^{240} \mathrm{Pu}$ (6600 yrs), non-radiometric techniques such as mass spectrometry, which measure the Pu isotopes directly, are inherently more sensitive than alpha-counting techniques which measure Pu only by the detection of relatively infrequent alpha-decay events.

A complete description of the chemical procedures used to isolate and purify $\mathrm{Pu}$ from marine samples is provided in Chapter 3 of this thesis. Briefly, the sediment samples are hot acid leached (twice in $8 \mathrm{~N} \mathrm{HNO}_{3}$ ) in the presence of a ${ }^{242} \mathrm{Pu}$ spike and the leachate is purified by ion exchange chromatography. Pu from seawater and pore water is collected via an Fe-hydroxide precipitation step after equilibration with a ${ }^{242} \mathrm{Pu}$ yield monitor. Similar to the sediment samples, purification is achieved with multiple ion exchange separation steps. The sediment trap samples are totally dissolved in the presence of the ${ }^{242} \mathrm{Pu}$ spike and purified. In general, the purification procedures used on m.s. samples are similar to procedures used in standard alpha-counting techniques (Wong, 1971; Livingston et al., 1975; Larsen and 0ldham, 1975). High purity acids in the final column steps and clean room techniques throughout ensure consistently low blanks (see Chapter 3).

The errors on the Pu data reported in Table 6.2 are propagated from the standard deviation on the m.s. determination of the ${ }^{242} \mathrm{Pu},{ }^{239} \mathrm{Pu}$ and $240 \mathrm{Pu}$ atom abundances and from the error on the procedural blank. Since $240 \mathrm{Pu}$ is the least abundant $\mathrm{Pu}$ isotope, the largest source of error arises from its determination by m.s.. Replicate analyses are found to agree within the reported precisions (Chapter 3, this thesis). A complete listing of all of the m.s. data is given in Appendix III of this 
Table 6.2. Pu data by mass spectrometry

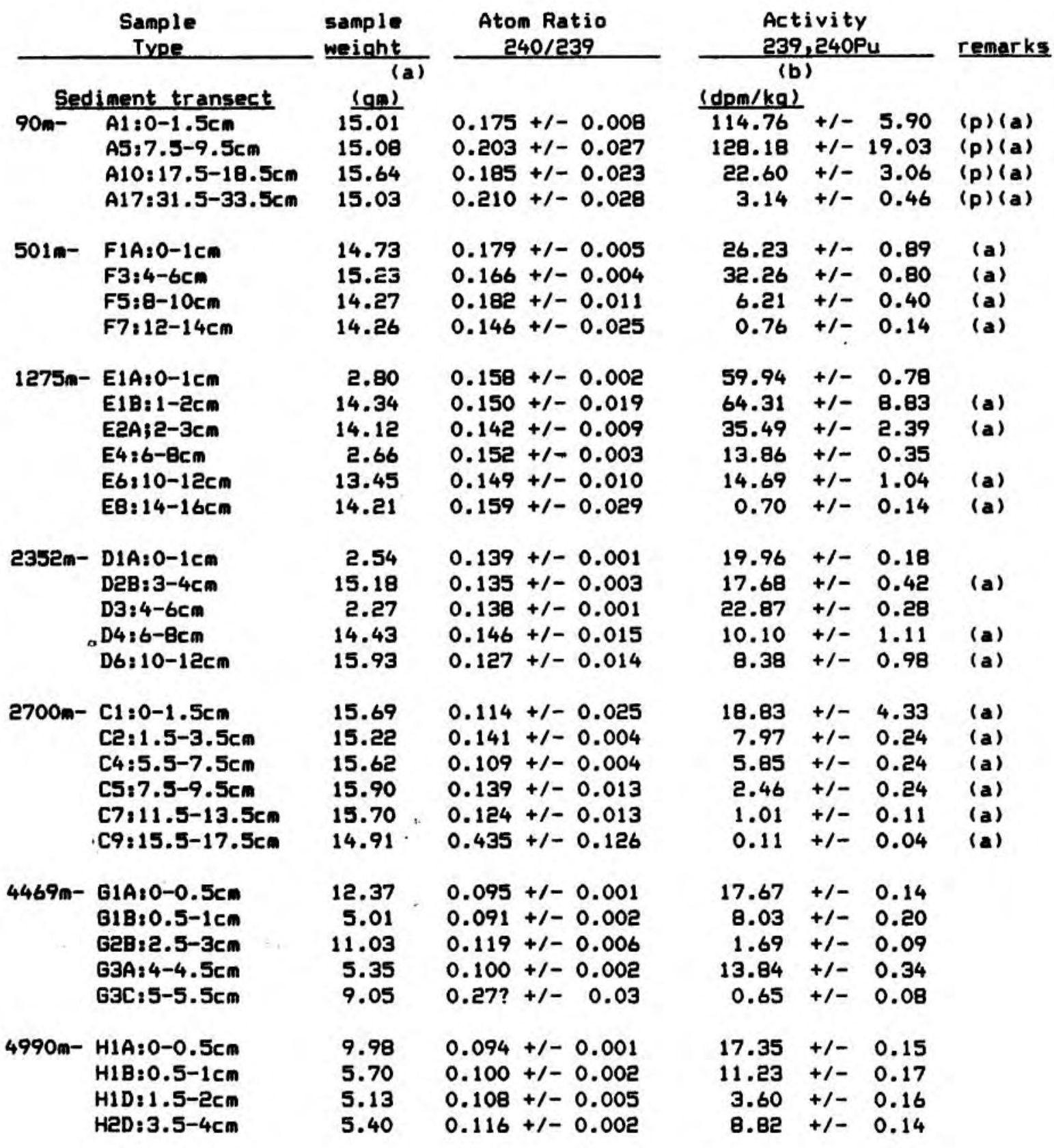


Table 6.2. cont. Pu data by mass spectrometry

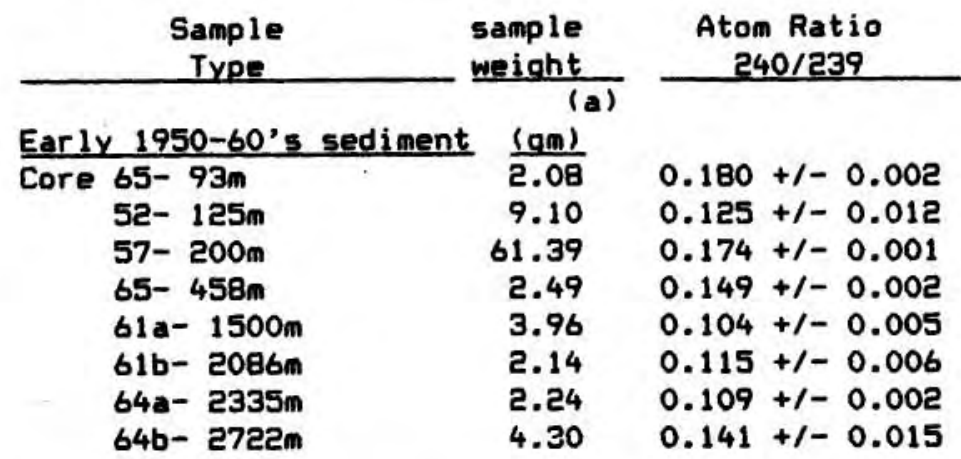

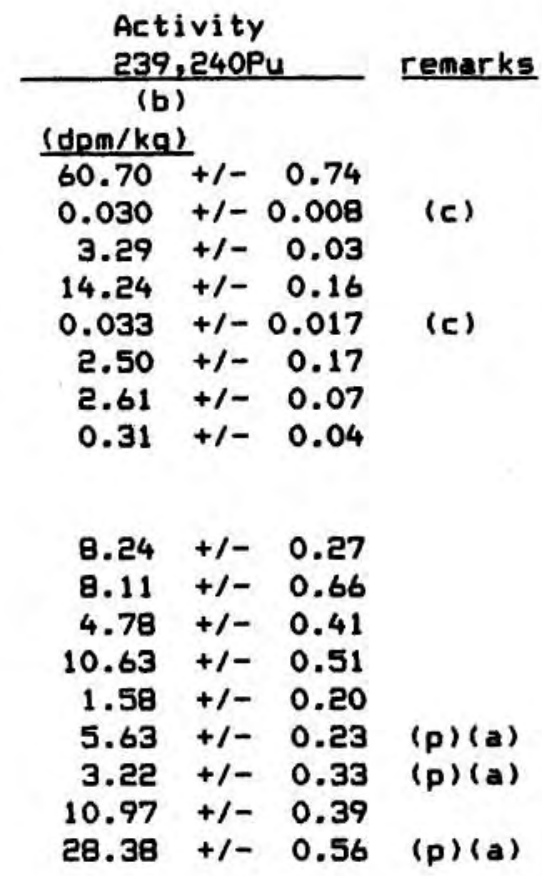

Surface sediment: deep-sea

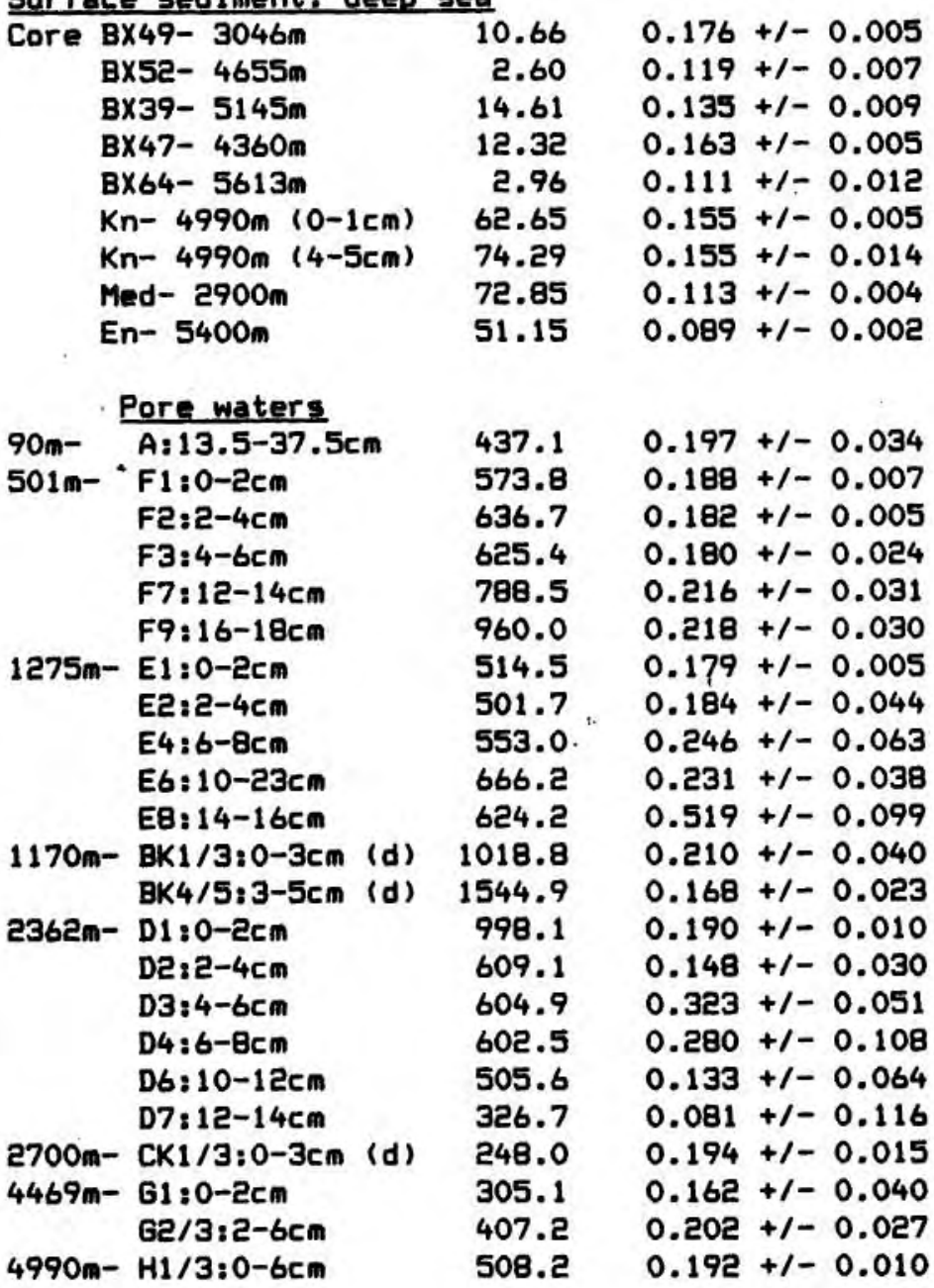

$(\mathrm{dpm} / 100 \mathrm{~kg})$

\begin{tabular}{|c|c|c|c|}
\hline 0.122 & $\frac{14}{+1-}$ & 0.015 & \\
\hline 0.181 & $+1-$ & 0.004 & \\
\hline 0.424 & $+1-$ & 0.008 & \\
\hline 0.059 & $+1-$ & 0.003 & \\
\hline 0.036 & $+1-$ & 0.003 & \\
\hline 0.007 & $+1-$ & 0.001 & \\
\hline 0.567 & $+1-$ & 0.007 & \\
\hline 0.122 & $+1-$ & 0.012 & \\
\hline 0.016 & $+1-$ & 0.002 & \\
\hline 0.012 & $+1-$ & 0.001 & \\
\hline 0.002 & $+1-$ & 0.001 & \\
\hline 0.123 & $+1-$ & 0.014 & \\
\hline 0.012 & $+1-$ & 0.001 & \\
\hline 0.188 & $+1-$ & 0.006 & \\
\hline 0.034 & $+1-$ & 0.003 & \\
\hline 0.006 & $+1-$ & 0.001 & (c) \\
\hline 0.005 & $+1-$ & 0.001 & (c) \\
\hline 0.003 & $+1-$ & 0.002 & (c) \\
\hline 0.009 & $+1-$ & 0.004 & (c) \\
\hline 0.750 & $+1-$ & 0.049 & \\
\hline 0.223 & $+1-$ & 0.023 & \\
\hline 0.137 & $+1-$ & 0.010 & \\
\hline 0.154 & $+1-$ & 0.005 & \\
\hline
\end{tabular}


Table 6.2. cont. Pu date by mass spectrometry

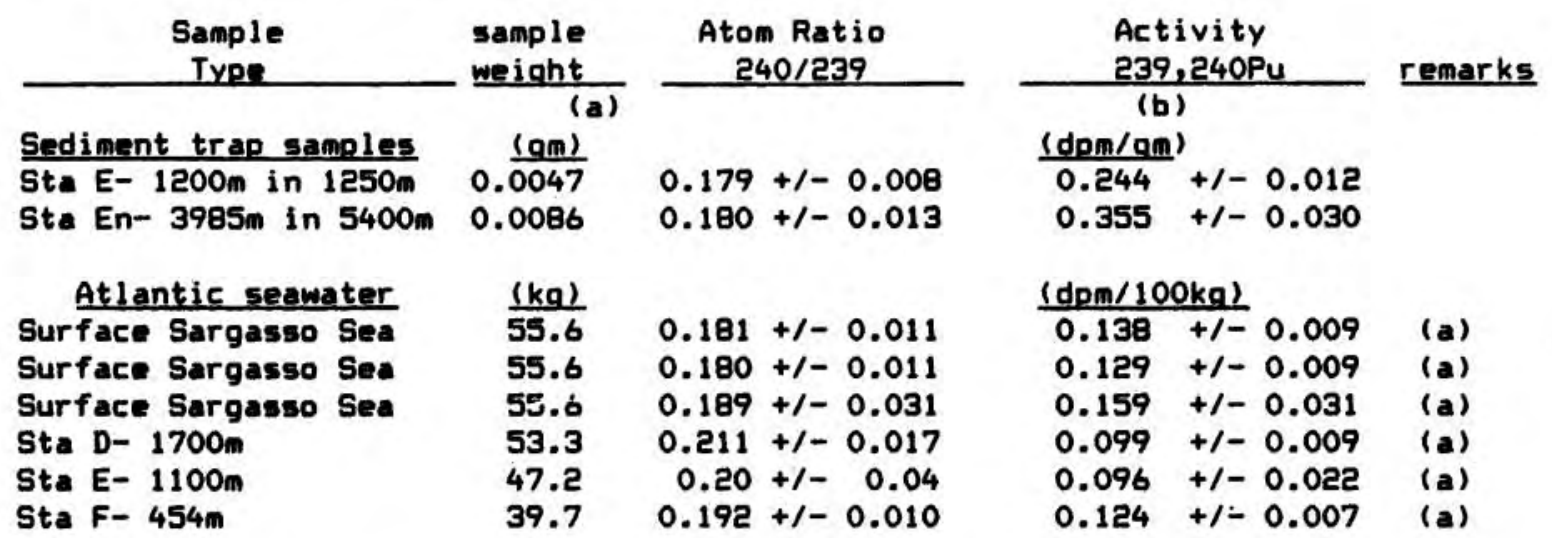

(a)- These are the original sample weights- some of the sediment and sea water samples are actually sub-samples (1/50th) of larger samples used for alpha-counting. These subsamples are marked with an (a) in the remarks column.

(b)- All activity data are reported with an error propigated from the error on the m.s. determination of the Pu isotopes and the error on the procedural blanks.

(c)- The blank correction on these samples represents $>25 \%$ of the total Pu activity.

(d)- Cores BK and CK were taken at the same ships station as cores E and C, respectively.

(p)- These samples were leached off of previously analyzed alpha-counting stainless steel planchetts 
thesis. Ratios of ${ }^{240} \mathrm{Pu} /{ }^{239} \mathrm{Pu}$ are always given on an atom basis while ${ }^{239} \mathrm{Pu}$ and ${ }^{240} \mathrm{Pu}$ concentrations have been converted into $239,240 \mathrm{Pu}$ activities for easier comparison to existing Pu activity data.

\section{RESULTS AND DISCUSSION}

A. ${ }^{240} \mathrm{Pu} /{ }^{239} \mathrm{Pu}$ Ratios a long a Sediment Transect from the N.W. Atlantic

A major feature of the sediment data along the transect of box cores $A(90 \mathrm{~m})$ through $H(4990 \mathrm{~m})$ is a systematic decrease in the $240 \mathrm{Pu} /{ }^{239} \mathrm{Pu}$ ratio with increasing water depth (Fig. 6.2). The mean ${ }^{240} \mathrm{Pu} /{ }^{239} \mathrm{Pu}$ ratios from these sediment cores are $0.193,0.176,0.152$, $0.137,0.128,0.105$ and 0.101 at 90, 501, 1275, 2362, 2700, 4469 and $4990 \mathrm{~m}$, respectively (Table 6.2 ). The values are roughly equal to the proposed average global fallout ${ }^{240} \mathrm{Pu} /{ }^{239} \mathrm{Pu}$ ratio of 0.18 in the shallower cores dropping off to progressively lower values with depth. Also, there is very little variability in these ratios within each core (Table 6.2). These trends are very similar to the Gulf of Mexico data of Scott et al. (1983) and a common process responsible for this shift in the Pu isotopic signature must be sought.

One possible process, the fractionation of ${ }^{239} \mathrm{Pu}$ from ${ }^{240} \mathrm{Pu}$ during the removal of $\mathrm{Pu}$ to the sea floor, can be discounted. The isotopic signature of the present day flux of $P u$ to the sea floor has been measured in sediment trap material. A ${ }^{240} \mathrm{Pu} /{ }^{239} \mathrm{Pu}$ ratio of $0.179 \pm 0.008$ is found in sediment trap debris from a trap located in $1200 \mathrm{~m}$ of water above core $\mathrm{E}\left(1275 \mathrm{~m}\right.$ ) (see Table 6.2). Similarly a ${ }^{240} \mathrm{Pu} /{ }^{239} \mathrm{Pu}$ ratio of $0.180 \pm 0.013$ is found in a trap in $3985 \mathrm{~m}$ of water above core En $(5400 \mathrm{~m})$. The seawater in this region has an average ${ }^{240} \mathrm{Pu} /{ }^{239} \mathrm{Pu}$ ratio of $0.190 \pm 0.014$ (Table 6.2), which is similar to the trap debris and consistent with the expected ${ }^{240} \mathrm{Pu} /{ }^{239} \mathrm{Pu}$ ratio of global stratospheric fallout. The similarity between the seawater and sediment trap samples argues against any present day fractionation of ${ }^{239} \mathrm{Pu}$ from ${ }^{240} \mathrm{Pu}$ in the water column.

A second possible explanation for the systematic decrease in the 

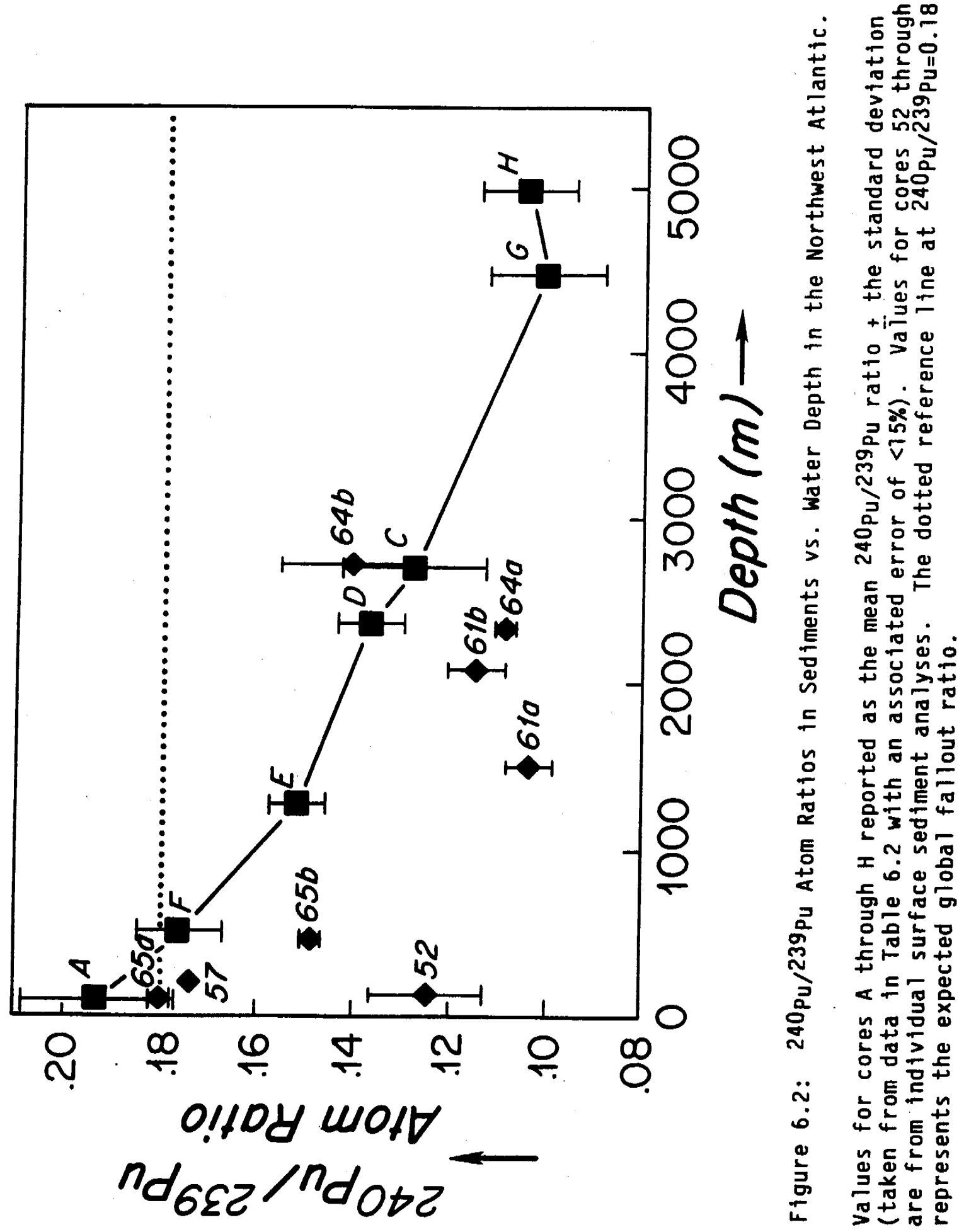
$240 \mathrm{Pu} /{ }^{239} \mathrm{Pu}$ ratios with increasing water depth is the existence of a unique source of low ratio $\mathrm{Pu}$ to the deep-sea at these sites. This second mechanism is shown schematically in Fig. 6.3, and will be the focus of the remaining discussions. The essential feature of this model is the deposition of two isotopically distinct sources of fallout $\mathrm{Pu}$ with different geochemical properties. The largest source of fallout Pu to the surface oceans is known to be global stratospheric fallout with an average ${ }^{240} \mathrm{Pu} /{ }^{239} \mathrm{Pu}$ ratio of 0.18 . Fallout $\mathrm{Pu}$ from this source remains primarily in solution, given that $>95 \%$ of the total Pu inventory of the deep Atlantic is found throughout the water column today (Buesseler et a1., 1985; Livingston and Buesseler, 1985). I suggest that the second $\mathrm{Pu}$ source is tropospheric fallout from the Nevada Test Site since this is the largest source of low ratio fallout $\mathrm{Pu}$ in the Northern Hemisphere. If the Nevada fallout is rapidly removed to marine sediments, then the ${ }^{240} \mathrm{Pu} /{ }^{239} \mathrm{Pu}$ ratio in marine sediments will be a function of the additional supply of stratospheric fallout Pu added to any given site. Hence in the shallow water cores, where the sedimentary $\mathrm{Pu}$ inventories are highest, the ${ }^{240} \mathrm{Pu} /{ }^{239} \mathrm{Pu}$ ratio is dominated by the stratospheric inputs while in the deep sea, where Pu sediment inventories are low, the Nevada fallout signature is more readily observed (Fig. 6.3).

Several lines of evidence will be used to test this model. First, we need to look at the arrival history of Nevada fallout versus global fallout since samples from the early testing years should show stronger evidence of Nevada fallout inputs (1951-1958) if our model is correct. Secondly, a discussion of the physical/chemical characteristics of different fallout types will be given followed by an evaluation of the inventories of Nevada debris and the extent of travel of Nevada fallout across the North Atlantic basin.

B. ${ }^{240} \mathrm{Pu} /{ }^{239} \mathrm{Pu}$ Data in Sediments from the 1950's and 1960's

If Nevada is the source of low ${ }^{240} \mathrm{Pu} /{ }^{239} \mathrm{Pu}$ material to the North Atlantic, then one would expect to see the effects of this input most easily in the early 1950's, which are the years of the relatively 
N. W. Atlantic fallout Pu model
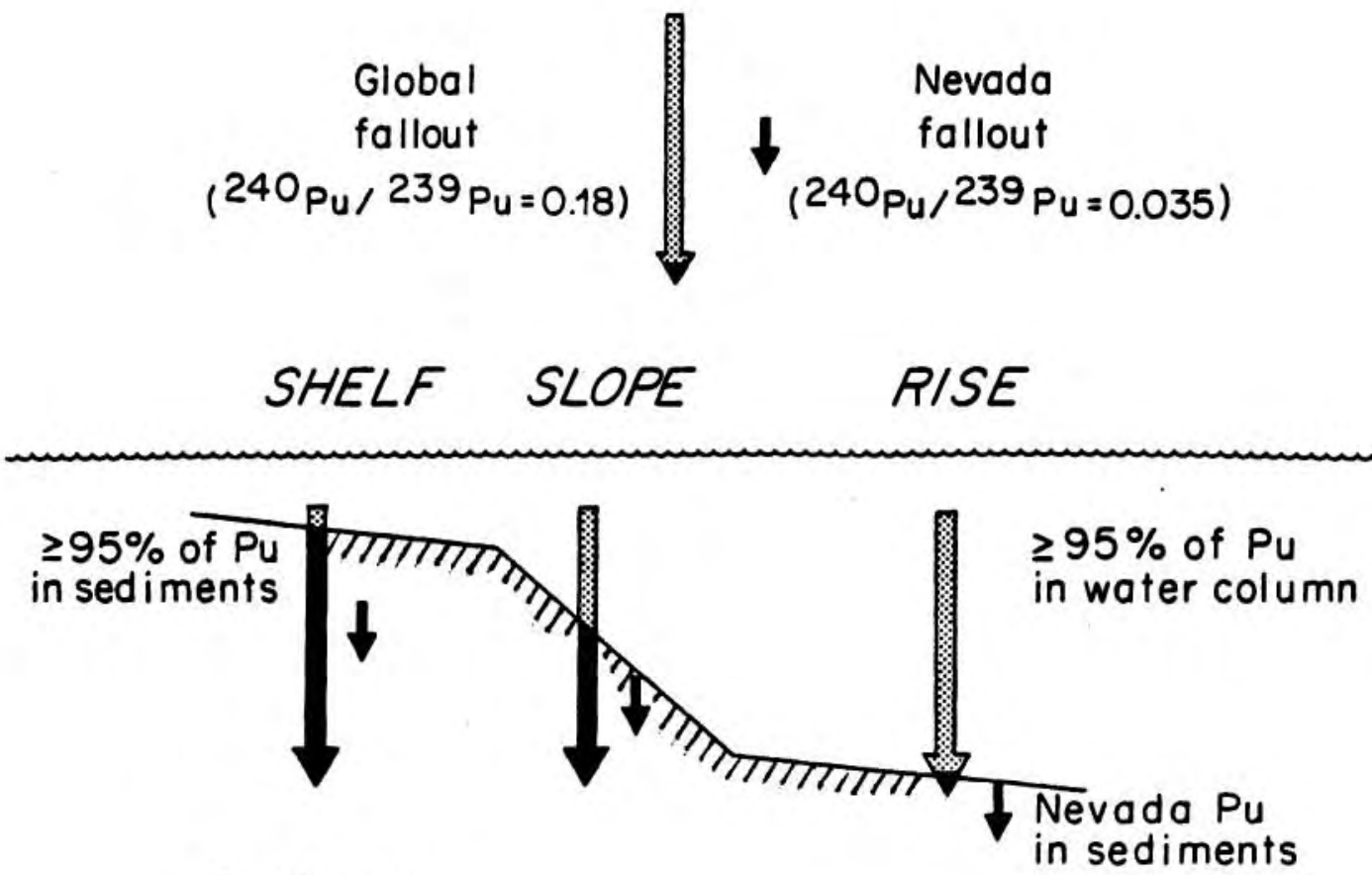

Sediment

$240 \mathrm{Pu}_{2} 239 \mathrm{Pu}_{\mathrm{Pu}} \sim \mathrm{18} \sim 0.14-0.16 \quad \sim 0.09$

NevadaPu $\leq 1 \% \quad 10-20 \% \quad$ up to $50 \%$

Total Pu

\section{Figure 6.3:}

\footnotetext{
Nevada fallout $(240 \mathrm{Pu} / 239 \mathrm{Pu}=0.035)$ which is deposited to the $N$. Atlantic is rapidiy removed to the sediments at all depths. Global stratospheric fallout $(240 \mathrm{Pu} / 239 \mathrm{Pu}=0.18)$ is delivered in much larger quantities to the $N$. Atlantic; however, only the shallow shelf and slope sites have sufficient removal rates to deposit the bulk of this Pu to the sediments, while at the deep ocean sites, the bulk of stratospheric Pu remains in the watercolumn. The relative inventory of stratospheric vs. Nevada fallout in sediments therefore changes systematically with depth resulting in the observed decrese in the $240 p_{u} / 239 p_{u}$ ratio with increasing depth (as shown below the figure). The percentage Nevada Pu inventorles are from Table 6.3 and are discussed in the text.
} 
highest Nevada fallout inputs (see Fig. 6.4). This evidence can best be seen in lake cores, where undisturbed Pu fallout records can be obtained (Breteler et al., 1984; Krey, 1983). Figure 6.5 shows significantly lower ${ }^{240} \mathrm{Pu} /{ }^{239} \mathrm{Pu}$ ratios in the early 1950 's in lake cores from both the southwest (Utah) and northeast (New York) U.S.A. This data provides evidence supporting both the timing (early 50's) of the Nevada inputs and the minimum distances which this Nevada fallout material has apparently traveled (at least to N.Y.).

Unfortunately, there are no other comparable records of ${ }^{240} \mathrm{Pu} /{ }^{239} \mathrm{Pu}$ in early fallout from this region. The ice core ${ }^{240} \mathrm{Pu} /{ }^{239} \mathrm{Pu}$ records of Koide et al. (1985) at Greenland only begin with the 1954-1956 band, missing the earliest fallout signals. Due to rapid sediment mixing in oxic marine cores, an historical profile of Pu inputs would not be retained in the present day sediment proflles from the study region.

In an attempt to reconstruct the historical record of ${ }^{240} \mathrm{Pu} /{ }^{239} \mathrm{Pu}$ ratios along the Woods Hole to Bermuda transect, nine surface sediment samples from the 1950's and 1960's were found in sediment core libraries which could be analyzed for ${ }^{239} \mathrm{Pu}$ and ${ }^{240} \mathrm{Pu}$ by m.s. The core locations are given in Figure 6.1, and the data are provided in Table 6.2 and shown versus water depth in Figure 6.2. A major feature of the historical samples is that all sediments show lower or equivalent ${ }^{240} \mathrm{Pu} /{ }^{239} \mathrm{Pu}$ ratios relative to present day sediments. The best evidence for the input of low ratio Nevada fallout in the early 1950's can be seen in a time sequence of cores from the muddy shelf in this region (cores 52, 57 and $65 \mathrm{a})$. The sediment sample from 1952 has a ${ }^{240} \mathrm{Pu} /{ }^{239} \mathrm{Pu}$ ratio of $0.125 \pm 0.012$ and a ${ }^{239,240} \mathrm{Pu}$ activity of $0.03 \mathrm{dpm} / \mathrm{kg}$. By 1957, the $240 \mathrm{Pu} /{ }^{239} \mathrm{Pu}$ ratio of the shallow sediments $(200 \mathrm{~m})$ are $0.174 \pm 0.001$ and a Pu activity of $3.3 \mathrm{dpm} / \mathrm{kg}$ is found. In 1965 the ${ }^{240} \mathrm{Pu} /{ }^{239} \mathrm{Pu}$ ratio in shelf sediments is $0.180 \pm 0.002$ and the activity is now $60 \mathrm{dpm} / \mathrm{g}$. At core $A(90 \mathrm{~m})$ in 1983 on the muddy shelf, the surface sediments have the same ${ }^{240} \mathrm{Pu} /{ }^{239} \mathrm{Pu}$ ratio but their activity has increased to over 100 $\mathrm{dpm} / \mathrm{g}$. It has been shown that the highest sediment inventories of Pu and hence the strongest removal fluxes of Pu to the sediments are found in the muddy shelf sites along this transect (Santschi et al., 1980; 
Figure 6.4: Testing Yield Data vs. Time for the Nevada Test Site and Global Fallout Sources.

Nevada vs. Global Fallout Yields

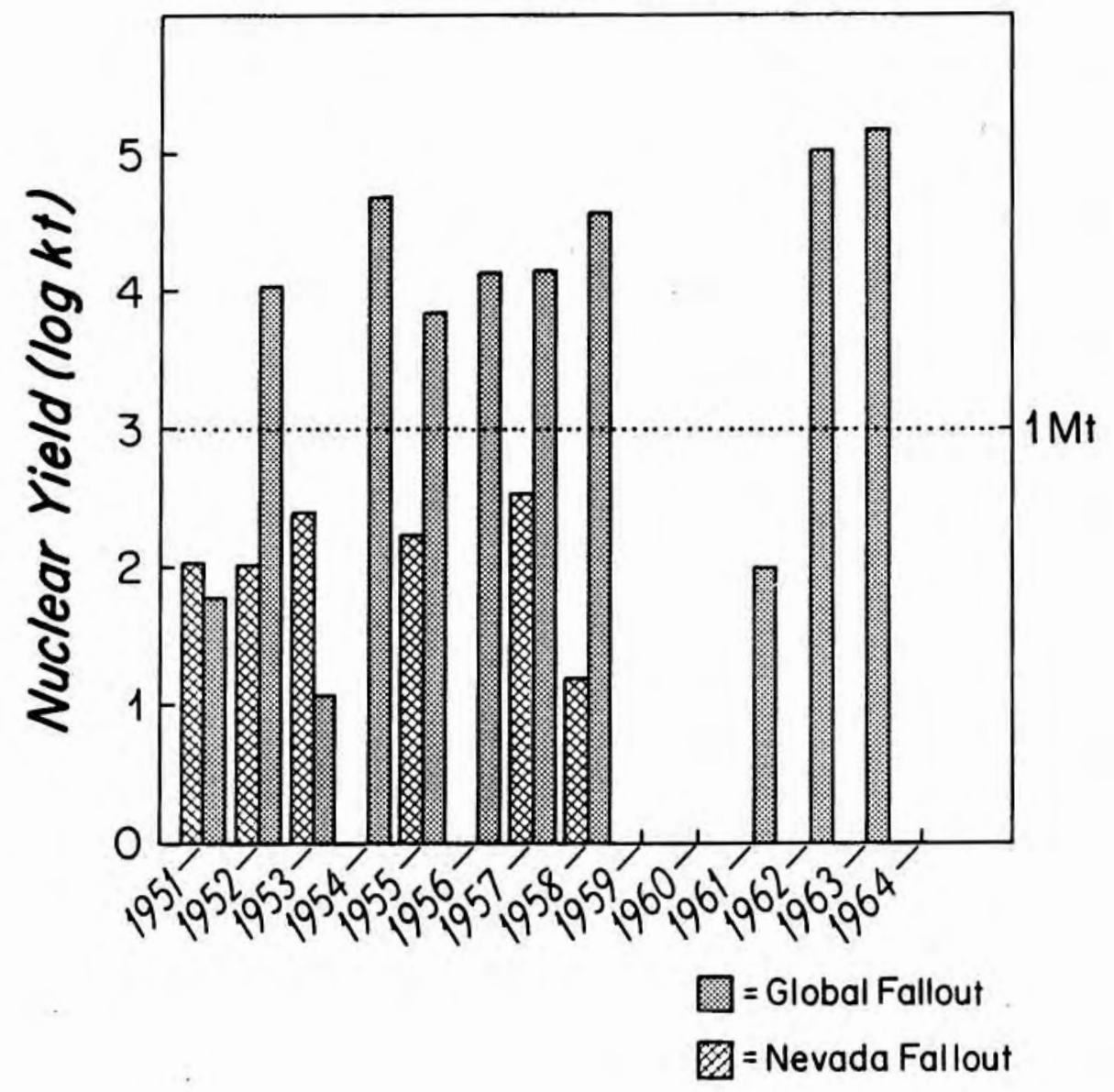

Yield data taken from D.O.E. (1982); Perkins and Thomas (1980); and Hicks and Baar (1984). Note log scale. 


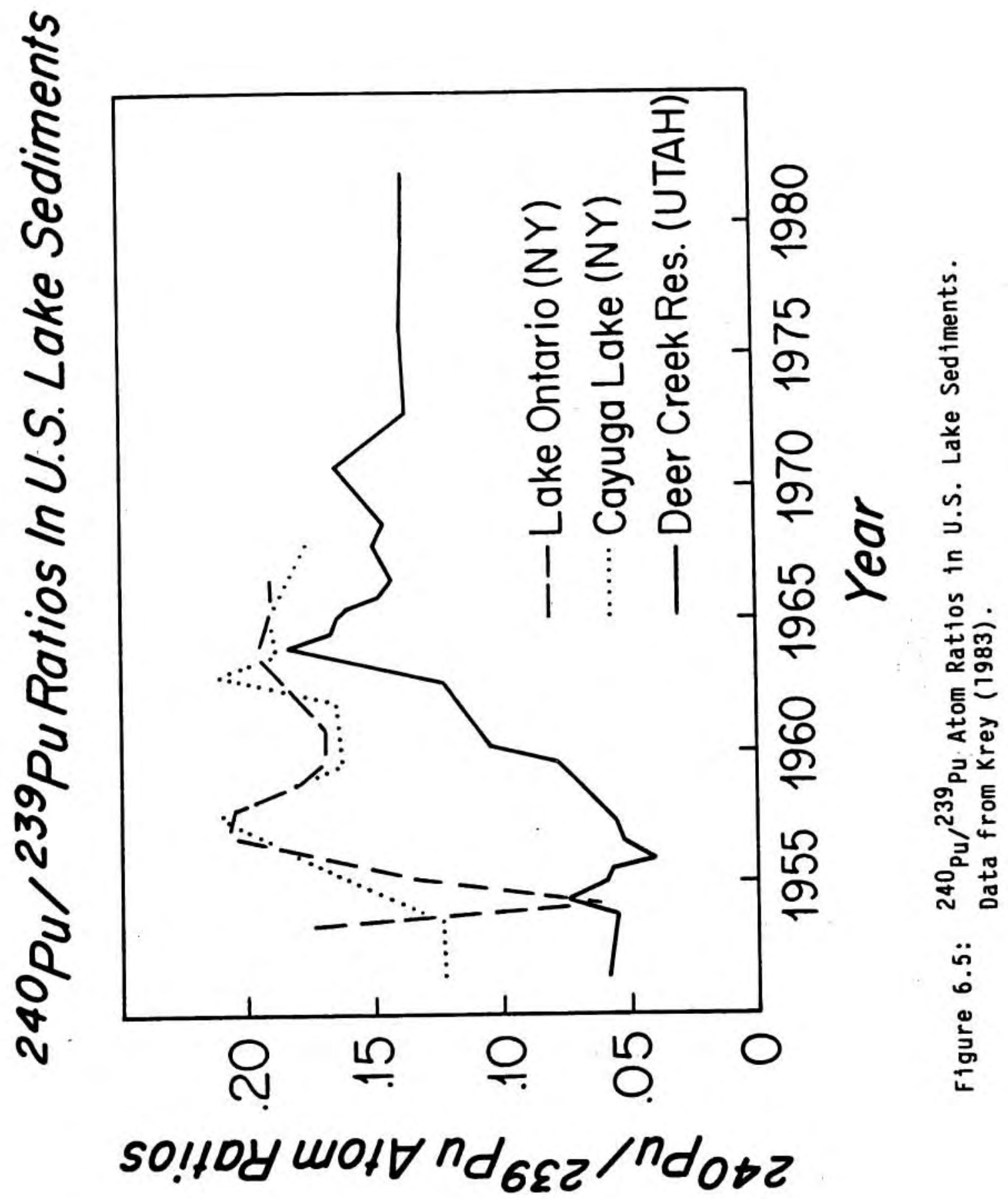


Buesseler et al., 1985). The ${ }^{240} \mathrm{Pu} /{ }^{239} \mathrm{Pu}$ ratio of 0.125 in 1952 suggests that some combination of Nevada fallout and early global fallout has already reached the sediments on the shelf by this time. By 1957, due to the rapid scavenging of global fallout Pu the $240 \mathrm{Pu} /{ }^{239} \mathrm{Pu}$ ratios have increased to essentially present day values while the surface activities continue to increase with time. While the 1960 's samples from the shelf have essentially present day ${ }^{240} \mathrm{Pu} /{ }^{239} \mathrm{Pu}$ ratios, some of the deeper samples (cores 65, 61a, 61b and 64a) have lower than present day ${ }^{240} \mathrm{Pu} /{ }^{239} \mathrm{Pu}$ ratios due perhaps to the generally slower removal rates of global fallout $\mathrm{Pu}$ to the deeper sediments. With time, the continued flux of $\mathrm{Pu}$ to the deeper sediments should continue to slowly raise the overall ${ }^{240} \mathrm{Pu} /{ }^{239} \mathrm{Pu}$ ratio in the sediments until the global fallout ${ }^{240} \mathrm{Pu} /{ }^{239} \mathrm{Pu}$ ratio of $\simeq 0.18$ is obtained along the entire transect.

C. The Solubility and Removal Rates of Global Versus Nevada Fallout The model I have proposed for the separation of global versus Nevada fallout Pu (Fig. 6.3) is based on the assumption that upon entering the ocean, tropospheric debris from the Nevada Test Site $\left({ }^{240} \mathrm{Pu} /{ }^{239} \mathrm{Pu}=0.035\right)$ is geochemically separated from fallout from stratospheric sources (i.e. the Nevada debris is more rapidly removed to marine sediments). This difference in the removal rates between these two classes of fallout particles can be explained if we explore the contrasting modes of fallout particle formation in surface based (Nevada) versus high altitude (global) tests. Surface based nuclear tests are characterized by the existence in the cooling fireball of large amounts of material swept up from the ground by the explosion. Condensation reaction of the vaporized materials would therefore proceed in large measure upon the surfaces provided. In Nevada, partially and completely melted soll silicates condense as crystalline and glass-like particles which become the carriers of significant fallout radioactivity (Adams et a1., 1960; Joseph et a1., 1971). Air bursts in contrast, produce smaller metal oxide particles which originate from direct vaporization and subsequent condensation reactions of the vaporized 
nuclear bomb materials (the major components being iron and the fissioned and unfissioned radionuclides) (Adams et al., 1960).

Early studies of the solubility of fallout particles can be used to demonstrate the major differences in the behavior of these two classes of fallout debris upon deposition. As one might expect, the leachabilty (and hence solubility) of air burst debris is much greater than the silicate-burst debris (Mamuro et al., 1965; Joseph et al., 1971; Larson, 1982). More specifically, Larson (1982) compared the solubility of fallout debris generated in surface based tests (tower shots) and high altitude balloon tests at Nevada. In this study, less than $2 \%$ of the total sample beta-activity is released into a deionized water solution after one hour from the surface based fallout particles. This is in contrast to 14-37\% of the activity being released under identical conditions from the high-altitude fallout particles. In a similar experiment, Weimer and Langford (1978) examined the solubility of fallout ${ }^{55} \mathrm{Fe}$ from aerosol samples collected on the U.S. west coast (this would presumably represent average global fallout debris). In one test, up to $30 \%$ of the total ${ }^{55} \mathrm{Fe}$ present in the aerosol samples was released into seawater after 24 hours and in another test $67-97 \%$ of the ${ }^{55} \mathrm{Fe}$ was solubilized. They concluded that the radioactive $\mathrm{Fe}$ was held as amorphous $\mathrm{Fe}$ oxides on the surfaces of fine atmospheric particulate matter and was rapidly released to solution. A simflar process could be expected for Pu which would condense as a trace impurity on or in the Fe oxide particles which form the core of stratospheric fallout (Adams et al., 1960; Weimer and Langford, 1978).

If Pu from the Nevada source is being carried by small, unreactive and insoluble glass-like particles, a simple Stoke's settling velocity calculation may be appropriate for estimating the potential sinking rates of these particles through the water column. The Stoke's settling velocity equation is:

$$
\text { velocity }=\frac{(\text { Dta })^{2}\left(\rho_{\text {fallout }}-\rho_{\text {seawater }}\right) \cdot g}{18 \eta}
$$


where the velocity is in $\mathrm{cm} / \mathrm{sec}$; the mean diameter of Nevada fallout is $10 \mu \mathrm{m}\left(1-100 \mu \mathrm{m}\right.$ is typical - Joseph et a1., 1971; Larsen, 1985); $\rho_{\text {Nevada }}$ $=2.6 \mathrm{~g} / \mathrm{cm}^{3}$ (1.e. that of quartz); $\rho_{\text {sea water }}=1 ; g=980 \mathrm{~cm} / \mathrm{sec}$; and $n=0.014$ poises (at $7^{\circ} \mathrm{C}$ ). The calculated settling velocity is $5.4 \mathrm{~m} /$ day, or a transit time of $\simeq 1$ year for a $2000 \mathrm{~m}$ water column. This rate is consistent with the idea of rapid settling of Nevada tropospheric fallout particles to the sea floor. Indeed, if the fallout particles were incorporated into fecal pellets, their sinking rates would be enhanced.

\section{Pore Water $240 \mathrm{Pu} / 239 \mathrm{Pu}$ Ratios}

Pore water data from along the transect of cores $A$ through $H$ provide direct evidence of the insoluble and unreactive nature of the fallout particles carrying the low ${ }^{240} \mathrm{Pu} /{ }^{239} \mathrm{Pu}$ ratio Nevada $\mathrm{Pu}$. In cores where the solid phase ${ }^{240} \mathrm{Pu} /{ }^{239} \mathrm{Pu}$ ratio is 0.18 (cores $\mathrm{A}$ and $\mathrm{F}$ ), the pore water ${ }^{240} \mathrm{Pu} /{ }^{239} \mathrm{Pu}$ ratio is equal to the global average $240 \mathrm{Pu} /{ }^{239} \mathrm{Pu}$ ratio of $\cong 0.18$ (Fig. 6.6 ). However, in cores with average solid phase ${ }^{240} \mathrm{Pu} /{ }^{239} \mathrm{Pu}$ ratios of 0.15 (core $\mathrm{E}$ at $1275 \mathrm{~m}$ ), 0.14 (core D at $2362 \mathrm{~m}$ ), 0.13 (core $C$ at $2700 \mathrm{~m}$ ) and 0.10 (cores $G$ and $H$ at 4469 and $4990 \mathrm{~m}$, respectively) the pore water ${ }^{240} \mathrm{Pu} /{ }^{239} \mathrm{Pu}$ ratios remain $\simeq 0.18$, in dis-equilibrium with the solid phase (Fig. 6.6). These data suggest that the Nevada debris in the sediments $\left({ }^{240} \mathrm{Pu} /{ }^{239} \mathrm{Pu}=0.035\right)$ is more tightly bound by its solid phase carrier than the global fallout Pu $\left({ }^{240} \mathrm{Pu} /{ }^{239} \mathrm{Pu}=0.18\right)$, and is therefore not participating in the $\mathrm{Pu}$ solid/solution exchangereactions. This is supporting evidence for the preferential solubility of global fallout relative to tropospheric Nevada fallout Pu in marine sediments. A simtlar pattern should emerge if sequential leaching experiments on these sediments were to be performed in the laboratory.

These data also raise the question of the completeness of our laboratory $\mathrm{Pu}$ sediment extraction procedures which use hot $8 \mathrm{~N} \mathrm{HNO}_{3}$ to remove Pu from the sediments for total Pu analysis. While the procedure may be appropriate for sediments in which the Pu is predominantly derived from global fallout, future deep-sea sediment analysis should 


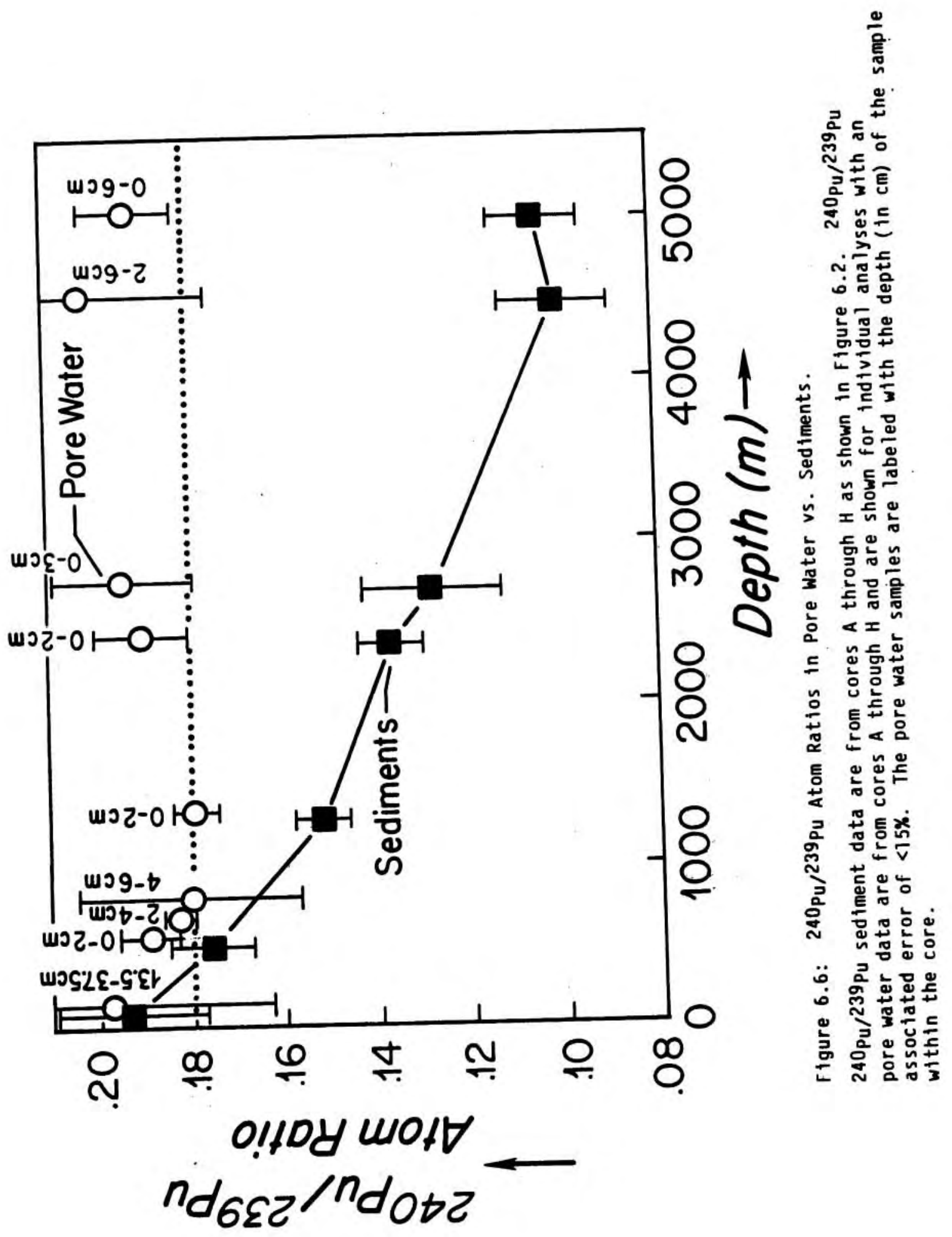


include total dissolution steps to examine if the leaching steps are truly quantitative. Indeed, researchers who study fallout Pu in solls have found that a total dissolution procedure is necessary in their analyses of samples which contain significant fallout from the Nevada Test Site (Perrin et a1., 1985; Krey and Bogen, 1986).

E. Nevada Fallout Inventories and the Spatial Extent of this Debris Using the simple two end-member mixing model of Krey et al. (1976) (see Table 6.3) and a ${ }^{240} \mathrm{Pu} /{ }^{239} \mathrm{Pu}$ atom ratio of 0.18 and 0.035 for global stratospheric fallout and Nevada tropospheric fallout respectively, I have calculated the fraction of the total Pu activity at any given site from the Nevada source alone. The results in Table 6.3 show that over $40 \%$ of the total ${ }^{239,240} \mathrm{Pu}$ activity in the deep-sea cores $G$ and $H$ is due to the Nevada source. The percentage of Nevada fallout decreases in the shallower cores where $28 \%$ (at $2700 \mathrm{~m}$ ), 22\% (at $2362 \mathrm{~m}$ ), 14\% (at $1275 \mathrm{~m}$ ), 2\% (at $501 \mathrm{~m}$ ) and 1ess than 1\% (at $90 \mathrm{~m}$ ) of the activity of $239,240 \mathrm{Pu}$ is supplied by the low ratio Nevada fallout. I have also calculated in Table 6.3 the sensitivity range of the two end-member model to changes in the assumed ${ }^{240} \mathrm{Pu} /{ }^{239} \mathrm{Pu}$ ratios of Nevada and global fallout. Within a range of ${ }^{240} \mathrm{Pu} /{ }^{239} \mathrm{Pu}$ ratios from 0.030-0.040 for Nevada fallout and 0.175-0.185 for global fallout, the percent fraction of the total Pu activity from the Nevada source varies by only $\pm 3 \%$, given a sample ${ }^{240} \mathrm{Pu} /{ }^{239} \mathrm{Pu}$ ratio of 0.10 or 0.15 .

As mentioned previously, the influence of the Nevada fallout becomes less significant in the shallower cores due to the enhanced scavenging and removal of stratospheric $\mathrm{Pu}$ in the shallower regions (Buesseler et al., 1985). The relatively high percentages of Nevada fallout in the deep-sea may at first appear surprising considering that relative to global fallout the Nevada source contributed less than $1 \%$ to the total Pu supply to the environment (based upon total yields calculated from D.0.E., 1982). The very low total Pu inventory in the deep-sea sediments must accentuate the effect of Nevada fallout at these sites. 
Table 6.3. Percentage of Nevada Fallout in N.W. Atlantic Sediments

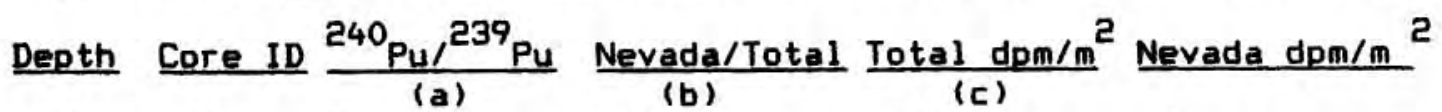

$\begin{array}{llllll}90 \mathrm{~m} & \text { A } & 0.193 & <0 \% & 12400 & 0 \\ 501 \mathrm{~m} & \text { F } & 0.176 & 2 \% & 2660 & 50 \\ 1275 \mathrm{~m} & \text { E } & 0.152 & 14 \% & 2270 & 308 \\ 2362 \mathrm{~m} & \text { D } & 0.137 & 22 \% & 1270 & 283 \\ 2700 \mathrm{~m} & \text { C } & 0.128 & 28 \% & 290 & 80 \\ 4469 \mathrm{~m} & \text { G } & 0.101 & 45 \% & 260 & 117 \\ 4990 \mathrm{~m} & \text { H } & 0.105 & 42 \% & 430 & 181\end{array}$

(a) - ${ }^{240} \mathrm{Pu} /{ }^{239} \mathrm{Pu}$ sediment data from Table $6-2$

(b)- Calculated from the two fallout end-member model of Krey et al. (1976):

$$
\frac{(\text { Pu Activity })_{1}}{(\text { Pu Activity })_{2}}=\frac{\left(R_{2}-R\right)}{\left(R-R_{1}\right)} \frac{\left(1+3.68 R_{1}\right)}{\left(1+3.68 R_{2}\right)}
$$

where $\mathrm{R}={ }^{240} \mathrm{Pu} /{ }^{239} \mathrm{Pu}$ atom ratio of sample

where $R_{1}={ }^{240} \mathrm{Pu}^{239} \mathrm{Pu}$ atom ratio of source 1 (i.e. Nevada $=0.035$ )

where $R_{2}={ }^{240} \mathrm{Pu} /{ }^{239} \mathrm{Pu}$ atom ratio of source 2 (i.e. Global $=0.18$ ).

* This equation converts ${ }^{240} \mathrm{Pu} /{ }^{239} \mathrm{Pu}$ atom ratio data to activity ratios of $239,240 \mathrm{Pu}$ from two sources. The constant 3.68 is the ratio of the specific activities of ${ }^{240} \mathrm{Pu}$ to ${ }^{239} \mathrm{Pu}$.

Sensitivity of Krey model to varying end-member atom ratios

- Calculated for $R=0.15$ and $R=0.10$

- Reported as the \% Nevada/Total activity

$\begin{array}{lllllll} & R_{2}=0.175 & R_{2}=0.180 & R_{2}=0.185 & R_{2}=0.175 & R_{2}=0.180 & R_{2}=0.185 \\ R_{1}=0.030 & 12 \% & 14 \% & 16 \% & 42 \% & 43 \% & 45 \% \\ R_{1}=0.035 & 13 \% & 15 \% & 17 \% & 44 \% & 46 \% & 47 \% \\ R_{1}=0.040 & 14 \% & 16 \% & 18 \% & 47 \% & 48 \% & 49 \%\end{array}$

(c)- Sediment Pu inventory data from Chapter 4 and in Buesseler et al., 1985 
Another means of examining the contribution of Nevada fallout Pu to these sediments is to use the Nevada fallout percentages and the measured total sediment Pu inventory to estimate the total inventory of Nevada fallout Pu deposited at each site. The results suggest (Table 6.3) that between 50 and $300 \mathrm{dpm} / \mathrm{m}^{2}$ of $239,240 \mathrm{Pu}$ from the Nevada test site was deposited along this transect (cores $F$ through $H$ ). This can be compared to a total global fallout ${ }^{239,240} \mathrm{Pu}$ delivery estimate of 5600 $\mathrm{dpm} / \mathrm{m}^{2}$ at these latitudes (Hardy et a 1., 1973). This sediment inventory calculation suggests that $1-5 \%$ of the total Pu deposited along this transect is from the Nevada source while yield data suggest that $<1 \%$ of the total Pu should have been generated from the Nevada tests. The apparent discrepancy between these two estimates may reflect problems with the simple two end-member mixing approach or errors in the delivery estimates and/or test yields. The Nevada fallout ${ }^{240} \mathrm{Pu} /{ }^{239} \mathrm{Pu}$ ratios do vary between tests (Hicks and Barr, 1984), and rather than representing a well mixed average the fallout deposition at any one site may reflect a very patchy input of deposition from specific tests (as seen for example in Troy, N.Y. where tropospheric fallout from a nuclear test at Nevada was deposited as a localized "hot spot" - clark, 1954). The factor of six range in the sediment ${ }^{239,240} \mathrm{Pu}$ inventory atributable to the Nevada source may reflect the patchiness of the Nevada fallout deposition.

An independent estimate of the total Nevada fallout inventory which one might expect in this region can be obtained from data on total fallout ${ }^{90} \mathrm{Sr}$ deposition from the Nevada tests (Larsen, 1985). Larsen estimates that $20 \mathrm{mCi} / \mathrm{km}^{2}$ of ${ }^{90} \mathrm{Sr}$ from the Nevada tests was delivered as tropospheric fallout, calculated from the Nevada test yields and assuming that this fallout were spread only across the continental U.S. Given a $239,240 \mathrm{Pu} /{ }^{90} \mathrm{Sr}$ ratio in fallout of 0.017 (Harley, 1980), one would expect $\simeq 750 \mathrm{dpm} / \mathrm{m}^{2}$ of Nevada fallout Pu over this same region. This agrees reasonably well with my data $\left(50-300 \mathrm{dpm} / \mathrm{m}^{2}\right)$, considering that if the Nevada debris was spread beyond U.S. boundaries (as suggested by my data) the Larsen estimate would decrease substantially.

To estimate the spatial extent of the Nevada tropospheric fallout, 
surface samples from box cores across the North Atlantic were analyzed for their ${ }^{240} \mathrm{Pu} /{ }^{239} \mathrm{Pu}$ ratios. At locations where the total $\mathrm{Pu}$ inventory was known, the net sediment inventory from the Nevada source was estimated by the same procedure used in Table 6.3. Figure 6.7 shows the location of these cores and results of their analysis. Also included in Figure 6.7 are the calculated Nevada Pu inventories from the data of Scott et al. (1983) in the Gulf of Mexico. The existence of deep-sea sediment samples with ${ }^{240} \mathrm{Pu} /{ }^{239} \mathrm{Pu}$ ratios $<0.18$ across the entire North Atlantic basin is somewhat surprising. While the inventories of Nevada Pu in the Gulf of Mexico $\left(60-500 \mathrm{dpm} / \mathrm{m}^{2}\right)$ are similar to those in the N.W. Atlantic $\left(50-300 \mathrm{dpm} / \mathrm{m}^{2}\right)$, the apparent Nevada inventories in the Mid-and Eastern Atlantic and the Eastern Mediterranean are lower $\left(15-30 \mathrm{dpm} / \mathrm{m}^{2}\right)(\mathrm{Fig} .6 .7)$. Clearly more data are needed, but the wide extent of the $10 \mathrm{w}{ }^{240} \mathrm{Pu} /{ }^{239} \mathrm{Pu}$ ratio sediments is evident. Estimates of the trajectories of tropospheric fallout from the Chinese tests (U.N., 1982) and the U.S. Marshall Islands tests (Machta et a1., 1956) do support the transport of tropospheric fallout around the globe within a matter of weeks. Interestingly, the one deep-sea core analyzed at $2^{\circ} \mathrm{S}$, did not show any evidence of the Nevada component $\left({ }^{240} \mathrm{Pu} /{ }^{239} \mathrm{Pu}=0.18\right)$, which is consistent with the expected lack of inter-hemispheric mixing of Nevada fallout in the troposphere. More analyses at cores with complete Pu inventory and isotope ratio data are needed to further elucidate the source(s) of Pu to the deep-sea across the entire Atlantic basin.

\section{F. ${ }^{240} \mathrm{Pu} /{ }^{239} \mathrm{Pu}$ Profiles within Individual Cores}

While the average ${ }^{240} \mathrm{Pu} /{ }^{239} \mathrm{Pu}$ ratio is decreasing in the sediments with increasing water depth, the ${ }^{240} \mathrm{Pu} /{ }^{239} \mathrm{Pu}$ profiles within a given core remain essentially constant. As is shown in Figure 6.8 both the near surface samples with the highest Pu activities and the deepest samples in the profiles with the lowest Pu activities have identical $240 \mathrm{Pu} /{ }^{239} \mathrm{Pu}$ values. These constant downcore ${ }^{240} \mathrm{Pu} /{ }^{239} \mathrm{Pu}$ ratios must be the result of relatively rapid sediment mixing given the input of $\mathrm{Pu}$ 


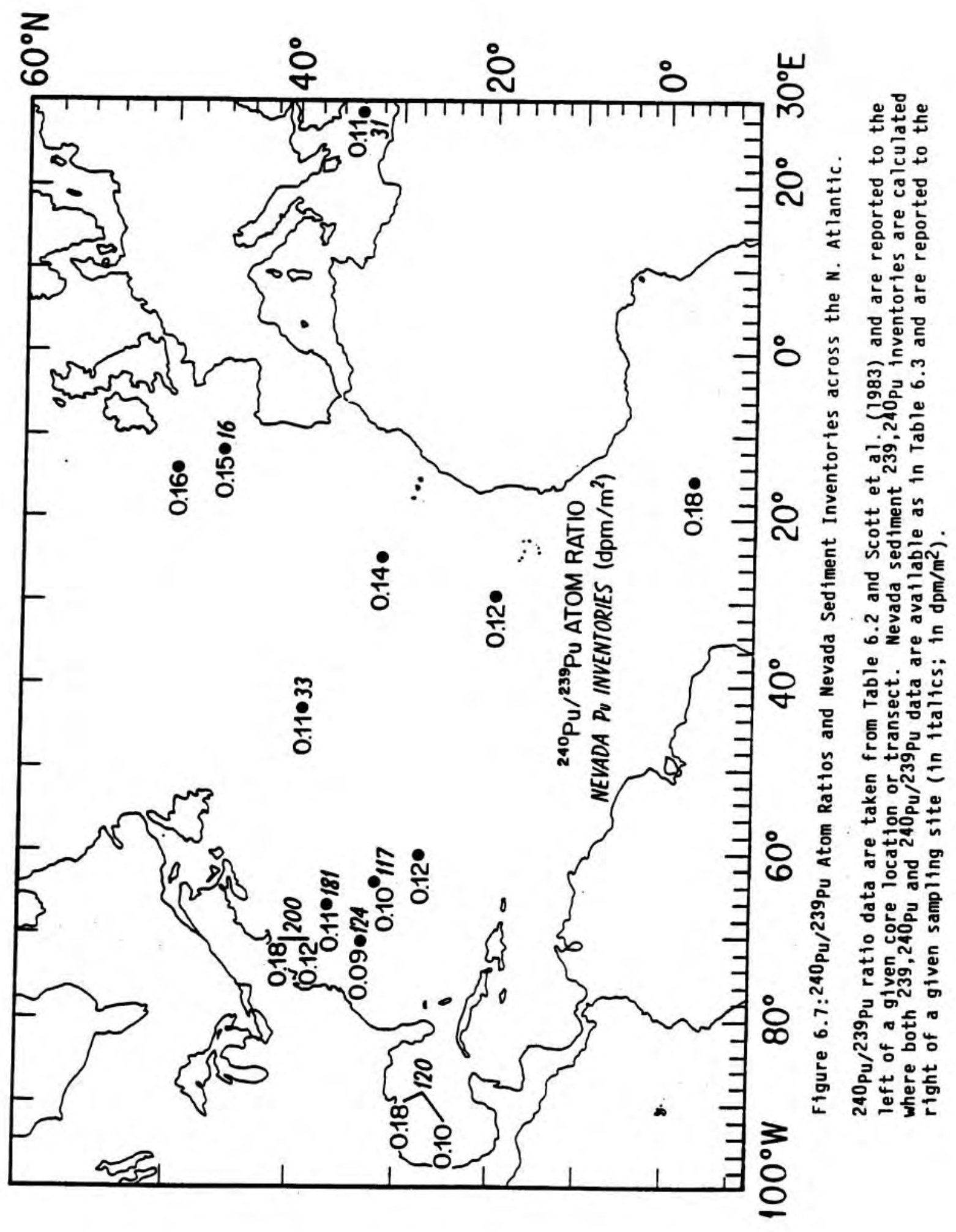



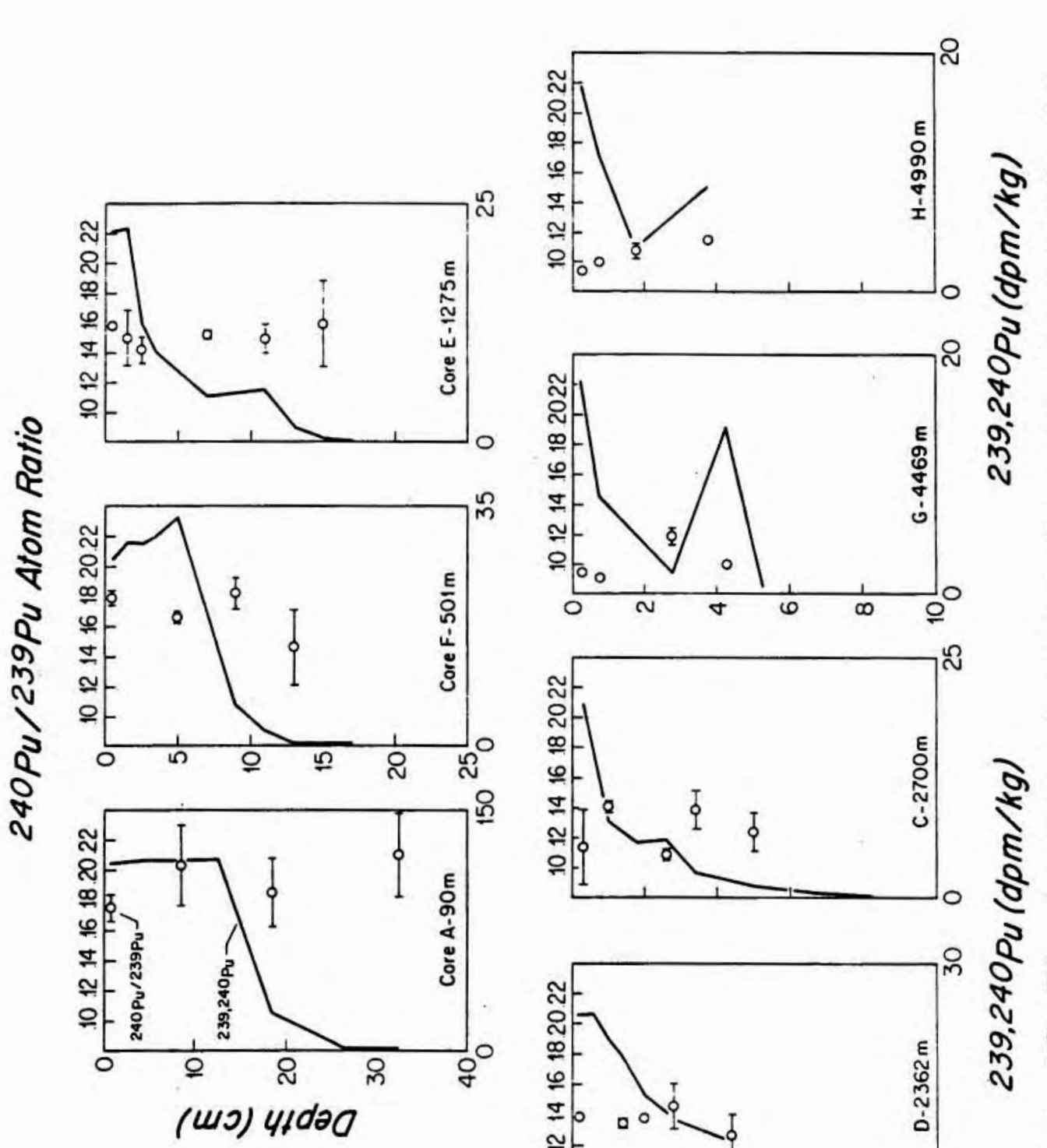

$x \quad 4$

莘

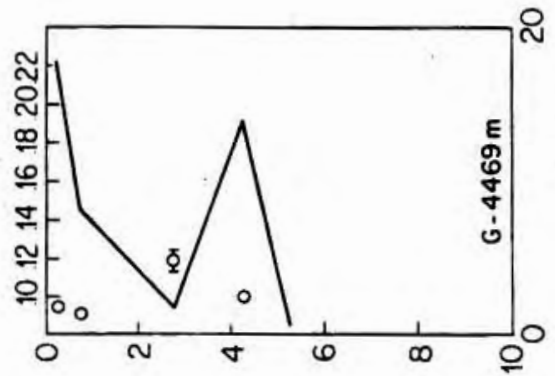

$\frac{8}{2}$

.

ธธ

$\simeq$

$\frac{0}{0}$

ज出

范

(

훈

总品

$\frac{2}{2}$

证

岕

岳筫

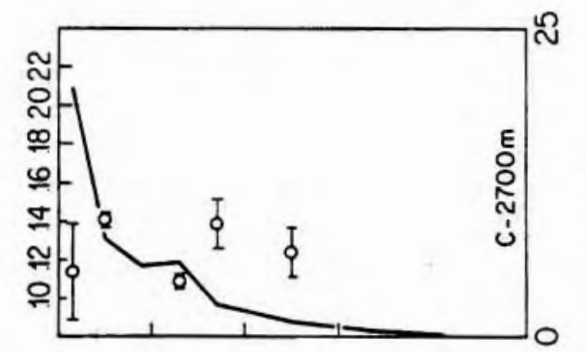

है

突

址

站

$\pm \frac{\pi}{0}$

क :

운

E

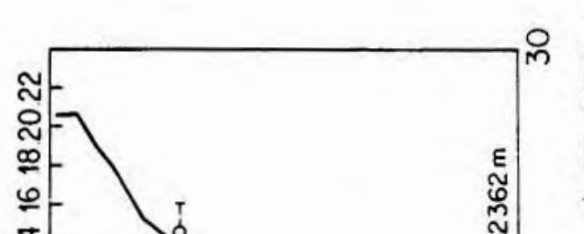

永

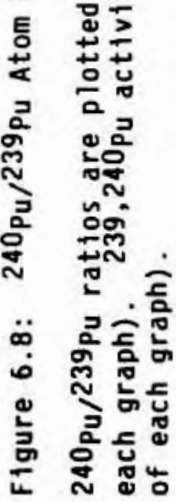

(wo) 41000 
from both low and high ${ }^{240} \mathrm{Pu} /{ }^{239} \mathrm{Pu}$ ratio sources. A brief model calculation will be used below to demonstrate this effect and to show how the isotope ratio data can be used to further our understanding of the removal rate of Pu to marine sediments.

Any model which is used to estimate sediment mixing rates based upon Pu activity profiles requires that the input function of $\mathrm{Pu}$ to the sediments be known. Two commonly used Pu input functions are either the Pulse input model, whereby the bulk of $\mathrm{Pu}$ in the sediments arrived soon after its deposition to the ocean or the continuous input model, whereby the supply of Pu to the sediments has been constant since its introduction (Guinasso and Schink, 1975; Officer and Lynch, 1983; Cochran, 1985; Sayles and Livingston, 1985; Anderson et a1., 1986; and references therein). Arguments for and against either input function have been made and intermediate input models with characteristics of both scenarios have also been used (Santschi et al., 1980; Anderson et a1., 1986; Lapique et al., 1986). While the Pu activity data may often be fit with some degree of success by either input assumption, the calculated sediment mixing rates from these Pu mixing models will change significantly depending the chosen input function (Cochran, 1985; Chapter 7, this thesis). The Pu isotope data will be used to chose the most appropriate input scenario.

The Pu sediment mixing model I will demonstrate satisfies both the observed $\mathrm{Pu}$ activity profiles and the ${ }^{240} \mathrm{Pu} /{ }^{239} \mathrm{Pu}$ data. The model wi11 be run for core $D(2362 \mathrm{~m}$; Table 6.2) since the data at this site are complete and since the ${ }^{240} \mathrm{Pu} /{ }^{239} \mathrm{Pu}$ ratio in the sediments at this site $\left({ }^{240} \mathrm{Pu} /{ }^{239} \mathrm{Pu}=0.14\right)$ lies between the two fallout source extremes. For a more complete discussion of this model and its application to other sites the reader is referred to Chapter 7 of this thesis.

The model assumes that a pulse of low ratio Nevada fallout Pu $\left({ }^{240} \mathrm{Pu} /{ }^{239} \mathrm{Pu}=0.035\right)$ arrived at the sediment/water interface in 1956 (1956 was chosen since it lies between the two highest Nevada fallout years - Hicks and Baar (1984)). The rate at which this fallout is mixed downward is fixed by the sediment mixing rate determined 
independently on the exact same samples with a steady-state $210 \mathrm{~Pb}^{\text {ex }}$ mixing model as described in Chapters 4 and 7 of this thesis and used by many previous researchers (Goldberg and Koide, 1962; Nosaki et al., 1977; Peng et a1., 1979; Krishnaswami et al., 1980; Demaster and Cochran, 1982, among others). In addition, a second source of fallout Pu will be added to the sediments in this model with a ${ }^{240} \mathrm{Pu} /{ }^{239} \mathrm{Pu}$ ratio of 0.18 (1.e. global fallout), such that the combined ${ }^{240} \mathrm{Pu} /{ }^{239} \mathrm{Pu}$ ratio in the core equals the average value detected at this site today. For example, at core $D(2362 \mathrm{~m})$ the Nevada fallout pulse in 1956 would represent 22\% of the total sedimentary Pu as calculated in Table 6.3.

What remains to be fixed in this model is the input function of the second source of (global) fallout Pu, and as suggest above, two extremes will be attempted. In the first case, the global fallout Pu $\left({ }^{240} \mathrm{Pu} /{ }^{239} \mathrm{Pu}=0.18\right)$ will be added to the sediments continuously since the year 1960 (mid-way in the global fallout record), such that in the case of core $D$, by 1984 a total inventory of $78 \% \times 1270 \mathrm{dpm} / \mathrm{m}^{2}$ (the total Pu inventory) $=991 \mathrm{dpm} / \mathrm{m}^{2}$ of global fallout $\mathrm{Pu}$ is added to the sediments. I will call this the "pulse/continuous" model, since the Nevada Pu pulse $\left({ }^{240} \mathrm{Pu} /{ }^{239} \mathrm{Pu}=0.035\right)$ is followed by the continuous addition of global fallout $\mathrm{Pu}\left({ }^{240} \mathrm{Pu} /{ }^{239} \mathrm{Pu}=0.18\right)$ to the sediments. This is shown schematically in Figure $6.9 \mathrm{a}$ along with the appropriate analytical solutions to this mixing equation. The ${ }^{240} \mathrm{Pu} /{ }^{239} \mathrm{Pu}$ profile which the "pulse/continuous" model generates in the sediments is shown in Figure 6.9b. This model results in systematically increasing ${ }^{240} \mathrm{Pu} /{ }^{239} \mathrm{Pu}$ ratios towards the sediment surface since sediment mixing (as determined by ${ }^{210}{ }_{\mathrm{Pb}}{ }^{\mathrm{ex}}$ ) is not fast enough to obliterate any increases in the ${ }^{240} \mathrm{Pu} /{ }^{239} \mathrm{Pu}$ ratios due to the continuous supply of global fallout Pu to the sediments.

The second model is similar to the first except that after the initial pulse of low ratio Nevada fallout in 1956, the remainder of the global fallout $\mathrm{Pu}$ is input into the sediments as a pulse in 1960 (Fig. 6.9a). In this "pulse/pulse" model, the ${ }^{240} \mathrm{Pu} /{ }^{239} \mathrm{Pu}$ ratios in the sediments would not change appreciably from core top to bottom, given 
Figure 6.9a: Schematic Diagram of "Pulse/Pulse" and "Pulse/Continuous" Models.
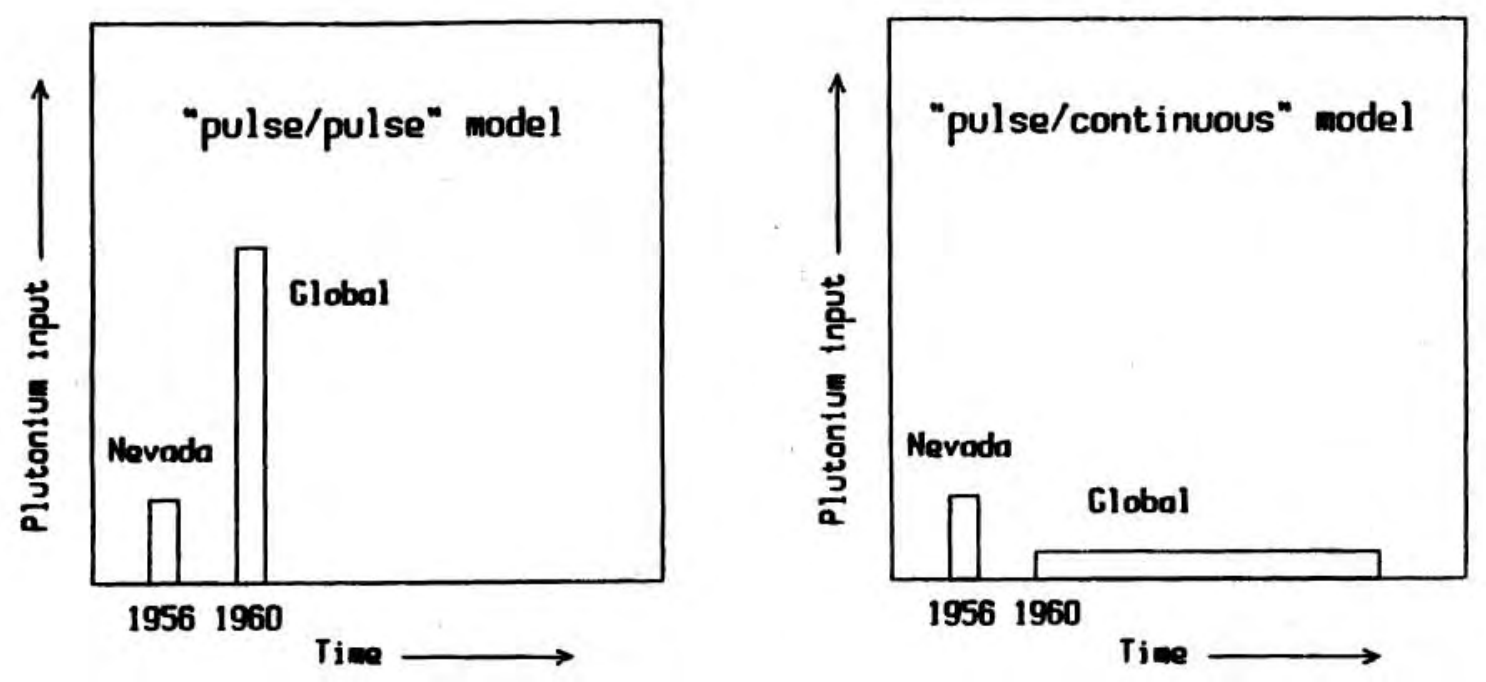

The analytical solutions to a eddy diffusive sediment mixing model for Pu assuming negligible sedimentation, $D_{b}$ (mixing rate) and porosity are constant, and the activity, $A=A_{0}$ at $z=0$, are (see Duursma and Hoede, 1967; Cochran, 1985; Chapter 7 this thesis):

$$
\begin{aligned}
& \text { for a pulse input scenario- } A / A_{0}=\exp \left[-z^{2} / 4 D_{b} t\right] \\
& \text { for a continuous ingut- } A / A_{0}=\exp \left[-z^{2} / 4 D_{b} t\right]-2 / 2\left(\frac{\pi}{D_{b} t}\right)^{1 / 2} \operatorname{erfc}\left[z / 2\left(D_{b} t\right)^{1 / 3}\right.
\end{aligned}
$$

where erfc is the error function compliment, $t$ is the time in years since the pulse input occurred, or over which the continuous input occurred, $\mathrm{D}_{\mathrm{b}}$ is fixed by ${ }^{210_{\mathrm{Pb}}}{ }^{\mathrm{ex}}$ modelling, the relative sizes of the $\mathrm{Pu}$ inputs are fixed by the ${ }^{240} \mathrm{Pu} /{ }^{239} \mathrm{Pu}$ data and the two endmember model (Table 6.3). These solutions are summed to obtain the "pulse/pulse" and "pulse/continuous" model curves. See text and Chapter 7 for details. 


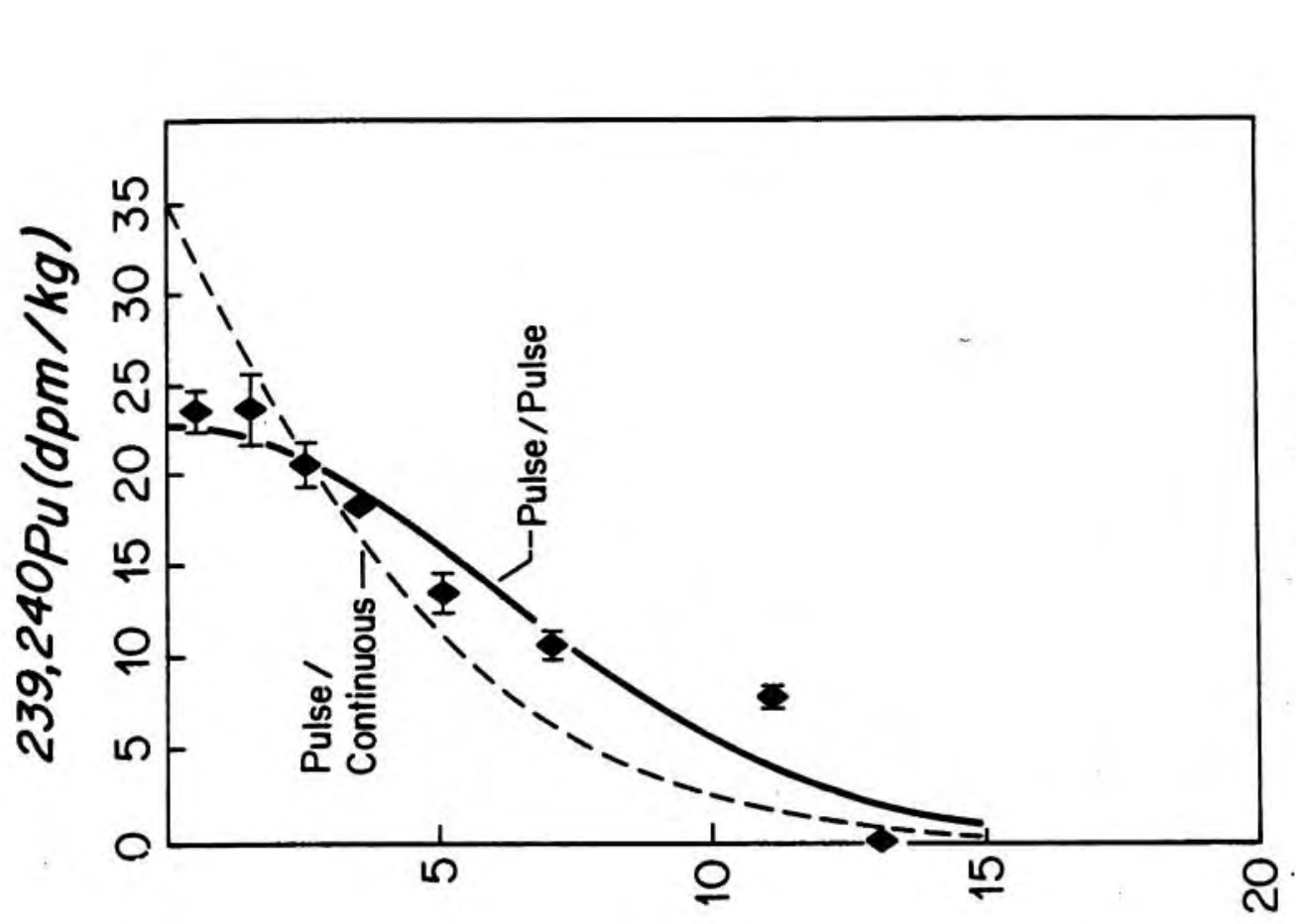

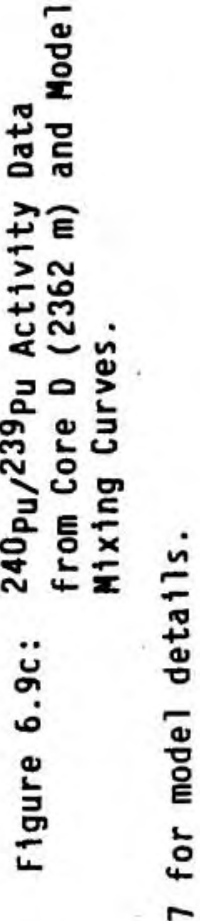

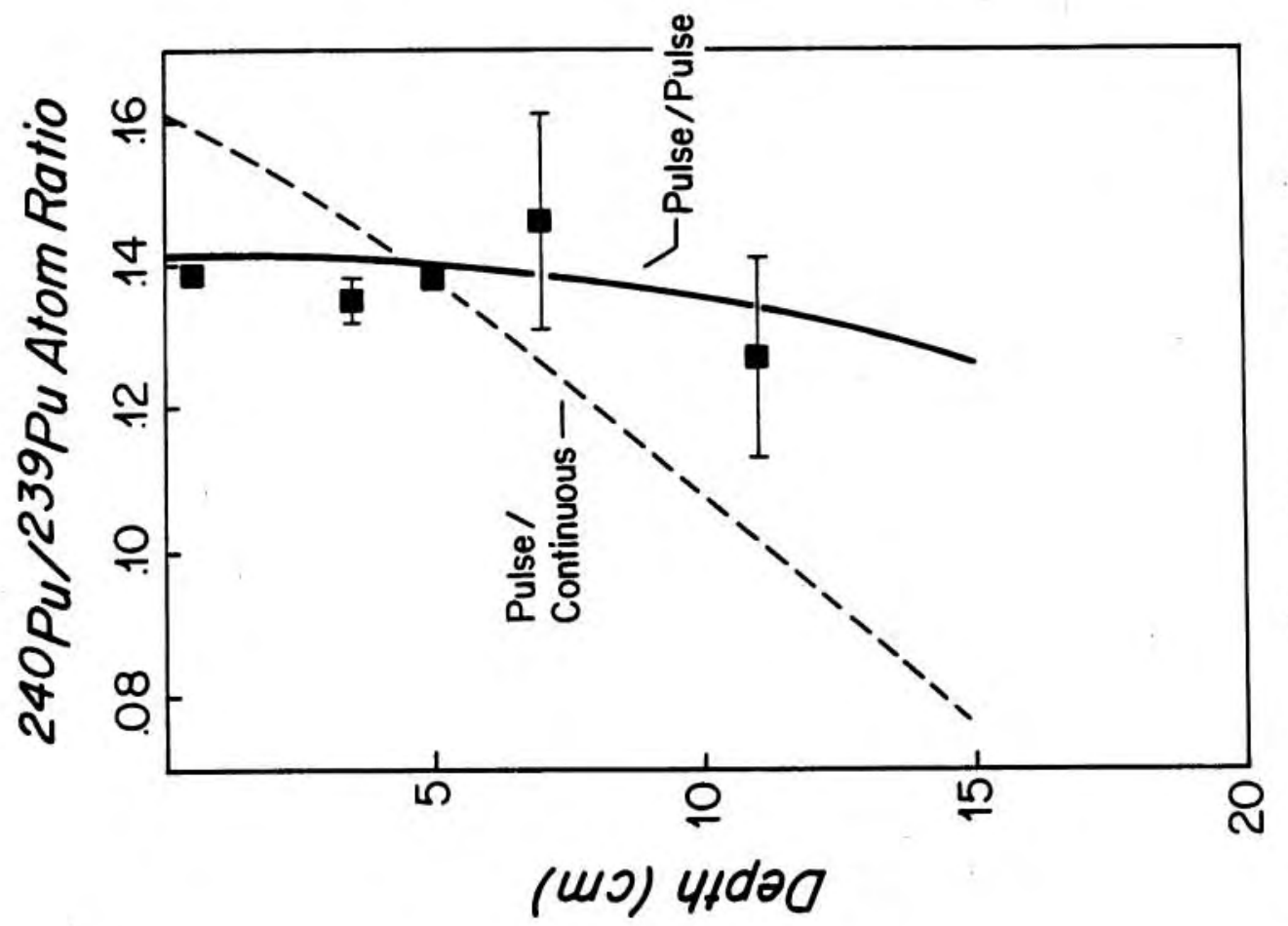

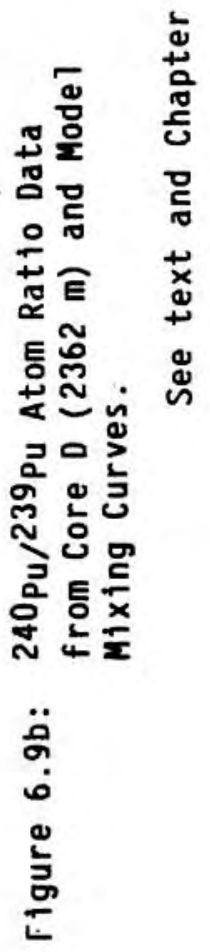


the observed mixing rates and given that both sources of Pu arrived to the sediments within a relatively short time span (4 years in this case) (Fig. 6.9b).

Altering the years of either the Nevada input or global fallout inputs by two to six years will not appreciably alter the ${ }^{240} \mathrm{Pu} /{ }^{239} \mathrm{Pu}$ profiles which are generated (Chapter 7 ). A faster mixing rate would decrease the slope in the "pulse/continuous" model ${ }^{240} \mathrm{Pu} /{ }^{239} \mathrm{Pu}$ curve, but the general shape would be the same (see Chapter 7 for more detalled sensitivity analyses of this mode1). Figure 6.9 c depicts the 239,240 Pu activity profiles generated from these models with the ${ }^{210} \mathrm{~Pb}^{e x}$ derived sediment mixing rates. The "pulse/pulse" model appears to fit the 239,240 pu activity data quite we 11 and also satisfies the uniform ${ }^{240} \mathrm{Pu} /{ }^{239} \mathrm{Pu}$ ratio distribution within the core. Similar results are reached when the data from cores E (1275 $\mathrm{m})$ and $C(2700 \mathrm{~m})$ are modeled (Chapter 7$)$.

The major conclusion of this modeling exercise is that the bulk of $\mathrm{Pu}$ in the sediments at sites $E, D$, and $C$ arrived shortly after the peak depositional years of both the Nevada and global fallout sources. This is a general conclusion that should apply to global fallout Pu inputs to continental slope and deep ocean sediments outside of the North Atlantic. Perhaps removal rates of Pu from the surface waters were generally much greater in the past when in contrast to today, the surface waters were not yet depleted in $\mathrm{Pu}$.

In apparent contradiction to the pulse-like Pu input models, recent evidence for the continuous deposition of $\mathrm{Pu}$ to deep-sea sediments is suggested by sediment trap studies (Livingston and Anderson, 1983; Fowler et a1., 1983; Bacon et al., 1985). In an extensive study by Bacon et a1. (1985), sediment trap 239,240 $\mathrm{Pu}$ fluxes over a three year period at the Bermuda station of Deuser (1986) are estimated to be $5.6 \mathrm{dpm} / \mathrm{m}^{2}$ per year. This sediment trap station is approximately above my core $G$ where a $239,240 \mathrm{Pu}$ sediment inventory of $260 \mathrm{dpm} / \mathrm{m}^{2}$ is found. If the flux had been constant, then $\approx 50 \%$ of the observed $239,240 \mathrm{Pu}$ sediment inventory can be accounted for by this mechanism $\left(5.6 \mathrm{dpm} / \mathrm{m}^{2} \mathrm{yr} \times 25 \mathrm{yrs}\right)$. This comparison may be too 
simplistic however due to: 1) the considerable spatial variability between Pu sediment inventories amongst deep-sea cores within the same area (Buesseler et al., 1985; Druffel et al., 1984), 2) the neglect in this calculation of deep water Pu inventories which must have similarly been supplied by the rapidly sinking biogenic particles, 3) a lack of understanding concerning decade-long varlability in trap fluxes (Deuser et al., 1986), 4) the resolubilization of blogenic trap material at the sediment/water interface (Reimers and Suess, 1983; Liu and Kaplan, 1984) and the potential release of Pu back into the overlying waters. While the pulse/pulse model requires that the bulk of $\mathrm{Pu}$ added to the sediments have arrived early-on, this would hold only for the deeper cores. At shallower sites, the continuous removal of Pu is more intense as evidenced by the progressively larger total $239,240 \mathrm{Pu}$ sediment inventories (Buesseler et al., 1985) and the higher $240 \mathrm{Pu} /{ }^{239} \mathrm{Pu}$ ratios. Basically there is a range of removal processes occurring and the relative intensities of these processes will determine the true input function of Pu to the sediments at a given site. At the shallower sites, inorganic particle-related scavenging and removal processes would be the dominant Pu scavenging mechanism. As the water depth increases and boundary scavenging processes become inherently less effective, the dominant removal process becomes the biological packaging and rapid sinking of large particles. At these deeper sites the earlier removal fluxes were apparently greater than present day fluxes. The potential range in Pu input functions as a function of water depth is therefore quite large and ranges between these two extremes. In summary, at water depths $>1200 \mathrm{~m}$ in this region, a pulse-like input scenario is consistent with both the Pu activity and isotope data. On the shelf, I feel that a continuous input model would be more appropriate.

\section{VI. ${ }^{240} \mathrm{PU} /{ }^{239} \mathrm{PU}$ RATIOS IN THE PACIFIC}

It is interesting to speculate on the significance of close-in fallout in determining the geochemical behavior of Pu in the Pacific 
basin. From test yield data (D.0.E., 1982) one can calculate that $95 \%$ of all surface based nuclear testing worldwide was conducted at these islands (this includes all surface, tower, barge and balloon tests at $<500 \mathrm{ft}$ ). Certainly, both the elevated water column and sediment inventories of $239,240 \mathrm{Pu}$ in the North Pacific support the deposition of substantial Pu from the Marshall Islands tests to the Pacific (Bowen et al., 1980; Livingston, personal communication, 1986).

With a surface based nuclear test on a coral island, fallout Pu would be carried by particles consisting largely of calcium oxide, calcium hydroxide, and calcium carbonate phases (Adams, 1960). The delivery of large quantities of these fallout particles to the surface of the Pacific and their subsequent transport to depth and resolubilization would be important in determining Pu's removal from the water column to the sediments. For instance, the Pacific GEOSECS data of Bowen et al. (1980) are characterized by a subsurface Pu activity maximum, and of ten a near-bottom enrichment of $239,240 \mathrm{Pu}$. This Pu distribution contrasts with that of the Atlantic (Livingston et al., 1985) and may represent a more complicated picture of Pu sources than originally thought. Isotopic Pu studies which can separate between the stratospheric fallout $\mathrm{Pu}\left({ }^{240} \mathrm{Pu} /{ }^{239} \mathrm{Pu}=0.18\right)$ and Marshall Is lands fallout $\left({ }^{240} \mathrm{Pu} /{ }^{239}{ }_{\mathrm{Pu}}>0.22\right)$ will be needed before a complete understanding of Pu geochemistry in the Pacific is obtained.

I have analyzed sea water from $38^{\circ} \mathrm{N} 180^{\circ} \mathrm{W}$ in the Pacific at mid-water depths and found a ${ }^{240} \mathrm{Pu} /{ }^{239} \mathrm{Pu}$ ratio of $0.234 \pm 0.005$ (data in Appendix III). Closer to the Marshall Islands $\left(18^{\circ} \mathrm{N} 152^{\circ} \mathrm{E}\right)$, a near bottom ${ }^{240} \mathrm{Pu} /{ }^{239} \mathrm{Pu}$ ratio of $0.291 \pm 0.016$ was found, while a surface sediment sample had a ratio of $0.357 \pm 0.024$ at this same site. These data suggest that there is an apparent increase in the $240 \mathrm{Pu} /{ }^{239} \mathrm{Pu}$ ratio in seawater and sediments near the source of close-in Pu inputs (1.e. the Marshall Islands). Bertine et al. (1986) found ${ }^{240} \mathrm{Pu} /{ }^{239} \mathrm{Pu}$ ratios ranging from 0.19 to 0.27 in 12 water column samples from $12^{\circ} \mathrm{N} 162^{\circ} \mathrm{E}$ and $32^{\circ} \mathrm{N} 162^{\circ} \mathrm{E}$. In contrast to my data, they did not find a consistent increase in the ${ }^{240} \mathrm{Pu} /{ }^{239} \mathrm{Pu}$ ratios at the station which was located closer to the Marshalls. 
Unfortunately, Bertine et al., do not report the associated error on their ${ }^{240} \mathrm{Pu} /{ }^{239} \mathrm{Pu}$ ratios so that the range of values they found may represent analytical scatter which obscures any real spatial trend in the data.

The elevated Pacific water column ${ }^{240} \mathrm{Pu} /{ }^{239} \mathrm{Pu}$ ratios over those I found in the Atlantic and by Scott (personal communication) in the Gulf of Mexico ( $\left.{ }^{240} \mathrm{Pu} /{ }^{239} \mathrm{Pu}=0.18\right)$ are at least strong evidence that the characteristics of the Marshall Islands close-in fallout must be considered when interpreting Pu activity data from the North Pacific basin. Differences between global fallout particles and close-in fallout from a coral island surface burst may result in a separation of these two fallout types in the ocean, but this has yet to be shown.

\section{CONCLUSIONS}

The mass spectrometric analysis of ${ }^{239} \mathrm{Pu}$ and ${ }^{240} \mathrm{Pu}$ in North Atlantic marine samples has provided a unique insight into the sources and geochemistry of fallout $\mathrm{Pu} .{ }^{240} \mathrm{Pu} /{ }^{239} \mathrm{Pu}$ ratios are found to vary systematically due to a separation of Pu carried by global stratospheric fallout and Pu carried by tropospheric fallout from surface based testing in Nevada, each of these sources being identified by their characteristic ${ }^{240} \mathrm{Pu} /{ }^{239} \mathrm{Pu}$ ratio. This relationship between the specific source of $\mathrm{Pu}$ and its behavior in the oceans suggests a more complex oceanographic chemistry for $\mathrm{Pu}$ than previously suspected. More specifically, this study concludes:

1) ${ }^{240} \mathrm{Pu} /{ }^{239} \mathrm{Pu}$ ratios in Atlantic seawater, pore waters, sediment trap samples and continental shelf sediments are all close to 0.18 , the global stratospheric fallout average. In contrast, systematically decreasing ${ }^{240} \mathrm{Pu} /{ }^{239} \mathrm{Pu}$ ratios are found in sediments with increasing water depth in the Northwest Atlantic (ranging from 0.18 at $90 \mathrm{~m}$ to 0.10 at $4990 \mathrm{~m})$.

2) A unique source of $10 \mathrm{w}{ }^{240} \mathrm{Pu} /{ }^{239} \mathrm{Pu}$ ratio $\mathrm{Pu}$ must exist that is rapidily transported to these deep-sea sediments. Since the isotopic data rule out the present day fractionation of ${ }^{239} \mathrm{Pu}$ from ${ }^{240} \mathrm{Pu}$ in 
the water column, I have concluded that tropospheric debris from surface based nuclear testing at the Nevada Test Site is the most likely source of low ratio $\mathrm{Pu}\left({ }^{240} \mathrm{Pu} /{ }^{239} \mathrm{Pu}=0.035\right)$.

3) $240 \mathrm{Pu} / 239 \mathrm{Pu}$ ratios and $239,240 \mathrm{Pu}$ activity data from archived sediment samples from the 1950's and 1960's are consistent with the expected timing of Pu inputs to this region from the Nevada source.

4) The pronounced dis-equilibrium between pore water $240 \mathrm{Pu} /{ }^{239} \mathrm{Pu}$ ratios $(\approx 0.18)$ and deep-sea sediment ${ }^{240} \mathrm{Pu} /{ }^{239} \mathrm{Pu}$ ratios (=0.10-0.15) supports a difference in the physical/chemical character of the Nevada and global fallout types. The Nevada fallout Pu appears to be more tightly bound by the solid phase than the global fallout $\mathrm{Pu}$, and is therefore not participating in the Pu solid/solution exchange reactions.

5) Using a two end-member mixing model, one can calculate that over $40 \%$ of the total 239,240 Pu activity in the deep Northwest Atlantic sediments (at depths $>4500 \mathrm{~m}$ ) was supplied by the Nevada fallout source.

6) Deep-sea sediments across the North Atlantic basin all show some evidence of the Nevada fallout signal (1.e. ${ }^{240} \mathrm{Pu} /{ }^{239} \mathrm{Pu}<0.18$ ). The total Pu inventory from the Nevada source decreases as one examines the Eastern Atlantic sites which are more distant from the Nevada Test Site.

7) The availability of ${ }^{240} \mathrm{Pu} /{ }^{239} \mathrm{Pu}$ data and $239,240 \mathrm{Pu}$ activity data in the sediments allows me to constrain the input function of fallout Pu to deep ocean sediments $(>1200 \mathrm{~m})$. The data are consistent with a "pulse/pulse" model whereby the input of Nevada fallout $\mathrm{Pu}$ to the sediments is followed quite closely in time by the input of global fallout Pu. The continued net flux of Pu to deep ocean sediments appears to be minor, relative to scavenging and removal processes at the more shallow coastal sites.

8) The relationship between the geochemistry of Pu and the specific sources of fallout Pu can have major implications for understanding the behavior of fallout $P u$ in the Pacific basin. In this basin, water column ${ }^{240} \mathrm{Pu} /{ }^{239} \mathrm{Pu}$ ratios which are elevated over the 
global 0.18 average are found $(0.19-0.27)$. These elevated ratios are likely due to the large input of Pu carried by close-in fallout from the Marshall Islands. The geochemistry of Pu carried by fallout particles from surface based testing at these coral atolls need not be identical to the geochemistry of global fallout Pu, but this has yet to be confirmed. 
$-160-$ 
CHAPTER 7

The Modeling of Sediment Mixing using

$210_{\mathrm{Pb}}{ }^{\mathrm{ex}}, 239,240 \mathrm{Pu}$ and ${ }^{240} \mathrm{Pu} /{ }^{239} \mathrm{Pu}$ data

\section{INTRODUCTION}

In this chapter sediment mixing rates will be calculated based upon the distributions of ${ }^{210} \mathrm{~Pb}^{\text {ex }}$ and $239,240 \mathrm{Pu}$ activities and ${ }^{240} \mathrm{Pu} /$ ${ }^{239} \mathrm{Pu}$ ratios in shelf, slope and deep-sea sediments from the Northwest Atlantic. This discussion is intended to expand upon earlier discussions in this thesis of the models used to estimate sediment mixing rate estimates, and the inherent errors and assumptions behind their use. The models used here are adapted from extensive work by many researchers, and the reader is referred to these original studies for further background information (Goldberg and Koide, 1962; Guinasso and Schink, 1975; Nosakt et a1., 1977; Benninger et al., 1979; Peng et a1., 1979; Krishnaswaml et a1., 1980; Demaster and Cochran, 1982; Carpenter et al.,, 1982; Officer and Lynch, 1982, 1983; Cochran, 1985).

The application of sediment mixing rates to topics of concern to this thesis can be briefly summarized as follows. In Chapter 4, evidence for or against the remobilization of ${ }^{239,240} \mathrm{Pu}$ from marine sediments was sought from a comparison between sediment mixing rates calculated by both the $239,240 \mathrm{Pu}$ and ${ }^{210}{ }_{\mathrm{Pb}}{ }^{\text {ex }}$ tracers. In Chapter 6 , sediment mixing rate data were used in conjunction with ${ }^{240} \mathrm{Pu} /{ }^{239} \mathrm{Pu}$ isotopic ratios in a model which can be used to constrain the input function of fallout Pu to marine sediments. Furthermore, Anderson et al. (1986) have used the sediment mixing data from this study combined with additional data from this region to examine the accumulation of total organic carbon and chlorinated hydrocarbons along the SEEP-I transect (along $71^{\circ} \mathrm{W}$ out to $3000 \mathrm{~m}$ ).

\section{PARTICLE MIXING RATES -210 Pb ex}

The basic assumption behind any of the models presented here is 
that the process of sediment mixing is analogous to eddy diffusion over the time scale of interest provided by our tracer. In actuality, this is an idealization of the truly discontinuous processes responsible for sediment mixing, such as the feeding and burrowing activities of benthic organisms. In practice, the simplified diffusive formulation of sediment mixing can be applied if the time and spatial scales over which a tracer profile integrates include sufficient mixing activity to obscure any discreet mixing events. For a tracer such as $210 \mathrm{~Pb}$ with a half-life of 22.3 years, Boudreau (1986a) demonstrates that for the diffusive models to hold, mixing should occur much more frequently than on a yearly basis and the scale of sampling must be intermediate between the scale of microscopic variations in sediment grain size and composition and the macroscopic scale over which the tracer is changing significantly in activity (i.e. the mixing depth). Given these constraints, the general equation for particle mixing, accumulation and radioactive decay can be written as:

(1) $\frac{\delta}{\delta t}[\rho A]=\frac{\delta}{\delta z}\left[D_{b} \frac{\delta A}{\delta z}\right]-\frac{\delta}{\delta z}[\rho S A]-\lambda \rho A$

where $t=t$ ime $(y r)$

$\rho=$ dry bulk density ( $g$ dry sediment $/ \mathrm{cm}^{3}$ wet sediment)

$A=$ activity of the radionuclide (dpm/dry weight of sediment)

$z=$ depth in sediment profile $(\mathrm{cm})$

$D_{b}=$ sediment mixing rate $\left(\mathrm{cm}^{2} / \mathrm{yr}\right)$

$S=$ sedimentation rate $(\mathrm{cm} / \mathrm{yr})$

$\lambda=$ decay constant of the radionuclide $\left(0.031 \mathrm{yr}^{-1}\right.$ for $\left.{ }^{210} \mathrm{~Pb}\right)$. Given any single tracer such as $210_{\mathrm{Pb}}$ ex or $239,240 \mathrm{Pu}$, efther $\mathrm{D}_{\mathrm{b}}$ or $S$ can be calculated if it can be shown that sediment mixing or sediment accumulation is negligible relative to the other variable. The above equation is typically solved assuming that both the dry bulk density and the mixing rate are constant throughout the region of interest. In the case of my data, the dry bulk density is known, and by converting the depth variable, $z$, to a cumulative mass per unit area scale $\left(\mathrm{g} / \mathrm{cm}^{2}\right)$ a density independent mixing rate, $E$, can be calculated (Officer and Lynch, 1982; Cochran, 1985). $D_{b}$ is related to $E$ by the equation 
$D_{b}=E / p^{2}$, and when these two mixing rates are compared from my data set, they are in agreement within the associated errors. I have therefore opted to report the sediment mixing rates as $D_{b}$ values $\left(\mathrm{cm}^{2} / \mathrm{yr}\right)$ which were calculated assuming constant porosity throughout the mixed zone.

With respect to the assumption of a constant sediment mixing rate over the depth of the mixed zone, it is obvious from my data that in cores $A(90 \mathrm{~m})$ and $F(501 \mathrm{~m})$ much more rapid sediment mixing occurs in the upper $\mathrm{cm}$ 's of the sediment column which obscures any downcore gradient in ${ }^{210} \mathrm{~Pb}^{\mathrm{ex}}$ or $\mathrm{Pu}$ in the surface sediments. In these cases, a two-layer system can be envisioned. In the upper layer, sediment mixing is so rapid that essentially complete homoginization of the ${ }^{210} \mathrm{~Pb}^{\text {ex }}$ and $239,240 \mathrm{Pu}$ tracers occurs within the decada long time scales of these tracers. This is underlain by a zone of decreased benthic mixing activity, characterized by decreasing $210_{\mathrm{Pb}}{ }^{e x}$ and $239,240 \mathrm{Pu}$ activities with increasing depth, where the sediment mixing rates were calculated. In general, there is not sufficient evidence to warrant the further development of depth dependent mixing rate models for this data set.

If the input of $210 \mathrm{~Pb}$ to the sediment is assumed to be in steady-state, then the solution to equation (1) is:

$$
A=A_{0} \exp \frac{S-\left(S^{2}-4 D_{b} \lambda\right)^{1 / 2}}{2 D_{b}} \cdot z
$$

where $A_{0}$ is the activity of $210{ }^{20 x}$ at $z=0$ and $A$ is the activity at depth $z$. From this solution one can see that sedimentation can be ignored if $s^{2} \ll 4 D_{b} \lambda$. Ignoring sedimentation, equation (2) reduces to the more commonly used form:

(3) $\quad A=A_{0} \exp \left[-\left(\lambda / D_{b}\right)^{1 / 2} \cdot z\right]$.

The mixing rates in my cores, will be shown to range between 0.1 to 3 $\mathrm{cm}^{2} / \mathrm{yr}$, similar to other studies in this region (Santschi et al., 1980; Anderson et a 1., 1986). The sedimentation rates are constrained by a ${ }^{14} \mathrm{C}$ estimate of $13 \mathrm{~cm} / 1000 \mathrm{yr}$ at $1170 \mathrm{~m}$ from a core along my sediment transect (Tanaka, 1986) and a reconstructed sedimentation rate over the past 18,000 years of $5-20 \mathrm{~cm} / 1000 \mathrm{yr}$ based upon $\mathrm{CaCO}_{3}$ distributions in 
the slope regions (Anderson et al., 1986). Within this range of mixing rates and accumulation rates the sedimentation term can indeed be neglected and equation ( 3 ) used to solve for $D_{b}$. Independently, it can be argued (Anderson et al., 1986) that the equivalent penetration depths of $210 \mathrm{~Pb}^{\text {ex }}$ and $239,240 \mathrm{Pu}$ in the solid phase profiles and their constant ratios throughout the cores support the overall dominance of sediment mixing over sediment accumulation at these sites.

The solutions for $D_{b}$ calculated from equation (3) and my $210 \mathrm{~Pb}^{\text {ex }}$ data are provided in Table 7.1a. To calculate the mixing coefficient, a statistical curve fitting package ("RS/I" - BBN Software Products Corp.) was used which calculates the best fit exponential curve minimizing the sum of the squares of the errors between the calculated curve and the $210 \mathrm{~Pb}^{\text {ex }}$ data. This curve is of the form $-A_{0}=A \exp [-B \cdot z]$, where $B$ $\left(=\left(\lambda / D_{b}\right)^{1 / 2}\right)$ is the calculated best fit slope. From the $90 \%$ confidence limits on $B$, the $90 \%$ confidence limits on $D_{b}$ have been calculated and are given as the $D_{b}$ ranges in Table 7.1a. It is not unusual for the $90 \%$ confidence ranges for $D_{b}$ to span a factor of two or more. This estimate of the $D_{b}$ range is important to obtain, if one wishes to use the calculated mixing rates in any diagenetic modeling, or if one wishes to compare $D_{b}$ 's found with different tracers or at different locations. The best fit mixing line for ${ }^{210} \mathrm{pb}^{e x}$ is plotted with the data in Figures 7.la-h (solid curve), and the curves corresponding to the $90 \%$ confidence limits have been plotted for cores $E, D$ and $C$ as well (dotted line in Fig. 7.1e, 7.1f, and 7.1h, respectively).

As can be seen for example in Figure 7.1e (core E), the model mixing curves which correspond to the $90 x$ confidence limits on $D_{b}$ are qualitatively not vastly different than the best fit line, however these curves represent a factor of two range in the calculated sediment mixing rate $\left(0.67-1.35 \mathrm{~cm}^{2} / \mathrm{yr}\right.$; Table $\left.7.1 \mathrm{a}\right)$. An important point to be made is that the reported mixing rates can change quite dramatically due to relatively small shifts in the best fit curve, or alternatively due to subtle shifts in one's data or sampling strategy. Ideally, many data points covering a large depth range are needed to determine the sediment mixing rate with a high degree of certainty. In practice, this may be 
Table 7.1 a Sediment mixing rates calculated ${ }^{*}$ from ${ }^{210} \mathrm{~Pb}{ }^{\text {ex }}$ data

--Exponential Fit----

Core I.D. Water Depth Mixing Rate Range

\begin{tabular}{llllll} 
& \multicolumn{1}{c}{$(\mathrm{m})$} & $\frac{\left(\mathrm{cm}^{2} / y r\right)}{1.4}$ & $\frac{+1-90 \%}{(0.6-5.5)}$ & $\frac{\left(\mathrm{cm}^{2} / y r\right)}{2.2}$ \\
A & 90 & 2.9 & & $(2.3-3.6)$ & 2.4 \\
AK & 80 & 0.42 & $(0.15-4.5)$ & 0.36 \\
F & 501 & 0.49 & $(0.34-0.67)$ & 0.90 \\
BK & 1170 & 0.92 & $(0.67-1.35)$ & 0.80 \\
E & 1275 & 0.71 & $(0.55-0.95)$ & 0.71 \\
D & 2362 & 0.73 & $(0.53-1.34)$ & 0.99 \\
CK & 2700 & 0.60 & $(0.33-1.47)$ & 0.85 \\
C & 2700 & & & &
\end{tabular}

--Linear Fit--

Mixing Rate

* see text for details of model

Table 7.16 Sediment mixing rates calculated ${ }^{*}$ from $239,240 \mathrm{Pu}$ data

$$
\text { -Pulse input (1962)- }
$$

Core Mixing Rate Range

I.D. $\left(\mathrm{cm}^{2} / \mathrm{yr}\right)+1-90 \%$

A $\quad 1.32$

F $\quad 0.11$

E $\quad 0.24$

D $\quad 0.59$

C 0.23
-Continuous input (1962)Mixing Rate

$\left(\mathrm{cm}^{2} / y r\right)$
0.82
0.32
0.66
2.6
0.52

* see text for details of model

** (i.d.) = insufficient data to determine $90 \%$ confidence 1 imits

Table 7.1c $\mathrm{D}_{b}$ 's recalculated from core $E$ Pu data for different input years

1958

-Pulse input-

$D_{\mathrm{b}}\left(\mathrm{cm}^{2} / \mathrm{yr}\right)$

19620.24

$1964 \quad 0.27$
-Continuous input-

D $_{\mathrm{b}}\left(\mathrm{cm}^{2} / \mathrm{yr}\right)$

0.56

0.61

0.66

0.72 
Figures 7.1a-h: Solid Phase 210pbex Proftles and Model Mixing Curves

Fig. 7.1a

Core A- 90m

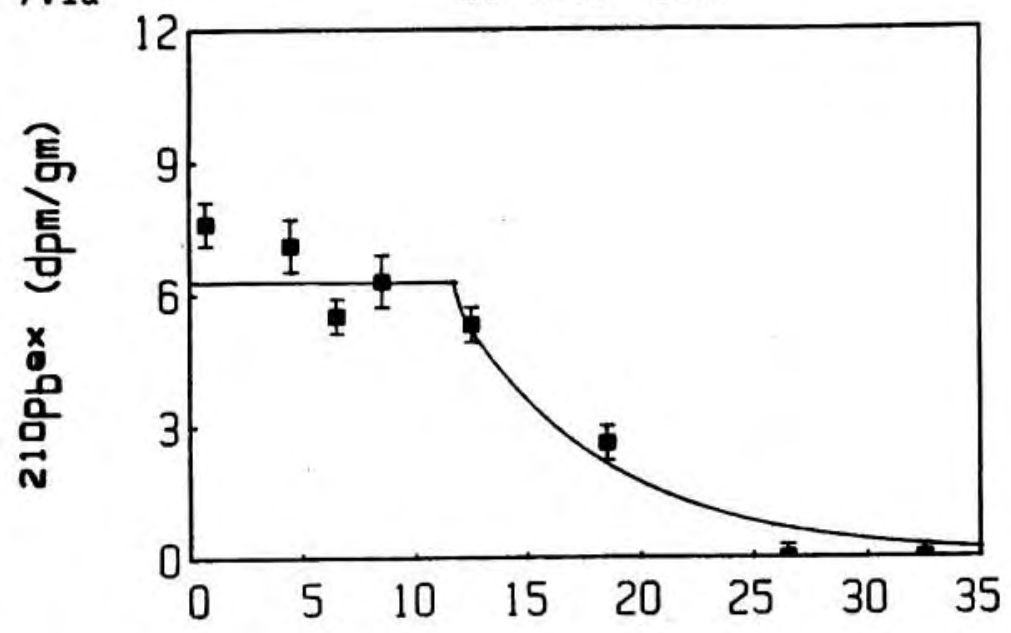

Fig. 7.1b

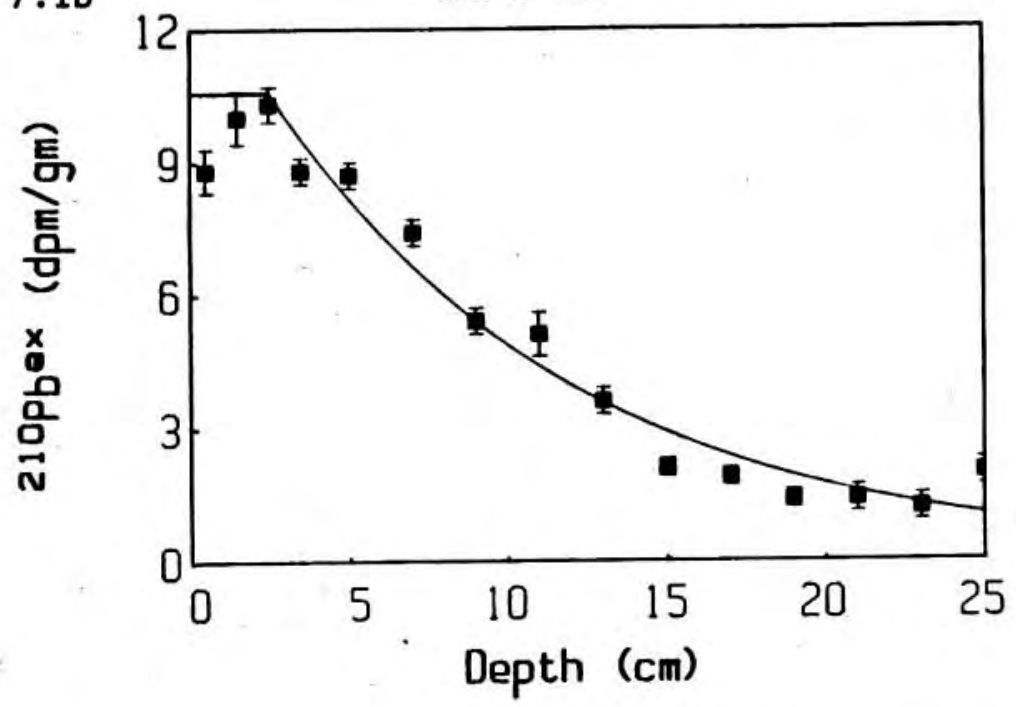

$210 \mathrm{~Pb}$ ex data are represented by solid squares with an assoctated one standard deviation error bar. The solid line represents the model best fit sediment mixing curve for $210 \mathrm{~Pb} e x$ (as given in equation (3)). The dashed line in Fig. 7.1c represents the best fit mixing curve using equation (4) to fit the $210 \mathrm{pb}^{\mathrm{ex}}$ data. The dotted lines in Figs. 7.1e, $7.1 \mathrm{f}$, and $7.1 \mathrm{~h}$ represent the $90 \%$ confidence 1 imits for $\mathrm{D}_{b}$ as reported in Table 7.1a. 
Fig. 7.1c

Core F- 501m

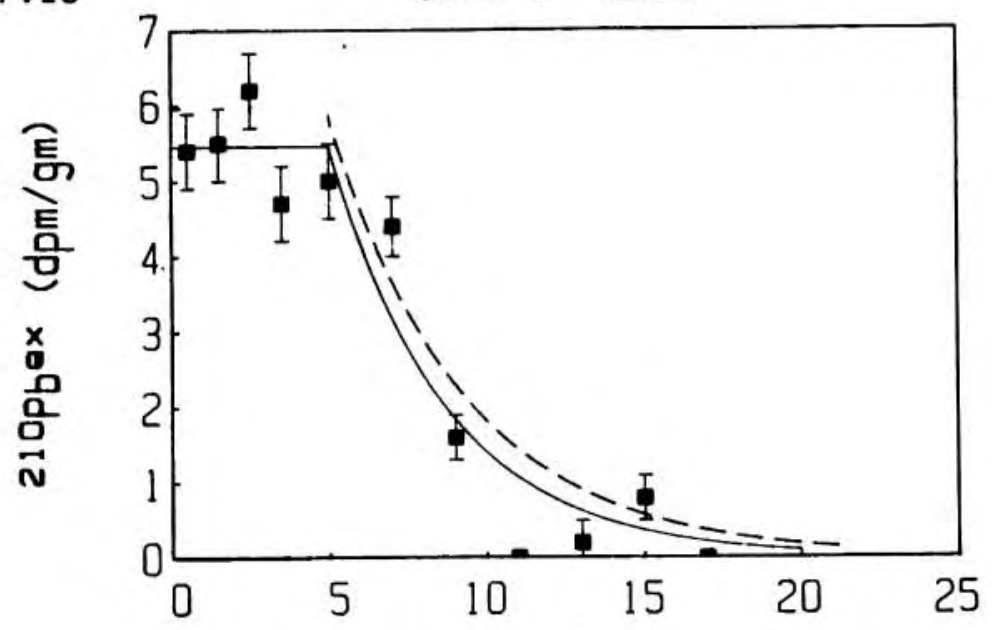

Fig. 7.1d

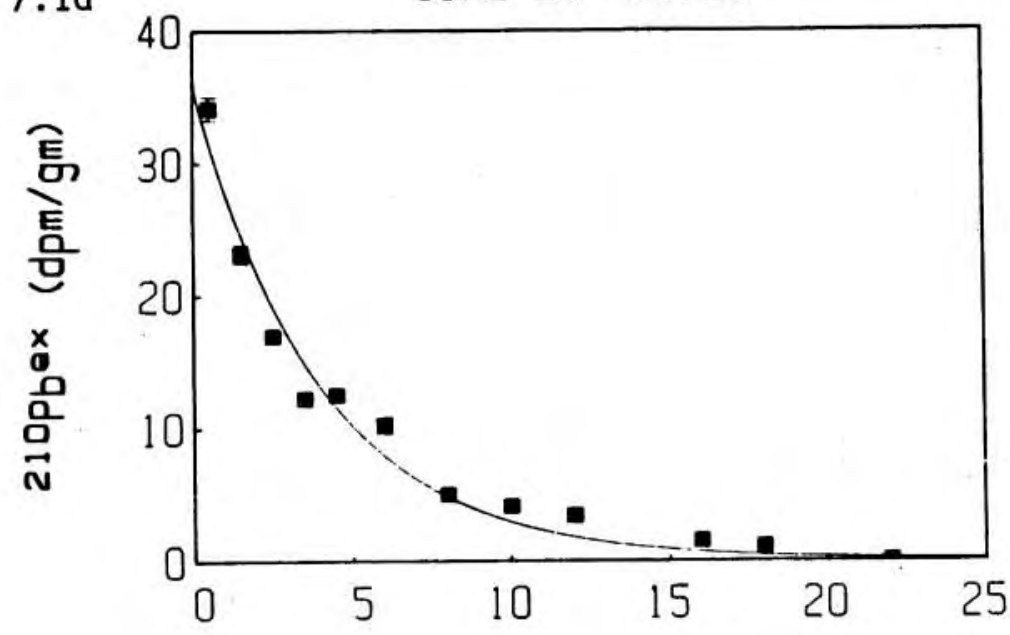

Fig. 7.1e

Core E- 1275m

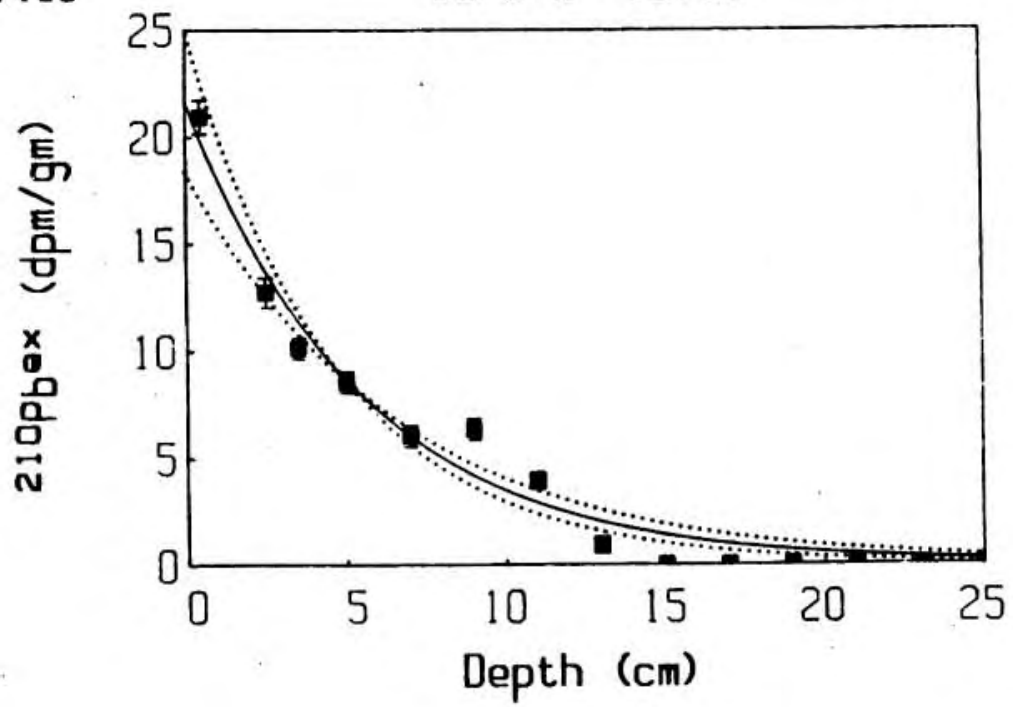


Fig. $7.1 \mathrm{f}$

Core D- 2362m

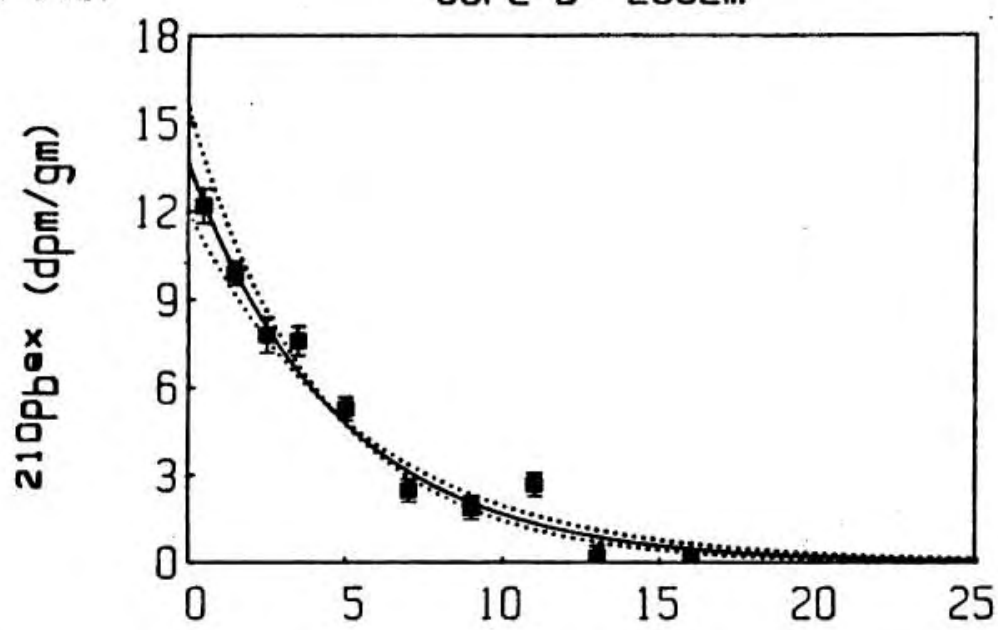

Fig. $7.1 \mathrm{~g}$

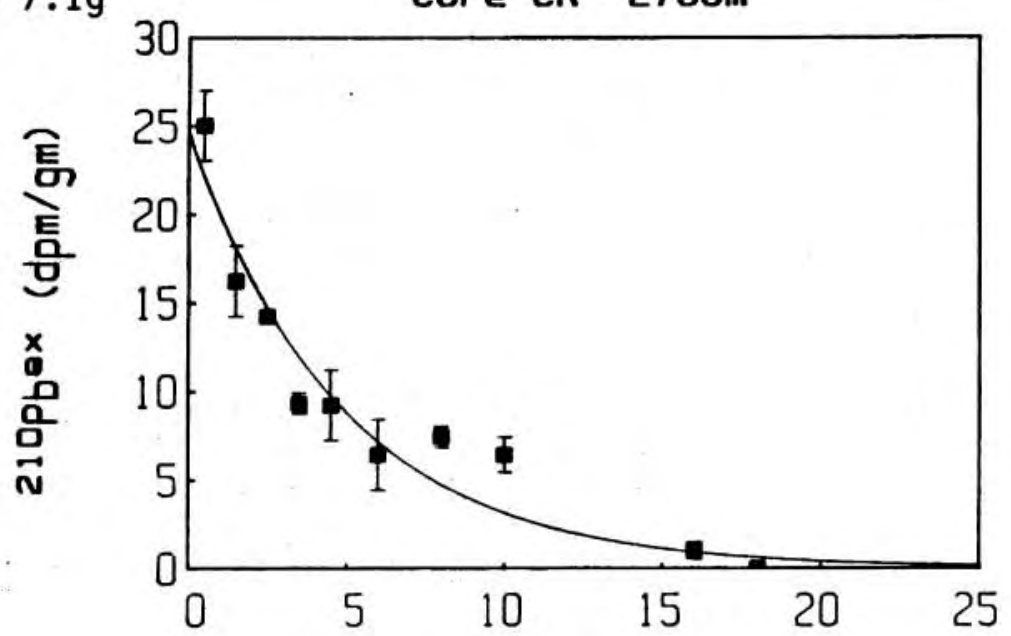

Fig. $7.1 \mathrm{~h} \quad$ Core C- 2700m

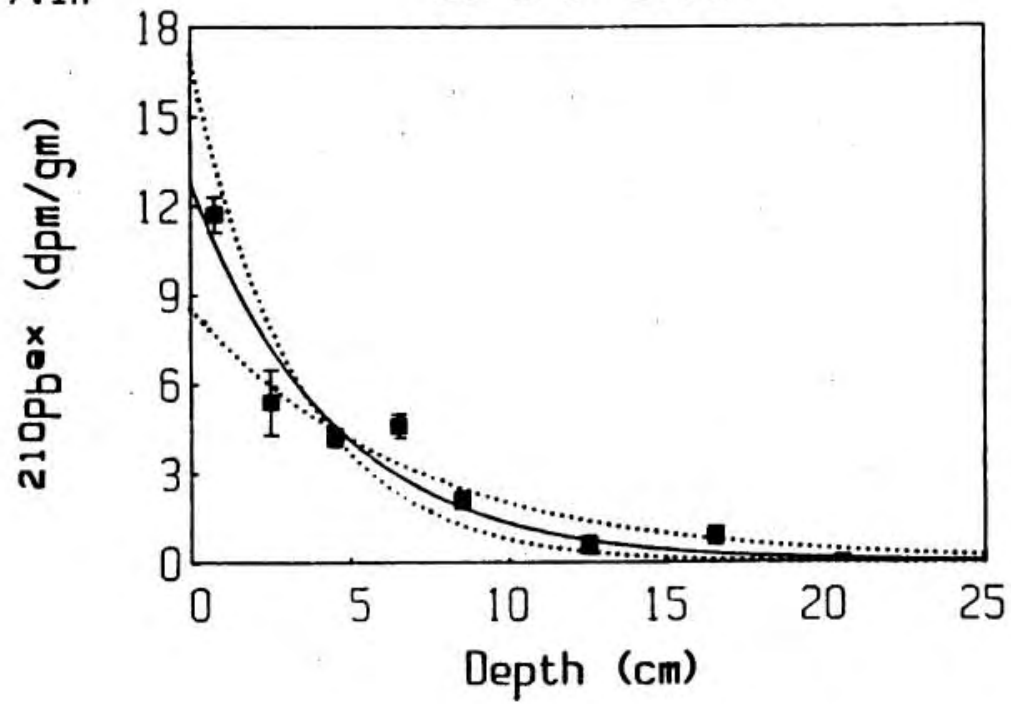


very difficult to achieve espectally in deep-sea cores where the mixing zone is confined to the upper $5-10 \mathrm{~cm}$ of the core. In addition, if one's solid phase profile includes points which do not fit the steadystate exponentially decreasing $210_{\mathrm{pb}}{ }^{\mathrm{ex}}$ model (for example if elevated activities are found deep in a core due to the sampling of a large worm tube) then the decision to include or exclude these "odd" data points can significantly alter the calculated sediment mixing rate.

In Table 7.1a, I have also provided the mixing rates calculated from a linear fit to the in converted form of equation (3), which is:

(4) $\quad \ln A=\ln A_{0}-\left[\left(\lambda / D_{b}\right)^{1 / 2} \cdot z\right]$.

This is the most popular form of the ${ }^{210} \mathrm{~Pb}^{\text {ex }}$ mixing model solution whereby on a plot of InA vs. $z$, the resulting straight line fit can be easily visualized and from the slope of this line the sediment mixing rate can be obtained. In every case except core $B K$, the $D_{b}$ calculated from the linear fit is within the $90 \%$ confidence range of the previous estimate, however the best fit $D_{b}$ from equations (3) and (4) are not identical. In general, the linear fit approach is acceptable if a large number of data points are avallable, and if these points are not clustered at the low activity range deep in the core. With the in conversion, low activity points with relatively large errors are equally weighted in the standard straight line fitting procedures, and this can bias the fit towards the deeper sections of the curve (see the dashed line fit to core $F$ in Fig. 7.1c). In these cases (and preferably in every case), a weighted fitting procedure should be employed whereby the data points are fit according to a weighting factor which is inversely proportional to the variance associated with each point (Bevington, 1978).

III. PARTICLE MIXING RATES - $239,240 \mathrm{Pu}$

Given the relatively recent introduction of $\mathrm{Pu}$ into the environment, a steady-state solution to equation (1) cannot be used to model the $239,240 \mathrm{Pu}$ sediment distributions. In order to solve the Pu mixing models, an input function for Pu to the sediments must be chosen. As 
suggested by previous researchers (Guinasso and Schink, 1975; Officer and Lynch, 1982; Cochran, 1985; Stordal et al., 1985; Sayles and Livingston, 1985), two input extremes will be used for which an analytical solution is avallable. The first case is called the "pulse" input model, since as the name suggests, the input of Pu to the sediments is taken as an instantaneous deposition of tracer at a chosen time, for example in 1962 which was the peak year of fallout Pu input (Perkins and Thomas, 1980). The second case is termed the "continuous" input model since the flux of Pu to the sediments is considered to be constant since its introduction. For both of these input assumptions, equation (1) will be solved assuming constant porosity, negligible sedimentation and given the long half life of Pu, assuming negligible Pu decay. Given these conditions, equation ( 1 ) reduces to:

$$
\text { (5) } \quad \frac{\delta A}{\delta t}=D_{b} \frac{\delta^{2} A}{\delta z^{2}} \text {. }
$$

The solution to equation (5) assuming the pulse input scenario is (Duursma and Hoede, 1967; Cochran, 1985):

$$
A / A_{0}=\exp \left[-z^{2} / 4 D_{b} t\right] \text {. }
$$

The solution to equation (5) assuming a continuous input of $\mathrm{Pu}$ is obtained by integrating equation (5) over time (Duursma and Hoede, 1967; Cochran, 1985):

$$
A / A_{0}=\exp \left[-z^{2} / 4 D_{b} t\right]-z / 2\left(\frac{\pi}{D_{b} t}\right)^{1 / 2} \operatorname{erfc}\left[z / 2\left(D_{b} t\right)^{1 / 2}\right]
$$

where erfc is the error function compliment (erfc(x) is equal to 1 for $x=0$ and decreases to zero quite quickly for $x>1)$.

The 239,240 Pu data from cores $A, F, E, D$, and $C$ were $f$ it to both the pulse and continuous input models, and the resulting best fit line was used to calculated the sediment mixing coefficient, $D_{b}$. In both cases, the best fit is obtained by minimizing the sum of the squares of the errors between the calculated model value and the observed data points (both $D_{b}$ and $A_{0}$ are variable). For the pulse model, 1962 was used as the time of the Pu input and for the continuous model, 1962 
was chosen as the date since which the Pu has been continuously deposited. The resulting sediment mixing rates are given in Table $7.1 \mathrm{~b}$ and for the case of the pulse input model, the $90 \%$ confidence ranges for $D_{b}$ are provided. The best fit mixing curve from both the pulse and the continuous model is plotted in Figure 7.2a-c for cores E, D, and C. As is evident in this figure, either input function can be made to fit the data with the appropriate mixing coefficient. In every case except core $A$ where insufficient data points are available to constrain the $D_{b}$ calculation, the mixing coefficient calculated from the continuous input model is greater than the $D_{b}$ from the pulse model. This is expected since sediment mixing rates must be increased in order to mix $\mathrm{Pu}$ to equivalent depths when the supply of Pu has occurred on average much more recently as in the continuous scenario compared to the pulse model.

Based upon curve fitting procedures alone, it is very difficult to select which input function is most appropriate for the data, and hence which $D_{b}$ best represents the "true" mixing rate. Also, given the wide ranges in the $90 \%$ confidence limits for both the $\mathrm{Pu}$ and $210 \mathrm{~Pb}^{\text {ex }} \mathrm{D}_{\mathrm{b}}$ calculations, there is generally an overlap between the estimated mixing rates using these two tracers (the exceptions being the $D_{b}$ from the pulse $\mathrm{Pu}$ model and $210_{\mathrm{Pb}}{ }^{\mathrm{ex}}$ model at core $\mathrm{E}$, and the continuous $\mathrm{Pu}$ model and the ${ }^{210} \mathrm{~Pb}^{\mathrm{ex}}$ model at core $D$ - see Tables $7.1 \mathrm{a}$ and $7.1 \mathrm{~b}$ ). Due to this overlap, the solid phase $239,240 \mathrm{Pu}$ and ${ }^{210} \mathrm{~Pb}^{\text {ex }} \mathrm{mixing}$ rate data cannot be reliably used to argue for or against the preferential mobility of Pu in the sediments, as discussed in Chapter 4 of this thesis.

In Table 7.1c I have calculated the best fit Pu mixing rates from the pulse and continuous models for core $E$ over a range of chosen input years $(1958,1960,1962,1964)$. As can be seen, the earlier that the Pu input occurs, the lower the required mixing rate needed to fit the data. In general, a shift of a few years in the Pu input date does not significantly alter the final mixing rate within the confidence limits of these models.

As discussed in Chapter 4, similar Pu mixing models have been used by previous researchers to argue for or against Pu diagenes is in 
Figure 7.2a-c: Solid Phase 239,240 pu Data and Model Mixing Curves

Fig. $7.2 a$

Core E- $1275 \mathrm{~m}$

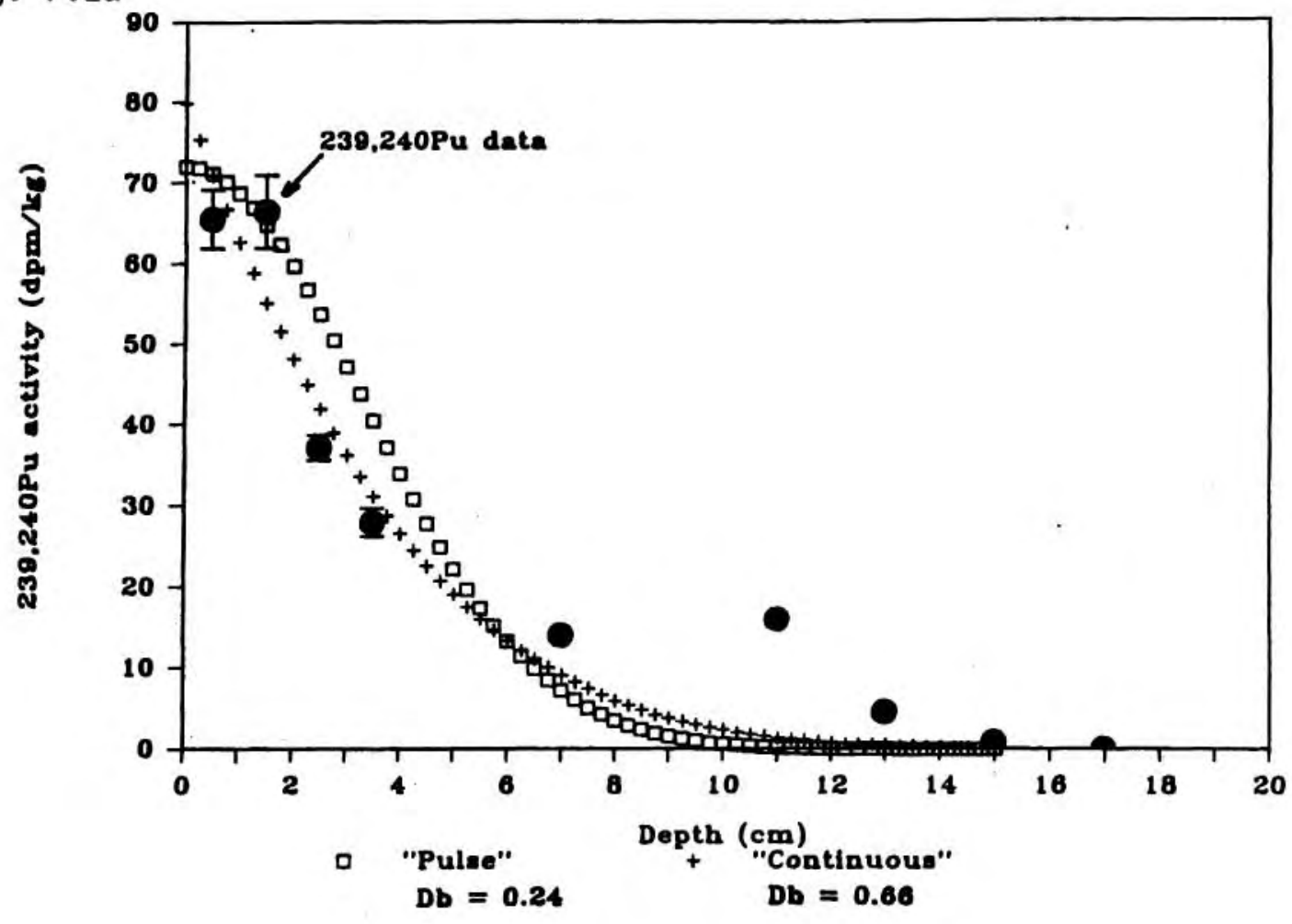

239,240 Pu data are represented by solid circles and the associated one standard deviation error bar is depicted if it is larger than the chosen symbol. The open squares represent the best fit model curve to the "pulse" input Pu mixing model which the crosses represent the best fit model curve to the "continuous" input Pu mixing model. 
Fig. 7.2b

Core D- 2362m

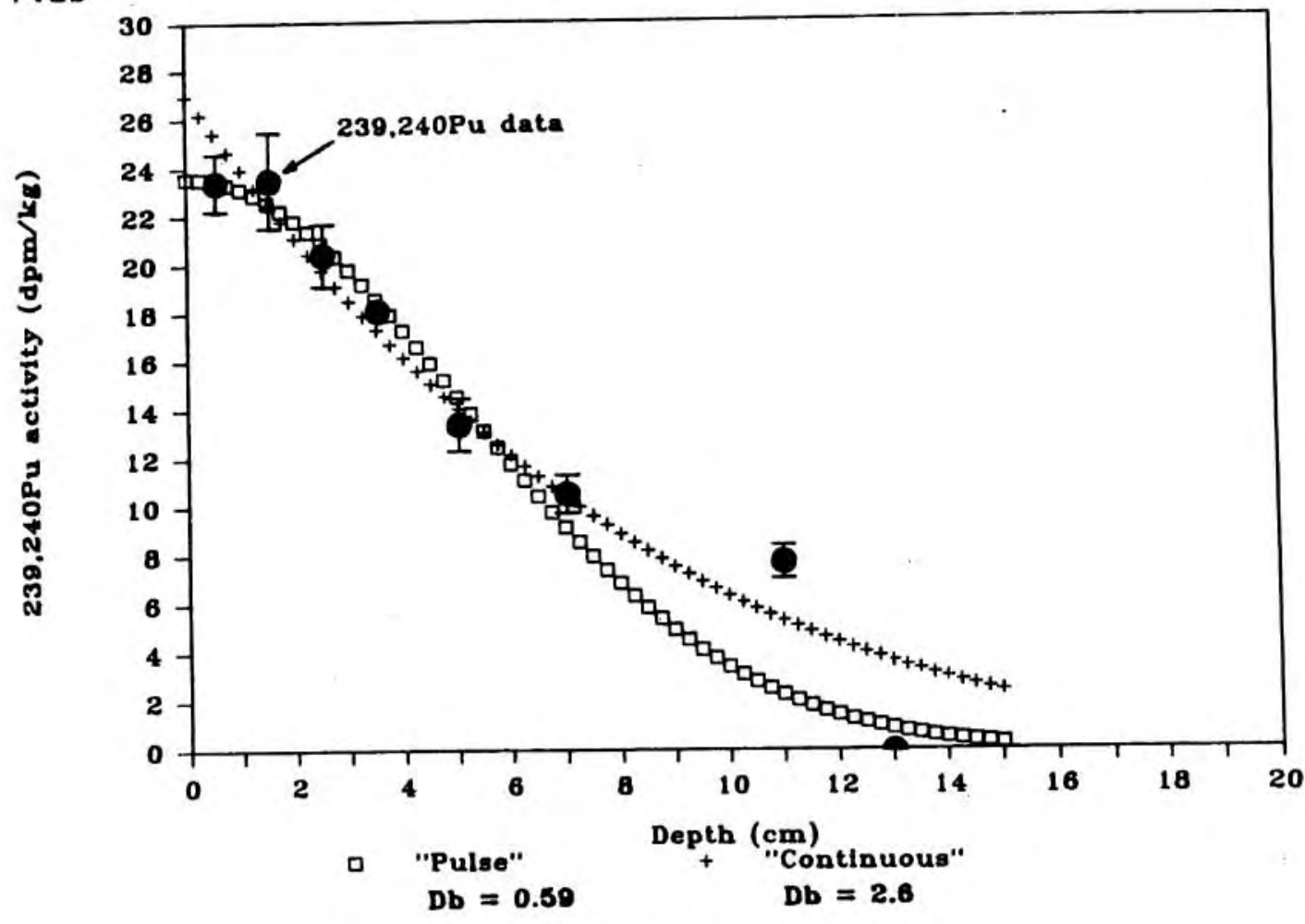

Fig. $7.2 \mathrm{c}$

Core C $-2700 \mathrm{~m}$

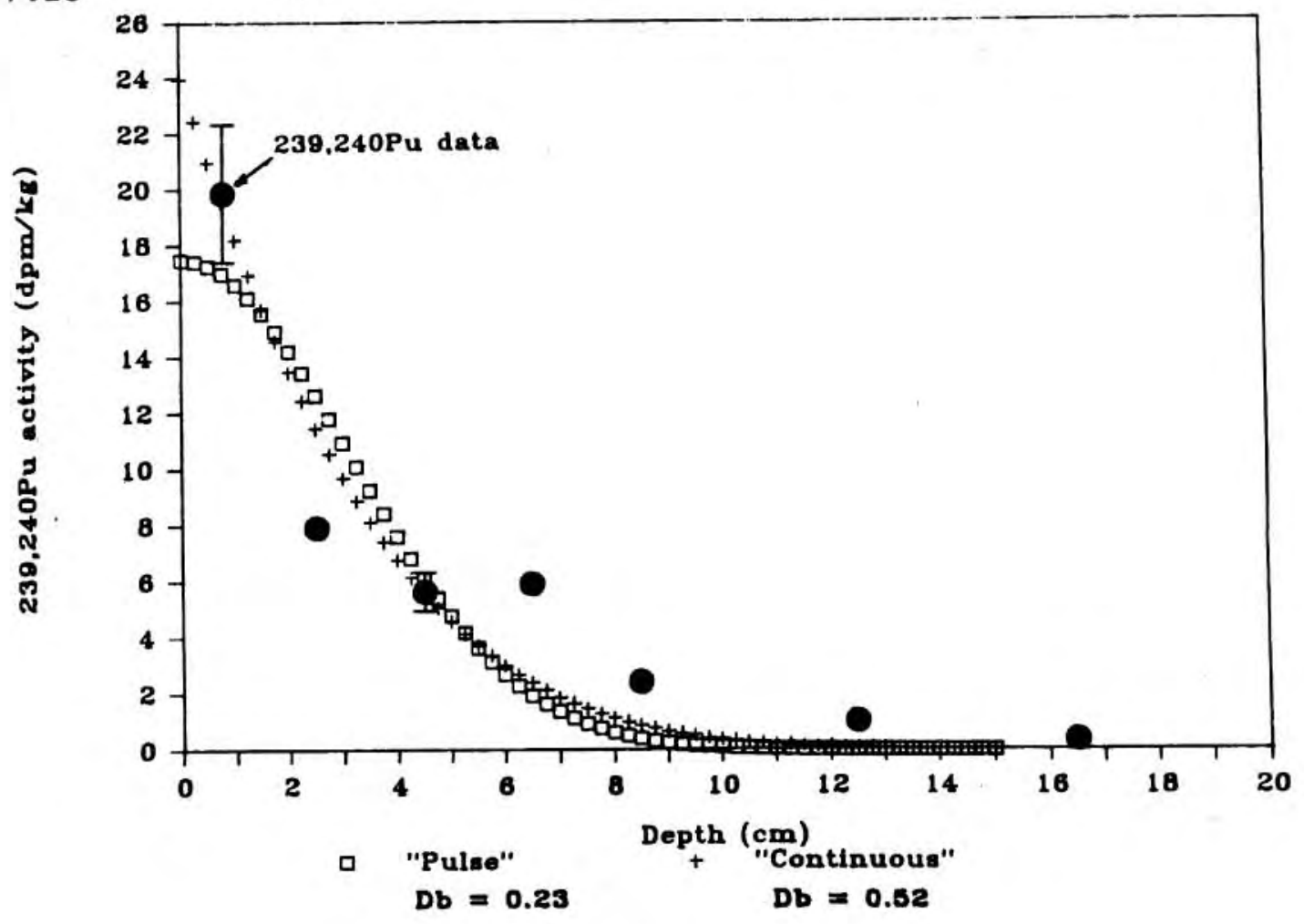


sediments (Cochran, 1985; Stordal et al., 1985; Sayles and Livingston, 1985). It should be pointed out that both different curve fitting techniques and different model assumptions have been employed by different research groups. For instance, Cochran (1985) used the exact same pulse and continuous Pu model solutions (6) and (7) as done here to fit his deep-sea Pu data. In contrast to the curve fitting procedures used here, his model curve is forced through the uppermost $239,240 \mathrm{Pu}$ solid phase data point when obtaining his best fit curve. I recalculated a Pu mixing rate which was $40 \%$ higher than his estimate using the same data and the pulse Pu solution (6), but in my procedure the interface Pu activity, $A_{0}$, is variable (see discussion of MANOP site $C$ in Chapter 4).

In another similar study, Sayles and Livingston (1985) argue for increased Pu mobllity deep in their cores based upon a change in slope at depth in their "continuous" Pu input model curve. In their study, Sayles and Livingston chose a solution to equation (1) which does assume the continual supply of $\mathrm{Pu}$, but does so by fixing $A_{0}$, the activity of Pu at the interface. The solution to their input assumption is shown graphically in Figure 7.3, and the differences in the two Pu "continuous" models should be noted. I feel that the solution I have used to model the continued input of Pu which assumes a constant flux to the sediments rather than a constant $A_{0}$ activity is a better representation of the continuous input scenario. Indeed in my historical Pu activity data from the shelf of the Northwest Atlantic as discussed in Chapter 6, the surface sediment ${ }^{239,240} \mathrm{Pu}_{\text {activities are found to }}$ increase quite dramatically with time as the flux of Pu continues.

The Pu input question can become quite complicated since at every site some combination of both a pulse-like and continuous-like input function may be most appropriate. Within the errors of the mixing rate estimates, attempts to combine these Pu input scenarios in either an analytical fashion (Lapique et al., 1986) or a numerical fashion (Anderson et al., 1986) do not produce dramatically altered mixing rate estimates from the Pu activity data. The true input will vary from site to site depending upon the importance of the continued scavenging 
Figure 7.3: Graphical representation of three diffusion problems for constant time (taken from Duursma and Hoede, 1967)

"Continuous" Input Sayles and Livingston (1985)

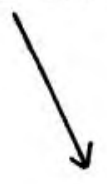

"Pulse" Input

and this thesis

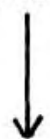

"Continuous" Input

Cochran (1985) and this thesis

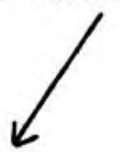

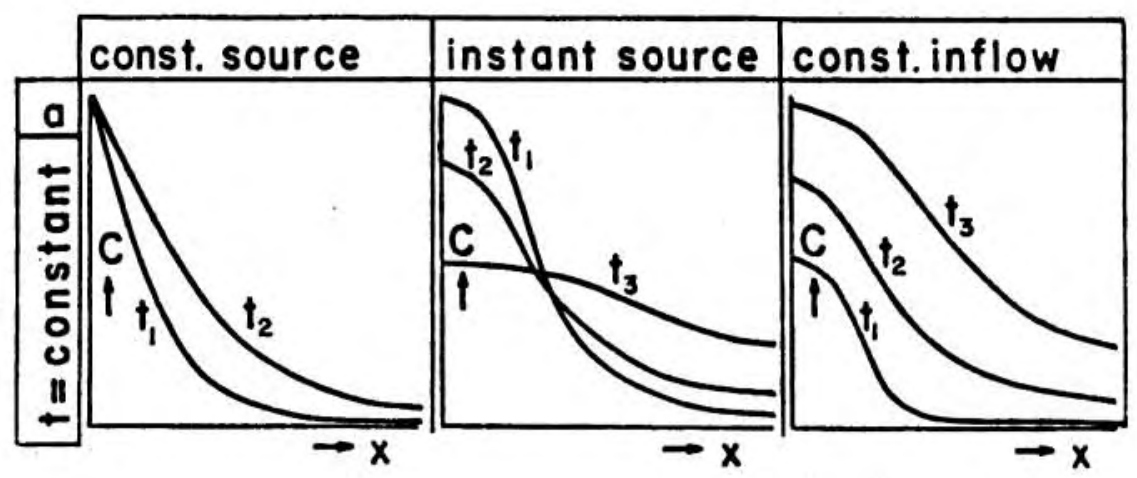


of Pu from the water column today, which is most significant in the shallower regions (Buesseler et al., 1985). While the mixing rate estimates themselves do not allow for the selection of the optimal $\mathrm{Pu}$ input scenario, in the following section Pu activity data will be combined with ${ }^{240} \mathrm{Pu} /{ }^{239} \mathrm{Pu}$ isotope ratio data in a model which does result in a clearer indication of the dominance of the early fallout years with respect to the net input of $\mathrm{Pu}$ to marine sediments.

\section{SEDIMENT MIXING MODEL $-239,240 \mathrm{PU}$ ACTIVITIES AND $240 \mathrm{Pu} / 239 \mathrm{Pu}$ RATIOS}

As discussed in Chapter 6, there appears to have been at least two distinct sources of fallout Pu to the North Atlantic sediments, each with its distinctive ${ }^{240} \mathrm{Pu} /{ }^{239} \mathrm{Pu}$ signature. In the following model, advantage will be taken of the relatively large difference in the isotopic ratio of these two sources (tropospheric Nevada fallout $240 \mathrm{Pu} /{ }^{239} \mathrm{Pu}=0.035$; global stratospheric fallout ${ }^{240} \mathrm{Pu} /{ }^{239} \mathrm{Pu}=0.18$ ) in order to constrain the input function of global fallout Pu to marine sediments.

As presented schematically in Figure 6.9 of the last chapter, the main difference between this new model and the previous single pulse and continuous Pu mixing models is the addition of a pulse of low $240 \mathrm{Pu} /{ }^{239} \mathrm{Pu}$ ratio Nevada fallout to the sediments centered around 1956 (1955 and 1957 being the peak Nevada fallout input years - Hicks and Baar, 1984). As shown previously in Table 6.3, we can use a two end-member mixing model to calculate the relative amounts of Nevada and global fallout at every site from the average sediment ${ }^{240} \mathrm{Pu} /{ }^{239} \mathrm{Pu}$ ratio. Also, my data suggest that the Nevada fallout is rapidiy and efficiently transported to the sediments, and hence a pulse input solution is well suited for modeling the Nevada Pu input (see Figs. 6.2, 6.6, and discussions in Chapter 6).

In my "pulse/pulse" model, global fallout $\mathrm{Pu}$ is added to the sediments as a pulse shortly after the Nevada pulse (1960 vs. 1956). In essence, the combination of the two pulses results in a Pu activity curve which looks very much like the single pulse model described in 
the previous section. In the "pulse/continuous" model, the Nevada pulse is followed by the continuous input of global fallout Pu. Given the dominance of global fallout with respect to the total Pu inventory (Table 6.3), the resulting "pulse/continuous" activity profiles looks very much 11ke the single continuous input model described in the last section (both the "pulse/pulse" and "pulse/continuous" model Pu activity profiles are plotted for core $D$ in Fig. 6.9). The main difference in these models is that deep in the core, with the "pulse/continuous" case, the Nevada component becomes progressively more important such that the ${ }^{240} \mathrm{Pu} /{ }^{239} \mathrm{Pu}$ ratio is drastically lowered. This shift in the ${ }^{240} \mathrm{Pu} /{ }^{239} \mathrm{Pu}$ ratio with depth in the "pulse/continuous" model should be easily observable in the Pu ratio data.

To calculate the ${ }^{240} \mathrm{Pu} /{ }^{239} \mathrm{Pu}$ ratio curves for these models I first assume that I can use the ${ }^{210} \mathrm{~Pb}^{\text {ex }}$ derived sediment mixing rate in calculating the expected distribution of Pu at every site if the correct input assumption is chosen. The general overlap between the apparent mixing rates derived by both ${ }^{210} \mathrm{~Pb}^{\mathrm{ex}}$ and $\mathrm{Pu}$ has been confirmed in the last section. To create the "pulse/pulse" ${ }^{240} \mathrm{Pu} /{ }^{239} \mathrm{Pu}$ curve, I first need to determine the relative size of each Pu pulse that is added to the sediments. The total quantity of tracer added at time zero can be calculated from equation (6) to be (Duursma and Hoede, 1967):

(8) $s=A_{0}\left(4 \pi D_{b} t\right)^{1 / 2}$,

where $s$ is equivalent to the amount ot tracer added at $t=0$. I use the two end-member mixing model and the average ${ }^{240} \mathrm{Pu} /{ }^{239} \mathrm{Pu}$ ratios within each core to $f 1 x$ the relative amounts of $P u$ from each of the pulses. For example at core $D, s{ }^{2} v_{a d a} / s_{\text {total }}$ equals 0.22 (see relative inventory calculations in Table 6.3). I then calculate two separate Pu activity profiles, setting $A_{0}$ in equation (6) for the larger pulse of global fallout Pu by taking the best fit $A_{0}$ from the single Pulse model (Fig. 7.2) times its relative activity ratio from the ${ }^{240} \mathrm{Pu} /{ }^{239} \mathrm{Pu}$ data $\left(=1-\left(\mathrm{s}_{\mathrm{Nevada}} / \mathrm{s}_{\text {tota }}\right) ;\right.$ for example in the 
case of core $D$, the $A_{0}$ of the global pulse $=24 \times 0.78=18.7$ ). This is a somewhat arbitrary decision which in effect is used to set sglobal with equation ( 8$)$, so that in both the "pulse/pulse" and "pulse/continuous" models the total amount of Pu added from global and Nevada fallout doesn't change. Given the sglobal calculated above, it is straightforward to calculate the Nevada pulse Pu profile, working back from our estimate of the percent of Nevada Pu added (Table 6.3) to calculate $S_{\text {Nevada }}$ and hence $A_{0}$ from equation (8). An activity profile is calculated from equation $(6)$, the $A_{0}$ value, and the $210 \mathrm{~Pb}^{\mathrm{ex}}$ mixing rate. I then sum over $0.25 \mathrm{~cm}$ intervals the resulting $239,240 \mathrm{Pu}$ activities from the two pulse distributions and from this the ${ }^{240} \mathrm{Pu} /{ }^{239} \mathrm{Pu}$ ratios in the solid phase can be calculated.

In the "pulse/continuous" model, the Pu Nevada activity profile is calculated as just described, while the continuous global fallout curve has yet to be determined. For the continuous input calculations, an amount of tracer, sglobal (the same amount as in the "pulse/pulse" mode1), is added over time such that the yearly flux of Pu, q, equals s/dt. In the solution to the continuous input model, equation ( 7 ), the interface activity of $\mathrm{Pu}$ is related to $\mathrm{q}$ by the following equation (Duursma and Hoede, 1967):

(9) $\quad A_{0}=q \cdot\left(t / D_{b} \pi\right)^{1 / 2}$.

From this equation and the known amount of global fallout added (1.e. $q)$, the continuous input curve for global fallout $\mathrm{Pu}$ is calculated. Similar to the previous case, both the Nevada and continuous curves are summed, and the resulting ${ }^{240} \mathrm{Pu} /{ }^{239} \mathrm{Pu}$ ratio at each depth is calculated.

In Figure 7.4a-c I have plotted the model ${ }^{240} \mathrm{Pu} /{ }^{239} \mathrm{Pu}$ curves for both Pu input scenarios for cores $E, D$, and $C$, which are the three sites where I have sufficient activity and ${ }^{240} \mathrm{Pu} /{ }^{239} \mathrm{Pu}$ data to reliably distinguish between these models. In every case, the "pulse/pulse" model produces relatively constant ${ }^{240} \mathrm{Pu} /{ }^{239} \mathrm{Pu}$ ratios throughout the core. Basically, if two separate sources of Pu are 
added to the sediments at roughly the same time, then mixing will result in little separation between Pu from these sources some 20 or more years after their input. In the "pulse/continuous" case the model does exhibit a large shift in the expected ${ }^{240} \mathrm{Pu} /{ }^{239} \mathrm{Pu}$ ratio of the sediment with depth in the core. At the sediment/water interface, higher ${ }^{240} \mathrm{Pu} /{ }^{239} \mathrm{Pu}$ ratios than the core average would be found while at depth, progressively lower ${ }^{240} \mathrm{Pu} /{ }^{239} \mathrm{Pu}$ ratios are expected. This shift in the $240 \mathrm{Pu} /{ }^{239} \mathrm{Pu}$ curve reflects the relatively deeper mixing of the earlier pulse of Nevada Pu relative to global fallout Pu which is added in the model at a constant rate over time. Clearly, the data resemble the "pulse/pulse" model much more than the "pulse/continuous" case. The calculated ${ }^{240} \mathrm{Pu} /{ }^{239} \mathrm{Pu}$ distributions in the "pulse/pulse" case are relatively insensitive to the estimate of $D_{b}$, but in the "pulse/ continuous" case the ${ }^{240} \mathrm{Pu} /{ }^{239} \mathrm{Pu}$ curve will shift if a different mixing rate is assumed. Given the $90 \%$ confidence limits from the ${ }^{210} \mathrm{~Pb}^{\text {ex }}$ derived mixing rate, the resulting effects on the "pulse/continuous" model ${ }^{240} \mathrm{Pu} /{ }^{239} \mathrm{Pu}$ ratto curve can be calculated, and these are shown in Fig. 7.4a-c. As the mixing rate increases, the slope on the ${ }^{240} \mathrm{Pu} /{ }^{239} \mathrm{Pu}$ ratio curve decreases, but the change in slope is not sufficient to eliminate the ${ }^{240} \mathrm{Pu} /{ }^{239} \mathrm{Pu}$ gradients. The model is also fairly insensitive to the choice of the input times for both the Nevada and global sources. The basic conclusion is that if the net flux of $\mathrm{Pu}$ to the sediments continued to be large, then a trend towards the higher global fallout ${ }^{240} \mathrm{Pu} /{ }^{239} \mathrm{Pu}$ ratio should be detectable in the surface sediment data, and lower ratios should be evident deep in the cores. The lack of any strong downcore gradient in the ${ }^{240} \mathrm{Pu} /{ }^{239} \mathrm{Pu}$ data is the strongest evidence supporting a pulse-like input for Pu from any of its sources at these sites.

In the shallower cores, this model cannot be applied since the average ${ }^{240} \mathrm{Pu} /{ }^{239} \mathrm{Pu}$ ratio is too close to the global fallout average, and hence too little Nevada $\mathrm{Pu}$ is present to alter the ${ }^{240} \mathrm{Pu} /{ }^{239} \mathrm{Pu}$ ratios significantly at any depth. Given the high $\mathrm{Pu}$ inventories in cores $F(501 \mathrm{~m})$ and $A(90 \mathrm{~m})$ (Buesseler et al., 1985; Chapter 4, this thesis) and given the historical increases in the surface sediment $\mathrm{Pu}$ 
Figure 7.4a-c: ${ }^{240} \mathrm{Pu} /{ }^{239} \mathrm{Pu}$ Atom Ratio Data and Model Mixing Curves.

Fig. 7.4a Core E- 1275m

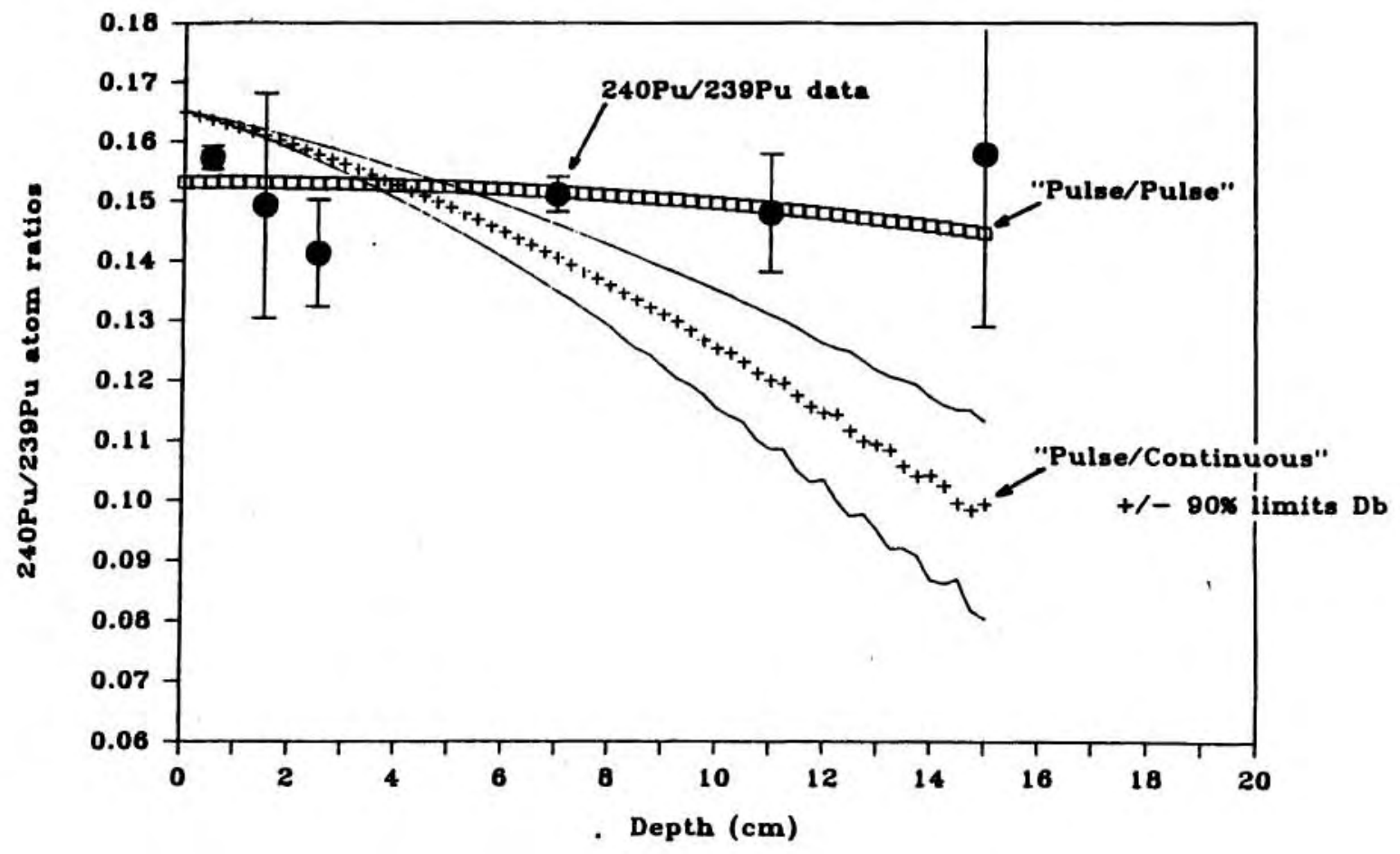

$240 \mathrm{pu} / 239 \mathrm{pu}$ atom ratio data are represented by a solid circle and their associated one standard deviation error bars are plotted. The open squares represent the resulting model $240 \mathrm{Pu} / 239 \mathrm{Pu}$ curve for the "pulse/ pulse" model, while the crosses represent the model $240 \mathrm{Pu} / 239 \mathrm{Pu}$ curve for the "pulse/continuous" mixing model (see text for detalls). Also included with the"pulse/continuous" model curve are the resulting $240 \mathrm{Pu} / 239 \mathrm{Pu}$ curves (solid 1ine) if the chosen $\mathrm{D}_{\mathrm{b}}$ includes the $90 \%$ confidence limits as discussed in the text. 
Fig. 7.4b

Core D- 2362m

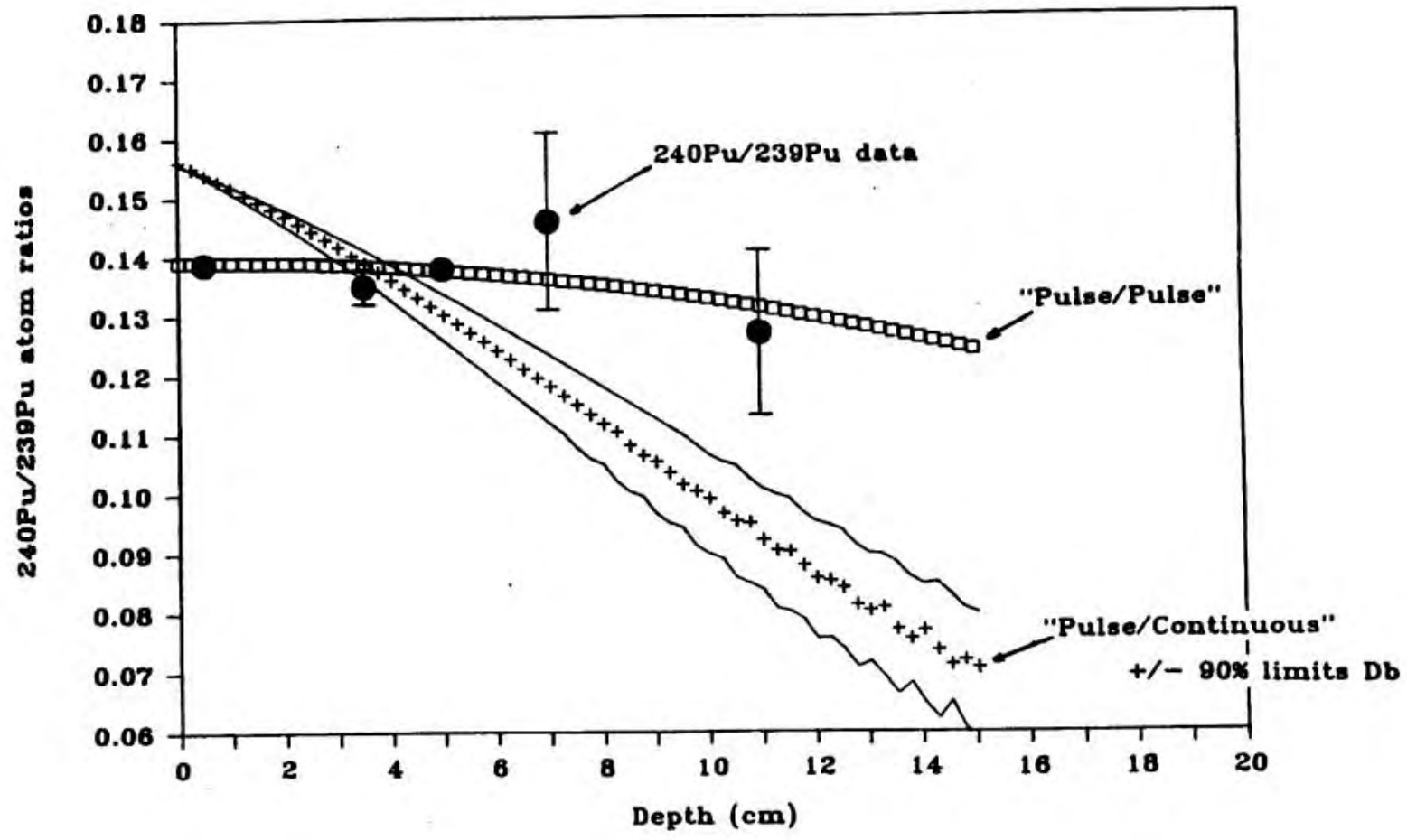

Fig. $7.4 \mathrm{c}$

Core C- $2700 \mathrm{~m}$

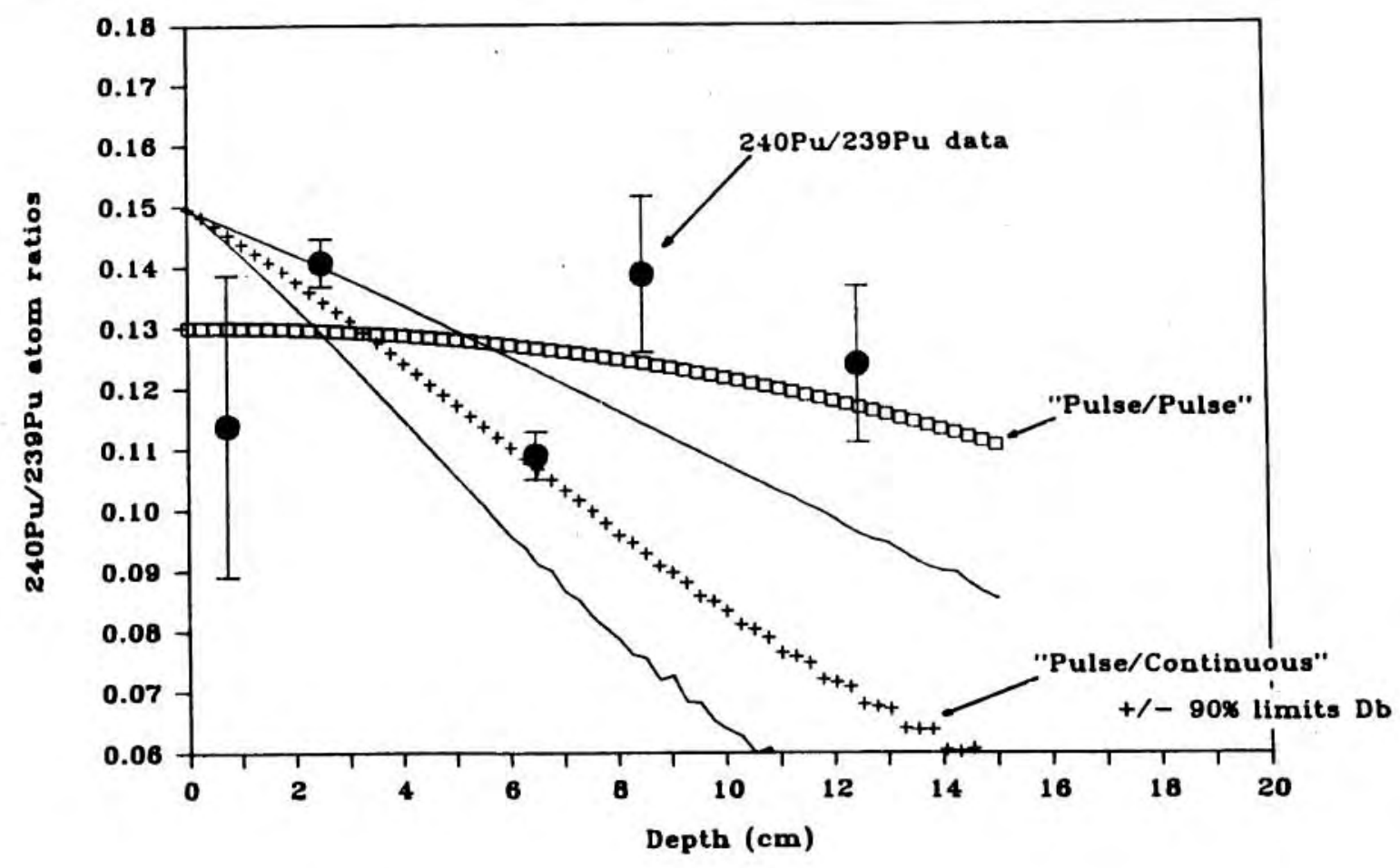


activity on the shelf (Chapter 6 ), there appears to be considerable continued scavenging of $\mathrm{Pu}$ at these shallow sites in contrast to the deeper cores.

Figure 7.5 is a schematic summary of the range of Pu input scenarlos suggested by the data and models discussed in this thesis. Essentially there are a range of input scenarios depending upon the water depth and hence the relative magnitude of the early fallout inputs (most significant in the deep-sea) and continued scavenging processes (progressively more imporant in the shallower cores).

\section{SEDIMENT MIXING PROCESSES - DEEP-SEA CORES G AND H}

The two deep-sea cores $G(4469 \mathrm{~m})$ and $H(4990 \mathrm{~m})$ were collected with the intention of obtaining both deep-sea Pu pore water data (Chapter 4) and in order to examine solid phase activity data from sites where the Nevada input would be most significant relative to my other cores. With respect to the latter, ${ }^{240} \mathrm{Pu} /{ }^{239} \mathrm{Pu}$ ratios close to 0.1 were found throughout the cores indicating that over $40 \%$ of the total $239,240 \mathrm{Pu}$ activity at these sites originated from the Nevada fallout source (Table 6.3). As shown in Figure 4.3 in Chapter 4 , there is a sharp sub-surface maximum in both the $210 \mathrm{~Pb}^{\mathrm{ex}}$ and $239,240 \mathrm{Pu}$ activities at $3-4 \mathrm{~cm}$ in core $H$ and at $4-4.5 \mathrm{~cm}$ in core $G$. Because of these subsurface features, I cannot use the models discussed in the previous sections which assume that sediment mixing processes are purely diffusive in nature. Given the constant ${ }^{240} \mathrm{Pu} /{ }^{239} \mathrm{Pu}$ ratios throughout the sediment profiles in cores $G$ and $H$, at least qualitatively the Nevada and global fallout sources must have arrived predominantly early on, otherwise a wider range of ${ }^{240} \mathrm{Pu} /{ }^{239} \mathrm{Pu}$ ratios would be expected.

As discussed in Chapter 4, I belleve that these subsurface peaks could be caused by surface deposit feeders which defecate a portion of their ingested material at a discreet depth in the sediment column. This can be considered an "inverse conveyor-belt" feeding pattern in the terminology of Rhodes (1974) and others. Recently, Boudreau (1986b) has attempted to model this type of mixing process. Given typical 


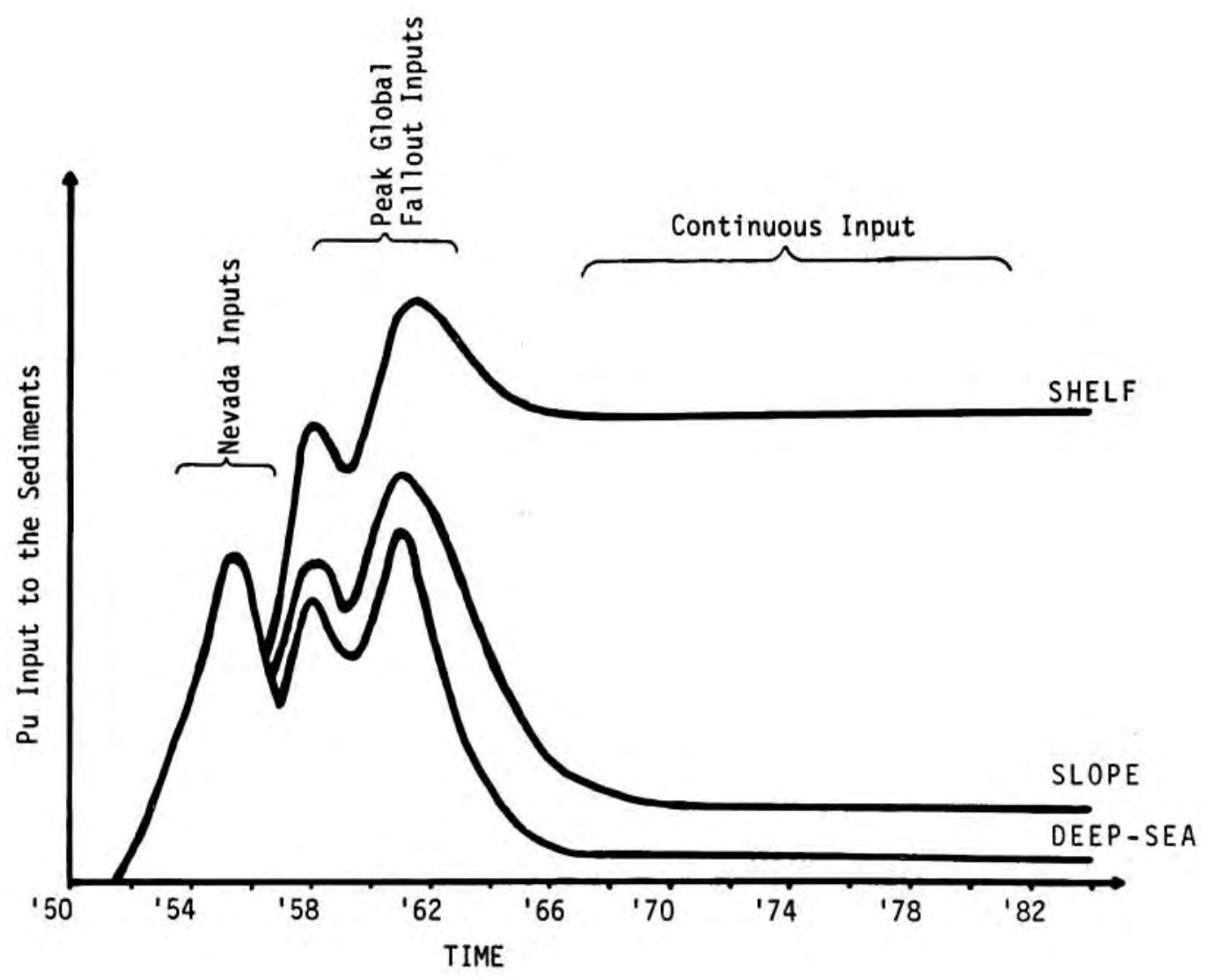

Figure 7.5: Schematic summary of Pu input scenarios to the sediments of the Northwest Atlantic

The Pu input function to the sediments is plotted schematically vs. time for deep-sea, slope and muddy shelf sediments. At the deep-sea sites, the early 50's Nevada fallout Pu inputs are followed closely by global fallout inputs in the 50 's and early 60 's with relatively minor continuous fluxes of Pu being incorporated into the sediments. At the slope sites, the total global fallout inputs are somewhat larger than the Nevada inputs, with the bulk of the Pu arriving in the 50's and 60's. At the shelf sites, the continuous input of $\mathrm{Pu}$ will dominate the Pu input function. The relative amounts of Nevada and global fallout Pu incorporated into the sediments with this scheme is consistent with the average trend in the sediment $240 \mathrm{Pu} / 239 \mathrm{Pu}$ ratios. The Pu sediment mixing models suggest the pulse-like input scenario for the deeper cores. The Pu inventory data and the time sequence of $\mathrm{Pu}$ activity and $240 \mathrm{Pu} / 239 \mathrm{Pu}$ data on the shelf all support a higher rate of continued Pu scavenging in the shelf region. 
Figure 7.6: Sediment Mixing Rates vs. Water Depth from 80-2700 $\mathrm{m}$ in the Northwest Atlantic

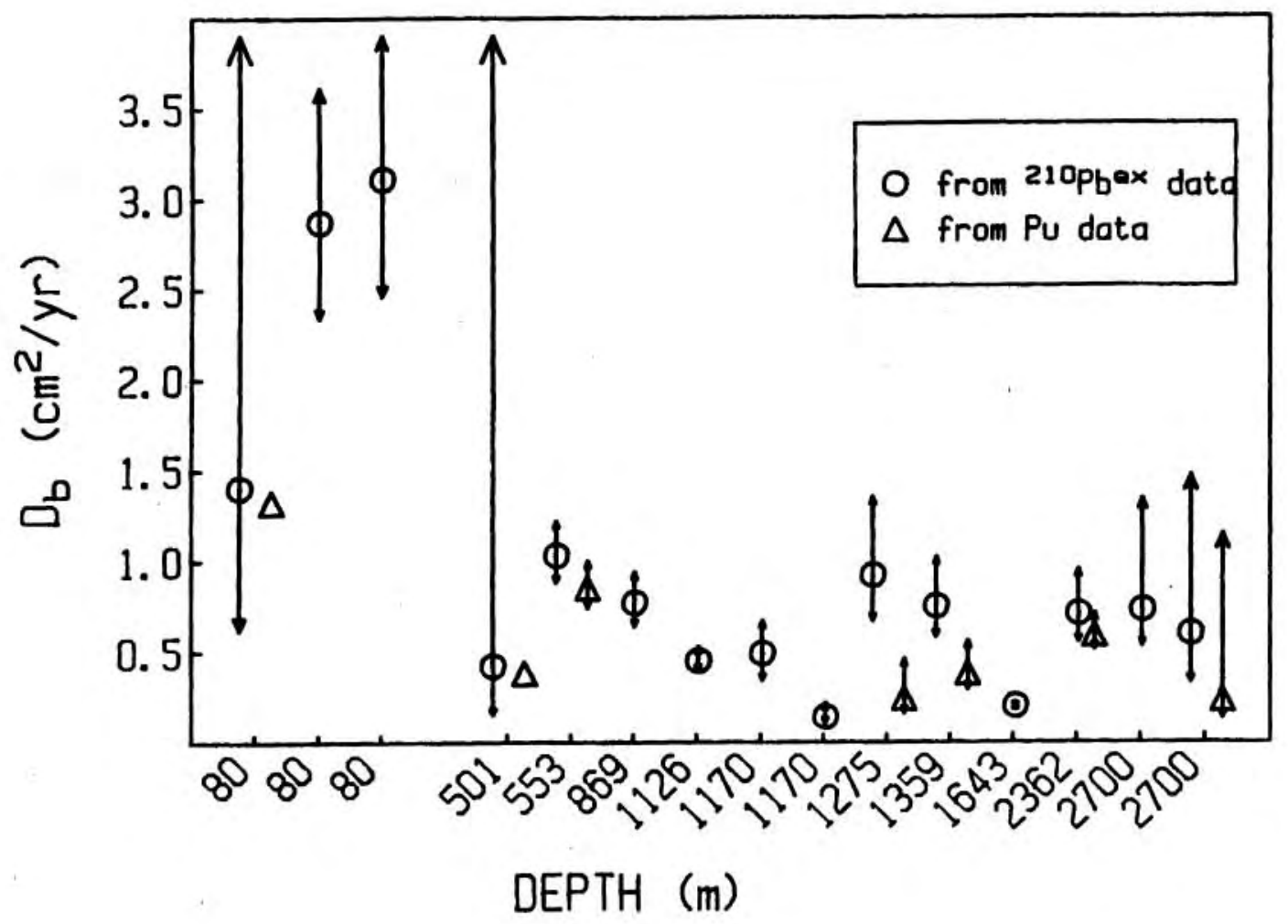

Mixing rates calculated from $210 \mathrm{~Pb} e x$ and $239,240 \mathrm{Pu}$ modeling are shown as open circles and open triangles, as respectively. The $90 \%$ confidence ranges are represented by the arrows at the data points. Data taken from this thesis and Anderson et al. (1986). 


\section{CHAPTER 8}

\section{Summary}

\section{INTRODUCTION}

This thesis examines the distribution and behavior of fallout Plutonium in the marine environment. By developing a more sensitive technique to measure both ${ }^{239} \mathrm{Pu}$ and $240 \mathrm{Pu}$ in marine sediments, pore waters, sea water and sediment trap samples, a variety of research questions can be addressed. In general, my research falls into four areas: a) the early diagenesis of $\mathrm{Pu}$, 1.e. the blogeochemical processes which can alter the distribution of $\mathrm{Pu}$ once it is buried, b) the factors controliing the accumulation and inventories of $\mathrm{Pu}$ within the sediments of a given region, c) the input history of fallout Pu to marine sediments and the variability in the geochemical properties of Pu from its different nuclear testing sources, and d) the processes (primarily sediment mixing) controlling the distribution of $\mathrm{Pu}$ within a given core. The conclusions of this thesis will be summarized below, point by point, starting with the development of the mass spectrometric detection technique.

\section{CONCLUSIONS}

1. A thermal ionization mass spectrometric technique was developed which enabled me to detect ${ }^{239,240} \mathrm{Pu}$ down to the $10^{-3} \mathrm{dpm}$ per sample level of $239,240 \mathrm{Pu}$, or lower. This is well over an order of magnitude more sensitive than current alpha-counting techniques. This increase in sensitivity allowed me to detect the extremely low activities of $239,240 \mathrm{Pu}$ found in slope and deep-sea pore waters. An additional bonus of the m.s. technique is the abllity to separate the ${ }^{239} \mathrm{Pu}$ and ${ }^{240} \mathrm{Pu}$ isotopes. The wide range in the ${ }^{240} \mathrm{Pu} /{ }^{239} \mathrm{Pu}$ ratios of my samples proved informative. With ${ }^{240} \mathrm{Pu} /{ }^{239} \mathrm{Pu}$ ratio data, a 1 ink could be made between the specific source of fallout Pu (identified by their characteristic ${ }^{240} \mathrm{Pu} /{ }^{239} \mathrm{Pu}$ ratio) and the geochemical behavior of $\mathrm{Pu}$ in the 
oceans (see conclusion \#4).

2. Plutonium pore water chemistry was examined along a transect of seven box cores between Woods Hole and Bermuda. These cores exhibit a systematic transition between highly reducing muddy sediments on the shelf, to more oxic and carbonate rich sediments in the deep-sea. I show that Pu diagenesis cannot be reliably predicted based upon solid phase data alone; Pu pore water data remain the most sensitive indicators of Pu diagenesis. The major question which was posed was how does the solubility and hence potential diffusive flux of Pu out of the sediments vary at these sites?

Along the entire transect of cores I have found that the Pu pore water distribution is predominantly controlled by the solid phase Pu profile. The calculated $239,240 \mathrm{Pu}$ distribution coefficients $\left(K_{d}=d p m\right.$ on solids/dpm in solution) range between $0.2-23 \times 10^{4}$. Within this data set there is also a suggestion of lower $k_{d}$ values in the deeper cores (with $K_{d}$ 's of $10^{4}-10^{5}$ in the shelf and slope cores out to $2362 \mathrm{~m}$, and $K_{d}$ 's of $0.3-0.6 \times 10^{4}$ in the deeper cores). No single mechanism (redox, sediment type, complexation, Fe/Mn cycling, etc.) was found which could account for the relatively higher solubility of Pu in the pore waters of the deeper cores.

A diffusive flux of $\mathrm{Pu}$ out of the sediments is suggested since in the upper sections of the core the pore water ${ }^{239,240} \mathrm{Pu}$ activities are elevated over the near bottom water $239,240 \mathrm{Pu}$ activities. Diffusive flux estimates for Pu are quite small however $\left(0.2-24 \times 10^{-5} \mathrm{dpm}\right.$ $239,240 \mathrm{Pu} / \mathrm{cm}^{2} \mathrm{yr}$ ), suggesting that since its introduction, negligible Pu has been remobilized out of the sediments. On a longer time scale $\left(\approx 10^{2}-10^{3}\right.$ years) Pu remobilization may become significant relative to the observed solid phase $239,240 \mathrm{Pu}$ inventories.

3. Sediment inventories of $239,240 \mathrm{Pu}$ and ${ }^{210} \mathrm{~Pb}$ ex were examined over a large area of the Northwest Atlantic shelf and slope region. These two tracers were compared since both isotopes are supplied predominantly by atmospheric delivery to coastal waters, and since both $239,240 \mathrm{Pu}$ and $210 \mathrm{~Pb}$ are used to study recent accumulation and mixing processes in marine sediments. From this sediment inventory compilation an estimate 
could be made of the magnitude and location of $\mathrm{Pu}$ and ${ }^{210} \mathrm{~Pb}$ ex deposition and accumulation. A major conclusion is that the sediment inventories decrease with increasing water depth, reflecting a decrease in the net scavenging rate of these elements off-shore. Pu sediment inventories drop-off with increasing water depth much more rapidly than $210 \mathrm{~Pb}$ inventories, either due to the shorter residence time of $210 \mathrm{~Pb}$ compared to $\mathrm{Pu}$ with respect to water column removal processes, or due to comparisons between the naturally occurring ${ }^{210} \mathrm{~Pb}$ steady-state scenario and the more recently introduced fallout $\mathrm{Pu}$.

A mass balance calculation indicates that the inventory of $210 \mathrm{~Pb}$ in the sediments is roughly in balance $(83 \pm 15 \%)$ with $210 \mathrm{~Pb}^{\mathrm{ex}}$ atmospheric and water column sources over the entire Northwest Atlantic Shelf and slope region out to $4000 \mathrm{~m}$. Based upon a more limited number of sediment inventories at greater water depths $(n=5 ; 4000-6000 \mathrm{~m})$ a deficiency in $210 \mathrm{~Pb}^{\mathrm{ex}}$ is found in deep-sea sediments (measured ${ }^{210} \mathrm{~Pb}^{\mathrm{ex}}$ inventory/expected supply $\simeq 45 \%$ ). These inventory data argues against strong lateral inputs of ${ }^{210} \mathrm{~Pb}$ into this continental margin region. For $239,240 \mathrm{Pu}$, only about $24 \%$ of the known fallout inputs are found in the sediments out to $4000 \mathrm{~m}$; the remainder has yet to be removed from the water column.

4. ${ }^{240} \mathrm{Pu} /{ }^{239} \mathrm{Pu}$ ratio data provide a unique insight into the relationship between the specific sources of $\mathrm{Pu}$ and its behavior in the oceans. Specifically, sediment ${ }^{240} \mathrm{Pu} /{ }^{239} \mathrm{Pu}$ ratios were found to vary systematically from 0.18 on the shelf to 0.10 in the deep-sea (at 4500-5000 m) in the Northwest Atlantic. This decrease is consistent with a two source model, whereby fallout Pu from surface based testing at Nevada $\left({ }^{240} \mathrm{Pu} /{ }^{239} \mathrm{Pu}=0.035\right)$ is rapidly removed to the sediments at all depths, while global fallout $\mathrm{Pu}\left({ }^{240} \mathrm{Pu} /{ }^{239} \mathrm{Pu}=0.18\right)$ is only efficiently deposited to the sediments in the shallower cores where scavenging is more intense. This model was chosen since the Pu isotopic data rule out any present day fractionation of ${ }^{239} \mathrm{Pu}$ from ${ }^{240} \mathrm{Pu}$ in the water column.

This two source model is supported by a variety of findings. Surface sediments from the 1950's and 1960's from my study region have lower or equivalent ${ }^{240} \mathrm{Pu} /{ }^{239} \mathrm{Pu}$ ratios compared to present day samples 
from the same water depths (Nevada fallout was confined to 1951-1958 while global fallout inputs peaked around 1961/62). The $239,240 \mathrm{Pu}$ activities and ${ }^{240} \mathrm{Pu} /{ }^{239} \mathrm{Pu}$ ratios in a series of shelf cores was found to increase quite rapidly over time (between 1952, 1957, 1964 and 1983), corresponding to increased scavenging of global fallout Pu and a shift to higher $240 / 230$ ratios. In a suite of core tops from the across the Atlantic, it was found that in general, all North Atlantic deep-sea sediments show some evidence of the Nevada fallout signal (1.e. ${ }^{240} \mathrm{Pu} /$ 239

Pu<0.18). As expected, the Pu inventory attributable to the Nevada source in the sediments decreases as one examines more distant cores in the Eastern vs. the Western North Atlantic basin. In deep-sea cores from the Northwest Atlantic $(>4500 \mathrm{~m})$, I have calculated that approximately $40 \%$ of the total 239,240 Pu activity in the sediments was supplied by the Nevada source.

While the solid phase ${ }^{240} \mathrm{Pu} /{ }^{239} \mathrm{Pu}$ ratio decreases with increasing water depth, the pore water ${ }^{240} \mathrm{Pu} /{ }^{239} \mathrm{Pu}$ ratio remains roughly 0.18 at all depths. This pronounced dis-equilibrium between the solid phase and pore water ${ }^{240} \mathrm{Pu} /{ }^{239} \mathrm{Pu}$ data reflects a difference in the physical/ chemical properties of the Nevada and global fallout sources. The Nevada tropospheric fallout is apparently more tightly bound by its solid phase fallout carrier than Pu from global fallout sources and is therefore not participating in the solid/solution exchange reactions. The formation of partially and completely melted glass-like particles from surface based testing at Nevada likely resulted in the creation of these highly unreactive and inert carriers of fallout Pu.

This evidence for the input of different types of fallout Pu carriers with different geochemical behaviors in the ocean could have major implications for the Pacific ${ }^{239,240} \mathrm{Pu}$ activity data. In the North Pacific, close-in inputs of Pu from nuclear weapons testing at the Marshall Islands are quite large (estimated to be equal in magnitude to global fallout $\mathrm{Pu}$ inputs) and are characterized by elevated ${ }^{240} \mathrm{Pu} /$ ${ }^{239} \mathrm{Pu}$ ratios (relative to global fallout). The geochemistry of Pu carried by close-in fallout particles from surfaced based testing at these coral atolls need not be identical to the geochemistry of global 
fallout $\mathrm{Pu}$, but this has yet to be shown.

5. With sediment 239,240 Pu activity data alone, it is impossible to determine the most appropriate input function to use for Pu when modeling sediment mixing. However, by combining both Pu activity data and ${ }^{240} \mathrm{Pu} /{ }^{239} \mathrm{Pu}$ ratio data in the sediments, I was able to constrain the input function of $\mathrm{Pu}$ to the slope and deep ocean cores. The constant ${ }^{240} \mathrm{Pu} /{ }^{239} \mathrm{Pu}$ ratios throughout an individual core are consistent with a model which suggests that the bulk of the Pu deposited to the deep ocean sediments (both from Nevada and global fallout sources) arrived early-on in the fallout record. In shallower cores $(<1000 \mathrm{~m})$ from this region, the appropriate $\mathrm{Pu}$ input function will therefore depend upon the relative magnitude of the early $\mathrm{Pu}$ inputs and continued scavenging processes. 
- 192 - 


\section{REFERENCES}

Adams, C. E., N. H. Farlow and W. R. Sche11, 1960. The compositions, structures and origins of radioactive fall-out particles. Geochim. Cosmochim. Acta 18: 42-56.

Alberts, J. J. and Orlandini, K. A. 1981. Laboratory and field studies of the relative mobility of $239,240_{\mathrm{Pu}}$ and $241_{\mathrm{Am}}$ from lake sediments under oxic and anoxic conditions. Geochim. Cosmochim. Acta 45: 1931-1940.

Allard, B., Kipasti H., and Liljenzin, J. 0., 1980. Expected species of uranium, neptunium and plutonium in neutral aqueous solutions. Inorg. Nucl. Chem. 42: 1015-1027.

Aller, R. C., 1982. The effects of macrobenthos on chemical properties of marine sediment and overlying water. In: Animal-Sediment Relations (eds P. L. McCall and M. J. S. Teuesz), Plenum Press, pp. 53-102.

Aller, R. C., 1984. The importance of relict burrow structures and burrow irrigation in controling sedimentary solute distributions. Geochim. Cosmochim. Acta 48: 1928-1934.

Andelman, J. B. and Rozze11, T. C., 1970. Plutonium in the water environment. I. Characteristics of aqueous plutonium. In: (E. C. Freiling, Chairman) "Radionuclides in the Environment." Adv. Chem. Ser. No. 93 (Amer. Chem. Soc.), 118-137.

Anderson, R. F., Bacon, M. P. and Brewer, P. G., 1982. Elevated concentrations of actinides in Mono Lake. Science 216: 514-516.

Anderson, R. F., R. F. Bopp K. O. Buesseler, and P. E. Biscaye, 1986. Mixing of particles and organic constituents in sediments from the Continental Shelf and slope off Cape Cod: SEEP-I results. Continental Shelf Res. (submitted).

Anon., 1973. Global atmospheric plutonium-239 and plutonium isotopic ratios for 1959-1970. Fallout Program Quarterly Summary Rept., HASL-273, pp. III-2 - III-28.

Aston, S. R., 1980. Evaluation of the chemical forms of plutonium in seawater. Mar. Chem. ㅇ: 319-325.

Aston, S. R., D. J. Assinder and M. Kelly, 1985. Plutonium in intertidal coastal and estuarine sediments in the northern Irish Sea. Estuarine, Coastal and Shelf Sc1. 20: 761-771.

Bacon, M. P., C.-A. Huh, A. P. Fleer and W. G. Deuser, 1985.

Seasonality in the flux of natural radionuclides and plutonium in the deep Sargasso Sea. Deep-Sea Res. 32(3): 273-286. 
Bacon, M. P., 1986. Personal communication.

Benninger, L. K. and S. Krishnaswami, 1981. Sediment processes in the inner New York Bight: evidence from excess $210 \mathrm{~Pb}$ and $239,240 \mathrm{Pu}$. Earth Planet. Sc1. Lett. 53: 158-174.

Beasley, T. M., L. A. Ball, J. E. Andrews, III and J. E. Halverson, 1981. Hanford-derived plutonium in Columbia River sediments. Science 214: $913-915$.

Benninger, L. K., R. C. Aller, J. K. Cochran, and K. K. Turekian, 1979. Effects of biological sediment mixing on the $210 \mathrm{pb}$ chronology and trace metal distribution in a Long Island Sound sediment core. Earth Planet. Sc1. Letters 43: 241-259.

Benninger, L. K. and Krishnaswami, S., 1981. Sedimentary processes in the inner New York Bight: evidence from excess $210 \mathrm{~Pb}$ and $239,240 \mathrm{Pu}$. Earth Planet. Sci. Lett. 53: 158-174.

Berner, R. A., 1976. Inclusion of adsorption in the modeling of early diagenesis. Earth Planet. Sci. Lett. 29: 333-340.

Berner, R. A., 1976. The benthic boundary layer from the viewpoint of a geochemist. In: "The Benthic Boundary Layer" (E. N. McCave, ed.), Chap. 3, pp. 33-56.

Berner, R. A., 1980. "Early Diagenesis - A Theoretical Approach," Princeton Series in Geochemistry (H. D. Holland, ed.), Princeton Univ. Press, Princeton, N.J.,-241 pp.

Bischoff, J. L., R. E. Greer and A. 0. Luistro, 1970. Composition of interstitial waters of marine sediments: temperature of squeezing effect. Sclence 167: 1245-1246.

Bertine, K. K., T. J. Chow, M. Kolde and E. D. Goldberg, 1986. Plutonium isotopes in the environment: some existing problems and some new ocean results. 3 . Environ. Radioactivity $\underline{3}$ : 189-201.

Bevington, P. R. (ed.), 1978. "Data Reduction and Error Analys is for the Physical Sciences" (McGraw-Hall, New York), 335 pp.

Bondiett1, E. A. and F. H. Sweeton, 1977. Transuranic speciation in the environment. Nevada Applied Ecology Group, USDOE, Rept. NVO-178, pp. 449-476.

Bothner, M. H., Spiker, E. C., Johnson, P. P., Rendigs, R. R. and Aruscavage, P. J., 1981. Geochemical evidence for modern sediment accumulation on the continental shelf off southern New England. $J$. Sed. Petrol. 51: 281-292. 
Boudreau, B. P., 1986a. Mathematics of tracer mixing in sediments: I. Spatially-dependent, diffusive mixing. Am. J. Sci. 286:; 161-198.

Boudreau, B. P., 1986b. Mathematics of tracer mixing in sediments: II. Nonlocal mixing and biological conveyor-belt phenomena. Am. J. Sc1. 286: 199-238.

Bowen, V. T., V. E. Noshkin, H. D. Livingston and H. L. Volchok, 1980. Fallout radionuclides in the Pacific ocean: vertical and horizontal distributions, largely from GEOSECS stations. Earth Planet. Sci. Lett. 49: $411-434$.

Breteler, R. J., V. T. Bowen, R. Henderson and D. L. Schneider, 1984. Sedimentological reconstruction of the recent pattern of mercury pollution in the Niagara River. Environ. Sci. Tech. 18: 404-409.

Buesseler, K. O. and E. R. Sholkovitz, 1984. Early diagenesis of plutonium in marine sediments. Eos $\underline{65}(45): 956$.

Buesseler, K. O. and E. R. Sholkovitz, 1985. $240 \mathrm{Pu} / 239_{\mathrm{Pu}}$ ratios and the significance of the Nevada test site as a source of Pu to North Atlantic sediments. Abstract 1986 Ocean Sciences Meeting, New Orleans. Eos 67(51): 1292 .

Buesseler, K. O., H. D.Livingston and E. R. Sholkovitz, 1985. $239,240 \mathrm{Pu}$ and excess $210 \mathrm{~Pb}$ inventories along the shelf and slope of the northeast U.S.A. Earth Planet. Sc1. Lett. 76: 10-22.

Buesseler, K. O., G. Benoit and E. R. Sholkovitz, 1985. A pore water study of plutonium in a seasonally anoxic lake. J. Environ. Radioactivity 2: 283-292.

Cameron, A. G. W., 1959. Multiple neutron capture in the Mike fusion explosion. Can. J. Phys. 37: 322-333.

Carpenter, R. and Beasley, T. M., 1981. Plutonium and americium in anoxic marine sediments: evidence against remobilization. Geochim. Cosmochim. Acta 45: 1917-1930.

Carpenter, R., Peterson, M. L. and Bennett, J. T., 1982.

$210 \mathrm{~Pb}-d e r i v e d$ sediment accumulation and mixing rates for the Washington continental slope. Mar. Geol. 48: 135-164.

Chanton, J. P., C. S. Martens and G. W. Kipphut, 1983. Lead-210 sediment geochronology in a changing coastal environment. Geochim. Cosmochim. Acta 47: 1791-1804.

Clark, H. M., 1954. The occurrence of an unusually high-level radioactive rainout in the area of Troy, N.Y. Science 119: 619-622. 
Cleveland, J. M., 1970. "The Chemistry of Plutontum," (Gordon and Breach, N.Y.), 653 pp.

Cleveland, J. M., 1979. Critical review of plutonium equilibria of environmental concern. In: "Chemical Modeling in Aqueous Systems" (E. A. Jenne, ed.). Amer. Chem. Soc. Sympos. Ser., 93: 321-338.

Cochran, J. K. and S. Krishnaswami, 1980. Radium, thorium, uranium and $239,240 \mathrm{Pu}$ in deep-sea sediments and sediment pore waters from the North Equatorial Pacific. Amer. J. Sc1. 280: 849-889.

Cochran, J. K., 1985. Particle mixing rates in sediments of the eastern equatorial Pacific: Evidence from $210 \mathrm{~Pb}, 239,240 \mathrm{Pu}$ and $137_{\mathrm{Cs}}$ distributions at MANOP sites. Geochim. Cosmochim. Acta 49: 1195-1210.

Cutshall, N. H., I. L. Larsen and C. R. 01sen, 1983. Direct analysis of $210 \mathrm{~Pb}$ in sediment samples: self-absorption corrections. Nucl. Inst. and Methods 206: 309-312.

DeMaster, D. J. and J. K. Cochran, 1982. Particle mixing rates in deep-sea sediments determined from excess $210 \mathrm{~Pb}$ and $32 \mathrm{si}$ profiles. Earth Planet. Sc1. Lett. 61: 257-271.

DeMaster, D. J., B. A. McKee, C. A. Nittrouer, D. C. Brewster and P. E. Biscaye, 1985. Rates of sediment reworking at the HEBBLE sites based on measurements of Th-234, Cs-137 and Bp-210. Marine Geol. 66: 133-148.

Department of Energy, 1982. Announced United States Nuclear Tests July 1945 through December 1981.

Deuser, W. G., 1986. Seasonal and interannual variations in deep-water particle fluxes in the Sargasso Sea and their relation to surface hydrography. Deep-Sea Res. 33: 225-246.

Diamond, H., P. R. Fields, C. S. Stevens, M. H. Studier, S. M. Fried, M. G. Inghram, D. C. Hess, G. L. Pyle, J. F. Mech, W. M. Manning, Ghiorso, A., S. G. Thompson, G. H. Higgins, G. T. Seaborg, C. I. Browne, H. L. Smith and R. W. Spence, 1960. Heavy isotope abundances in Mike thermonuclear device. Physical Rev. 119: 2000-2004.

Dietz, L. A., 1965. Basic properties of electron multiplier ion detection and pulse counting methods in mass spectrometry. Rev. of Sct. Inst. $\underline{36}(12): 1763-1770$.

Druffel, E. R. M., P. M. Williams, H. D. Livingston and M. Koide, 1984. Variability of natural and bomb-produced radionuclide distributions in abyssal red clay sediments. Earth Planet. Sci. Lett. 71: 205-214. 
Duursma, E. K. and C. Hoede, 1967. Theoretical, experimental and field studies concerning molecular diffusion of radioisotopes in sediments and suspended solic particles of the sea. Netherlands J. Sea Res. $\underline{3}$ : 423-457.

Duursma, E. K. and M. G. Gross, 1971. Marine sediments and radioactivity. In: Radioactivity in the Marine Environment (National Academy of Sciences), pp. 147-160.

Edgington, D. N., Alberts, J. J., Wahlgren, M. A., Karttunen, J. 0. and Reeve, C. A., 1976. Plutonium and americium in Lake Michigan sediments. In: "Transuranium nuclides in the Environment" (IAEA Symposium), IAEA-SM-199/47, pp. 493-516.

Edgington, D. N., 1981. Characterization of transuranic elements at environmental levels. In: "Techniques for Identifying Transuranic Speciation in Aquatic Environments" (IAEA, Vienna), pp. 3-26.

Elderfield, H., R. J. McCaffrey, N. Luedtke, M. Bender and V. W. Truesdale, 1981. Chemical diagenesis in Narragansett Bay sediments. Am. Jour. Sci. 281: 1021-1055.

Embley, R. W., 1980. The role of mass transport in the distribution and character of deep-ocean sediments with special reference to the North Atlantic. Marine Geol. 38: 23-50.

Emerson, S., 1976. Early diagenesis in anaerobic lake sediments: chemical equilibria in interstitial waters. Geochim. Cosmochim. Acta 40: 925-934.

Emerson, S., D. Jahnke, M. Bender, P. Froelich, G. Klinkhammer, C. Bowser and G. Setlock, 1980. Early diagenesis in sediments from the southern Equatorial Pacific. I. Pore water nutrient and carbonate results. Earth Planet. Sci. Lettr. 49: 57-80.

Environmental Measurement Laboratory, 1980. EML Environmental Quarterly, EML-370 Appendix., p. A-3.

Fassett, J. D. and W. R. Kelly, 1984. Interlaboratory Isotopic Ratio Measurement of Nanogram Quantities of Uranium and Plutonium on Resin Beads by Thermal Ionization Mass Spectrometry. Anal. Chem. 56: 550-556.

Fowler, S. W., S. Ballestra, J. LaRosa and R. Fuka1, 1983. Vertical transport of particulate-associated plutonium and americium in the upper water column of the Northeast Pacific. Deep-Sea Res. 30(12A): $1221-1233$.

Freeman, D. H., L. A. Currie, E. C. Kuehner, H. D. Dixon and R. A. Paulson, 1970. Development and characterization of ion-exchange bead microstandards. Anal. Chem. 42: 203- . 
Freeman, J. H. and L. K. Benninger, 1985. Fallout plutonium and naturally-occurring radionuclides in annual bands from Montastrea annularis, Broward County, Florida. Eos 66(51): 1330.

Froelich, P. N., Klinkhammer, G. P., Bender, M. L., Lueathe, N. A., Heath, G. R., Cullen, D., Dauphin, P., Hammond, D., Hartmen, B., Maynard, V., 1979. Early oxidation of organic matter in pelegic sediments of the eastern equatorial Atlantic: Suboxic diagenesis. Geochim. Cosmochim. Acta 43: 1075-1090.

Fuka1, R., A. Yamato and M. Thein, 1981. Speciation of plutonium in the Mediterranean environment. In: "Techniques for Identifying Trasuranic Speciation in Aquatic Environments," Proceedings of a Technical Committee Meeting ISPRA (IAEA, Vienna), pp. 37-41.

Garrison, L. E. and R. L. McMaster, 1966. Sediments and geomorphology of the Continental Shelf off southern New England. Marine Geol. 4: 273-289.

Goldberg, E. D. and M. Koide, 1962. Geochronological studies of deep-sea sediments by the ionium/thorium method. Geochim. Cosmochim. Acta 26: $417-450$.

Grassle, J. F., 1977. Slow recolonization of deep-sea sediment. Nature 265(5595): 618-619.

Grassle, J. F., 1986. Personal communication.

Guinasso, N. L. and D. R. Schink, 1975. Quantitative estimates of blological mixing rates in abyssal sediments. J. Geophys. Res. 80: 3032-3043.

Halverson, J. E., 1981. A Three-Stage Mass Spectrometer for Isotope Analysis of Radionuclides in Environmental Samples. E. I. du Pont de Nemours \& Co. Environmental Sc1. Div. Rpt. DP-1611, pp. 1-13.

Hardy, E. P., P. W. Krey and H. L. Volchok, 1972. Plutonium fallout in Utah. HASL-257, pp. I-95 - I-118.

Hardy, E. P., P. W. Krey and H. L. Volchok, 1973. Global inventory and distribution of fallout plutonium. Nature 241: 444-445.

Harley, J. H., 1980. Plutonium in the environment--a review. Radiat. Res. 21: 83-104.

Hathaway, J. C. (ed.), 1971. "Data File Continental Margin Program Atlantic Coast of the United States. Vol. 2 Sample Collection and Analytical Data," Tech. Rept. 7-15 (Woods Hole Oceanographic Institution). 
Hathaway, J. C., 1972. Regional clay mineral facies in estuaries and continental margin of the United States East Coast. The Geological Soc. of America, Inc., pp. 293-316.

Hetherington, J. A., 1978. The uptake of plutonium nuclides by marine sediments. Mar. Sci. Comm. 4: 239-274.

Hicks, H. G. and D. W. Barr, 1984. Nevada Test Site Fallout Atom Ratios: $240 \mathrm{Pu} / 239 \mathrm{Pu}$ and $241_{\mathrm{Pu} / 239} \mathrm{Pu}$. UCRL-53499/1 (Lawrence Livermore National Laboratory), 4 pp.

Higgo, J. J. W., L. V. C. Rees and D. S. Cronan, 1985. Sorption of plutonium by deep-sea sediments. Radloactive Waste Management and the Nuclear Fuel Cycle 6: 143-159.

Higgo, J. J. W. and L. V. C. Rees, 1986. Adsorption of actinides by marine sediments: effect of the sediment/seawater ratio on the measured distribution ratio. Environ. Sci. Technol. 20: 483-490.

Holloway, R. W. and D. W. Hayes, 1982. Mean residence time of plutonium in the troposphere. Environ. Sc1. Technol. 16: 127-129.

Joseph, A. B., P. F. Gustafson, I. R. Russell, E. A. Schuert, H. L. Volchok and A. Tamplin, 1971. Sources of radioactivity and their characteristics. In "Radioactivity in the Marine Environment" (National Academy of Sciences), Chapter 2, pp. 6-41.

Kadko, D. C., 1981. A detalled study of uranium series nuclides for several sedimentary regimes of the Pacific. Ph.D. Thesis (Columbia Univ.), 312 pp.

Keeney-Kennicutt, W. L. and J. W. Morse, 1985. The redox chemistry of $\mathrm{Pu}(\mathrm{V}) \mathrm{O}_{2}{ }^{+}$interaction with common mineral surfaces in dilute solutions and seawater. Geochim. Cosmochim. Acta 49: 2577-2588.

Kelley, J. M. and D. M. Robertson, 1985. Plutonium Ion Emission from Carburized Rhenium Mass Spectrometer F1laments. Anal. Chem. 57: 124-130.

Kershaw, P. J., D. J. Swift, R. J. Pantreath and M. B. Lovett, 1983. Plutonium redistribution by biological activity in Irish Sea

sediments. Nature 306: 774-775.

Kim, K. H. and W. C. Burnett, 1983. a-ray spectrometric determination of uranium-series nuclides in marine phosphorties. Anal. Chem. 55: 1796-1800.

Knebel, H. J., 1984. Sedimentary processes on the Atlantic Continental Slope of the United States. Marine Geol. 61: 43-74. 
Koide, M., Griffin, J. J. and Goldberg, E. D., 1975. Records of plutonium fallout in marine and terrestrial samples. J. Geophys. Res. 80: $4153-4162$.

Koide, M., R. Michel and E. D. Goldberg, 1979. Depositional history of artificial radionuclides in the Ross Ice Shelf, Antartica. Earth Planet. Sci. Lett. 44: 205-223.

Koide, M., Goldberg, E. D. and Hodge, V. F., 1980. 241 Pu and $241_{\mathrm{Am}}$ in sediments from coastal basins off California and Mexico. Earth Planet. Sci. Lett. 48: 250-256.

Koide, M. and E. D. Goldberg, 1982. Transuranic nuclides in two coastal sediments off Peru. Earth Planet. Sc1. Lett. 57: 263-277.

Koide, M., K. K. Bertin, Chow, T. J. and E. D. Goldberg, 1985. The $240 \mathrm{Pu} / 239 \mathrm{Pu}$ ratio, a potential geochronometer. Earth Planet. Sci. Lett. 72: 1-8.

Krey, P. W., E. P. Hardy, C. Pachucki, F. Rourke, J. Coluzza and W. K. Benson, 1976. Mass isotopic composition of global fall-out plutonium in sol1. In "Transuranium Nuclides in the Environment," IAEA-SM-199/39 (IAEA, Vienna), pp. 671-678.

Krey, P. W., 1983. "Reporters' Manscript of 8th Dose Assessment Advisory Group Meeting," Vol. II (U.S. Dept. of Energy, Nevada Operations office), pp. 5-33-5-48.

Krey, P. W., 1986. Personal communication.

Krey, P. W. and D. C. Bogen, 1986. "Determination of Acid-Leachable and Total Plutonium in Large Soll Samples." Conference Proceedings: "Low-level Measurements of Actinides and Long-lived Radionuclides in Biological and Environmental Samples. (Lund, Sweden), June 1986.

Krishnaswami, S., L. K. Benninger, R. C. Aller and K. L. von Damm, 1980. Atmospherically-derived radionuclides as tracers of sediment mixng and accumulation in near-shore marine and lake sediments: evidence from $7 \mathrm{Be}, 210 \mathrm{~Pb}$, and $239,240 \mathrm{Pu}$. Earth Planet. Sct. Lett. 47: $307-318$.

Lagergren, C. R. and J. J. Stoffels, 1970. A Computer-Controlled, Three-Stage Mass Spectrometer. Int. J. Mass Spectrom. Ion Physics, $\underline{3}$ : 429-438.

Lally, A. E., 1982. Chemical Procedures. In: "Uranium Series Disequilibriums: Applications to Environmental Problems" (M. Ivanovich and R. S. Harman, eds.), Oxford Untv. Press, New York. Chap. 4, pp. 79-106. 
Lapicque, G., H. Livingston, C. E. Lamberg and L. Labeyrie, 1986. Interpretation of $\mathrm{Pu}-239,240$ in Atlantic sediments with a non-steady state input model. Deep-Sea Res., submitted.

Larsen, R. P. and R. D. 01dham, 1974. Anton-exchange separation of plutonium in hydrochloric-hydrobromic acid media. Talanta 22: 577-580.

Larson, K. H., 1985. Continental close-in fallout - its history, measurement, and characteristics. In "The Radioecology of Transuranics and other Radionuclides in Desert Ecosystems - December 1982." (Howard, W. A., P. B. Dunaway and R. G. Fuller, eds.), Report NVO-224, (DE86001243), pp. 1-31.

L1, Y-H and S. Gregory, 1974. Diffusion of ions in seawater and in deep-sea sediments. Geochim. Cosmochim. Acta 38: 703-714.

Leu, K.-K. and I. R. Kaplan, 1984. Denitrification rates and availability of organic matter in marine environments. Earth Planet. Sc1. Lett. 68: 88-100.

Livingston, H. D., D. R. Mann and V. T. Bowen, 1975. Analytical procedures for transuranic elements in seawater and marine sediments. In "Analytical Methods in Oceanography" (T. R. P. Gibbs, ed.), Am. Chem. Soc. Adv. Chem. Ser. 147, pp. 124-138.

Livingston, H. D. and Bowen, V. T., 1979. Pu and ${ }^{137} \mathrm{Cs}$ in coasta 1 sediments. Earth Planetary Sci. Letters 43: 29-45.

Livingston, H. D. and R. F. Anderson, 1983. Large particle transport of plutonium and other fallout radionuclides to the deep ocean. Nature 303: 228-231.

Livingston, H. D., D. L. Schneider and L. D. Surprenant, 1984.

"Radiochemical Studies in Support of the Low Level Waste Ocean Disposal Program." Final Rept. of Contract 61-1034 with Sandia National Laboratories, Albuquerque, NM (W.H.O.I.).

Livingston, H. D., 1985. Annual Progress Report - Subseabed Disposal Program (Contract 25-8712 with Sandia National Laboratories).

Livingston, H. D. and K. O. Buesseler, 1985. Fallout transuranic behavior in the Northwest Atlantic Ocean margin. AGU Spring Meeting. Eos 66(18): 284 .

Livingston, H. D., V. T. Bowen, S. A. Casso, H. L. Volchok, V. E. Noshkin, K. M. Wong and T. M. Beasley, 1985. Fallout Nuclides in Atlantic and Pacific Water Columns: GEOSECS Data. Woods Hole Oceanographic Institution Technical Report, WHOI-85-19, 73 pp. 
Lynch, D. R. and C. B. Officer, 1984. Nonlinear parameter estimation for sediment cores. Chem. Geol. 44: 203-225

Machta, L., R. J. List and L. F. Hubert, 1956. World-wide travel of atomic debris. Science 124: 474-477.

MacKenzie, A. B. and R. D. Scott, 1982. Radiocaestum and plutonium in intertidal sediments from southern Scotland. Nature 299: 613-616.

Mamuro, T., T. Matsunami and N. Maki, 1965. Solubility of fallout particles. Health Physics 11: 316-320.

Mangelsdorf, P. C., Jr., T. R. S. Wtlson and E. Daniell, 1969. Potassium enrichments in interstitial waters of recent marine sediments. Science 165: 171-174.

Mann, D. R., L. D. Surprenant and S. A. Casso, 1984. In situ chemisorption of transuranics from seawater. Nuclear Instruments and Methods in Physics Research 223: 235-238.

Mathieu, G. G., 1977. 222 Rn and 226 Ra technique of analysis. Ann. Tech. Rept. COO-2185-0 to ERDA, Lamont-Doherty Geological Observatory, Palisades, NY.

Milliman, J. D., O. H. Pilkey and D. A. Ross, 1972. Sediments of the Continental margin off the Eastern United States. Geol. Soc. Am. Bull. 83: 1315-1334.

Milyukova, M. S., N. I. Gusev, I. G. Sentyurin, and I. S. Sklyarenko, 1969. "Analytical Chemistry of Pu" (Ann Arbor-Humphrey Sci.

Publishers, Ann Arbor, Mich.), 440 pp.

Nagaya, Y. and K. Nakamura, 1984. $239,240 \mathrm{Pu}, 137 \mathrm{Cs}$ and ${ }^{90} \mathrm{Sr}$ in the central North Pacific. J. Oceanographical Soc. Japan 40: 416-424.

Needler, G. T. and W. C. Templeton, 1981. Radioactive waste: the need to calculate an oceanic capacity. Oceanus 24: 60-67.

Nelson, D. M. and Lovett, M. D., 1978. Oxidation state of plutonium in the Irish Sea. Nature 276: 599-602.

Nelson, D. M., K. A. Orlandint, 1979. Identification of Pu(V) in natural waters. Argonne Nat1. Lab. Ann. Rept. ANL-79-65 (Part III), pp. 57-59.

Nelson, D. M. and M. B. Lovett, 1981. Measurement of the oxidation state and concentration of plutonium in interstitial waters of the Irish Sea. In "Impacts of Radionuclides into the Marine Environment" (IAEA-SM-248/145), pp. 105-118. 
Nelson, D. M., Carey, A. E. and Bowen, V. T. (1984). Plutonium oxidation state distributions in the Pacific Ocean during 1980-1981. Earth Planet. Sc1. Lttr. 68, 422-430.

Nelson, D. M., W. R. Penrose, J. O. Karttunen and P. Mehlhaff, 1985. Effects of dissolved organic carbon on the adsorption properties of plutonium in natural waters. Environ. Sc1. Technol. 19: 127-131.

Noshkin, V. E. and E. DeAgazio, 1966. Low background beta detector for solld sample assay. Nucl. Instr. Methods 39: 265-270.

Noshkin, V. E., Jr. and C. Gatrousis, 1974. Fallout 240 Pu and $239 \mathrm{Pu}$ in Atlantic marine samples. Earth Planet. Sc1. Lett. 22: $111-117$.

Noshkin, V. E., 1978. Transuranium radionuclides in components of the benthic environment of Enewetak Ato 11. Preprint UCRL-80587 (Lawrence Livermore Laboratory).

Noshkin, V. E. and Wong, K. M., 1979. Plutonium mobilization from sedimentary sources to the marine environment. In: Third Nuclear Energy Agency Seminar on Marine Radioecology (Tokyo).

Nozaki, Y. J. K. Cochran, K. K. Turekian and G. Keller, 1977. Radiocarbon and $210 \mathrm{~Pb}$ distribution in submersible-taken deep-sea cores from Project FAMOUS. Earth Planet. Sc1. Lett. 34: 167-173.

Officer, C. B. and D. R. Lynch, 1982. Interpretation procedures for the determination of sediment parameters from time-dependent flux inputs. Earth Planet. Sci. Lett. 61: 55-62.

Officer, C. B. and D. R. Lynch, 1983. Determination of mixing parameters from tracer distributions in deep-sea sediment cores. Marine Geol. 52: 59-74.

Orlandini, K. A., W. R. Penrose and D. M. Nelson, 1986. Pu(V) as the stable form of oxidized plutonium in natural waters. Marine Chem. 18: 49-57.

Pallmer, P. G., Jr. and R. L. Gordon and M. J. Dresser, 1980a. The emissivity of carburized rhenium. J. Appl. Phys. 51(3): 1798-1801.

Pallmer, P. G., Jr. and R. L. Gordon and M. J. Dresser, 1980b. The work function of carburtzed rhentum. J. Apply. Phys. 51(7): 3776-3779.

Pedersen, T. F. and N. B. Price, 1982. The geochemistry of manganese carbonate in Panama Basin sediments. Geochim. Cosmochim. Acta 46: 59-68. 
Peng, T. H., W. S. Broecker and W. H. Berger, 1979. Rates of benthic mixing in deep-sea sediments as determined by radioactive tracers. Quat. Res. 11: 141-149.

Perkins, R. W. and C. W. Thomas, 1980. Worldwide fallout. In: "Transuranic Elements in the Environment" (W. C. Hanson, ed.).

Perrin, R. E., G. W. Knobeloch, V. M. Armijo and D. W. Efurd, 1985. Isotopic analysis of nanogram quantities of plutonium by using a SID ionization source. Int. J. of Mass Spec. and Ion Proc. 64: 17-24.

Ra1, D., Serne, R. J. and Swanson, J. L., 1980. Solution species of plutonium in the environment. J. Environ. Qual. 9: 417-420.

Reimers, C. E. and E. Suess, 1983. The partitioning of organic carbon fluxes and sedimentary organic matter decomposition rates in the ocean. Marine Chem. 13: 141-168.

Rhoads, D. C., 1974. Organism-sediment relations on the muddy sea floor. Oceanography and Marine Biology Ann. Rev. 12: 263-300.

Rowe, G. T., P. T. Polloni and S. G. Horner, 1974. Benthic biomass estimates from the northwestern Atlantic Ocean and the northern Gulf of Mexico. Deep-Sea Res. 21: 641-650.

Rowe, G. T., P. T. Polloni and R. L. Haedrich, 1982. The deep-sea macrobenthos on the continental margin of the northwest Atlantic Ocean. Deep-Sea Res. 29(2A): 257-278.

Sanchez, A. L., 1983. Chemical Speciation and Adsorption Behavior of Plutonium in Natural Waters. Ph.D. Thesis (Univ. of Washington), 192 pp.

Sanchez, A. L., J. W. Murray and TR. H. Sibley, 1985. The adsorption of plutonium IV and $V$ on goethite. Geochim. Cosmochim. Acta 49: 2297-2307.

Santschi, P. H., Y.-H. L1, J. Bell, R. Trier and K. Kawtaluk, 1980. Pu in coastal marine environments. Earth Planet. Sc1. Lett. 51: 248-265.

Santsch1, P. H., Y-H L1, D. M. Adler, M. Amdurer, J. Bell and U. R. Nyffeler, 1983. The relative mobility of natural (Th, $\mathrm{Pb}, \mathrm{Po}$ ) and fallout ( $\mathrm{Pu}, \mathrm{Am}, \mathrm{Cs}$ ) nuclides in the coastal marine environment: results from model ecosystems (MERL) and Narragansett Bay. Geochim. Cosmochim. Acta 47: 201-210

Sayles, F. L. and Livingston, H. D., 1985. The distribution of $239,240 \mathrm{Pu}, 137 \mathrm{Cs}$ and $55 \mathrm{Fe}$ in continental margin sediments: relation to sedimentary redox environment. In: Proc. 4th Intern'l. Ocean Disposal Symp., Plymouth, U.K., April 1983 (in press). 
Schlee, J., 1973. Atlantic Continental Shelf and Slope of the United States--Sediment Texture of the Northeastern Part. Geological Survey Professional Paper 529-L.

Scott, M. R., P. F. Salter and J. E. Halverson, 1983. Transport and deposition of plutonium in the ocean: evidence from Gulf of Mexico sediments. Earth Planet. Sci. Lett. 63: 202-222.

Seaborg, G. T., E. M. McMillan, J. W. Kennedy and A. C. Wahl, 1946. Radioactive element 94 from deuterons on urantum. Phys. Rev. 69: 366-367.

Sholkovitz, E., Carey, A., and Cochran, J. K., 1982. The aquatic chemistry of plutonium in seasonally anoxic lake waters. Nature $\underline{300}$ : 159-161.

Sholkovitz E. R., 1983. The geochemistry of plutonium in fresh and marine water environments. Earth Sci. Rev. 19: 95-161.

Sholkovitz, E. R., J. K. Cochran and A. E. Carey 1983. Laboratory studies of the diagenesis and mobility of $239,240 \mathrm{Pu}$ and $137 \mathrm{Cs}$ in nearshore sediments. Geochim. Cosmochim. Acta 47: 1369-1379

Sholkoyitz, E. R. and D. R. Mann, 1984. The pore water chemistry of $239,240 \mathrm{Pu}$ and $137_{\mathrm{Cs}}$ in sediment of Buzzards Bay, Massachusetts. Geochim. Cosmochim. Acta 48: 1107-1114.

Sholkovitz, E. R. and Mann, D. R., 1984. The pore water chemistry of $239,240 \mathrm{Pu}$ and $137 \mathrm{Cs}$ in the sediments of Buzzards Bay, Massachusetts. Geochim. et Cosmochim. Acta 48: 1107-1114.

Sllver, G. L., 1983. Comment on the evaluation of the chemical form of plutonium in seawater and other aqueous solutions. Marine chemistry 12: $91-96$.

Simpson, H. J., R. M. Trier, C. R. Olsen, D. E. Hammond, A. Ege, L. Miller and J. M. Melack, 1980. Fallout plutonium in an alkaline, saline lake. Science 207: 1071-1073.

Smith, David H., W. H. Cristie and R. E. Eby, 1980. The Resin Bead as a Thermal Ion Source: A Sims Study, 1980. International Journal of Mass Spectrometry and Ion Phystcs 36: 301-316.

Smith, J. N. and C. T. Schafer, 1984. Bloturbation processes in continental slope and rise sediments delineated by $\mathrm{Pb}-210$, microfoss 11 and textural indicators. J. Marine Res. 42: 1117-1145.

Spencer, D. W., M.P. Bacon and P. G. Brewer, 1981. Models of the distribution of $210 \mathrm{~Pb}$ in a section across the North equatorial Atlantic Ocean. J. Marine Res. 39: 119-138. 
Steinberg, S. and I. Kaplan, 1985. "Organic geochemical studies of SEEP sediments and pore waters from the North Atlantic Shelf." UCLA Data Report, pp. 21-80.

Stordal, M. C., J. W. Johnson, N. L. Guinasso, Jr. and D. R. Schink, 1985. Quantitative evaluation of bioturbation rates in deep ocean sediments. II. Comparison of rates determined by $210 \mathrm{~Pb}$ and 239,240 Pu. Marine Chem. 17: 99-114.

Strebin, R. S., Jr. and D. M. Robertson, 1977. Isotopic Composition Measurement on on Sub-Picogram Amounts of Plutonium. Analytica Chimica Acta, 91: 267-272.

Studier, Martin H., Eric N. Sloth and Leon P. Moore, 1962. The Chemistry of Uranium in Surface Ionization Sources. Talanta, 1: 127.

Swinbanks, D. D. and Y. Shirayama, 1986. High levels of natural radionuclides in a deep-sea infaunal xenophyophore. Nature 320 : 354-358.

Tanaka, N., 1986. Radiocarbon in sediments from the continental margin off Southern New England coast, U.S.A. (Yale Univ.), unpublished MS.

Taube, M., 1964. Chemical properties of Pu. In: "Plutonium" (Pergamnon Press (Chap. 2), pp. 39-84.

Thompson, J. and K. K. Turekian, 1976. 210 po and $210 \mathrm{~Pb}$ distributions in ocean water profiles from the Eastern South Pacific. Earth Planet.

Toole, J., J. Thomson, T. R. S. Wilson and M. S. Baxter, 1984. A sampling artefact affecting the uranium content of deep-sea porewaters obtained from cores. Nature 308: 263-266.

Troup, B. N., D. P. Bricker and J. T. Bray, 1974. Oxidation effect on the analysis of iron in interstitial water of recent anoxic sediments. Nature, 249: 237-239.

Tucholke, B. E., 1984. Marine geology. Chap. 4. In: "Environmental Summary of the U.S. Atlantic Continental Slope and Rise, $28-42^{\circ} \mathrm{N}, " \mathrm{Vol}$. I (Marine Geoscience Applications, Inc., Woods Hole, MA), pp. 4.1 4.172 .

Twiche11, D. C., C. E. McClennen and B. Butman, 1981. Morphology and processes associated with the accumulation of the fine-grained sediment deposit on the southern New England Shelf. J. Sed. Petrology 51: 269-280.

U.N. Scientific Committee, 1982. Exposures resulting from nuclear explosions. In "Ionizing Radiation: Sources and Blological Effects" (U.N. Scientific Committee on the Effects of Atomic Radiation). 
Ullman, W. J. and R. C. Aller, 1982. Diffusional coefficients in near-shore marine sediments. Limnol. Oceanogr. 27, 552-556.

Walker, R. L., R. E. Eby, C. A. Pritchard, J. A. Carter, 1974.

Simultaneous Plutonium and Uranium Isotopic Analysis from a Single Resin Bead - A simplified chemical technique for assaying spent reactor fuels. Analytical Letters, $\underline{7}(8 \& 9)$ : 563-574.

Walsh, J. J., E. T. Premuzic, J. S. Gaffney, G. T. Rowe, G. Harbottle, R. W. Stoenner, W. L. Balsam, P. R. Betzer and S. A. Macko, 1985.

Organic storage of $\mathrm{CO}_{2}$ on the continental slope off the mid-Atlantic bight, the southeastern Bering Sea, and the Peru coast. Deep-Sea Res. 32: 853-883.

Weimer, W. C, and J. C. Langford, 1978. Iron-55 and stable iron in oceanic aerosols: forms and availability. Atmospheric Environ. 12: $1201-1205$.

Wiebe, P. H., 1984. Biology. Chap. 6. In: "Environmental Summary of the U.S. Atlantic Continental Slope and and Rise, 28-42 $\mathrm{N}, "$ Vol. II (Marine Geoscience Applications, Inc., Woods Hole, MA), pp. 6.1 - 4.181.

Wong, K. M., 1971. Radiochemical determination of plutonium in sea water, sedients and marine organisms. Analytical Chimica Acta 56 : 355-364.

Yokoyama, Y. and H.-V. Nguyen, 1980. Direct and non-destructive dating of marine sediments, manganese nodules, and corals by high resolution gamma-ray spectrometry. In: "Isotope Marine Chemistry" (E. D. Goldberg,

Yingst, J. Y. and R. C. Aller, 1982. Biological activity and associated sedimentary structures in HEBBLE-area deposits, western North Atlantic. Marine Geol. 48: M7-M15.

Zander, I. and R. Araskog, 1973. Nuclear Explosions 1945-1972. Basic Data. (Research Inst. of National Defence, Stockholm, Sweden) FOA 4 Rept. A 4505-A1. 
- 208 - 
APPENDIX I - "CPM.BAS"- A Program in BASIC for Calculating Counting Rates from Gamma Spectrum

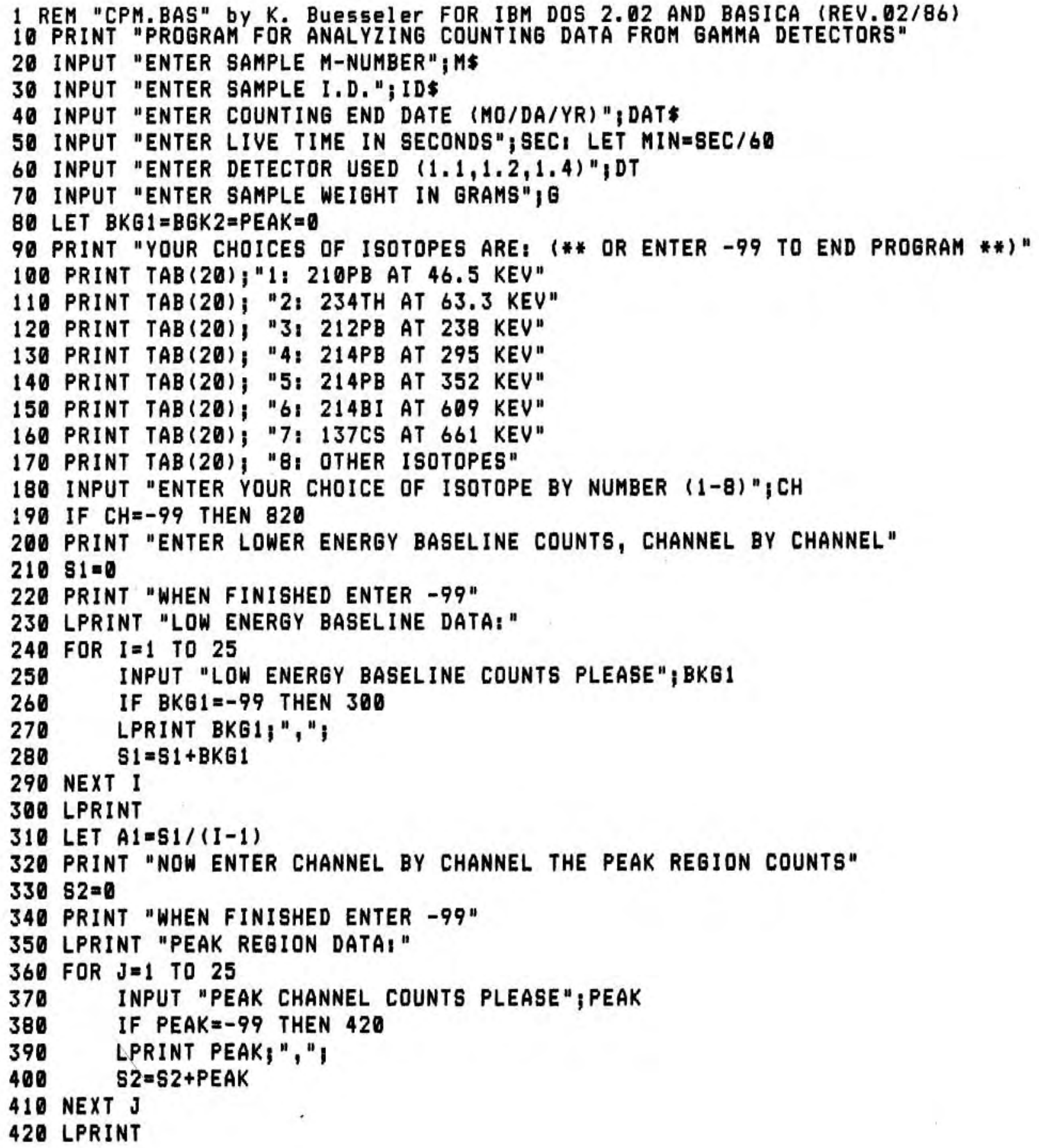


APPENDIX I, cont.

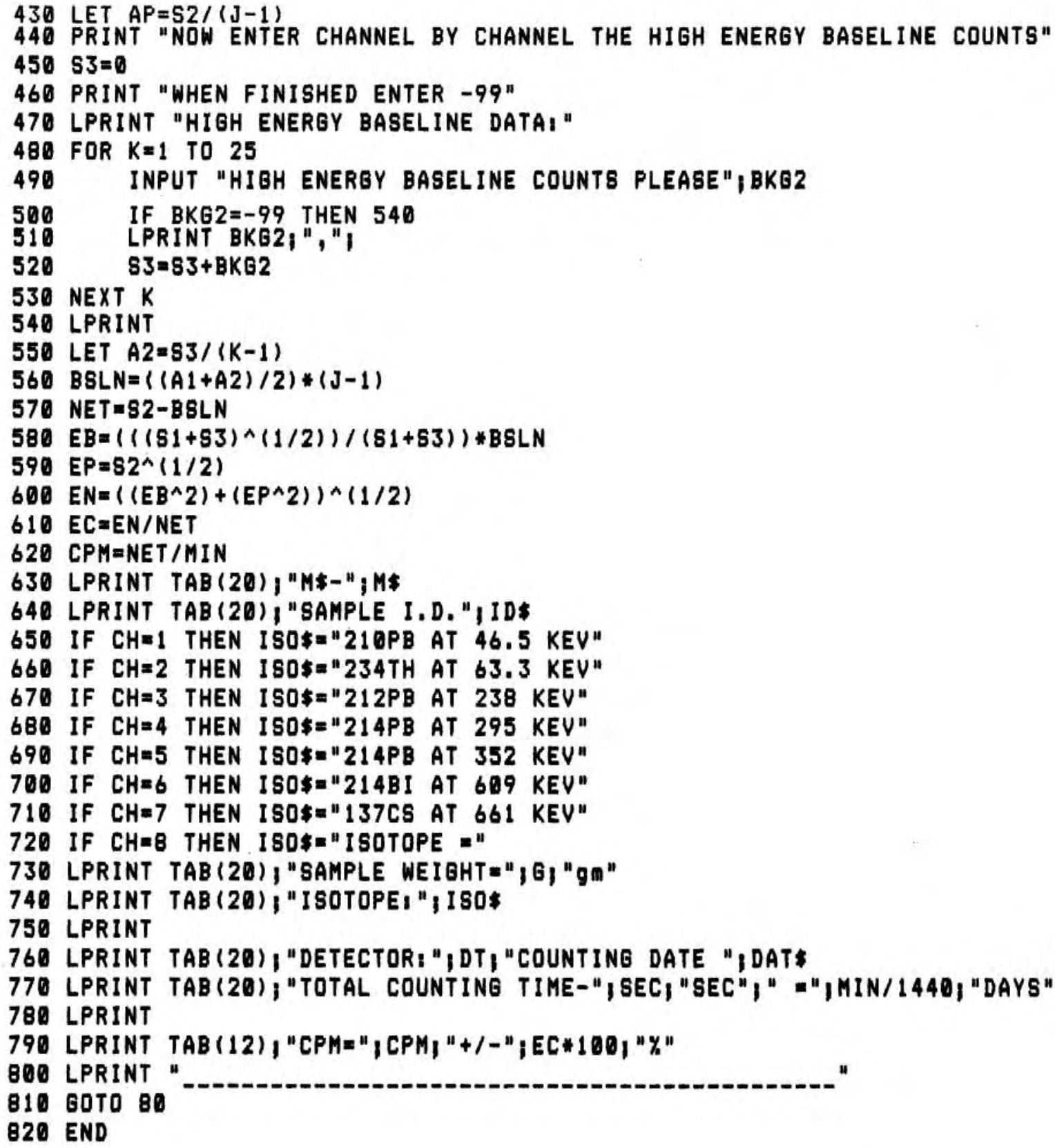




\begin{tabular}{|c|c|c|c|c|c|c|c|c|}
\hline $\begin{array}{c}\text { ID } \\
====\end{array}$ & $\begin{array}{c}\text { Depth } \\
\text { c } \\
=====\end{array}$ & $\begin{array}{c}\text { ERZ } \\
+/-C n \\
=====\end{array}$ & $\begin{array}{l}210 \mathrm{~Pb} \\
d p \mathrm{ga} \\
== \pm==\end{array}$ & $\begin{array}{l}\text { ERPb } \\
+1-1 \\
====\end{array}$ & $\begin{array}{l}226 R a \\
d p a / g a \\
=====\end{array}$ & $\begin{array}{l}\text { ERRa } \\
+/-1 \\
====\end{array}$ & $\begin{array}{c}\text { EXPb } \\
\text { dpa/ga } \\
=====\end{array}$ & $\begin{array}{l}\text { EREX } \\
+/-1 \\
===\end{array}$ \\
\hline Core A- & $=90 \mathrm{co}$ & llectec & o $7 / 28 / 83$ & $383-$ & GYRE-9 & 4028. & 1 'N 705 & $54 . I^{\prime \prime \prime}$ \\
\hline AI & -0.75 & 0.75 & 8.9 & 0.5 & 1.7 & 0.2 & 7.2 & 0.5 \\
\hline A2 & -2.5 & 1.0 & & & & & & \\
\hline A3 & -4.5 & 1.0 & 8.5 & 0.6 & 1.7 & 0.2 & 6.8 & 0.6 \\
\hline A4 & -6.5 & 1.0 & 7.0 & 0.4 & 1.7 & 0.2 & 5.3 & 0.4 \\
\hline A5 & -8.5 & 1.0 & 7.8 & 0.6 & 1.7 & 0.2 & 6.1 & 0.6 \\
\hline Ab & -10.5 & 1.0 & & & & & & \\
\hline A7 & -12.5 & 1.0 & 6.8 & 0.3 & 1.7 & 0.2 & 5.1 & 0.4 \\
\hline AB & -14.5 & 1.0 & & & & & & \\
\hline A9 & -16.5 & 1.0 & & & & & & \\
\hline A10 & -18.5 & 1.0 & 4.2 & 0.3 & 1.7 & 0.2 & 2.5 & 0.4 \\
\hline All & -20.5 & 1.0 & & & & & & \\
\hline A12 & -22.5 & 1.0 & & & & & & \\
\hline$A 13$ & -24.5 & 1.0 & & & & & & \\
\hline A14 & -26.5 & 1.0 & 1.7 & 0.2 & & & 0.0 & \\
\hline A15 & -28.5 & 1.0 & & & & & & \\
\hline A16 & -30.5 & 1.0 & & & & & & \\
\hline A17 & -32.5 & 1.0 & 1.7 & 0.2 & & & 0.0 & \\
\hline A18 & -35.5 & 2.0 & & & & & & \\
\hline
\end{tabular}

ID Depth ERZ 210Pb ERPb 226Ra ERRa EXPb EREX 234Th ERTh 137Cs ERCs ca $+/-c a \quad d p a / g n \quad+/-1 \quad d p a / g n \quad+/-1 \quad d p a / g n+/-1 \quad d p a / g n+/-1 \quad d p a / k g \quad+/-1$

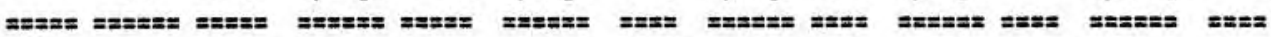
Core AK- 80n collected 7/28/83 93-6YRE-9 40 28.4' 70 55.2'W

$\begin{array}{rrrrrrrrrrrrr}\text { AK1 } & -0.5 & 0.5 & 10.6 & 0.5 & 1.8 & 0.05 & 8.8 & 0.5 & 10.8 & 0.7 & 271.0 & 22.0 \\ \text { AK2 } & -1.5 & 0.5 & 11.7 & 0.6 & 1.7 & 0.05 & 10.0 & 0.6 & 8.9 & 0.7 & 246.0 & 27.0 \\ \text { AK3 } & -2.5 & 0.5 & 12.1 & 0.4 & 1.8 & 0.04 & 10.3 & 0.4 & 4.1 & 0.4 & 252.0 & 20.0 \\ \text { AK4 } & -3.5 & 0.5 & 10.7 & 0.3 & 1.9 & 0.07 & 8.8 & 0.3 & 3.1 & 0.2 & 225.0 & 22.0 \\ \text { AK5 } & -5.0 & 1.0 & 10.6 & 0.3 & 1.9 & 0.10 & 8.7 & 0.3 & 3.0 & 0.2 & 261.0 & 18.0 \\ \text { AK6 } & -7.0 & 1.0 & 9.3 & 0.3 & 1.9 & 0.10 & 7.4 & 0.3 & 3.5 & 0.2 & 236.0 & 24.0 \\ \text { AK7 } & -9.0 & 1.0 & 7.2 & 0.3 & 1.8 & 0.05 & 5.4 & 0.3 & 3.4 & 0.3 & 273.0 & 20.0 \\ \text { AK8 } & -11.0 & 1.0 & 6.9 & 0.5 & 1.8 & 0.07 & 5.1 & 0.5 & 3.5 & 0.4 & 198.0 & 25.0 \\ \text { AK9 } & -13.0 & 1.0 & 5.8 & 0.3 & 2.2 & 0.10 & 3.6 & 0.3 & 3.3 & 0.3 & 113.0 & 23.0 \\ \text { AK10 } & -15.0 & 1.0 & 4.1 & 0.2 & 2.0 & 0.10 & 2.1 & 0.2 & 3.3 & 0.2 & 68.0 & 23.0 \\ \text { AK11 } & -17.0 & 1.0 & 3.8 & 0.2 & 1.9 & 0.10 & 1.9 & 0.2 & 2.9 & 0.2 & 82.0 & 21.0 \\ \text { AK12 } & -19.0 & 1.0 & 3.3 & 0.2 & 1.9 & 0.04 & 1.4 & 0.2 & 2.8 & 0.2 & 113.0 & 14.0 \\ \text { AK13 } & -21.0 & 1.0 & 3.3 & 0.3 & 1.9 & 0.10 & 1.4 & 0.3 & 2.7 & 0.3 & & \\ \text { AK14 } & -23.0 & 1.0 & 3.1 & 0.3 & 1.9 & 0.07 & 1.2 & 0.3 & 3.2 & 0.4 & 72.0 & 26.0 \\ \text { AK15 } & -25.0 & 1.0 & 3.8 & 0.3 & 1.8 & 0.05 & 2.0 & 0.3 & 2.6 & 0.2 & 68.0 & 15.0 \\ \text { AK16 } & -28.0 & 2.0 & 3.9 & 0.2 & 1.9 & 0.05 & 2.0 & 0.2 & 3.0 & 0.2 & 53.0 & 12.0\end{array}$




\begin{tabular}{|c|c|c|c|c|c|c|c|c|c|c|}
\hline ID & $\begin{array}{c}\text { Depth } \\
\text { ca } \\
== \pm= \pm=\end{array}$ & $\begin{array}{c}\text { ERZ } \\
+/-c \| \\
== \pm=\end{array}$ & $\begin{array}{l}210 \mathrm{~Pb} \\
\mathrm{dpa} / \mathrm{ga} \\
====\end{array}$ & $\begin{array}{l}\text { ERPb } \\
+/-1 \\
====\end{array}$ & $\begin{array}{l}226 R a \\
\mathrm{dpa} / \mathrm{ga} \\
===2=\end{array}$ & $\begin{array}{l}\text { ERRa } \\
+/-1 \\
===\end{array}$ & $\begin{array}{c}\text { EXPb } \\
\text { dps/ga } \\
=====\end{array}$ & $\begin{array}{l}\text { EREX } \\
+1-1 \\
===\end{array}$ & $\begin{array}{r}\text { 234Th } \\
d p=/ g \Delta \\
=====\end{array}$ & $\begin{array}{l}\text { ERTh } \\
+1-1 \\
===\end{array}$ \\
\hline tre F- & 501: c & collect & ed $4 / 30 /$ & $84 \quad 0 C$ & EEANUS- 15 & 239 & 55.1 'N ? & 7054. & & \\
\hline$F 1 A$ & -0.5 & 0.5 & 7.6 & 0.4 & 2.3 & 0.2 & 5.3 & 0.5 & 5.9 & 0.5 \\
\hline$F 18$ & -1.5 & 0.5 & 7.7 & 0.5 & 2.3 & 0.2 & 5.4 & 0.5 & 4.2 & 0.6 \\
\hline$F 2 A$ & -2.5 & 0.5 & 8.2 & 0.5 & 2.1 & 0.2 & 6.1 & 0.5 & ?? & 0.4 \\
\hline $\mathrm{F} 2 \mathrm{~B}$ & -3.5 & 0.5 & 6.8 & 0.5 & 2.2 & 0.2 & 4.6 & 0.5 & 5.0 & 0.6 \\
\hline F3 & -5.0 & 1.0 & 7.2 & 0.4 & 2.3 & 0.2 & 4.9 & 0.5 & 2.0 & 0.3 \\
\hline$F 4$ & -7.0 & 1.0 & 6.7 & 0.4 & 2.4 & 0.2 & 4.3 & 0.4 & 2.1 & 0.3 \\
\hline F5 & -9.0 & 1.0 & 3.8 & 0.3 & 2.2 & 0.2 & 1.6 & 0.3 & 2.0 & 0.2 \\
\hline $\mathrm{Fb}$ & -11.0 & 1.0 & 2.1 & 0.2 & 2.2 & 0.2 & 0.0 & & 2.2 & 0.2 \\
\hline F7 & -13.0 & 1.0 & 2.4 & 0.2 & 2.2 & 0.2 & 0.2 & 0.3 & 2.0 & 0.2 \\
\hline$F 8$ & -15.0 & 1.0 & 2.9 & 0.3 & 2.1 & 0.2 & 0.8 & 0.3 & 2.0 & 0.2 \\
\hline F9 & -17.0 & 1.0 & 2.0 & 0.2 & 2.2 & 0.2 & 0.0 & & 2.0 & 0.3 \\
\hline
\end{tabular}

ID Depth ERZ 210Pb ERPb 226Ra ERRa EXPb EREX 234Th ERTh ca $+/-c n d p a / g n+/-1 \quad d p a / g n \quad+/-1 \quad d p n / g n+/-1 \quad d p a / g n+/-1$

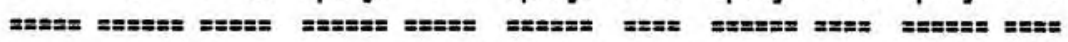
Core E- 1275. collected 4/29/84 OCEANUS-152 39 48.1'N 70 56.3'W

$\begin{array}{rrrrrrrrrrr}\text { E1A } & -0.5 & 0.5 & 22.8 & 0.7 & 2.9 & 0.3 & 19.9 & 0.8 & 1.6 & 0.4 \\ \text { E1B } & -1.5 & 0.5 & 6.3 ? & 0.5 & 2.9 & 0.3 & 3.5 ? & 0.5 & 2.3 ? & 0.3 \\ \text { E2A } & -2.5 & 0.5 & 14.9 & 0.6 & 2.7 & 0.3 & 12.2 & 0.7 & 2.1 & 0.4 \\ \text { E2B } & -3.5 & 0.5 & 12.3 & 0.4 & 2.6 & 0.3 & 9.7 & 0.5 & 2.0 & 0.2 \\ \text { E3 } & -5.0 & 1.0 & 11.0 & 0.3 & 2.8 & 0.3 & 8.2 & 0.5 & 2.7 & 0.2 \\ \text { E4 } & -7.0 & 1.0 & 8.7 & 0.3 & 2.9 & 0.3 & 5.8 & 0.5 & 2.7 & 0.3 \\ \text { E5 } & -9.0 & 1.0 & 9.0 & 0.3 & 2.9 & 0.3 & 6.1 & 0.5 & & \\ \text { E6 } & -11.0 & 1.0 & 6.7 & 0.3 & 2.9 & 0.3 & 3.8 & 0.4 & 3.4 & 0.3 \\ E 7 & -13.0 & 1.0 & 3.7 & 0.3 & 2.8 & 0.3 & 0.9 & 0.4 & 2.8 & 0.3 \\ E 8 & -15.0 & 1.0 & 2.7 & 0.3 & 2.8 & 0.3 & 0.0 & & 3.5 & 0.3 \\ E 9 & -17.0 & 1.0 & 2.2 & 0.3 & 2.9 & 0.3 & 0.0 & & 3.5 & 0.3 \\ E 10 & -19.0 & 1.0 & 2.8 & 0.3 & 2.7 & 0.3 & 0.0 & & 3.6 & 0.3 \\ E 11 & -21.0 & 1.0 & 2.1 & 0.2 & 2.9 & 0.3 & 0.0 & & 3.4 & 0.3 \\ E 12 & -23.0 & 1.0 & 2.4 & 0.2 & 2.6 & 0.3 & 0.0 & & 3.1 & 0.3 \\ E 13 & -25.0 & 1.0 & 2.7 & 0.2 & 2.7 & 0.3 & 0.0 & & 3.7 & 0.3\end{array}$




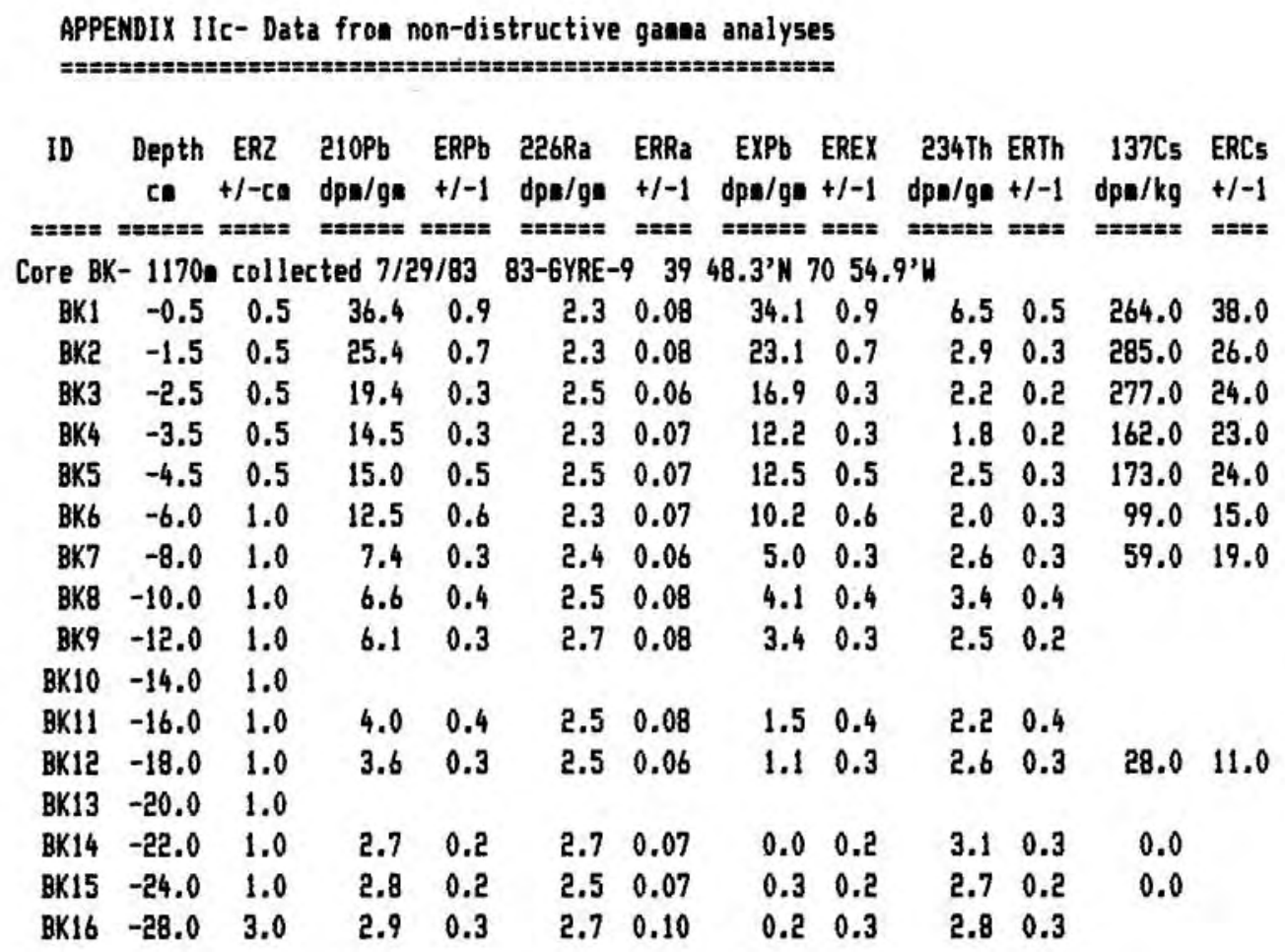

ID Depth ERZ 210Pb ERPb 226Ra ERRa EXPb EREX 234Th ERTh ca $+/-c a$ dpa/ga $+/-1$ dpa/gn $+/-1$ dpa/ga $+/-1$ dpa/ga $+/-1$

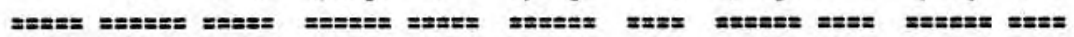
Core D- 2362 collected 4/29/84 DCEANUS-152 3935.0 'N 7056.8 ' W

$\begin{array}{rrrrrrrrrrr}D 1 A & -0.5 & 0.5 & 14.2 & 0.6 & 2.4 & 0.2 & 11.8 & 0.6 & 1.6 & 0.3 \\ D 1 B & -1.5 & 0.5 & 12.1 & 0.3 & 2.6 & 0.3 & 9.6 & 0.4 & 1.9 & 0.2 \\ D 2 A & -2.5 & 0.5 & 10.4 & 0.5 & 2.8 & 0.3 & 7.6 & 0.6 & 1.5 & 0.3 \\ \text { D2B } & -3.5 & 0.5 & 10.0 & 0.4 & 2.6 & 0.3 & 7.4 & 0.5 & 1.9 & 0.2 \\ D 3 & -5.0 & 1.0 & 7.7 & 0.3 & 2.5 & 0.3 & 5.2 & 0.4 & 2.0 & 0.2 \\ D 4 & -7.0 & 1.0 & 5.0 & 0.3 & 2.6 & 0.3 & 2.4 & 0.4 & 2.9 & 0.2 \\ D 5 & -9.0 & 1.0 & 4.6 & 0.2 & 2.8 & 0.3 & 1.8 & 0.4 & 3.0 & 0.2 \\ D 6 & -11.0 & 1.0 & 5.5 & 0.3 & 2.9 & 0.3 & 2.6 & 0.4 & 2.9 & 0.3 \\ D 7 & -13.0 & 1.0 & 2.8 & 0.3 & 2.6 & 0.3 & 0.2 & 0.4 & 2.8 & 0.3 \\ D 8 & -16.0 & 2.0 & 2.5 & 0.2 & 2.4 & 0.2 & 0.1 & 0.3 & 3.2 & 0.2\end{array}$




\begin{tabular}{|c|c|c|c|c|c|c|c|c|}
\hline $\begin{array}{c}\text { ID } \\
==2=\end{array}$ & $\begin{array}{c}\text { Depth } \\
\text { ca } \\
=\approx=\pi==\end{array}$ & $\begin{array}{c}\text { ERZ } \\
+I-c= \\
==m==\end{array}$ & $\begin{array}{l}\text { ट10Pb } \\
\text { dpa/gl } \\
=====\end{array}$ & $\begin{array}{l}\text { ERPb } \\
+/-1 \\
====\end{array}$ & $\begin{array}{l}\text { 226Ra } \\
\text { dpa/ge } \\
=====\end{array}$ & $\begin{array}{l}\text { ERRa } \\
+/-1 \\
====\end{array}$ & $\begin{array}{c}\text { EXPb } \\
\mathrm{dp} / \mathrm{g} \\
======\end{array}$ & $\begin{array}{l}\text { EREX } \\
+/-1 \\
====\end{array}$ \\
\hline Core $\mathrm{C}$ - & $-2700=\mathrm{c}$ & collect & ed $7 / 31 /$ & 8383 & 1-6YRE-9 & 3910 & 70 & $43.8^{\prime} \mathrm{W}$ \\
\hline $\mathrm{Cl}$ & -0.8 & 0.8 & 14.2 & 0.6 & 3.2 & 0.2 & 11.0 & 0.6 \\
\hline C2 & -2.5 & 1.0 & 9.1 & 1.0 & 4.0 & 0.2 & 5.1 & 1.0 \\
\hline C3 & -4.5 & 1.0 & 6.9 & 0.3 & 2.9 & 0.1 & 4.0 & 0.3 \\
\hline C4 & -6.5 & 1.0 & 7.4 & 0.4 & 3.0 & 0.1 & 4.4 & 0.4 \\
\hline C5 & -8.5 & 1.0 & 4.9 & 0.3 & 2.9 & 0.1 & 2.0 & 0.3 \\
\hline C6 & -10.5 & 1.0 & & & & & & \\
\hline C7 & -12.5 & 1.0 & 3.7 & 0.2 & 3.1 & 0.2 & 0.6 & 0.3 \\
\hline C8 & -14.5 & 1.0 & & & & & & \\
\hline C9 & -16.5 & 1.0 & 4.1 & 0.2 & 3.2 & 0.2 & 0.9 & 0.3 \\
\hline $\mathrm{ClO}$ & -18.5 & 1.0 & & & & & & \\
\hline C11 & -20.5 & 1.0 & 2.8 & 0.3 & 3.4 & 0.2 & 0.0 & 0.0 \\
\hline $\mathrm{Cl} 2$ & -23.5 & 1.0 & & & & & & \\
\hline
\end{tabular}

\begin{tabular}{|c|c|c|c|c|c|c|c|c|c|c|c|c|}
\hline$== \pm=$ & $\begin{array}{l}\text { Depth } \\
\text { ca }\end{array}$ & $\begin{array}{c}\text { ERZ } \\
+/-c a \\
===\end{array}$ & $\begin{array}{l}210 \mathrm{~Pb} \\
\mathrm{dpa} / \mathrm{ga} \\
=====\end{array}$ & $\begin{array}{r}\text { ERPb } \\
+/-1 \\
=z==2\end{array}$ & $\begin{array}{l}226 \mathrm{Ra} \\
d p a / g a \\
====\end{array}$ & $\begin{array}{l}\text { ERRa } \\
+/-1 \\
===\end{array}$ & $\begin{array}{c}\text { EXPb } \\
d p n / g a \\
==m==\end{array}$ & $\begin{array}{l}\text { EREX } \\
+1-1 \\
===\end{array}$ & $\begin{array}{r}234 T h \\
d p=/ g \otimes \\
=====\end{array}$ & $\begin{array}{l}\text { ERTh } \\
+1-1 \\
== \pm=\end{array}$ & $\begin{array}{r}137 C_{5} \\
d p a / k g \\
====x\end{array}$ & ERC: \\
\hline re CK & -2700 & coll & 7 & $1 / 83$ & 83-6YRE- & 39 & $0.9^{\prime}$ & 42. & & & & \\
\hline CKI & -0.5 & 0.5 & 28.0 & 2.0 & 3.0 & 0.1 & 25.0 & 2.0 & 1.8 & 0.2 & 611.0 & \\
\hline CX2 & -1.5 & 0.5 & 19.0 & 2.0 & 2.8 & 0.2 & 16.2 & 2.0 & 1.4 & 0.2 & 321.0 & \\
\hline CK3 & -2.5 & 0.5 & 18.0 & 0.4 & 3.8 & 0.1 & 14.2 & 0.4 & 1.7 & 0.2 & 255.0 & \\
\hline CK4 & -3.5 & 0.5 & 13.1 & 0.6 & 3.8 & 0.1 & 9.3 & 0.6 & 1.0 & 0.3 & 74.0 & \\
\hline CK5 & -4.5 & 0.5 & 12.0 & 2.0 & 2.8 & 0.1 & 9.2 & 2.0 & 1.0 & 0.3 & 114.0 & \\
\hline CK6 & -6.0 & 1.0 & 10.0 & 2.0 & 3.6 & 0.1 & 6.4 & 2.0 & 1.8 & 0.3 & 63.0 & \\
\hline CK7 & -8.0 & 1.0 & 10.1 & 0.6 & 2.7 & 0.1 & 7.4 & 0.6 & 2.0 & 0.3 & 32.0 & \\
\hline CKB & -10.0 & 1.0 & 9.0 & 1.0 & 2.6 & 0.1 & 6.4 & 1.0 & 2.5 & 0.2 & 122.0 & \\
\hline CK9 & -12.0 & 1.0 & & & & & & & & & & \\
\hline CK10 & -14.0 & 1.0 & 3.8 & 0.3 & & & & & 3.2 & 0.3 & & \\
\hline CK11 & -16.0 & 1.0 & 3.8 & 0.5 & 2.8 & 0.1 & 1.0 & 0.5 & 2.7 & 0.2 & 18.0 & \\
\hline CK12 & -18.0 & 1.0 & 3.3 & 0.3 & 3.5 & 0.1 & 0.0 & & 2.4 & 0.3 & 0.0 & \\
\hline CK13 & -20.0 & 1.0 & & & & & & & & & & \\
\hline CK14 & -22.0 & 1.0 & 3.3 & 0.3 & 3.4 & 0.1 & 0.0 & & 2.7 & 0.3 & 0.0 & \\
\hline CK15 & -24.0 & 1.0 & & & & & & & & & & \\
\hline CK16 & -26.0 & 1.0 & & & & & & & & & & \\
\hline CK17 & -28.0 & 1.0 & 3.0 & 0.5 & 2.9 & 0.1 & 0.0 & & 1.9 & 0.2 & & \\
\hline
\end{tabular}




\section{APPENDIX IIe- Data from non-distructive gasna analyses}

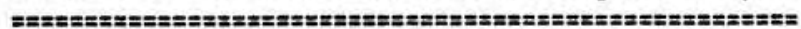

ID Depth ERZ 210Pb ERPb 226Ra ERRa EXPb EREX 234Th ERTh

\begin{tabular}{|c|c|c|c|c|c|c|c|c|c|c|}
\hline & =:==:= & $\begin{array}{l}+/-\mathrm{ch} \\
====\end{array}$ & $\begin{array}{l}d p s / g n \\
=====\end{array}$ & $t=1-1$ & $\begin{array}{l}d p=/ g \| \\
=====\end{array}$ & $\begin{array}{l}+1-1 \\
===\end{array}$ & $\begin{array}{l}d p a / g n \\
====\end{array}$ & $\begin{array}{l}+1-1 \\
===\end{array}$ & & $+1-1$ \\
\hline re & $-4469 m$ & collec & 2 & $1 / 85$ & OCEANUS- & 73 & $54.1^{\prime \prime}$ & & & \\
\hline 61A & -0.25 & 0.25 & 12.0 & 0.4 & 3.1 & 0.2 & 8.91 & 0.53 & 0.9 & \\
\hline 618 & -0.75 & 0.25 & 7.2 & 0.3 & 2.8 & 0.2 & 4.40 & 0.33 & 1.6 & \\
\hline G1C & -1.25 & 0.25 & 6 & 0.3 & 2.7 & 0.1 & 2.91 & 0.20 & 1.3 & \\
\hline G1D & -1.75 & 0.25 & 5.3 & 0.3 & 4.0 & 0.2 & .30 & 0.11 & 2.0 & 1.3 \\
\hline 62A & -2.25 & 0.25 & 4.2 & 0.2 & 3.3 & 0.1 & 0.91 & 0.05 & 1.3 & 0.1 \\
\hline 628 & -2.75 & 0.25 & 4.0 & 0.3 & 2.7 & 0.1 & 1.24 & 0.10 & 1.2 & .2 \\
\hline 622 & -3.25 & 0.25 & 4.2 & 0.2 & 3.7 & 0.2 & 0.54 & 0.04 & 1.4 & oL \\
\hline G2D & -3.75 & 0.25 & 4.9 & 0.3 & 3.9 & 0.2 & 1.03 & 0.08 & 1.2 & .2 \\
\hline GSA & -4.25 & 0.25 & 14.7 & 0.5 & 2.5 & 0.1 & 12.23 & 0.83 & 2.0 & .4 \\
\hline 638 & -4.75 & 0.25 & 5.9 & 0.3 & 3.4 & 0.2 & 2.52 & 0.16 & 1.1 & .2 \\
\hline G3C & -5.25 & 0.25 & 3.7 & 0.2 & 3.8 & 0.3 & 0.0 & & 1.0 & .2 \\
\hline 630 & -5.75 & 0.25 & 3.7 & 0.3 & 3.8 & 0.2 & 0.0 & & 1.8 & 0.2 \\
\hline 64A & -6.25 & 0.25 & 3.9 & 0.2 & 2.8 & 0.1 & 1.1 & 0.08 & & \\
\hline 648 & -6.75 & 0.25 & 3.2 & 0.2 & 3.2 & 0.2 & 0.0 & & 1.0 & \\
\hline 640 & -7.75 & 0.25 & 5 & 0.2 & 3.4 & 0.2 & 0.1 & 0.01 & 1.1 & .2 \\
\hline 658 & -8.75 & 0.25 & 4.1 & 0.2 & 3.2 & 0.2 & 0.9 & 0.07 & 1.4 & \\
\hline $66 \mathrm{~A}$ & -10.25 & 0.25 & 0.0 & 0.0 & 3.7 & 0.1 & 0.0 & & & \\
\hline $66 C$ & -11.25 & 0.25 & 0.0 & 0.0 & 3.5 & 0.1 & 0.0 & & & \\
\hline 67A/B & -12.50 & 0.50 & 3.5 & 0.2 & 3.5 & 0.1 & 0.0 & & 1.8 & \\
\hline
\end{tabular}

ID Depth ER2 210Pb ERPb 226Ra ERRa EXPb EREX 234Th ERTh

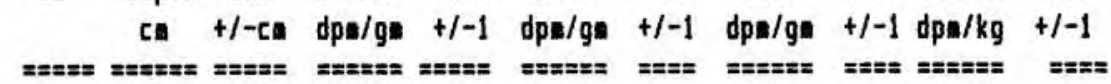
Core H- 4490 collected 12/8/85 OCEANUS-173 36 27.9' $\mathrm{N} 66$ 33.6' $\mathrm{K}$

$\begin{array}{rrrrrrrrrrr}\text { HIA } & -0.25 & 0.25 & 11.3 & 0.4 & 2.4 & 0.1 & 8.85 & 0.58 & 1.2 & 0.2 \\ \text { HIB } & -0.75 & 0.25 & 9.8 & 0.4 & 3.0 & 0.2 & 6.79 & 0.57 & 1.3 & 0.3 \\ \text { HIC } & -1.25 & 0.25 & 5.5 & 0.3 & 2.1 & 0.1 & 3.35 & 0.26 & 1.4 & 0.2 \\ \text { HID } & -1.75 & 0.25 & 4.2 & 0.3 & 3.2 & 0.2 & 1.05 & 0.09 & 1.9 & 0.3 \\ \text { H2A } & -2.25 & 0.25 & 5.9 & 0.3 & 2.1 & 0.1 & 3.85 & 0.27 & 1.6 & 0.3 \\ \text { H2B } & -2.75 & 0.25 & 7.2 & 0.2 & 2.1 & 0.1 & 5.17 & 0.33 & 0.0 & 0.0 \\ \text { H2C } & -3.25 & 0.25 & 11.6 & 0.4 & 3.3 & 0.2 & 8.32 & 0.53 & 1.5 & 0.3 \\ \text { HED } & -3.75 & 0.25 & 12.8 & 0.5 & 2.1 & 0.1 & 10.69 & 0.79 & 2.1 & 0.3 \\ \text { H3A } & -4.25 & 0.25 & 3.9 & 0.3 & 2.8 & 0.2 & 1.05 & 0.10 & & \\ \text { H3C } & -5.25 & 0.25 & 4.1 & 0.2 & 2.2 & 0.1 & 1.89 & 0.16 & 1.1 & 0.2 \\ \text { H4B } & -6.75 & 0.25 & 3.2 & 0.2 & 2.4 & 0.1 & 0.85 & 0.06 & 1.3 & 0.2 \\ \text { H4C } & -7.25 & 0.25 & 2.9 & 0.2 & 3.1 & 0.2 & 0.0 & & 1.5 & 0.2 \\ \text { H5A } & -8.25 & 0.25 & 2.7 & 0.2 & 2.7 & 0.1 & 0.0 & & 1.3 & 0.2 \\ \text { H5D } & -9.75 & 0.25 & 3.3 & 0.2 & 2.9 & 0.1 & 0.4 & 0.03 & 1.3 & 0.2 \\ \text { H6A } & -10.25 & 0.25 & 3.0 & 0.2 & 2.7 & 0.1 & 0.3 & 0.02 & 1.3 & 0.2 \\ \text { H6C } & -11.75 & 0.25 & 0.0 & 0.0 & 2.8 & 0.1 & 0.0 & & & \\ \text { H7A/B } & -12.50 & 0.50 & 3.2 & 0.2 & 3.2 & 0.1 & 0.0 & & 1.4 & 0.2 \\ \text { H7C/D } & -13.50 & 0.50 & 0.0 & 0.0 & 2.9 & 0.1 & 0.0 & & & \\ \text { H8A/B } & -14.50 & 0.50 & 0.0 & 0.0 & 3.1 & 0.1 & 0.0 & & & \\ \text { HBC/D } & -15.50 & 0.50 & 3.7 & 0.2 & 3.6 & 0.1 & 0.1 & 0.01 & 1.1 & 0.2\end{array}$


¿ิ૭

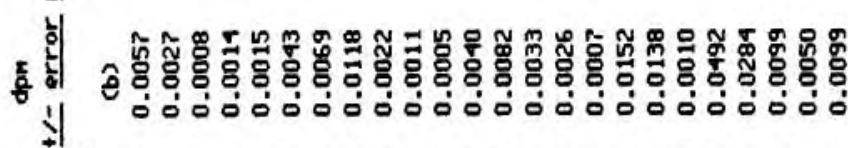

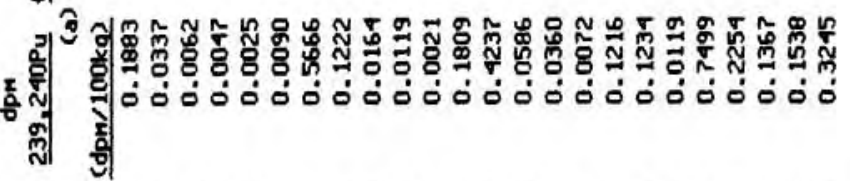

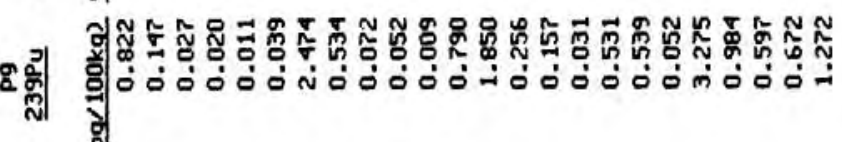

ะ

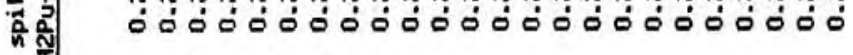

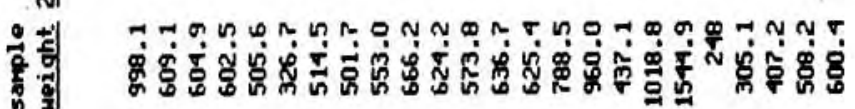

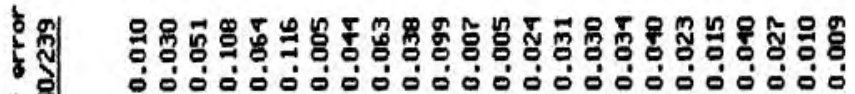

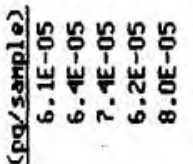

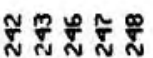

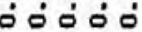

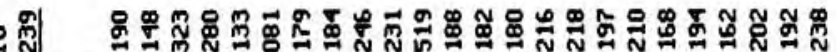

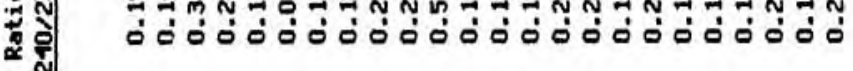

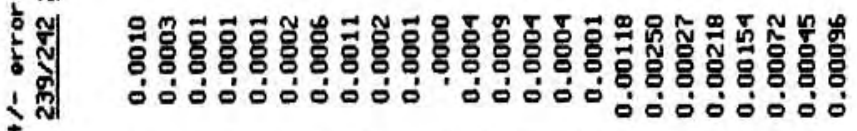

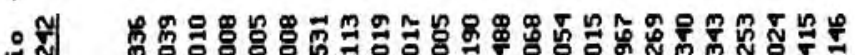

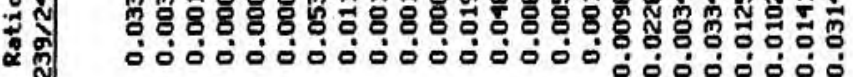

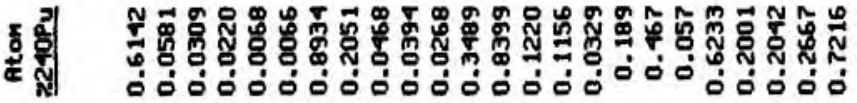

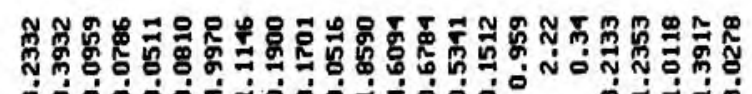

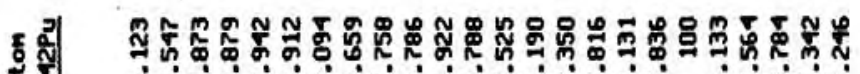

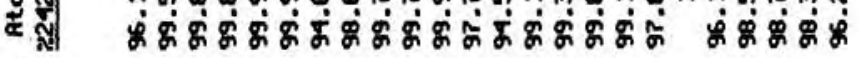

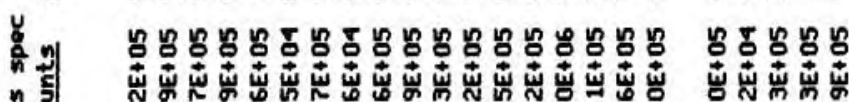
की

iों

ํํำ

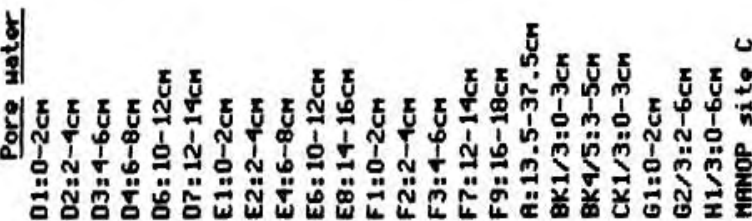

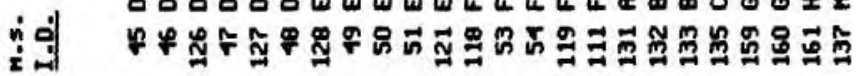

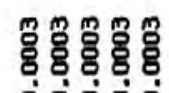
s.sos

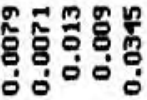

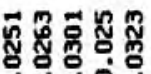

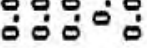

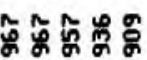

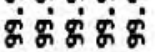
농

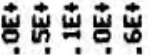
mंก่ก่

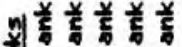

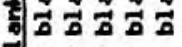

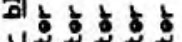

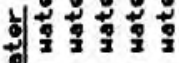

ㄱ.

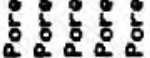

골 点思
है

골

क⿺

83

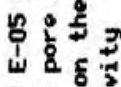

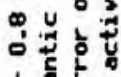

$\div$ 룽

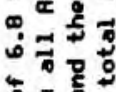

ธ 5 है

荺放

उ. के है

7 옹

需实

ชัญ

के हैं

ระ)

पू⿱

ชัญ影

영ํㄴ

n 형

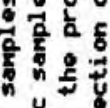

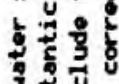

व

¿

表点点

วิ 


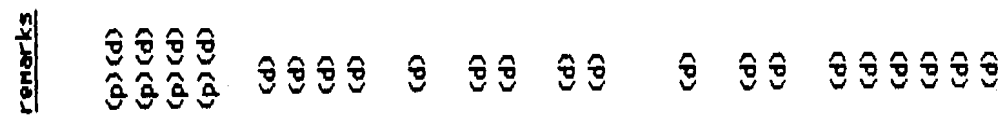

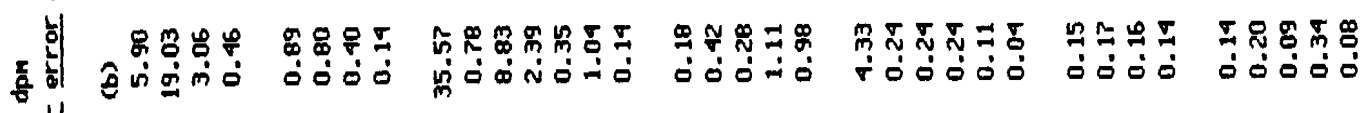

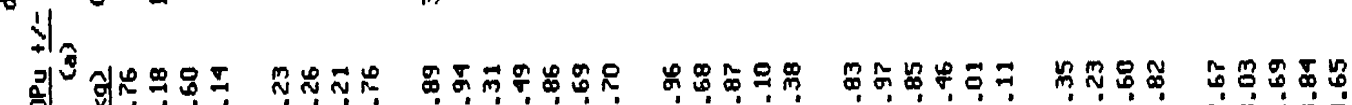

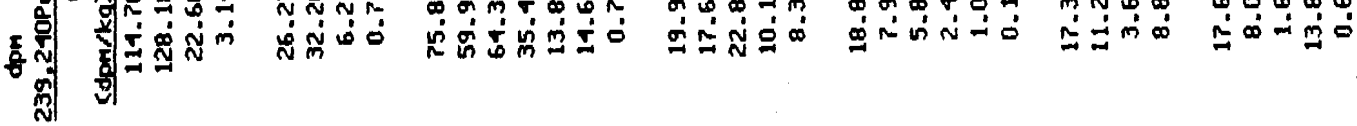

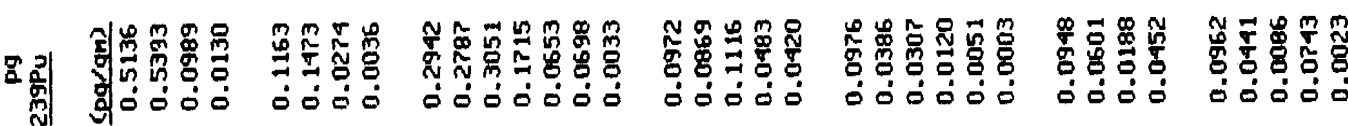

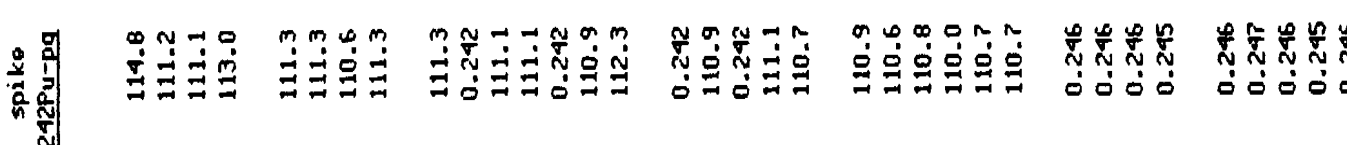

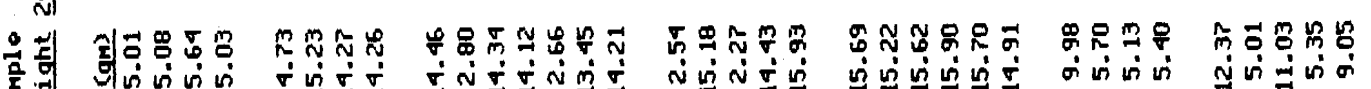

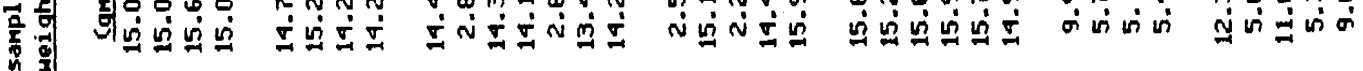

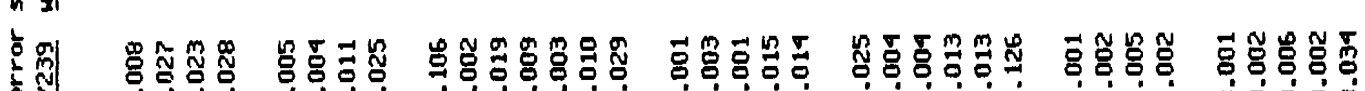

• 0

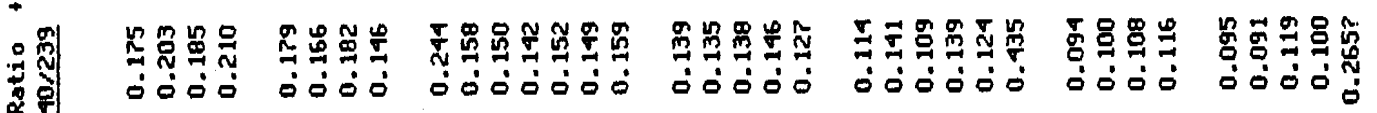

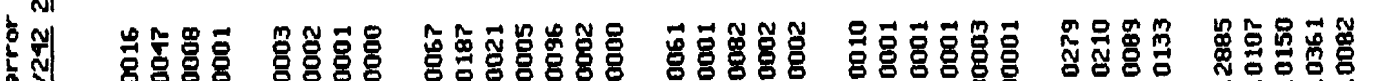

- 氕

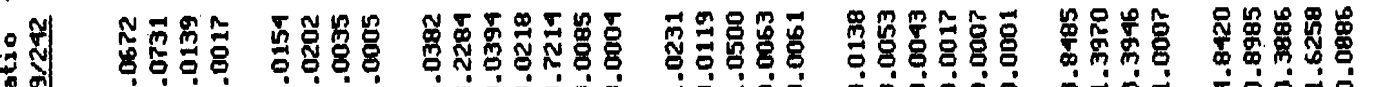

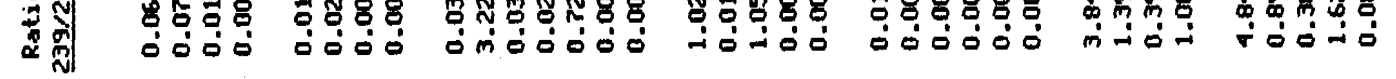

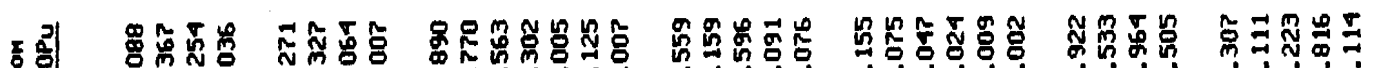

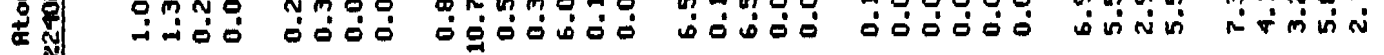

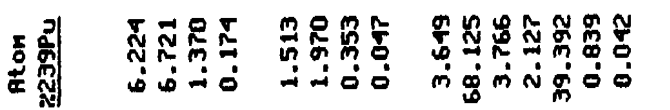

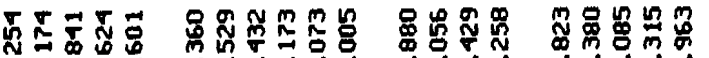

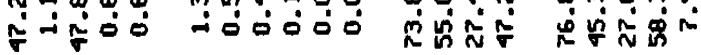

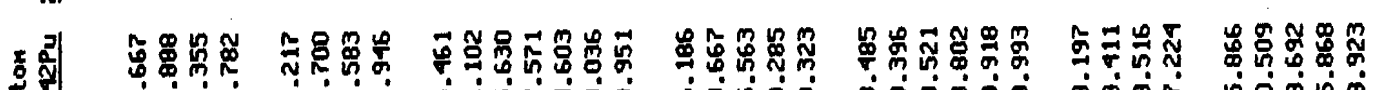

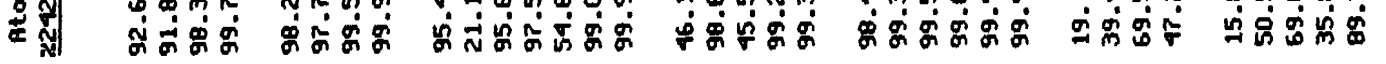

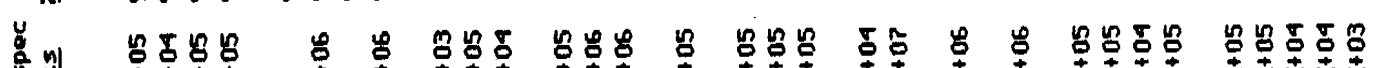

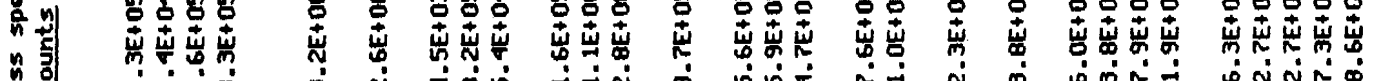

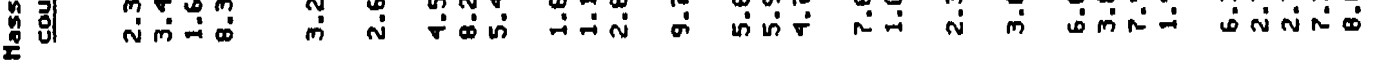

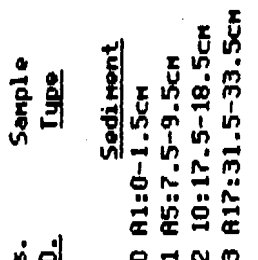

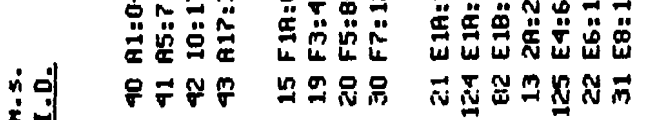

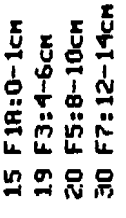

$=x=\underbrace{}_{0}$

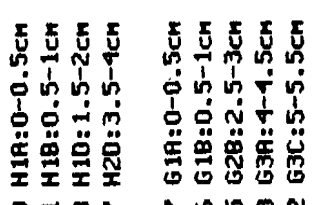

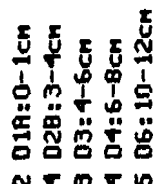

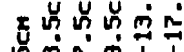

至

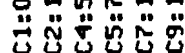

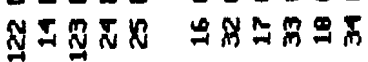

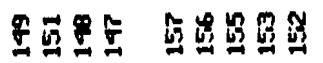

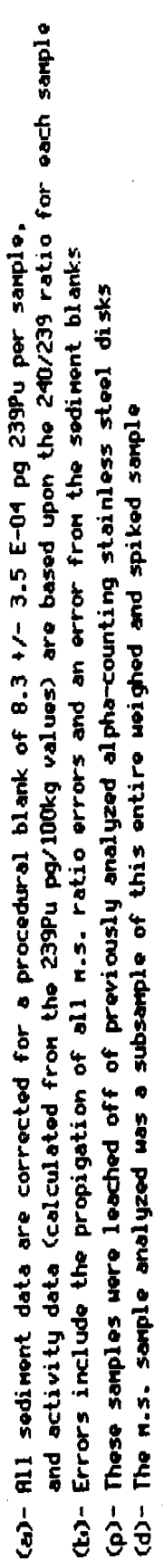




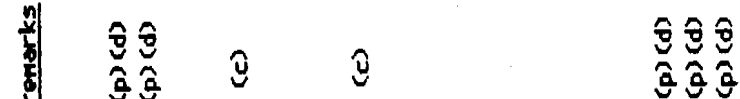

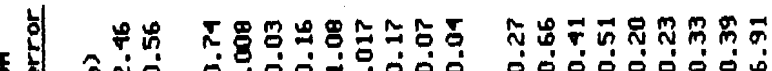

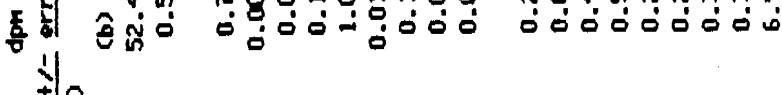

$+13$

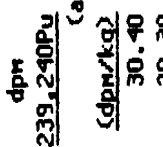

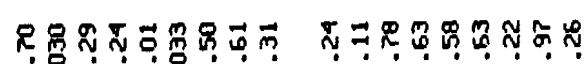

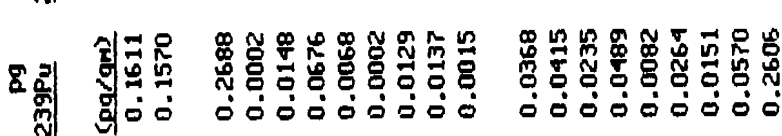

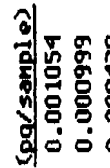

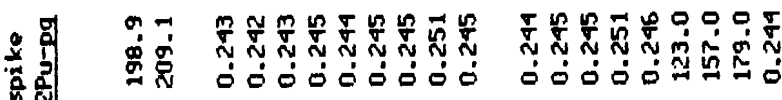

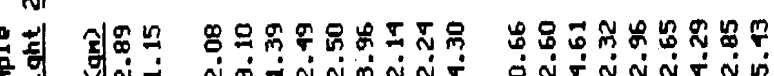

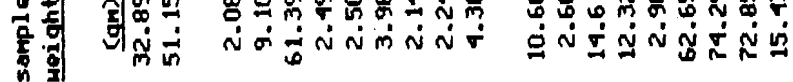

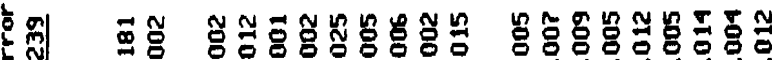

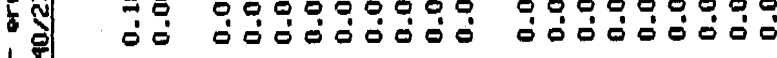

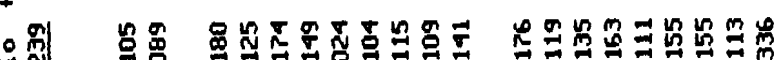

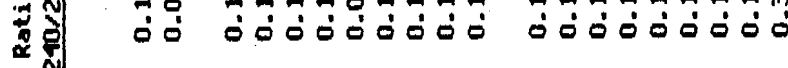

i 츈

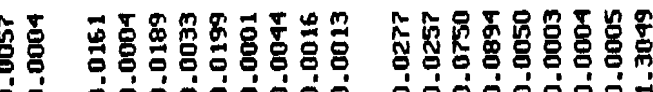

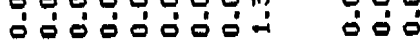

ข้

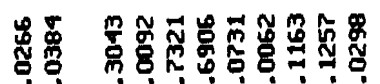

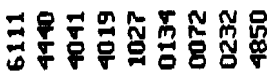

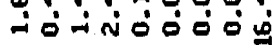

赵

N

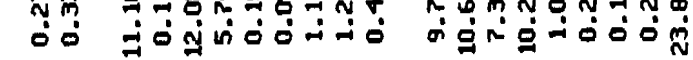

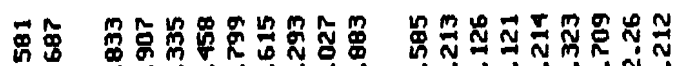

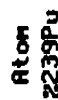
نं

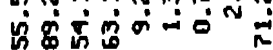

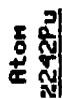

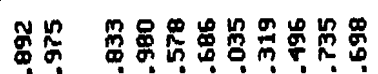

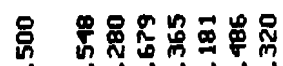

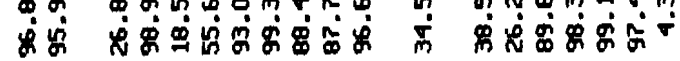

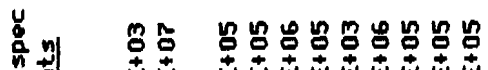

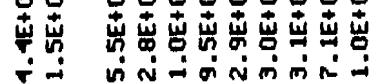

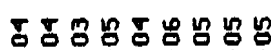

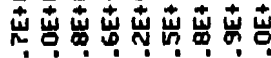

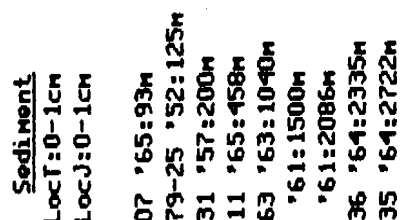

窝亭

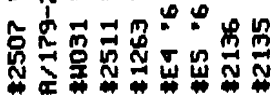

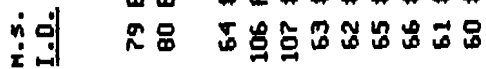

ris ơ

5

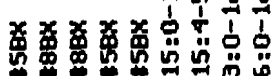

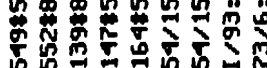

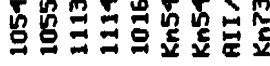

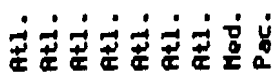

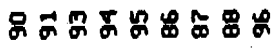

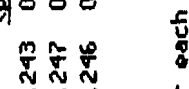

o.

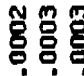

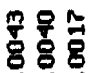

$\frac{0}{0}$
0
0
$\frac{1}{4}$
0
0
0
0

送

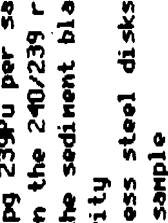

है

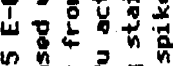

ñ.

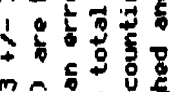

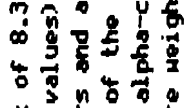

क⿺辶

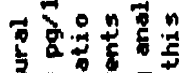

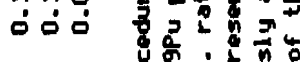

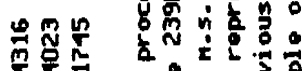

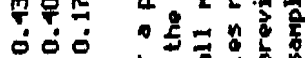

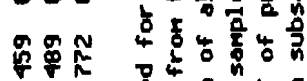

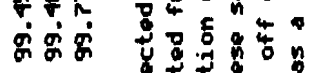

녕

苔若索

जi is

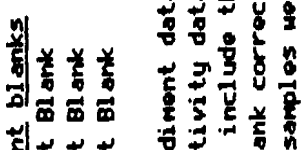

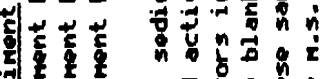

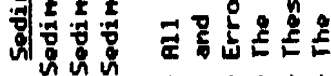

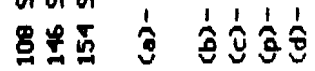




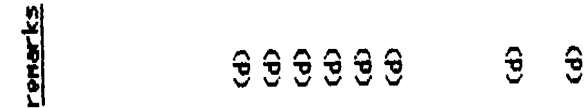

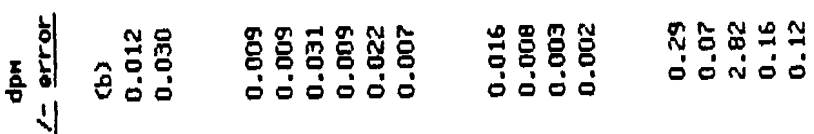

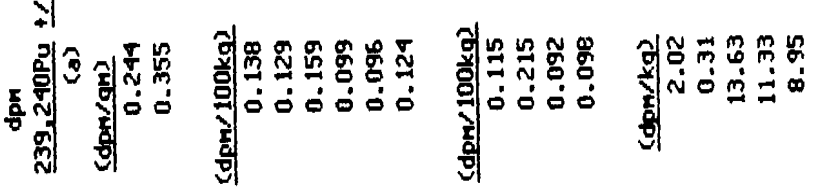

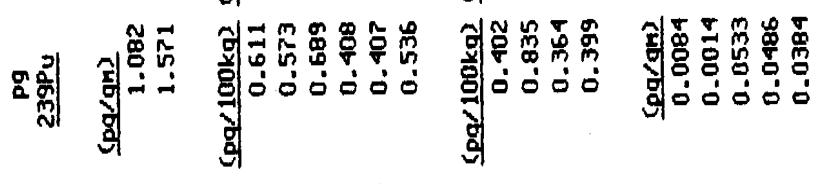

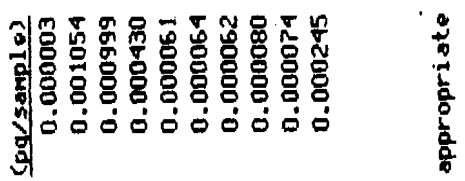

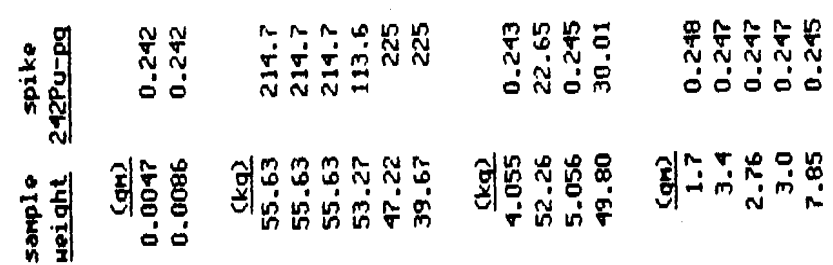

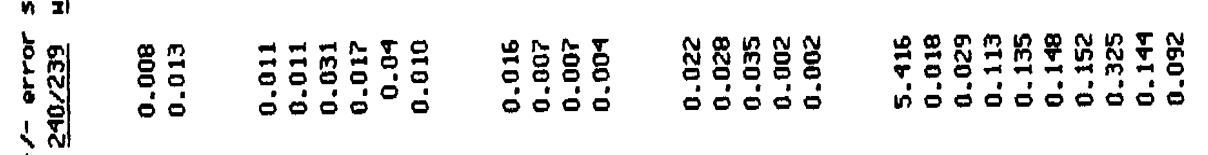

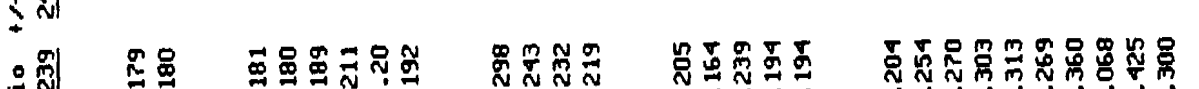

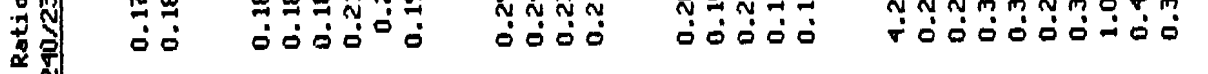

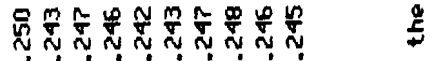

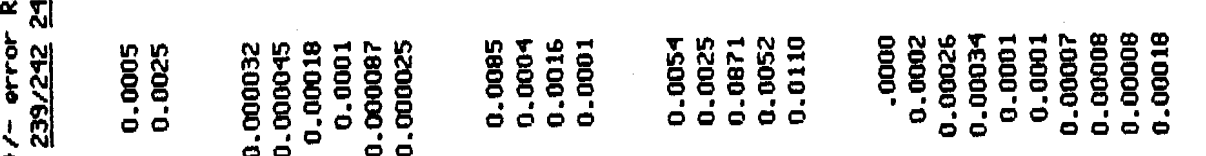

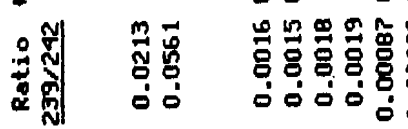

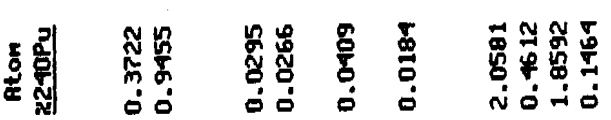

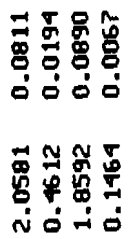

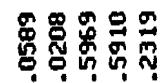

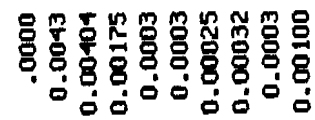

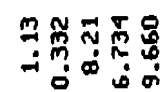

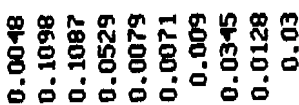

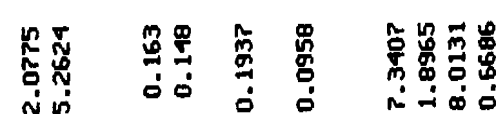

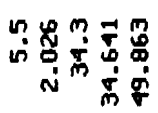

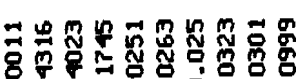

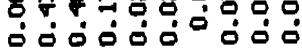

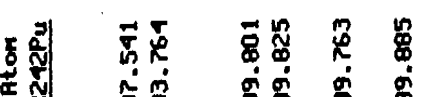

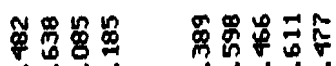

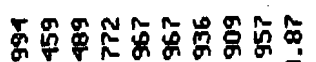

जूล

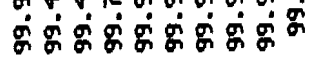

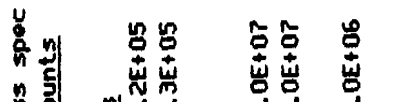

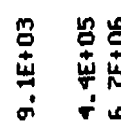

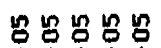

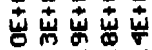

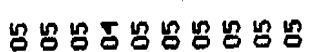

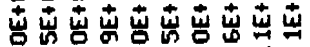

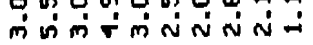

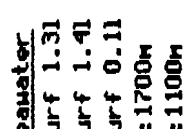

章

家量

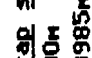

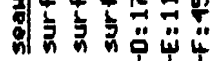

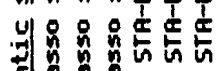

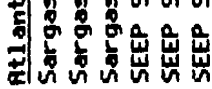

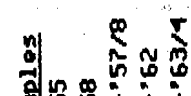

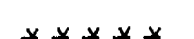

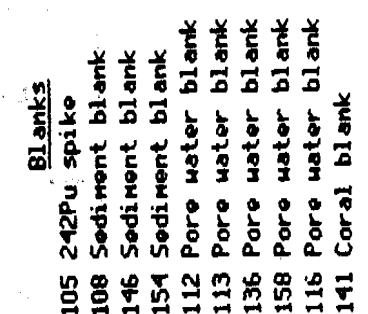

An

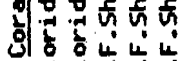




\section{BIOGRAPHICAL NOTE}

The author was born in Minneapolis, Minnesota on July 4, 1959. In 1964 he moved to Palos Verdes, California. In 1972 he moved to Emmen, The Netherlands, for four years - after which he returned to complete his last year of high school in California. He then attended the University of California at San Diego from 1977 to 1981. Since 1981 he has been a student in the M.I.T./W.H.O.I. Joint Program in Oceanography.

\section{Publications}

Buesseler, K. O., G. Benoit and E. R. Sholkovitz, 1985. A pore water study of plutonfum in a seasonally anoxic lake. J. Environ. Radioactivity 2: $283-292$.

Buesseler, K. O., H. D. Livingston and E. R. Sholkovitz, 1985/86. $239,240 \mathrm{Pu}$ and excess $210 \mathrm{~Pb}$ inventories along the shelf and slope of the northeast U.S.A. Earth Planet. Sci. Lett. 76: 10-22.

Anderson, R. A., R. F. Bopp, K. O. Buesseler and P. E. Biscaye. Mixing of particles and organic constituents in sediments from the continental shelf and slope off Cape Cod: SEEP-I Results. Continental Shelf Research, submitted.

Buesseler, K. O. and E. R. Sholkovitz. The pore water chemistry of plutonium in the N. E. Atlantic shelf, slope and rise. Geochim. Cosmochim. Acta, in preparation.

Buesseler, K. O., J. Halverson and E. R. Sholkovitz. Mass spectrometric analyses of fallout ${ }^{239} \mathrm{Pu}$ and $240 \mathrm{Pu}$ in marine samples. Anal. Chem, in preparation.

Buesseler, K. O. and E. R. Sholkovitz. $239 \mathrm{Pu}$ and $240 \mathrm{Pu}$ in N. Atlantic sediments, seawater and pore waters: evidence for a complex input and geochemistry. Geochim. Cosmochim. Acta, in preparation. 